ASPECTS OF THE BIOGEOCHEMISTRY

OF CARBOHYDRATES IN

AQUATIC ENVIRONMENTS

by

KENNETH MOPPER

B.S., Queens College, New York

(1968)

M.S., Massachusetts Institute of Technology

(1971)

SUBMITTED IN PARTIAL FULFILLMENT OF THE

REQUIREMENTS FOR THE DEGREE OF

DOCTOR OF PHILOSOPHY

at the

MASSACHUSETTS INSTITUTE OF TECHNOLOGY

and the

WOODS HOLE OCEANOGRAPHIC INSTITUTION

June, 1973

Signature of Author .

Joint Program in Oceanography, Massachusetts Institute of

Technology - Woods Hole Oceanographic Institution, and

Department of Earth and Planetary Sciences, and Department

of Meteorology, Massachusetts Institute of Technology, June, 1973

Certified by .

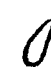




\begin{abstract}
Aspects of the Biogeochemistry of Carbohydrates

in Aquatic Environments
\end{abstract}

Kenneth Mopper

Submitted to the Department of Earth and Planetary Sciences in June, 1973, in partial fulfillment of the requirements for the degree of Doctor of Philosophy.

The goal of this thesis is to examine the distribution and diagenesis of carbohydrates in aquatic environments. The following questions are studied: what is the carbohydrate composition of sediment in different environments (e.g., deep-sea oxic; shallow-sea oxic; deep-sea anoxic; fresh-water anoxic; brackish-water anoxic, etc.)? How does the environment at the sediment-water interface affect the composition of the carbohydrate input? How do sedimentary carbohydrates compare to plankton carbohydrates? How do metal-carbohydrate interactions and biological degradation affect the diagenesis of carbohydrates in recent sediments? Can fossil carbohydrates be used as a means to elucidate paleo-environments?

In order to investigate these questions in a quantitative manner, a liquid chromatographic sugar analyzer sensitive to $10^{-10}$ moles was constructed. Various extraction techniques, involving acid hydrolysis and EDTA treatment, were thoroughly examined to determine lability of sugars, sources of contamination, maximum yields, and reproducibility. Furthermore, several experiments were performed to show that sugars extracted from sediment by EDTA were originally associated with in situ metal ion organic complexes.

Although the carbohydrate compositions of sediment from different aquatic environments are remarkably similar, the degree of metal binding of carbohydrates varies between oxidizing and reducing sediments and appears to be related to the degree of biological degradation at the sedimentwater interface. In an oxic environment, biological degradation produces a highly metal-bound carbohydrate residue. In a reducing environment, the degree of biological activity is low (relative to oxic environments) and hence the degree of metal binding of the resulting carbohydrate residue is low. There is no evidence for further abiotic alteration after burial in 


\section{either environment.}

Sewage material dumped into a shallow oxic environment is degraded rapidly despite the high content of potentially toxic metals; these metals are probably tied-up in the metal bound carbohydrate residue.

Metal binding appears to fix potentially soluble carbohydrates in situ, thereby inhibiting diffusion. This finding undercuts the previous belief that chromatographic separation of organic molecules along mineral surfaces is a significant diagenetic process.

The relative abundances of sugars in acid extracts of sediment and plankton from different aquatic environments are similar; this similarity suggests that plankton is the main source of sedimentary carbohydrates.

Carbohydrates in sediment may be used to interpret paleo-environmental fluctuations. For example, the degree of metal binding is indicative of the $\mathrm{Eh}$ at the sediment-water interface. The glucose and ribose contents of sediment may be used to estimate relative terrigenous and marine organic inputs, respectively. Paleo-eutrophication conditions in the surface waters also may be discerned.

Thesis Supervisor, Egon T. Degens

Title: Senior Scientist, Department of Chemistry, Woods Hole Oceanographic Institution, Woods Hole, Massachusetts 


\section{4 \\ ACKNOWLEDGEMENTS}

I wish to express my warmest and deepest appreciation to Egon T.

Degens, whose invaluable advice and criticism and unwavering guidance

has made this research effort both enjoyable and enlightening.

Stimulating discussions of the data with John M. Hunt, Holger W.

Jannasch, K. O. Emery, and Anne Boersma were greatly helpful.

Critical reviews of the preliminary manuscript by Paul Mangelsdorf, George Harvey, Robert Gagosian, Max Blumer, and John Edmond are also appreciated.

I also wish to acknowledge tro $\frac{x}{2}$ anful advice of H. Burr Steinbach and A. Lawrence Peirson of the Education Department at the Woods Hole Oceanographic Institution.

The typing assistance of Gay Mosier and Christine Johnson is also appreciated.

Drafting of the illustrations was carefully conducted by Dorothy Meinert.

The research was sponsored by a grant from the Petroleum Research Fund PRF-1943A, administered by the American Chemical Society, by grants from the National Science Foundation 20-25234 and 20-30641, and by a grant from the Woods Hole Oceanographic Institution Education Office ED- 1100 . 


\section{BIOGRAPHICAL NOTE}

I received a B.A. in chemistry from Queens College (N. Y.) in 1968. During my junior and senior years I participated in a research program at the Lamont-Doherty Geological Observatory, where I worked with Dr. G. D. Garlick on problems pertaining to oxygen isotope fractionation in biogenic silica.

Between 1968 and 1969 I attended the M.I.T. Graduate School, Department of Earth and Planetary Sciences. During the fall semester I instructed the laboratory for the undergraduate mineralogy course. At the end of the first year I transferred to the jeint prostam in oceanography between M.I.T. and the Woods Hole Oceanographic Institution. Based on research conducted at W.H.O.I., I received a M.S. degree from M.I.T. in 1971; the thesis title is "A new micro-analytical system for reducing sugars applications to sediment and seawater".

My contributions to the literature are:

i) Mopper K. and Garlick G. D. (1971) Oxygen isotope fractionation between biogenic silica and ocean water. Geochim. Cosmoschim. Acta $35,1185-1187$.

ii) Mopper K. (1971) Some considerations of the effects of natural and man-made anoxic conditions on the environment. In Papers on National Land Use Policy Issues, Committee on Interior and Insular Affairs (chairman H. M. Jackson), Senate, 92nd Congress. 
iii) Harvey G. R., Degens E. T., and Mopper K. (1971) Synthesis of nitrogen heterocycles on kaolinite from $\mathrm{CO}_{2}$ and $\mathrm{NH}_{3}$. Naturwissenschaften $\underline{12}, 624-625$.

iv) Mopper K. and Degens E. T. (1972) A new chromatographic sugar autoanalyzer with a sensitivity of $10^{-10}$ moles. Anal. Biochem. 45, 147153.

v) Harvey G. R., Mopper K., and Degens E. T. (1972) Synthesis of carbohydrates and lipids on kaolinite. Chem. Geol. 9 , 79-87.

vi) Mopper K. and Degens E. T. (1972) Aspects of the biogeochemistry of carbohydrates and proteins in aquatic environments. Techn. Rep. Woods Hole Oceanogr. Inst. Ref. No. $\underline{72-68}$.

vii) Hecky R. E., Mopper K., Kilham P. and Degens E. T. (1973) The amino acid and sugar composition of diatom cell walls. Mar. Biol. 18, in press.

viii) Mopper K. and Degens E. T. (1974) Distribution and diagenesis of amino acids and sugars in sediments. Geochim. Cosmochim. Acta, submitted for publication.

ix) Degens E. T. and Mopper K. (1974) Factors controlling the distribution and early diagenesis of organic material in marine sediments. In Chemical Oceanography (editors R. Chester and J. P. Riley), in press. 
TABLE OF CONTENTS

Page

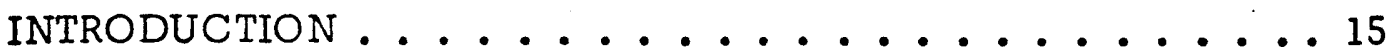

CHAPTER I . . . . . . . . . . . . 17

1. HISTORICAL REVIEW OF CARBOHYDRATE GEOCHEMISTRY . . . . . . . . . . 17

2. GOALS OF THE RESEARCH ........... 33

CHAPTER II: ANALYTICAL PROCEDURES . . . . . . . 34

1. AUTOMATIC SUGAR ChROMATOGRAPHY . . . . 34

a. Type of Eluent ............ . 40

b. Eluent Flow Pate $\ldots \ldots \ldots 40$



d. Dimensions of Resin Bed ...........41

e. Column Temperature ...........41

f. Dye Reagent .............41

2. APPLICATION OF SUGAR ANALYZER TO SEDIMENT . . 43

a. Clean-up Procedure ........... . 43

b. Co-chromatography .......... 43

c. Absolute Identification of Sugars by Gas

Chromatography-Mass Spectrometry . . . . . 45

3. EXTRACTION OF CARBOHYDRATES FROM SEDIMENT:

ACID HYDROLYSIS . . . . . . . . . . 49

a. Sample Drying Procedure ........ 50

b. HF Pretreatment ........... 52

c. Acid Hydrolyses ........... . . 54

d. Deionization Techniques ........ 62

e. Volume Reduction ........... 63

4. EXTRACTION OF CARBOHYDRATES FROM SEDIMENT:

EDTA TREATMENT . . . . . . . . . . 64

a. Optimal Time of Extraction ......... 64

b. Temperature Effects ..........668 
Page

c. Stability of Sugars in EDTA Solution . . . . . 68

d. Hydrolysis Effects . . . . . . . . 70

e. $\mathrm{pH}$ and $\mathrm{CaCO}_{3}$ Effects ......... . 72

5. GENERAL SAMPLE WORK-UP . • . . . . • . 75

CHAPTER III: SIGNIFICANCE OF THE EDTA EXTRACTS AND CARBOHYDRATE-METAL ION INTERACTIONS IN SEDIMENT AND SOIL . . . . . . . . . . 77

1. SOIL SCIENCE LITERATURE . . . . . . . . . 77

2. METAL-CARBOHYDRATE COMPLEXES . . . . 86

3. CHEMISTRY OF EDTA . . . . . . . . . 9 90

4. EXTRACTION OF METAL-BOUND CARBOHYDRATES FROM SEDIMENT . . . . + . . . . . • 94

CHAPTER IV: PRESENTATION AND DISCUSSION OF DATA

1. PRESENTATION OF DATA . . . . . . . . . 98

2. DISCUSSION OF SAMPLE TYPES . . . . . . . 99

a. Plankton . . . . . . . . . . . 99

b. Organic Waste Products .........101

c. New York Bight and Hudson Canyon . . . . . 105

d. Argentine Basin . . . . . . . . 107

e. Cariaco Trench ............. . . 113

f. Santa Barbara Basin ............118

g. Walvis Bay ..............119

h. Black Sea ........... . . 120

i. Oyster Pond . . . . . . . . . . . . 125

j. Lake Kivu . . . . . . . . . . 126

CHAPTER V . . . . . . . . . . . . . . 128

1. DISCUSSION OF GENERAL TRENDS . . . . . . . 128

2. PALEOENVIRONMENTAL CRITERIA . . . . . . 147

CHAPTER VI: SUMMARY AND CONCLUSIONS. . . . . . . 148

REFERENCES . . . . . . . . . . . . . 154 
Page

APPENDIX I: DISCUSSION OF SAMPLE MATERIAL . . . . • 164

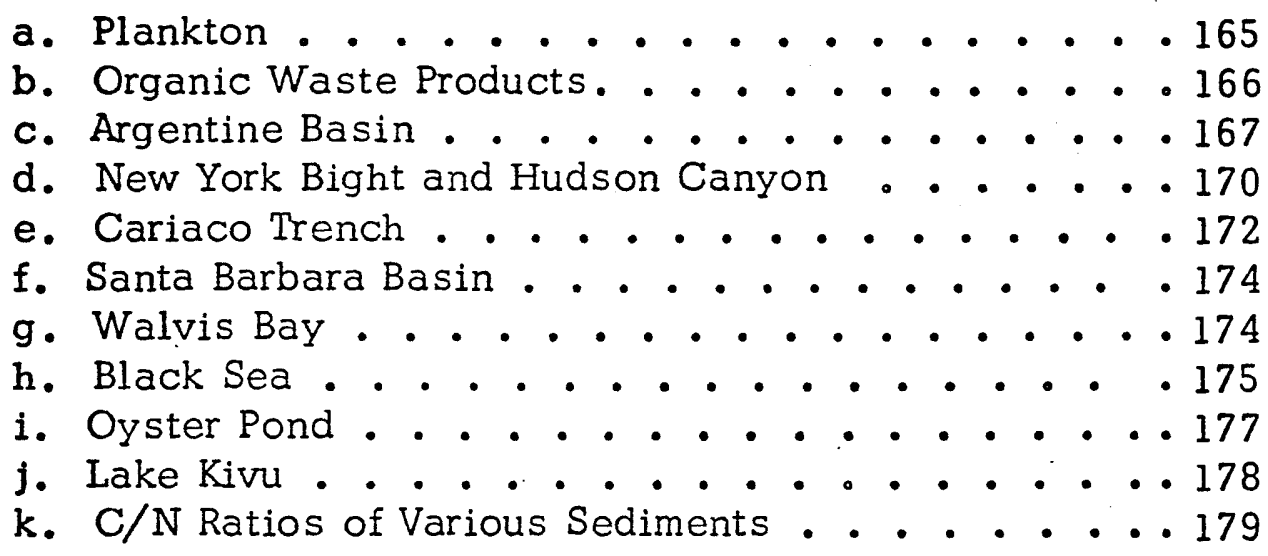

APPENDIX II: BACKGROUND DATA . . . . . . . . 182

APPENDIX III: DATA FILE OF CARBOHYDRATE ANALYSES . . • . 187

APPENDIX IV: GLOSSARY . . . . . . . . . . 216 


\section{LIST OF FIGURES}

Figure

Page

l Schematic of automatic sugar analyzer . . . . . 36

2 Chromatogram of a standard sugar solution . . . . 38 .

3 Quantification of sugar analyzer by peak area . . . . 39

4 Intercalibration between two laboratories of sugar analytical techniques ......... . 46-47

5 Intercalibration study continued ......... . 48

6 Tests of extraction techniques with standards . . . . 51

7 Determination of hydroiveis effi-iencies of various acids ................. . 53

8 Determination of hydrolysis time and acid concentration parameters for the hydrolysis of a sediment with $\mathrm{H}_{2} \mathrm{SO}_{4}$. . . . . . . . . . . . . . 55

9 Determination of hydrolysis time and acid concentration parameters for the hydrolysis of a sediment with $\mathrm{HCl}$. . . . . . . . . . . . 56

10 Comparison of hydrolysis efficiencies of $1.85 \mathrm{M}$ and $0.35 \mathrm{M} \mathrm{H}_{2} \mathrm{SO}_{4}$ for a sediment . . . . . . . . . 59

11 Comparison of the hydrolyzed EDTA extract and the total acid extract of a sediment . . . . . . . 65

12 Determination of optimal time of EDTA, and $\mathrm{H}_{2} \mathrm{O}$ extractions of a sediment . . . . . . . . 67

13 Determination of optimal temperature of EDTA, and $\mathrm{H}_{2} \mathrm{O}$ extractions of a sediment . . . . . . . . 69

14 Schematic of carbohydrate extraction techniques . . . 76

15 Coordination complex of EDTA and $\mathrm{Mn}^{+2}$...... 91 
16 Coordination polyhedron: $\mathrm{AB}_{7}$ of the $\mathrm{Mn}$ (EDTA) ${ }^{-2}$ complex ................. 93

17 Ribose and glucose fluctuations in Argentine Basin sediments . . . . . . . . . . 1 108

18 Depth changes in carbohydrate carbon relative to total organic carbon in Lake Kivu, Cariaco Trench, and Argentine Basin sediments . . . . . . . 110

19 Comparison of the temporal changes in the degree of metal binding of carbohydrates in Cariaco Trench and Argentine Basin sediments . . . . . 112

20 Relationship between the total organic carbon and total sugars in Cariaco Trench sediments . . . . . I114

21 Ribose and glucose fluctuations in Cariaco Trench sediments .............. 115

22 Electron micrographs of organic matter in a Black Sea sediment ............. 123-124

23 Relationship between glucose and ribose in samples analyzed ......................... 131

24 Relationship between sediment carbohydrate extracts and plankton . . . . . . . . . 135

25 Relationship between EDTA extractable monomers and polymers in different sediment samples . . . . . . 138

20 Comparison of the degree of metal binding of carbohydrates from various sedimentary environments . . 139

27 Relationship between sugar carbon and hydrolyzed EDTA extracts of samples studied . . . . . . 142

28 Relationship between $\mathrm{C}-\mathrm{N}$ ratios and hydrolyzed EDTA extracts of various samples . . . . . . 145

29 Hypothetical schematic of the biogeochemical cycle in the ocean . . . . . . . . . . . 149 
Figure

Page

30 A highly hypothetical schematic of the carbohydrate residue of sediment ................ . . 153

Appendix I:

I- 1 Fluctuations of organic carbon in cores from the Black Sea, Lake Kivu, and Argentine Basin . . . . . . . . 168

I-2 Seasonal positions of the subtropical convergence in the Argentine Basin . . . . . . . . . . .171

I-3 C- $\mathrm{N}$ ratios in cores from areas studied . . . . . . 180 


\section{LIST OF TABLES}

Table

Page

1 Spiking of Argentine Basin sediment with a standard sugar solution . . . . . . . . . . . . . .

2 Extraction of carbohydrates by acid hydrolysis of aliquots of a Black Sea sediment core . . . . . .

3 Spiking of Argentine Basin sediment with $\mathrm{CaCO}_{3}$. . .

4 Effects of EDTA and Chelex 100 on sugar standards . . pH values of EDTA extracts of sediment . . . . . .

6 Log of the equilibrium constants of metal-soil organic matter complexes o............ . . . . .

7 Log of the equilibrium constants of metal chelator complexes . . . . . . . . . . . •. . •

8 Comparison of major oxygen-containing functional groups and elemental compositions of organic extracts of soils and sediments . . . . . . . . . . .

9 Chelex experiment . . . . . . . . . . . •

10 Metal analyses of nitric acid digested, and EDTA extracted sewage sludges . . . . . . . . . . 104

11 Comparison of the carbohydrate composition of true landderived marine sediment and possible land-derived sediment . . . . . . . . . . . . . .

12 Summary of mole \% composition of carbohydrates in sediment and plankton: $\mathrm{HCl}$ hydrolysis . . . . . .

13 Summary of mole \% composition of carbohydrates in sediment: hydrolyzed EDTA extract . . . . . . . 132

14 Summary of mole \% composition of carbohydrates in sediment: unhydrolyzed EDTA extract . . . . . . . . 
24

Table

Page

III-1-17 Data file of carbohydrate analyses in Appendix III • • . 188-215 


\section{INTRODUCTION}

The bulk of organic carbon in the crust of the Earth is present in sedimentary rocks as a highly dispersed inert material called kerogen ${ }^{1}$ (e.g., Breger and Brown, 1962). Since most of this carbon has been cycled through the biosphere, biomolecules such as carbohydrates ${ }^{I}$ are the starting materials from which kerogen is formed.

During early diagenesis in sediment, decay and metabolic degradation of these biomolecules results in randomization of the original well-defined structural order of living matter. The various organic molecules present in sediment may not only interact ameng thetselves but may also interact with metal ions and mineral surfaces. As a result, the complexity of reaction schemes and resultant organic products becomes immense.

Dayhoff et al. (1964) demonstrated that biomolecules are far removed from thermodynamic equilibrium. Therefore, diagenesis of organic matter in sediment is expected to proceed in a direction of increasing thermodynamic stability; i.e.:

$$
\text { biomolecules } \underset{\text { fast }}{\stackrel{\text { early }}{\longrightarrow} \text { meta-stable products } \underset{\text { slow }}{\longrightarrow} \mathrm{C}, \mathrm{CO}_{2}, \mathrm{H}_{2} \mathrm{O}, \mathrm{CH}_{4} \text {, }} \begin{gathered}
\text { late } \\
\mathrm{CO} \text {, asphalts, etc. }
\end{gathered}
$$

The approach to thermodynamic stability, however, is extremely slow and for most organic matter it is never reached (Blumer, 1967). The

\footnotetext{
1 See glossary, Appendix IV.
} 
transformation of biomolecules appears to be kinetically inhibited by the formation of meta-stable associations during the early stages of diagenesis. In fact, fragile biomolecules such as carbohydrates (Swain, 1969) and amino acids (Hare, 1969) have been extracted from rocks of Paleozoic and Precambrian ages. The usefulness of organic geochemistry for understanding the origin of kerogen and humus ${ }^{2}$ and for discerning paleoenvironments has been limited by a lack of knowledge of the factors affecting the transformation of biomolecules during early diagenesis.

The advent of sophisticated instrumentation (i.e., high resolution gas chromatography-mass spectroscojyis has facilitated the compilation of an inventory of molecular species present in sediment (Simoneit and Burlingame, 1972).

The object of the present thesis research has been to elucidate some of the processes affecting the diagenesis of organic matter in recent sediments from different depositional environments. Insights into these processes can be gained by the detailed study even of only a few organic compounds.

I have chosen to investigate the problems of diagenesis in terms of in situ variations of carbohydrates. Carbohydrates represent a large fraction of the organic matter of many organisms (e.g., zooplankton $-5 \%$, diatoms $-30 \%$, phytoplankton $-60 \%$ ). Therefore, a significant fraction of the organic input of sediments is carbohydrates.

\footnotetext{
${ }^{2}$ See glossary, Appendix IV.
} 


\section{CHAPTER I}

\section{HISTORICAL REVIEW OF CARBOHYDRATE GEOCHEMISTRY}

Waksman (1933) proposed that sedimentary marine humus consists of two major fractions. One fraction is allochthenous (foreign origin) and is composed of land-derived lignin-protein complexes, which are of similar nature to terrigenous field soil humus. The other fraction is autochthenous (indigenous) and consists of carbohydrate-protein complexes. The source of the second fraction was postulated to be marine algae. The relative abundance of these fractions was found to vary from location to location with thie former being more important close to shore. A short distance from

- shore $(\sim 1 \mathrm{~km})$, however, the autochthenous fraction dominated. Although the actual composition of the carbohydrates within the extracted humus was not determined by Waksman (1933), I suggest in a later section that the carbohydrate compositionscef various sediments also reflect terrigenous and marine (algal) sources. The relative proportion of the terrigenous and marine carbohydrate fractions is reflected in the relative proportion of acid-extracted glucose and ribose (e.g., p. 107).

ZoBell and Grant (1943) showed that fresh water and marine microorganisms are capable of utilizing even the slightest traces of sugars (and other organics) from dilute nutrient solutions. Therefore, it was proposed that the concentration of free sugars in natural environments would be

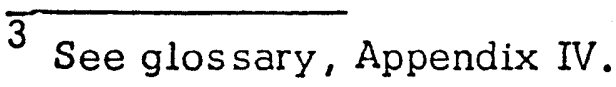


extremely low. This belief has been tested by Vallentyne and Bidwell (1956) who established a semi-quantitative method for the extraction and Identification of free sugars in lake muds.

Their sediments, dredged from various Connecticut lakes, were extracted several times with water and $70 \%$ aqueous ethanol. The combined extracts were deionized with strong cation and anion exchange resins. Losses up to $50 \%$ occurred when ribose and xylose $e^{4}$ standards were passed through the resins; other sugars were unaffected. (The sediment results were not corrected for these losses.) I encountered similar destructive effects when I tested various ion exchange resins (e.g.,p. 62). I found that the high basicity of the anion resin was mainly responsible for this destruction. Converting the anion resin from the hydroxide form to either the formate or bicarbonate form eliminates this problem.

Vallentyne and Bidwell (1956) separated and estimated sugars by means of paper chromatography; identification of sugars was achieved by co-chromatography with sugar standards. A few of the extracts were hydrolyzed in $3 \mathrm{~N} \mathrm{HCl}$ at $100^{\circ} \mathrm{C}$ for five minutes prior to deionization; the sediment residues were hydrolyzed in $0.25 \mathrm{~N} \mathrm{HCl}$ at $100^{\circ} \mathrm{C}$ for one hour. The authors claimed an accuracy of $20 \%$, however, the reproducibility of the extractions were not determined. The following sugars were identified: sucrose, glucose, galactose, fructose, arabinose, xylose, and ribose. Glucose was the most abundant free sugar and was present in concentrations of 100 to $250 \mathrm{mg}$ per $\mathrm{kg}$ sediment ignitable matter. The ignition 
procedure was not described, therefore, it can only be assumed that the ignitable matter represents the total organic matter.

The authors speculated that the source of the free sugars is either from free sugars of higher plants (terrigenous) or from the in situ breakdown of polysaccharides of algae and higher plants. They also proposed that if free sugars are unstable in the sedimentary environment (e.g., a half-life ranging from a few hours to a few weeks), their presence in sediment suggests a steady-state condition in which the input rate of sugars derived from plankton and in situ polysaccharide hydrolysis is balanced by the rate of microbial decomposition. If free sugars are stable in sediment (e.g., half-life of five years or more), then the authors proposed that they may be present in meta-stable sugar-mud associations which are inaccessible to microbial or free-enzyme degradation. In a later section I argue that incorporation of sugars into metal ion-organic complexes enhances their stability in sediment (e.g.,pp. 150-151).

Whittaker and Vallentyne (1957) also conducted a study of free sugars in lake muds (Ontario lakes). The analytical techniques employed were similar to those of Vallentyne and Bidwell (1956). Similar losses on ion exchange resins were reported. The sugars detected were: maltose, sucrose, glucose, fructose, galactose, arabinose, ribose, xylose, and two unknowns. Maltose and glucose were dominant. The total quantity of free sugars detected ranged from traces up to $2.9 \mathrm{~g} / \mathrm{kg}$ of sediment ignitable matter (the ignitable matter was 40 to $50 \%$ of the sediment on a dry weight 
basis; the ignition technique was not described).

Analyses of cores revealed that the concentration of free sugars decreased by two orders of magnitude between the surface and $20 \mathrm{~cm}$; the \% ignitable matter only decreased slightly in this interval ( $20 \%$ decrease), which suggested that sugars are gradually eliminated until a small amount is left below $20 \mathrm{~cm}$; in the interval of 0 to $20 \mathrm{~cm}$ a balance exists between the supply and decomposition of sugars. The authors estimated the decomposition period to be on the order of 20-120 years.

The authors presented evidence to show that tendipedid larvae (two-winged flies) and living bacteria are negligible sources for sedimentary free sugars. They considered seston (dominantly algae) to be the - main source; the seston samples examined contained 2.3 to $42.2 \mathrm{~g}$ sugar per kg dry weight, with glucose and maltose dominant. They speculated that seston could contribute free sugars either directly or indirectly by in situ hydrolysis of polysaccharides. Hydrolysis could be achieved through autolytic enzymes within the plankton cells, through microbial decomposition, and through free enzymes in the mud liberated from dead cells. Evidence for the existence of sedimentary free enzymes was presented by ZoBell (1939).

The seasonal carbohydrate compositions of sediments and associated aquatic plants from several Minnesota lakes were studied by Rogers (1965). The samples were hydrolyzed in $0.5 \mathrm{~N} \mathrm{H}_{2} \mathrm{SO}_{4}$ for 8 to 10 hours. (The extracts were neutralized with $\mathrm{BaCO}_{3}$ and desalted by "ethanolic precipitation" 
and "electronic desalting.") Amounts of sugars were determined by paper chromatography. The total ${ }^{5}$ carbohydrate content was determined by conversion of carbohydrates to furfural with hot $72 \%$ sulfuric acid. It is important to note that the $0.5 \mathrm{~N}$ acid hydrolysis yields are only $20-30 \%$ of the total carbohydrates determined by the furfural test. On pp. 54-58 of the present thesis, I show that the acid hydrolysis yields and the relative proportions of constituent sugars released varies strongly with the concentration of acid used. For example, the yield of the $2.0 \mathrm{~N} \mathrm{H}_{2} \mathrm{SO}_{4}$ hydrolysis is about four times larger than the yield of the $0.5 \mathrm{~N} \mathrm{H}_{2} \mathrm{SO}_{4}$ hydrolysis. In the latter extraction[pentoses] [hexoses], while in the former extraction [hexoses] > [pentoses]. Rogers' results, which are summarized - below, must be viewed in light of these findings.

The major sugars detected in the sediments were ribose, mannose, rhamnose, glucuronic acid, galactose, glucose, arabinose, and xylose. The major sugars detected in the plants were glucose, galactose, xylose, arabinose, and glucuronic acid. The sediment extracts obtained by $0.5 \mathrm{~N}$ $\mathrm{H}_{2} \mathrm{SO}_{4}$ contained on the average $9 \mathrm{mg}$ sugar per $\mathrm{g}$ dry weight of sediment. The plant extracts contained 400-500 mg sugar per g dry weight of plant material. In the plants the concentration of total hexoses (glucose, galactose, and mannose) was greater than the concentration of total pentoses (arabinose, xylose, and ribose). The reverse was observed for the sediments. No seasonal shifts in composition were observed for either plants

\footnotetext{
or sediments.

${ }^{5}$ Total refers to all carbohydrates detected by a concentrated sulfuric acid method.
} 
The author states that surface sediments contain les than $1 \%$ of the total carbohydrates in the standing crop of aquatic plants, although no biomass measurements are mentioned.

In core samples a sharp break in the total sugars (extracted with 0.5 $\mathrm{N} \mathrm{H}_{2} \mathrm{SO}_{4}$ ) with depth, of the sort observed by Whittaker and Vallentyne (1957), was not found. An irregular temporal variation was observed. The author hypothesized that this variation was due to changes in the rate of contribution, changes in the composition of the organic input, and changes in the conditions of preservation ( $\mathrm{Eh}$ and $\mathrm{pH}$ ). The results of the present thesis research support Rogers' hypothesis (e.g., pp. 113-118).

A relative increase in glucose and decrease in arabinose with depth was observed by Rogers (1965). He suggested that this pattern may reflect relative stabilities rather than a long-term change in the input.

The author proposed three mechanisms for the preservation of sedimentary carbohydrates: (1) decreased biological consumption in reducing environments; (2) adsorption onto and into clays; and (3) formation of large molecular or colloidal complexes with lignin, humus, kerogen, and chitin. 6

Swain and Bratt (1972) compared the carbohydrate geochemistry of sediments from Delaware Bay, Broadkill Marsh (Delaware), and Gulf of California. Free sugars were extracted by refluxing with boiling water for 8 hours. Polysaccharides were hydrolyzed with cold $72 \% \mathrm{H}_{2} \mathrm{SO}_{4}$ followed by refluxing at $100^{\circ} \mathrm{C}$ with $0.5 \mathrm{~N} \mathrm{H}_{2} \mathrm{SO}_{4}$ for 8 to 10 hours. The $72 \% \mathrm{H}_{2} \mathrm{SO}_{4}$ treatment breaks up resistant polysaccharides (Degens and Reuter, 1964). ${ }^{6}$ See glossary, Appendix IV. 
23

Sugars were separated by paper chromatography and quantified with a recording densitometer. A few polysaccharides were characterized by enzymatic analyses; the enzymes employed were $\alpha$ and $\beta$ amylase, cellulase, and laminarase. Polysaccharides of sufficient molecular weight to be detected were present in very low concentrations $(<10 \mathrm{ug} / \mathrm{g}$ sediment dry weight); cellulose and laminarose were the polysaccharides most commonly observed.

The sugars detected in all three environments after hydrolysis were: galactose, glucose, mannose, arabinose, xylose, ribose, and rhamnose. In the marsh environment 0.2 to $6.8 \mathrm{mg} \mathrm{sugar} / \mathrm{g}$ dry weight of sediment were detected after acid hydrolysis; the bay sediments released 0.06 to 0.26 $\mathrm{mg} / \mathrm{g}$ and the gulf sediments released 1.8 to $3.4 \mathrm{mg} / \mathrm{g}$. Free sugars constituted about $5 \%$ of the total (determined by acid hydrolysis) in the marsh sediment, $20-50 \%$ of the total in the bay sediments, and 1 to $2 \%$ of the total in the gulf sediments.

The authors classified the marsh sedimentary environment as highenergy oxic, and the bay environment as low-energy oxic. Carbohydrate material originating in the marsh was not detected to any great extent in the bay sediment, therefore, it was concluded that this material had undergone degradative oxidation before reaching the bay. The authors do not explain what is meant by degradative oxidation and furthermore they make the untested assumption that carbohydrates are transported out of the marsh. 
The gulf environment was classified as low-energy anoxic; it was concluded that carbohydrates were well preserved in this environment due to the lower biological consumption rate. The results of the present thesis (e.g., p. 140) support the conclusion that consumption rates are lower in anoxic environments.

The study of carbohydrates in ancient sediments has been largely conducted by Swain and his associates (e.g., Palacas et al. , 1960; Swain, 1963; Swain and Rogers, 1966; Swain et al., 1967; Swain et al. , 1968; Swain, 1969).

Swain and Rogers (1966) examined the stratigraphic distribution of carbohydrates in Middle Devonian Onondaga beds of Pennsylvania and - New York. The total carbohydrate content of 5 to $10 \mathrm{~g}$ of crushed rock sample, was determined by a phenol-sulfuric acid method in which carbohydrates were converted to furfural with $50 \% \mathrm{H}_{2} \mathrm{SO}_{4}$ and detected spectrophotometrically after reaction with phenol. The average total carbohydrate content was $50 \mathrm{mg} / \mathrm{kg}$ of rock. Significant variations were attributed to differences in source material, proximity to the cratonic land mass, and conditions of deposition.

Polysaccharides were hydrolyzed in $0.5 \mathrm{~N} \mathrm{H}_{2} \mathrm{SO}_{4}$ for 8 to 10 hours under reflux. Thus, the results of Swain and Rogers (1966) are subject to the same limitations as those of Rogers (1965). The samples were neutralized with $\mathrm{BaCO}_{3}$ and desalted by "ethanolic precipitation" and ion exchange resins; sugars were identified and measured by paper chromatography. 
Generally less than $10 \%$ of the total (phenol-sulfuric acid) were extracted by this method. Mannose, glucose, and xylose were the dominant sugars detected.

The authors concluded that the pentoses in the Onondaga rocks were dominantly land-derived while hexoses were dominantly marine-derived. This conclusion, however, is not well-established since post-depositional effects of ground water action and metamorphism were not considered.

Analysis of present-day sediments might more clearly define the natural variations in carbohydrate contents in different sedimentary environments; this is one of the goals of the present thesis research.

Swain et al. (1967) examined the distribution of carbohydrates in marine fossils and associated rock matrices. The goals of that research were to discern paleo-environmental factors and evolutionary changes. Extraction techniques were similar to those of Rogers (1965) and Swain and Rogers (1966) above and, hence, were subject to the same limitations. Again, less than $10 \%$ of the total was extracted with the $0.5 \mathrm{~N} \mathrm{H}_{2} \mathrm{SO}_{4}$ treatment.

The range of total carbohydrate content was 4 to $900 \mathrm{mg} / \mathrm{kg}$ of sample for the fossils and 15 to $660 \mathrm{mg} / \mathrm{kg}$ of rock for the matrices. Hexoses generally predominated in most of the samples. No clear-cut relationship was found between the sugar contents of the fos sils and of their associated matrices. Generally, the total carbohydrate concentrations in neritic fossils were approximately equal to those in littoral fossils. The 
carbohydrate content in littoral matrices, however, was about $30 \%$ greater than in neritic matrices. The authors stated that littoral sediments received land- derived particulate organics and are therefore relatively enriched in carbohydrates.

The effects of weathering and percolating ground-water were not assessed. The effect of metamorphism was considered for one sample; a Devonian shale was heated ('metamorphosed') for two hours at $150-225^{\circ} \mathrm{C}$; the total carbohydrate yield increased up to a point and then decreased. The effect of this treatment on the relative abundances was not determined.

In light of the errors arising from contamination, metamorphism, and incomplete extraction, conclusions drawn from the above studies of sedimentary rocks must be considered highly speculative.

Prashnowsky et al. (1961) studied the distribution of sugars in $4 \mathrm{~m}$ sediment core from the Santa Barbara Basin (off California). The core contained grey-green, sulfide-rich, laminated sediment; interspersed turbidite and oxic sediment bands were noted. Although the water above the sea floor is presently anoxic, bottom oxygen values must occasionally have been high enough to support benthic life to produce the oxic layers. The carbohydrate analyses were made with no selection according to sediment type.

Sugars were extracted with an unspecified $\mathrm{H}_{2} \mathrm{SO}_{4}$ technique, followed by desalting on ion exchange resins. Separation and quantification was accomplished by paper chromatography. The total sugars detected ranged 


\section{7}

from 0.2 to $2.2 \mathrm{mg} / \mathrm{g}$ dry weight; the percent of the total organic matter represented by extracted sugars was 0.6 to $4.3 \%$ (usually $2-4 \%$ ). No apparent correlations between sugar concentration,grain size, moisture and $\mathrm{CaCO}_{3}$ contents were observed.

Galactose and mannose were most abundant, followed by glucose and rhamnose; the pentoses, ribose, xylose, and arabinose, were least abundant. Four different temporal patterns were discerned: (1) one followed by galactose and mannose; (2) one followed by glucose and rhamnose; (3) one followed by xylose and arabinose; and (4) one followed by ribose. The authors speculated that these patterns were probably caused by variations in the supply of organic matter and by changes in theither at the time of deposition or during early diagenesis. An alternative explanation, involving the natural chromatographic separation of organic molecules along clay surfaces during compaction, was also suggested. In view of the variations in the sediment types (anoxic, oxic, turbidite) and the indiscriminant sampling, this latter explanation is probably unnecessary. In fact, in a later section I argue that the mobility of potentially soluble carbohydrates in sediment is strongly inhibited by binding with metals (p. 118).

From the low relative abundance of glucose in the sediment, compared to continental plants, the authors concluded that allochthenous (landderived) carbohydrates were insignificant sources for sedimentary carbohydrates. Marine algae was thought to be the most probable source. 
A study of carbohydrates in marine oxic sediments from the San Diego Trough was presented by Degens et al. (1963). The core was approximately $3 \mathrm{~m}$ Iong ( $\sim 35,000$ years B.P. at the bottom) and consisted of hemipelagic light green mud. A positive Eh $(+200$ to +300$)$ was observed throughout.

The extraction methods involve treatment of sediment in cold $72 \%$ $\mathrm{H}_{2} \mathrm{SO}_{4}$ and further hydrolysis in $1 \mathrm{~N} \mathrm{H}_{2} \mathrm{SO}_{4}$ followed by desalting and detection by paper chromatography. The concentration of total acid extractable sugars decreased from $850 \mathrm{mg} / \mathrm{kg}$ (dry weight) in surface sediments to $110 \mathrm{mg} / \mathrm{kg}$ at $3 \mathrm{~m}$. In surface sediments extracted sugars plus amino acids were approximately $15 \%$ of the total organic matter; at $3 \mathrm{~m}$ they repre-. sented less than $2 \%$.

The authors pointed out that differences in relative abundances and concentrations of individual sugars between an oxidizing environment (San Diego Trough) and a reducing environment (Santa Barbara Basin) are not very strong. It was suggested that in both environments sugars are consumed as an energy source and are not otherwise metabolically altered or transformed to any great extent. The results of the present thesis research (Chapter V) confirm that the relative abundances of sugars in oxidizing and reducing environments are similar. However, relative to total organic carbon, sugars are enriched in reducing environments and depleted in oxidizing environments, which suggests that the degree of consumption of carbohydrates in oxidizing environments is considerably higher. 
Degens et al. (1963) observed that total hexoses and total pentoses followed similar depth distribution patterns. However, a linear decrease in cellulose-glucose was also observed which suggests that even when sugars are in this stable combined form, they are biologically consumed in oxic environments.

From the presence of phenolic compounds (lignin derivatives), a $\delta \mathrm{C}^{13}$ value of -21.8 for the humic fraction, and an amino acid pattern within the humic fraction similar to that found in soils, the authors deduced a terrigenuus source for the organic matter in the San Diego Trough. This conclusion contradicts that of Waksman (1933) and Prashnowsky (1961).

Degens et al. (1964) proposed the existence of labile and refractory carbohydrate inputs to sediment. The labile input is thought to consist of indigenous algal material which is consumed rapidly in oxic sediments. The refractory input is attributed to clay-sugar complexes and humic-sugar complexes which the authors considered to be principally derived from terrigenous sources. This proposed bimodal organic input is similar to that presented by Waksman (1933).

Carbohydrate analyses of sediment from the experimental Mohole were presented by Rittenberg et al. (1963). The coring device penetrated $2.5 \mathrm{~m}$ of red clay and $173 \mathrm{~m}$ of calcareous and siliceous hemipelagic ooze. The oldest sediments were Middle Miocene in age. The sediments were oxic throughout $(E h \sim+300)$. The organic carbon varied between 0.2 and $2 \%$, which are typical values for oceanic sediment (Bordovskiy, 1965). 
Sugars were extracted as follows: 5-10 g of dried sediment were treated in $72 \% \mathrm{H}_{2} \mathrm{SO}_{4}$ for one hour at $4^{\circ} \mathrm{C}$ followed by dilution to $\mathrm{I} \mathrm{N}$ and further hydrolysis for 8 hours. $\mathrm{BaCO}_{3}$ was added for acid neutralization and ion-exchange resins were used to desalt the samples. Sugars were identified and measured by paper chromatography. The sugars detected were galactose, glucose, mannose, rhamnose, arabinose, xylose, and ribose. Total hexoses always exceeded total pentoses; the depth distribution patterns of the two groups of sugars were nearly identical.

The acid extractable sugars represented about $4 \%$ of the organic matter in the surface sediments and about $0.1 \%$ at a depth of $50 \mathrm{~m}$. Below $50 \mathrm{~m}$ the value fluctuated around $0.1 \%$. Free sugars (ethanol-extractable) were detected only in the upper meter of the core and represented less than $1 \%$ of the total acid extractable sugars.

Modzeleski et al. (1971) employed gas chromatographic-mass spectrometric (g.c.-m.s.) analysis of trimethylsilyl derivatives to determine the carbohydrate composition of Santa Barbara Basin sediment. Carbohydrates were extracted from exhaustively washed sediment (p. 119) by a sulfuric acid hydrolysis method followed by neutralization with $\mathrm{Ba}(\mathrm{OH})_{2}$ and desalting on ion exchangers.

Identification and quantification of sugars by g.c.-m.s. is not only more accurate and sensitive than paper chromatographic methods used by previous investigators, it also permits independent identification of sugar 


\section{1}

peaks. Prior to the study of Modzeleski et al. (1971) no absolute identification of sedimentary sugars had been performed. This lack of positive identification probably resulted in either mis-identification or lack of detection of certain sugars. For example, Modzeleski et al. (1971) determined that fucose (an important algal sugar) is present in their samples in concentrations comparable to that of glucose; Prashnowsky et al. (1961) detected only traces of this 'sugar' in Santa Barbara Basin sediments. In other investigations this sugar has remained completely undetected.

In addition to the problem of sugar identification, none of the above investigators thoroughly examined their extraction techniques for errors arising from contamination, incomplete extraction, and poor reproducibility. Furthermore, direct comparison of the results of different investigators has proved difficult because of the variations in extraction techniques and means of identification. For example, free sugars were extracted in either boiling or cold $70 \%$ ethanol for 5 minutes to eight hours; in a few instances distilled water alone was used as the extractant (Vallentyne and Bidwell, 1956; Whittaker and Vallentyne, 1957; Swain, 1969). Hydrolysis techniques varied widely; e.g. , Vallentyne and Bidwell (1956) used .25 N HCl for one hour at $100^{\circ} \mathrm{C}$ i Rogers (1965) used .5 $\mathrm{N} \mathrm{H}_{2} \mathrm{SO}_{4}$ for 8- 10 hours at $100^{\circ} \mathrm{C}$; Swain and Bratt (1972) used the technique of Rogers (1965) but treated the sediment in cold concentrated $\mathrm{H}_{2} \mathrm{SO}_{4}$ for one hour prior to hydrolysis in $.5 \mathrm{~N} \mathrm{H}_{2} \mathrm{SO}_{4}$; Degens et al. (1963) treated sediment in cold concentrated $\mathrm{H}_{2} \mathrm{SO}_{4}$ for 2-4 hours with further hydrolysis in $1.0 \mathrm{~N} \mathrm{H}_{2} \mathrm{SO}_{4}$ 
for 8 hours. Modzeleski et al. (1971) extracted sediment in $2 \mathrm{~N} \mathrm{H}_{2} \mathrm{SO}_{4}$ for 90 minutes at $100^{\circ} \mathrm{C}$ followed by centrifugation and re-extraction in $2 \mathrm{~N} \mathrm{H}_{2} \mathrm{SO}_{4}$ for an additional 60 minutes.

Neutralization was usually accomplished by addition of either $\mathrm{BaCO}_{3}$ or $\mathrm{Ba}(\mathrm{OH})_{2}$. A variety of desalting techniques were employed: "ethanolic precipitation", ion exchange resins (different types), and "electronic desalting" •

Different eluents and different sugar location reagents of varying sensitivities were employed in the paper chromatographic methods.

If the state of the art of sugar extraction from sediment had to be summarized briefly, that summary would have to be: crude, primitive, and uncertain. 


\section{GOALS OF THE RESEARCH}

The goals of the present thesis have been oriented toward elucidation of the following questions:

(i) What is the carbohydrate composition of sediment in different environments (e.g., deep-sea oxic; shallow-sea oxic; deep-sea anoxic; fresh-water anoxic; brackish-water anoxic, etc.)?

(ii) How does the environment at the sediment-water interface affect the composition of the carbohydrate input?

(iii) How do sedimentary carbohydrates compare to plankton carbohydrates?

(iv) How do metal-carbohydrate interactions and biological degradation affect the diagenesis of carbohydrates in recent sediments?

(v) Can fossil carbohydrates be used as a means to elucidate paleoenvironments?

From the previous section ('Historical Review') it is evident that before investigating these problems it is first necessary to establish reliable extraction procedures. Therefore, in the following chapter the various extraction techniques will be thoroughly examined in order to determine lability of sugars, sources of contamination, maximum yields, and reproducibility.

Establishment of a chromatographic sugar analyzer system and the positive identification of sedimentary sugars are also described. 


\section{4}

CHAPTER II

\section{ANALYTICAL PROCEDURES}

\section{AUTOMATIC SUGAR CHROMATOGRAPHY}

The distribution and diagenesis of carbohydrates in sediments has been largely ignored by investigators in the field of organic geochemistry. The primary hindrance to this research has been the lack of appropriate analytical techniques to: i) quantitatively extract sugars from sediment and ii) separate and identify the component sugars.

The latter difficulty has been resolved through the advent of automatic sugar analyzer systems which are based on the design of the liquid chromatographic amino acid analyzer (Moore and Stein, 1951). However, $\cdots$

in contrast to the ion exchange technique used in amino acid analyzers, the sugar analyzer employs a partition chromatographic technique. Other sugar instrumentation techniques, such as gas chromatography-mass spectrometry, paper chromatography, and thin layer chromatography are less satisfactory; a review of sugar instrumentation is presented in my Master's Thesis (Mopper, 1970).

The automatic sugar analyzer described in this section was constructed as part of my Master's Thesis research. Therefore, only a summary will be presented here.

Several investigators have constructed automatic sugar analyzers (Larsson and Samuelson, 1965; Kesler, 1967) and a system is available 
from Technicon Corporation. These systems suffer from three flaws: (I) concentrated sulfuric acid is employed in the dye reaction (e.g., p. 4l); (2) the detection limit is only $10^{-8}$ to $10^{-9}$ moles; and (3) the use of multichannel peristaltic pumps results in poor reproducibility due to rapid exhaustion of pump tubing. The above difficulties have been avoided in the present system (Mopper and Degens, 1971).

A schematic diagram of the sugar analyzer is depicted in Figure 1. A $200 \mathrm{~cm}$ nylon column (i.d. $0.28 \mathrm{~cm}$ ) filled to $180 \mathrm{~cm}$ with Technicon type $\mathrm{S}$ resin ( $8 \%$ cross-linked, ion-exchange styrene-divinylbenzene beads, $20 \mu$ in diameter) is placed in a glass heating jacket through which water at $76^{\circ} \mathrm{C}$ is circulated by a Haake type $F$ constant-temperature circulator. The resin bed is recessed several $\mathrm{cm}$ in the heating jacket to heat the eluent to the temperature of the column. Another Haake circulator is employed in the reaction bath. A Gilford 2000 spectrophotometer with a $5 \mathrm{~mm}$ flow-through cuvette is used for all color recognition and recording. A 3 meter reaction coil of Teflon spaghetti tubing $(0.0027 \mathrm{cc} / \mathrm{cm}$ capacity) is placed between column exit and cuvette exist. Tube fittings are stainless steel (Swagelok). The eluent and dye are pumped with Beckman Accu-Flo piston pumps .

The column was filled according to techniques described by Samuelson (1963). The resin, initially in the borate form, was converted to the sulfate form by pumping $200 \mathrm{ml} 0.5 \mathrm{M} \mathrm{Na}_{2} \mathrm{SO}_{4}$ through the resin bed. The column was washed with water and conditioned for $8 \mathrm{hr}$ by pumping the 


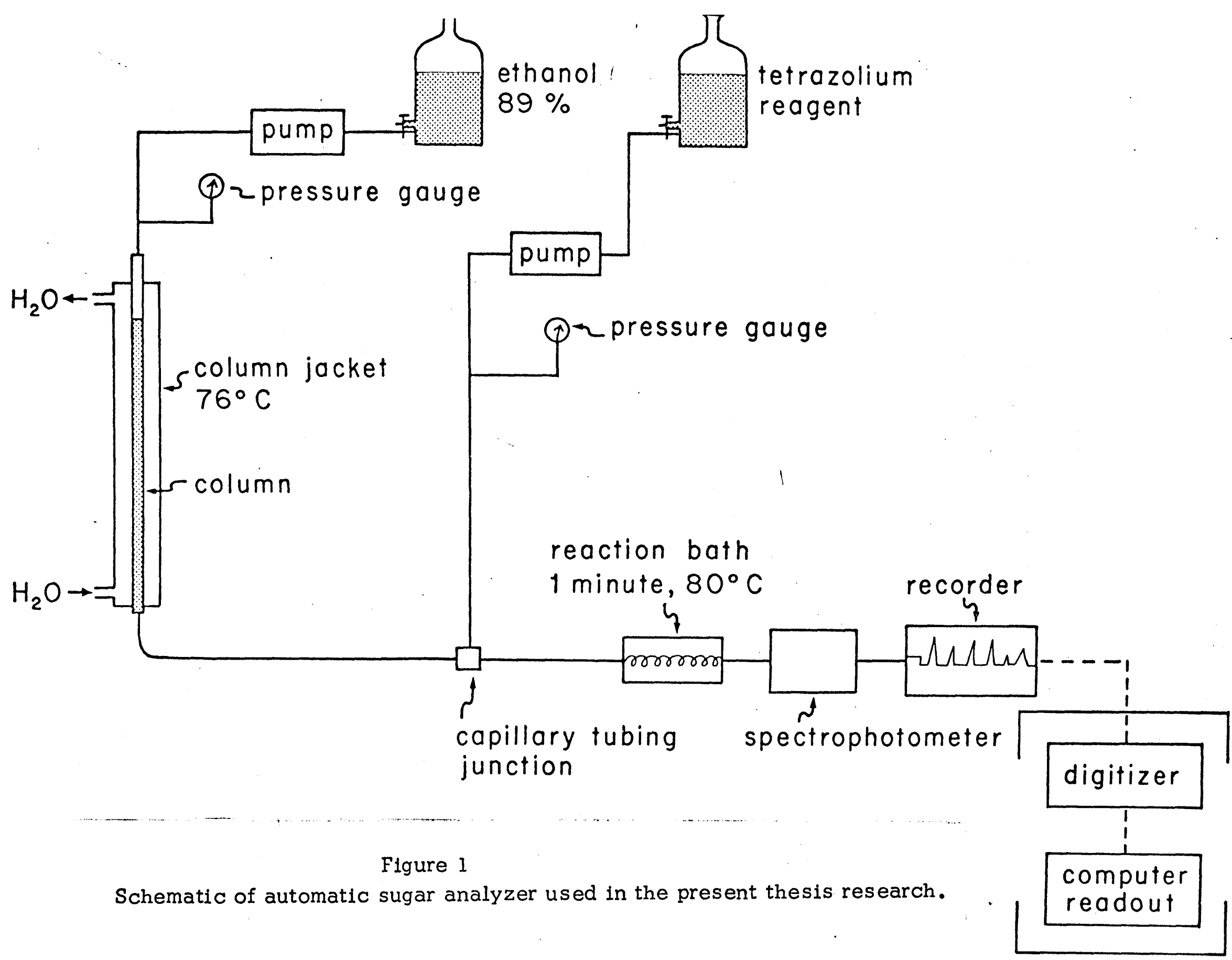


eluent at the flow rate and temperature used during analyses.

The eluent is made by diluting $95 \%$ ethanol (not denatured) to $88 \%$ with distilled water.

A 0.50 M solution of $\mathrm{Na}_{2} \mathrm{SO}_{4}$ is employed for column regeneration. The column is repacked and regenerated about every 50 samples.

Reagent grade sugars were purchased from Mann Research Laboratories. A standard was prepared by dissolving $0.1 \mathrm{gm}$ each of the following sugars in $100 \mathrm{ml} \mathrm{H}_{2} \mathrm{O}$ : deoxyribose (d-Ri), rhamnose $(\mathrm{Rh})$, ribose (Ri), arabinose (A), xylose (X), mannose (M), galactose (Ga), and glucose (Gl)。

The dye consists of $2.0 \mathrm{gm}$ tetrazolium blue (p-anisyltetrazolium chloride, $\mathrm{K} \& \mathrm{~K}$ Laboratories) in 1 liter of $0.18 \mathrm{M} \mathrm{NaOH}$. The tetrazolium blue is recrystallized several times from methanol until the melting point (with decomposition) is $239-240^{\circ} \mathrm{C}$ (Cheronis and Zymaris, 1957).

Samples are injected with a micro-syringe into the top of the resin bed. The eluent pump (set at $.36 \mathrm{ml} / \mathrm{min}$ ) is connected to the top of the column and the dye pump (set at $.12 \mathrm{ml} / \mathrm{min}$ ) is connected to the column eluate via a mixing chamber. Figure 2 depicts a chromatogram of a sțandard sugar solution containing $15 \mu \mathrm{g}$ of each sugar.

The elvtion order and retention time of individual monosaccharides were determined by spiking one sugar at a time into the standard. The system was calibrated by measuring peak areas. Aliquots of the standard solution $(5,10,15,20,25 \mu \mathrm{l})$ were analyzed. Figure 3 suggests that most sugars react in a similar manner with the tetrazolium dye. 


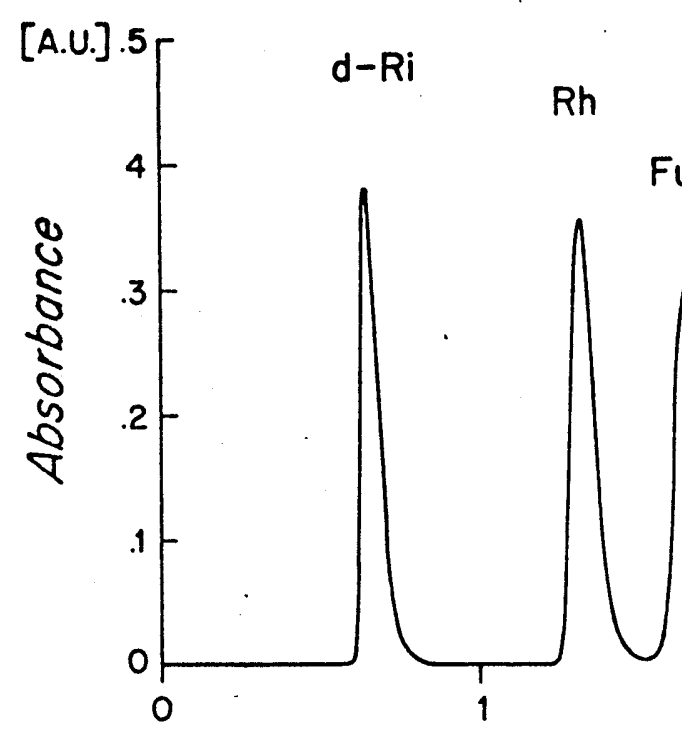

Fu Ri

Untreated Standard

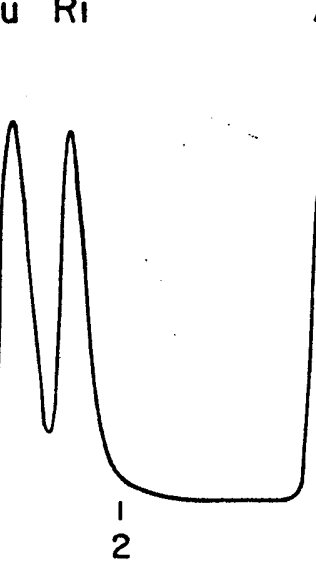

A
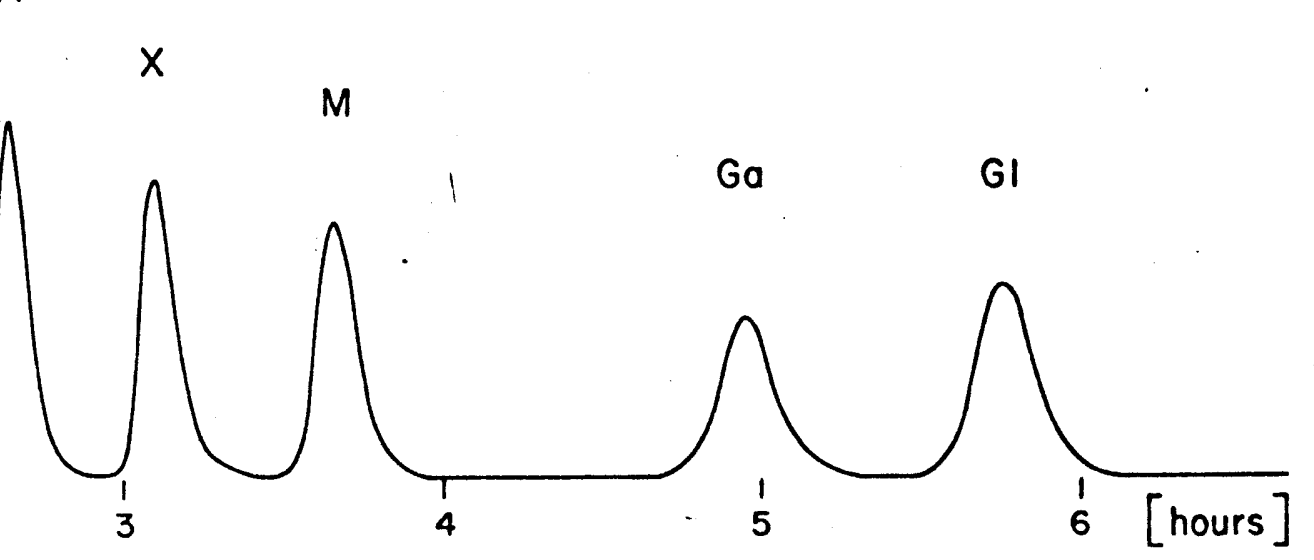

Time

Figure 2

Chromatogram of a standard sugar solution. The concentration of each sugar in the solution 1 s $1000 \mu \mathrm{g} / \mathrm{ml}$. Each peak represents $15 \mu \mathrm{g}$ of d-Ri: deoxyribose, Rh: rhamnose, Fu: fucose, Ri: ribose, A: arabinose, X: xylose, M: mannose, Ga: Galactose, and Gl: glucose. 

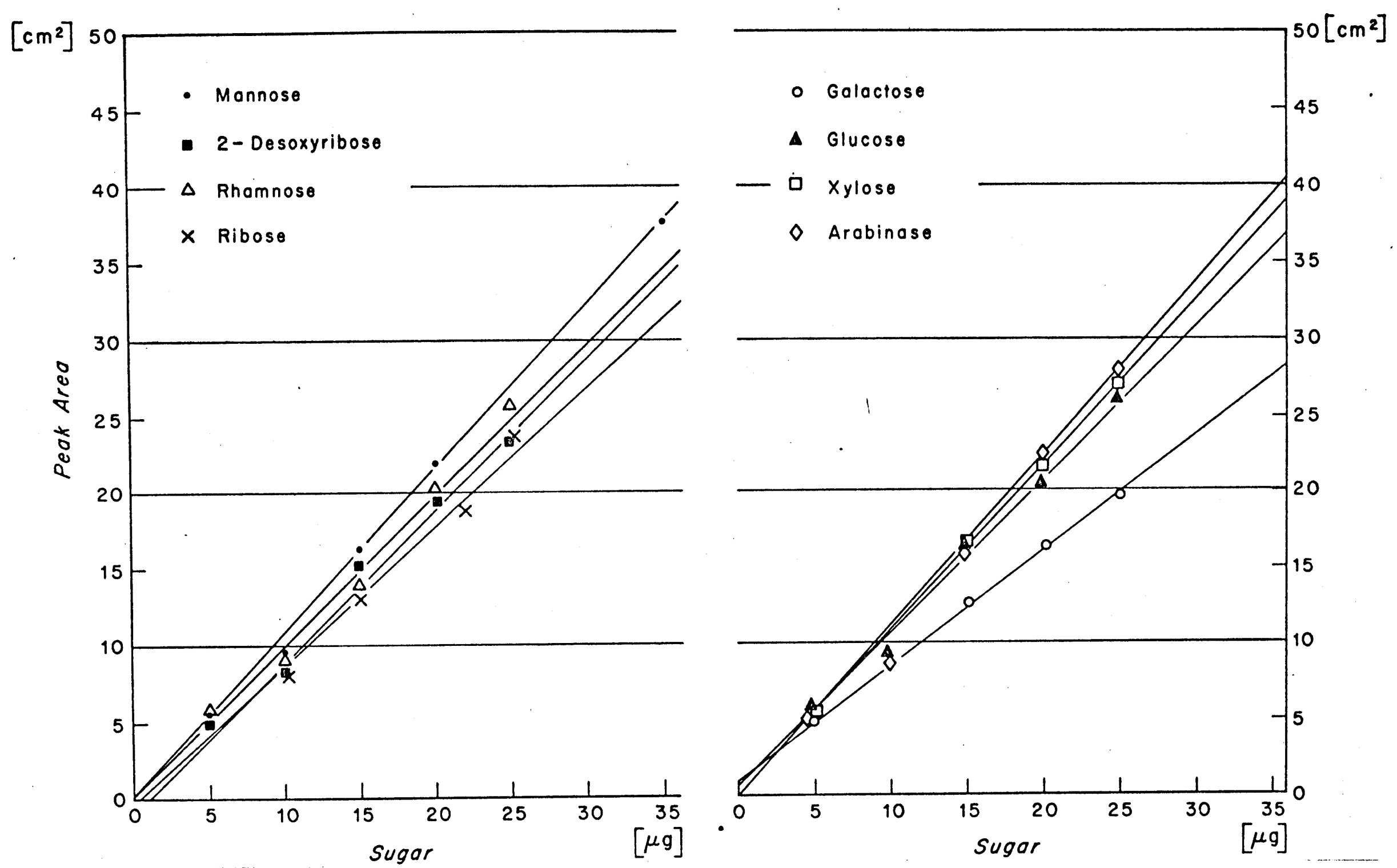

Quantification of sugar analyzer by peak areas. Slopes of most sugars are nearly identical, which indicates that most sugars react in a similar manner with the tetrazolium dye. A full-scale absorbance of . 4 absorbance units was employed. 
All absorbances are read at $520 \mathrm{m \mu}$. Beer's Law holds for sugar concentrations of less than $50 \mu \mathrm{g} / \mathrm{ml}$. The detection limit is $10^{-10}$ moles of sugar at a full-scale absorbance of 0.10 absorbance units. This system gives reproducible results of better than $\pm 5 \%$ at the $10^{-8}$ mole level.

The following parameters were investigated during the construction of the sugar analyzer:

\section{a. Type of Eluent}

Two elution methods are in common use: $\mathrm{NaCl} /$ borate eluent and ethanol,'water eluent. The ethanol eluent is employed in the present system because the tetrazolium blue-sugar reaction fails to give reproducible results in the presence of $\mathrm{NaCl} /$ borate solutions.

Ethanol concentrations greater than $92 \%$ results in excessive elution volumes and peak broadening. At concentrations under $85 \%$, peaks are insufficiently resolved to permit quantitative evaluation.

b. Eluent Flow Rate

High flow rates lead to decreased elution times and poor resolution. Xylose and mannose are poorly resolved at a flow rate of $1.2 \mathrm{ml} / \mathrm{min}$, but are completely resolved at $<0.6 \mathrm{ml} / \mathrm{min}$. Further, at the faster flow rate a higher pressure drop across the column is measured $(\dot{\sim} 700 \mathrm{psi})$. In the present system the pressure drop is about $500 \mathrm{psi}$.

\section{c. Resins}

Several strong anion- or cation-exchange resin can be used; fine-grained resins of uniform particle size gave the best resolution 
(Mopper, 1970). For this reason Technicon resin (type $S, 20 \mu$ ) is employed, although Dowex $21-\mathrm{K}(1-16 \mu)$ in chloride and sulfate forms and Dowex 50 $\mathrm{W}-\mathrm{X} 8(14-17 \mu)$ in potassium, sodium, and lithium forms have also been applied with success (Jonsson and Samuelson, 1967; Samuelson and Stromberg, 1968).

Separation of sugars is attributable to their partition between water held in the resin beads and water in the exterior solution. The more polar sugar molecules are held more strongly by the resin. The general order of elution is: deoxypentoses, deoxyhexoses, pentoses, hexoses, and disaccharides.

\section{d. Dimensions of Resin Bed}

Long columns $(>100 \mathrm{~cm})$ with narrow diameters $(<0.3 \mathrm{~cm})$ yield the greatest sensitivity and resolution.

\section{e. Column Temperature}

Increasing the column temperature increases the rate of diffusion

into and within the resin beads and: (i) reduces the time for analysis, (ii) reduces the pressure drop across the column, and (iii) increases the resolution. A temperature of $76^{\circ} \mathrm{C}$, which is just below the boiling point of ethanol, is used.

\section{f. Dye Reagent}

The usual dyes employed in automatic sugar analyzers are corrosive and dangerous to manipulate (i.e., orcinol-sulfuric acid, anthrone-sulfuric acid, and phenol-sulfuric acid). To avoid these difficulties a noncorrosive, 


\section{2}

yet highly sensitive, dye was developed: an alkaline $0.2 \%$ solution of tetrazolium blue (Cheronis and Zymaris, 1957). Until now this dye was inapplicable in automatic sugar analyzers because of the precipitation of diformazan which clogs the capillary tubing:

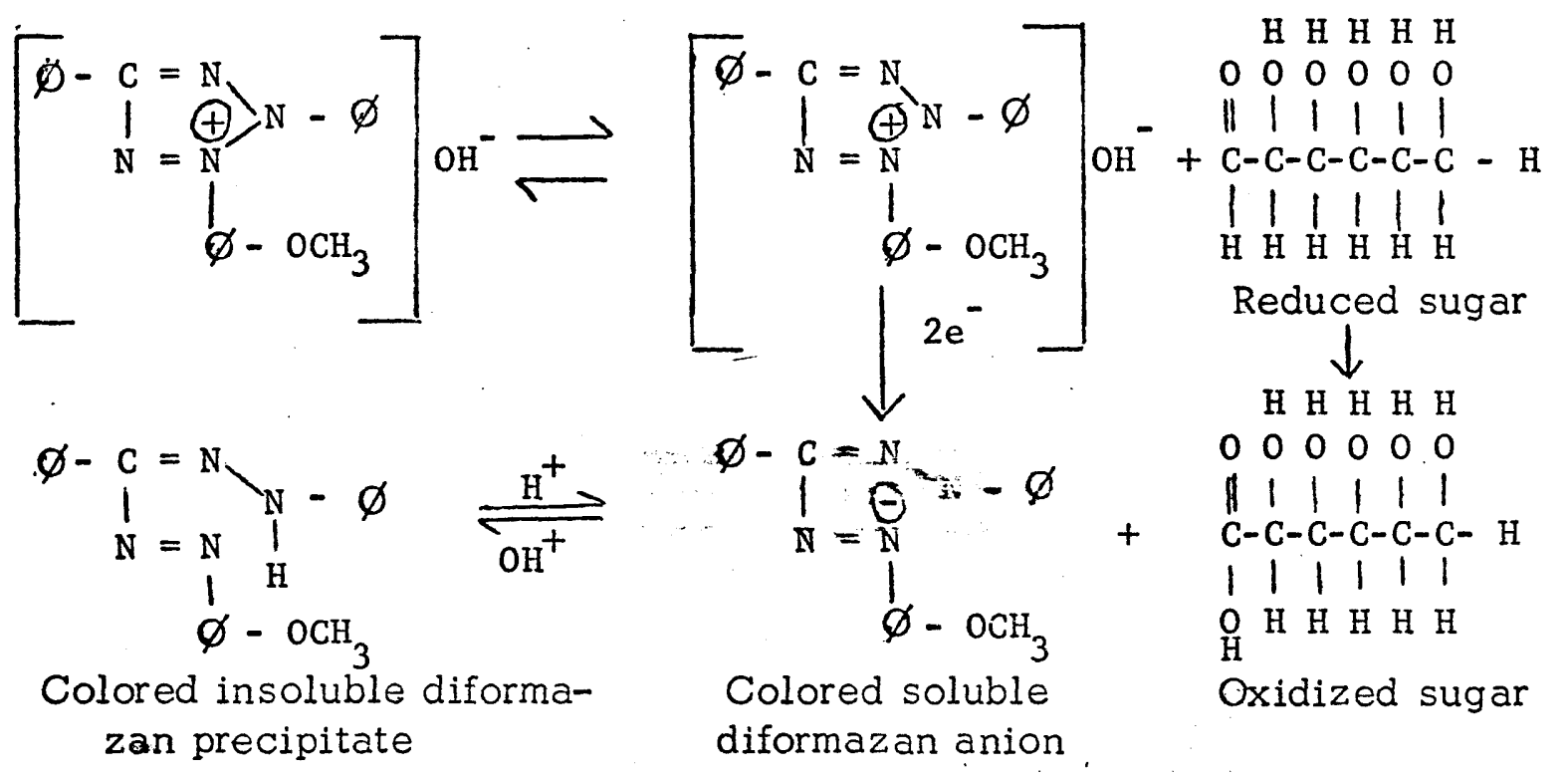

To overcome these difficulties solvents such as dioxane, acetone, and ethanol were added to the tetrazolium blue solution to test their effectiveness in preventing the precipitation of diformazan. Success was achieved only with ethanol; fortunately ethanol is a good eluent for the separation of sugars. By adjusting eluent and dye flow rates maximum dye sensitivity was achieved. 


\section{3}

\section{APPLICATION OF SUGAR ANALYZER TO SEDIMENT}

Presented in this section are various lines of evidence which show that the compounds isolated from sediment and recorded spectrophotometrically are indeed sugars.

\section{a. Clean-up Procedure}

Both the sediment extraction procedure and the sugar analyzer system are highly selective for reducing sugars. For example, hydrolysis in $1.8 \mathrm{~N}$ HCl eliminates all acid-labile compounds; the ion exchange resins used for desalting eliminates all compounds which are highly polar such as amino acids, fatty acids, uronic acids, glyconic asids, hexose amines, etc. Only compounds capable of reducing the tetrazolium reagent are detected on the sugar analyzer, hence sugar alcohols (mannitol, sorbitol, etc.) and glycaric acids elute undetected. Furthermore, only those reducing compounds which are eluted between a half hour and five hours are examined; compounds which are held weakly by the resin, such as furfural and furfural derivatives, are eluted early in the chromatogram; compounds which are held strongly by the resin, such as disaccharides and aromatic aldehydes (lignin derivatives), are eluted as very broad, almost imperceptible peaks many hours after the monosaccharides.

b. Co-chromatography

Argentine Basin sediment was spiked with the standard prior to extraction in order to determine the destructive effects of different extraction techniques. The peaks from both the sediment and spiked sugars co-chromatograph 


\section{TABLE 1}

Spiking of Argentine Basin sediment (2g) with a standard sugar solution

(numbers represent peak areas in $\mathrm{cm}^{2}$ )

A. HCl Hydrolysis

\begin{tabular}{|c|c|c|c|c|c|c|c|c|}
\hline Sugars: & $\mathrm{Rh}$ & Fu* & Ri & $A^{*}$ & $x$ & M & $\mathrm{Ga}^{*}$ & G1 \\
\hline unspiked sample & 6.6 & 7.8 & 2.7 & 7.0 & 6.8 & 10.9 & 14.0 & 14.8 \\
\hline spike added & 9.1 & -- & 8.3 & -- & 9.1 & 9.0 & -- & 9.0 \\
\hline spiked sediment & 15.6 & 8.2 & 7.7 & 7.4 & 15.4 & 19.4 & 13.9 & 22.9 \\
\hline spike found & 9.0 & +.4 & 5.0 & +.4 & 8.6 & 8.5 & -.1 & 8.1 \\
\hline $\begin{array}{l}\% \text { of spike des- } \\
\text { troyed }\end{array}$ & 1 & -- & 40 & -- & 5 & 6 & -- & 10 \\
\hline & & & Hydro & $\begin{array}{l}\% \text { ave } \\
\text { EDTA }\end{array}$ & $\begin{array}{l}\text { devia } \\
\text { action }\end{array}$ & for $s$ & sugars: & $12 \%$ \\
\hline unspiked sample & 5.0 & 5.6 & 2.8 & 3.8 & 5.9 & 5.2 & 9.0 & 7.2 \\
\hline spike added & 9.1 & -- & 8.3 & -- & 9.1 & 9.0 & -- & 9.0 \\
\hline spiked sediment & 13.5 & 5.5 & 9.4 & 3.8 & 14.1 & 14.3 & 8.7 & 16.3 \\
\hline spike found & 8.5 & -.1 & 6.6 & 0 & 8.2 & 9.1 & -.3 & 9.1 \\
\hline $\begin{array}{l}\% \text { of spike des- } \\
\text { troyed }\end{array}$ & 7 & -- & 20 & -- & 10 & 0 & -- & 0 \\
\hline
\end{tabular}




\section{5}

exactly. Table ${ }^{7}$ shows the results of this experiment. Changes in various parameters of the sugar analyzer system, e.g., column flow rate and column temperature, do not alter this exact correspondence of peaks.

\section{c. Absolute Identification of Sugars by Gas Chromatography-Mass Spec-} trometry

Figure 4 shows the results of an intercalibration experiment between my liquid chromatography system and the gas chromatography-mass spectrometry system described and operated by Modzeleski et al. (1971). It is important to note that all the gas chromatographic peaks were identified by comparing their mass spectral patterns with theses of standard sugars; thus, an absolute identification was cbtained.

In Figure $4 \mathrm{a}$ analyses of the same Santa Barbara Basin sediment sample ("50 years") were performed in both laboratories with the identical extraction procedure (Modzeleski et al., 1971). The linear correlation between the results as shown in the figure conclusively demonstrates that the sediment peak $\lambda_{\lambda}^{s}$ recorded spectrophotometrically are sugars. In Figure $4 \mathrm{~b}$, the yields of the Modzeleski extraction procedure are plotted against the yields of the extraction procedure employed in the thesis research. From this figure it can be seen that my hydrolysis technique is more efficient for the extraction of glucose, galactose, and mannose.

A similar correlation of results is observed for another sediment sample (Santa Barbara Basin "750 years"), as shown in Figure $5 a, b$. 7 Table 1 is discussed in the next section. 

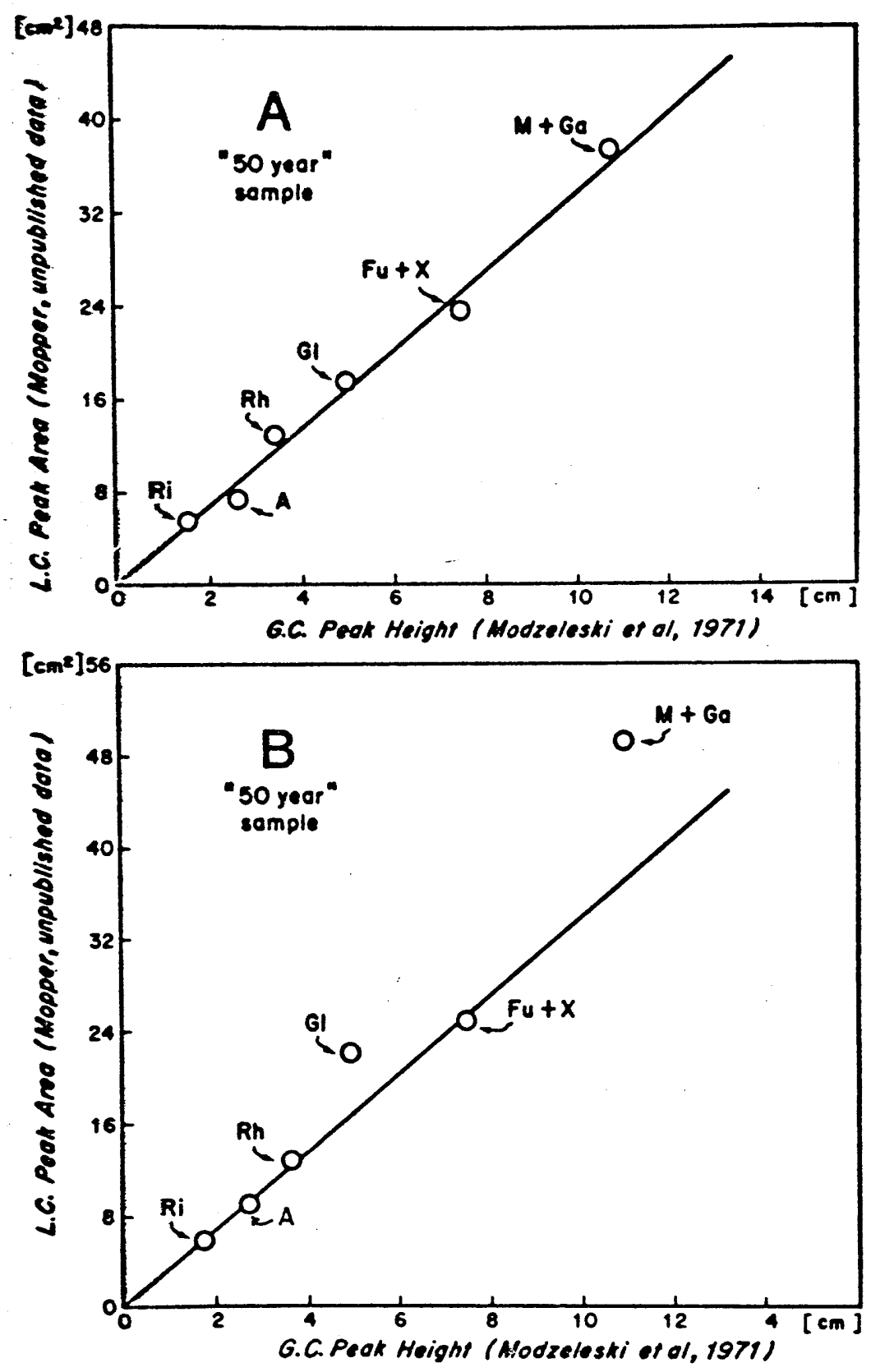

Figure 4

Caption on following page. 
Figure 4

(a) Intercalibration between two laboratories of sugar analytical techniques. An identical extraction procedure was employed in both laboratories: $1 \mathrm{~g}$ of exhaustively washed Santa Barbara Basin sediment ("50 years") was hydrolyzed at $100^{\circ} \mathrm{C}$ for 90 minutes in $2.0 \mathrm{~N} \mathrm{H}_{2} \mathrm{SO}_{4}$; the sample was centrifuged and re-hydrolyzed for 60 minutes in $2.0 \mathrm{~N}$ $\mathrm{H}_{2} \mathrm{SO}_{4}$ and then centrifuged acam; the conjined liquid fractions were deionized and analyzed by G.C.-M.... (M. (Mdzeleski et al. , 1971) and by the present liquid chromatographic system.

(b) The results of the Modzeleski et al. (1971) extraction procedure (above) are plotted against the results of the extraction procedure used in the present thesis research: $1 \mathrm{~g}$ of sediment was hydrolyzed at $100^{\circ} \mathrm{C}$ for 180 minutes in $1.8 \mathrm{~N} \mathrm{HCl}$ followed by centrifugation and deionization (see the following section for details). The extraction procedure used in the present thesis research releases larger quantities of glucose, mannose and galactose. The slope of the line in this figure is the same as in (a). Notation as in Figure 2。 




Figure 5

(a) and (b) Intercalibration results for Santa Barbara Basin sediment sample " 750 years". "See caption of Figure 4 for details. Notation as in Figure 2 . 


\section{9}

\section{EXTRACTION OF CARBOHYDRATES FROM SEDIMENT: ACID HYDROLYSIS}

In the previous section it was demonstrated that the compounds extracted from sediment and detected spectrophotometrically are, indeed, sugars. In the following sections, the various extraction techniques employed in the research are : presented in detail. The following extraction methods are used:

dry crushed sediment

$\mathrm{HCl}$ hydrolysis

(1)

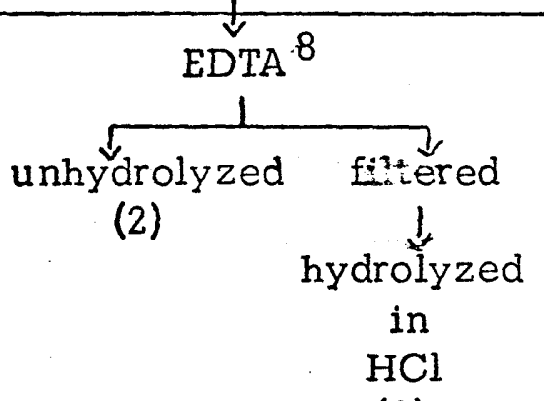

(3)

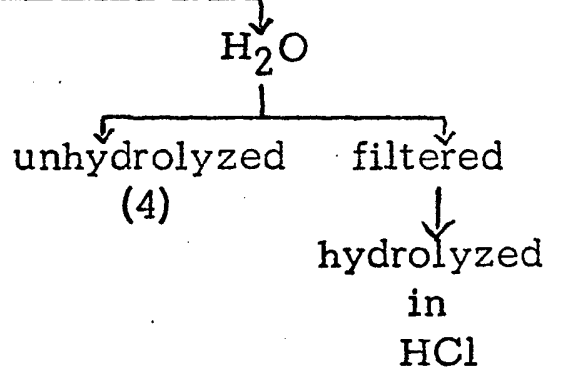

(5)

Most of the sediment samples were analyzed by methods 1, 2, and 3. The $\mathrm{H}_{2} \mathrm{O}$ extracts (methods 4 and 5) were used less frequently since these extracts yielded less information. Therefore, the extracts obtained by methods 1,2 , and 3 will be examined in greater detail in the following sections. A hypothetical acid extraction procedure was devised in order to delineate sources of error arising from contamination, destruction and incomplete extraction. Standard monomeric sugar solutions, aliquots of a Black Sea sediment (core $1474 \mathrm{~K}, 120-130 \mathrm{~cm}$ ) and aliquots of Argentine Basin sediments (AII 60, leg 2, st. 21, 20-50 cm and $30 \mathrm{~cm}$ ) were used to test the following extraction procedure:

${ }^{8} \mathrm{EDTA}=$ ethylenediaminotetraacetic acid 
Wet sediment<smiles>CCCC</smiles>

Dry sediment:

1) air-dry in oven at $60^{\circ} \mathrm{C}$

or

2) desiccation at $25^{\circ} \mathrm{C}$<smiles>CCCC</smiles>

Treat sediment with HF

followed by freeze-drying<smiles>CCCC</smiles>

Acid hydrolyses and a study of:

1) effect of different acids

2) effect of variations in acid concentration

and hydrolysis time

3) effect of variations in $\mathrm{CaCO}_{3}$ content of sediment

4) effect of variations in sample size<smiles>CCC</smiles>

Deionization:

1) neutralization of acid by precipitation followed by ion-exchange

or

2) only ion-exchange<smiles>CCCCC</smiles>

Volume reduction by rotary evaporation

\section{a. Sample Drying Procedure}

Two sediment drying techniques were examined: i) desiccation in a mild vacuum ( $~ 5$ torr) for 20 hours at room temperature and ii) oven drying at $60^{\circ} \mathrm{C}$ for 20 hours. Each technique was tested with an identical standard mixture of monomeric sugars $(1 \mathrm{mg} / \mathrm{ml})$ and organic-free kaolinite. Figures $6 a, b$, and $c$ indicate that oven drying induces losses of 40 to $90 \%$ of 

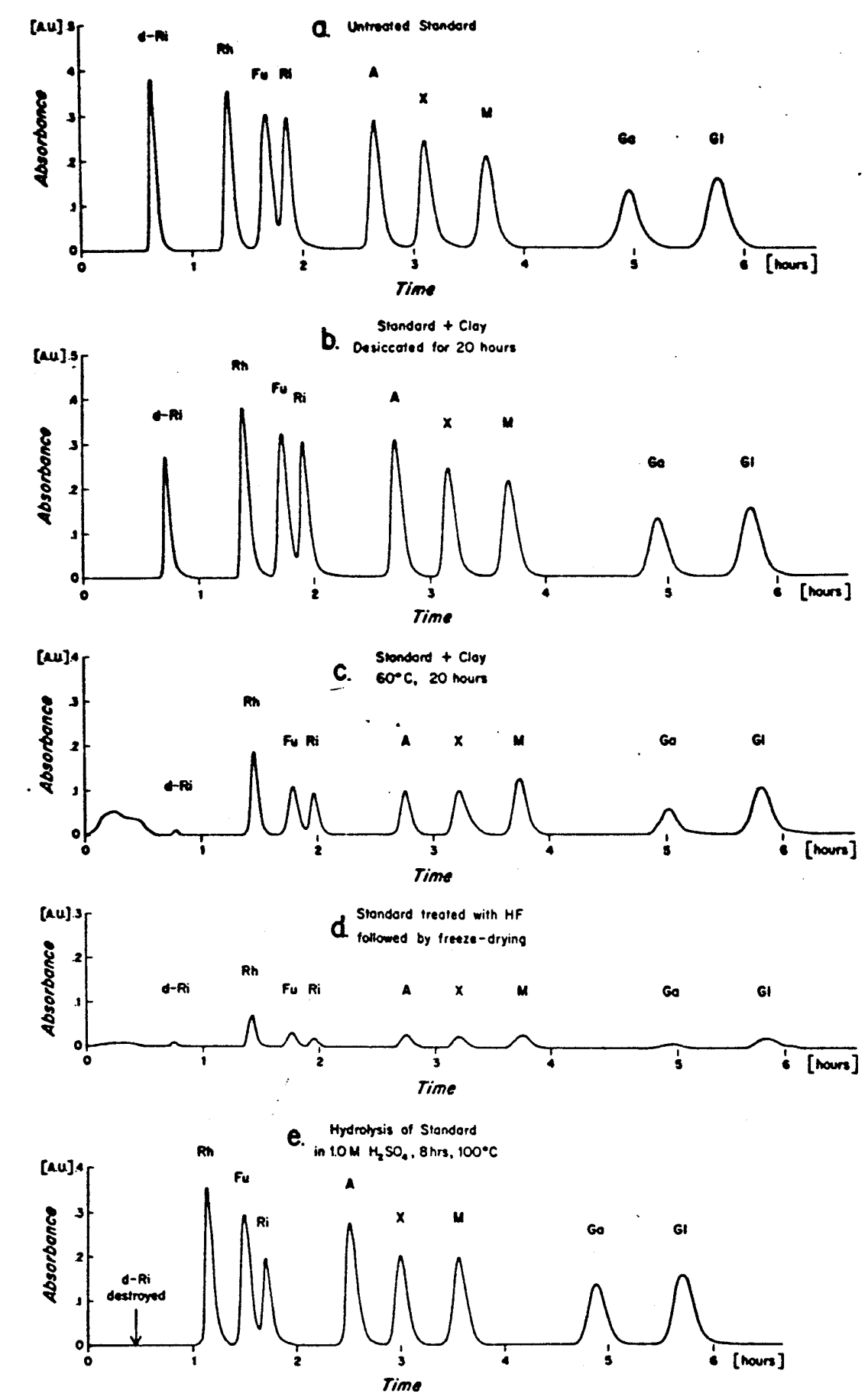

Figure 6

Tests of carbohydrate extraction procedures using a standard solution (the concentration of each sugar in this solution was $1000 \mu \mathrm{g} / \mathrm{ml}$ ). Initially $1 \mathrm{ml}$ of the standard was used for each experiment; an amount equal to $15 \mu \mathrm{g}$ of each sugar (assuming no loss occurred) was analyzed. Comparison of chromatograms ' $b$ ' through ' $e$ ' to the untreated standard 'a' reveals relative losses due to the experimental treatments; notation as in Figure 2. 
monomeric sugars. These losses are probably less significant for sediment samples because most carbohydrates are not present as free monomers (the unhydrolyzed $\mathrm{H}_{2} \mathrm{O}$ extraction releases $<2 \%$ of the sugars released by acid hydrolysis as shown in Chapter IV), , but are either insoluble polymers (cellulose, etc.) or are incorporated in humic-type complexes. Since the vacuum desiccation technique is milder, it is employed in the present research.

\section{b. HF Pretreatment}

Stevenson and Cheng (e.g., 1970) determined that amino acid yields are increased when sediment is treated at room temperature with a $5 \mathrm{~N}$ HF-0.1 N HCl solution prior to hydrolysis. This method was tested in order to determine its applicability to carbohydrate extraction procedures. One $\mathrm{ml}$ of a standard monosaccharide solution ( 9 sugars, $1 \mathrm{mg} / \mathrm{ml}$ each) was added to $4 \mathrm{ml}$ of a $5 \mathrm{~N} \mathrm{HF}-0.1 \mathrm{~N} \mathrm{HCl}$ solution and sealed under nitrogen. The solution was placed on a vibrator (as were the samples containing sediments) for 24 hours at room temperature and then freeze-dried. Figures $6 a$ and $\mathrm{d}$ indicate that approximately $80 \%$ of the sugar standards were eliminated by these operations. Most of this destruction was probably the result of sugar condensations which were induced by the high vacuum ( $<.5$ torr) of the freeze-drying apparatus. Therefore, until the analytical difficulties encountered during HF pretreatment are resolved, this method is inapplicable to carbohydrate extractions of sediment. I assume, however, that for most sediments the quantity of carbohydrates incorporated into the clay 
53
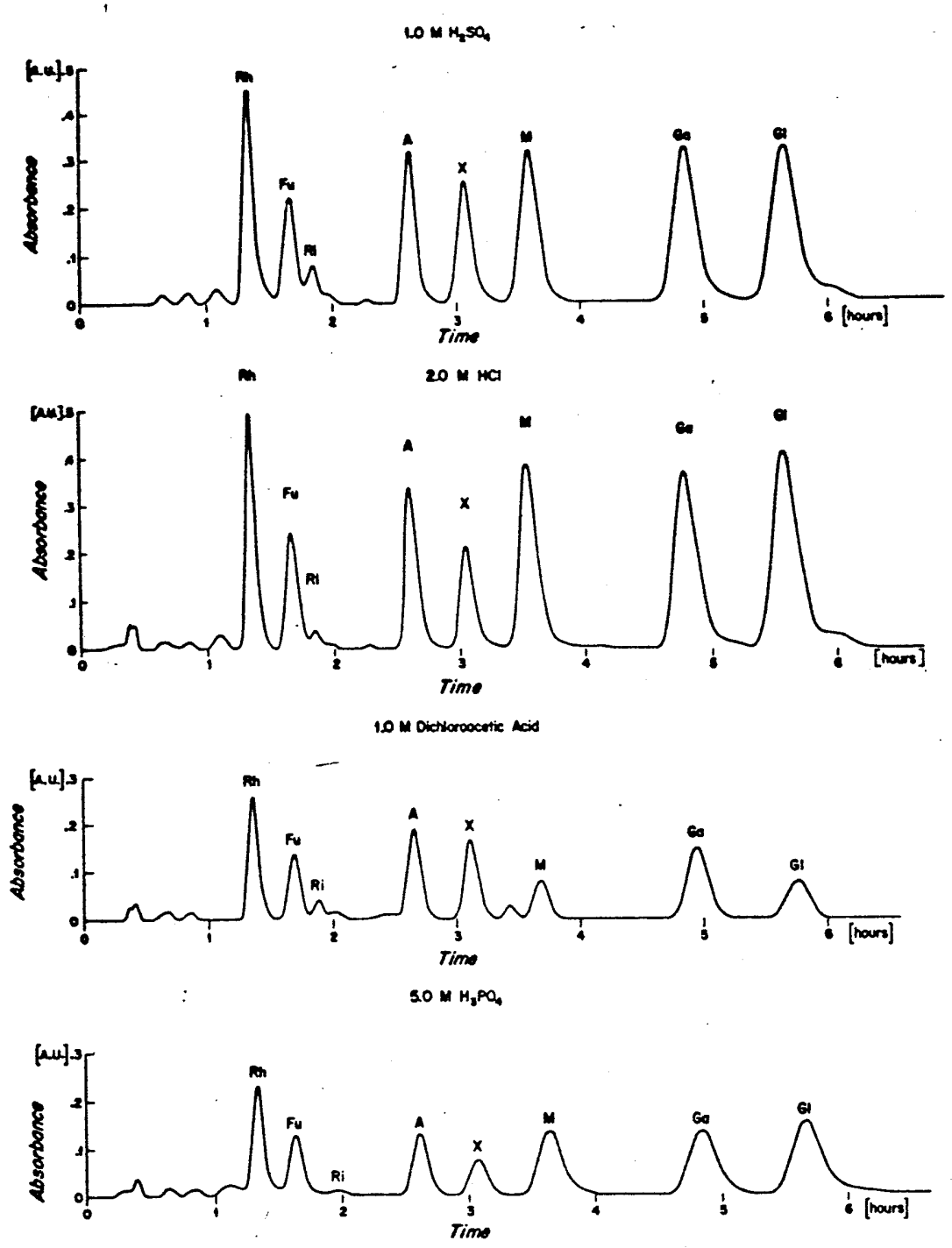

10 M Oralic Acio

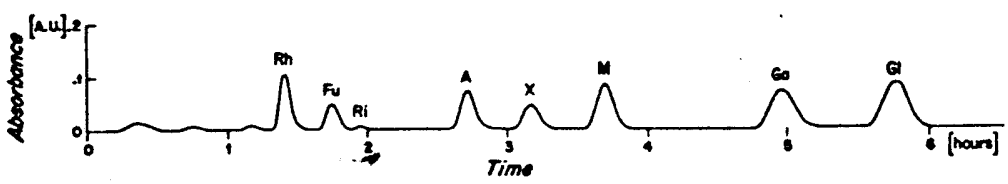

Figure 7

Extraction of carbohydrates from equal aliquots of a Black Sea sediment sample (core $1474 \mathrm{~K}, 120-130 \mathrm{~cm}$ ). The identical extraction procedure was employed for each chromatogram, therefore, the difference in sugar recoveries is directly related to the hydrolysis efficiency of the acids tested. Notation as in Figure 2. 
fraction is negligible as was demonstrated for the amino acids by Mopper and Degens (1972).

\section{c. Acid Hydrolyses}

The following acids were tested for their hydrolysis efficiency: $1 \mathrm{M} \mathrm{H}_{2} \mathrm{SO}_{4}, 2 \mathrm{M} \mathrm{HCl}, 5 \mathrm{M} \mathrm{H}_{3} \mathrm{PO}_{4}, 1 \mathrm{M}$ oxalic acid, and $1 \mathrm{M}$ dichloroacetic acid. One gram aliquots of sediment from Black Sea core $1474 \mathrm{~K}$ (120-130 cm, dried in a vacuum desiccator and crushed to less than .25 $\mathrm{mm}$ ) were hydrolyzed under nitrogen in $10 \mathrm{ml}$ of the above acids at $100^{\circ} \mathrm{C}$ for eight hours. The samples were then centrifuged, deionized, and reduced to a standard volume. Figure 7 indicates that the order of sugar recovery for the different acids is: sulfuric acid $\simeq$ hydrochloric acid $>$ dichloroacetic acid $\widetilde{\sim}$ phosphoric acid $>$ oxalic acid.

Figures 8 and 9 show the effect of variations in hydrolysis time and acid concentration of $\mathrm{H}_{2} \mathrm{SO}_{4}$ and $\mathrm{HCl}$ on the sugar yield from the above Black Sea sediment. Optimal extraction parameters are either 1.5-1.8 M $\mathrm{HCl}$ for 2-3 hours or 1.1-1.3 $\mathrm{M} \mathrm{H}_{2} \mathrm{SO}_{4}$ for 4-5 hours. Thus, reproducible extractions are achievable if the acid concentrations and hydrolysis times are within the plateau regions of the figures as shown in Table 2 . From this table can be seen that individual sugars demonstrate different reproducibilities. These differences appear to be related to differences in sugar lability. For example ribose, which is very labile, shows a $\pm 30 \%$ reproducibility; glucose, on the other hand, shows only a $\pm 2 \%$ reproducibility. The overall reproducibility is about $\pm 10 \%$. Considering the general 

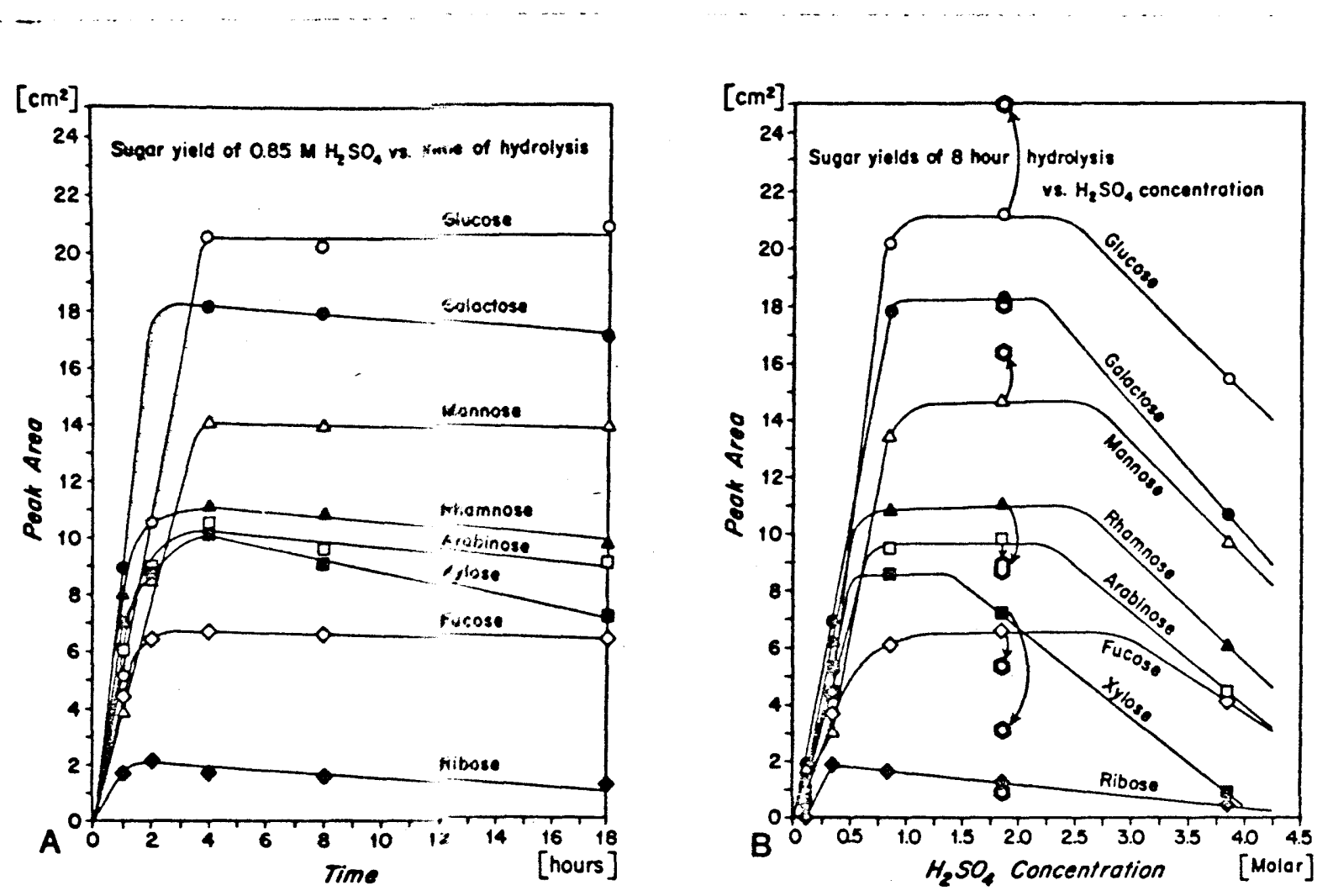

Figure 8

(a) Determination of the optimal hydrolysis time for $0.85 \mathrm{M} \mathrm{H}_{2} \mathrm{SO}_{4}$. Equal aliquots of a lilack Sea sediment sample (core $1474 \mathrm{~K}, 120-130 \mathrm{~cm}$ ) were extracted for varying time intervals. A minimum of 4 hours is required for optimal wraction.

(b) Determination of the optimal $\mathrm{H}_{2} \mathrm{SO}_{4}$ concentration for the extraction of the above Black iva sediment. Hydrolysis time was 8 hours for each test. The 0 notation depicts a sample which was hydrolyzed with $98 \%$ $\mathrm{H}_{2} \mathrm{SO}_{4}$ at $0^{\circ} \mathrm{C}$ for 2 hours and then diluted to $1.85 \mathrm{M}$ for further hydrolysis. (Plateau regions are somewhat exaggerated for clarity.) 

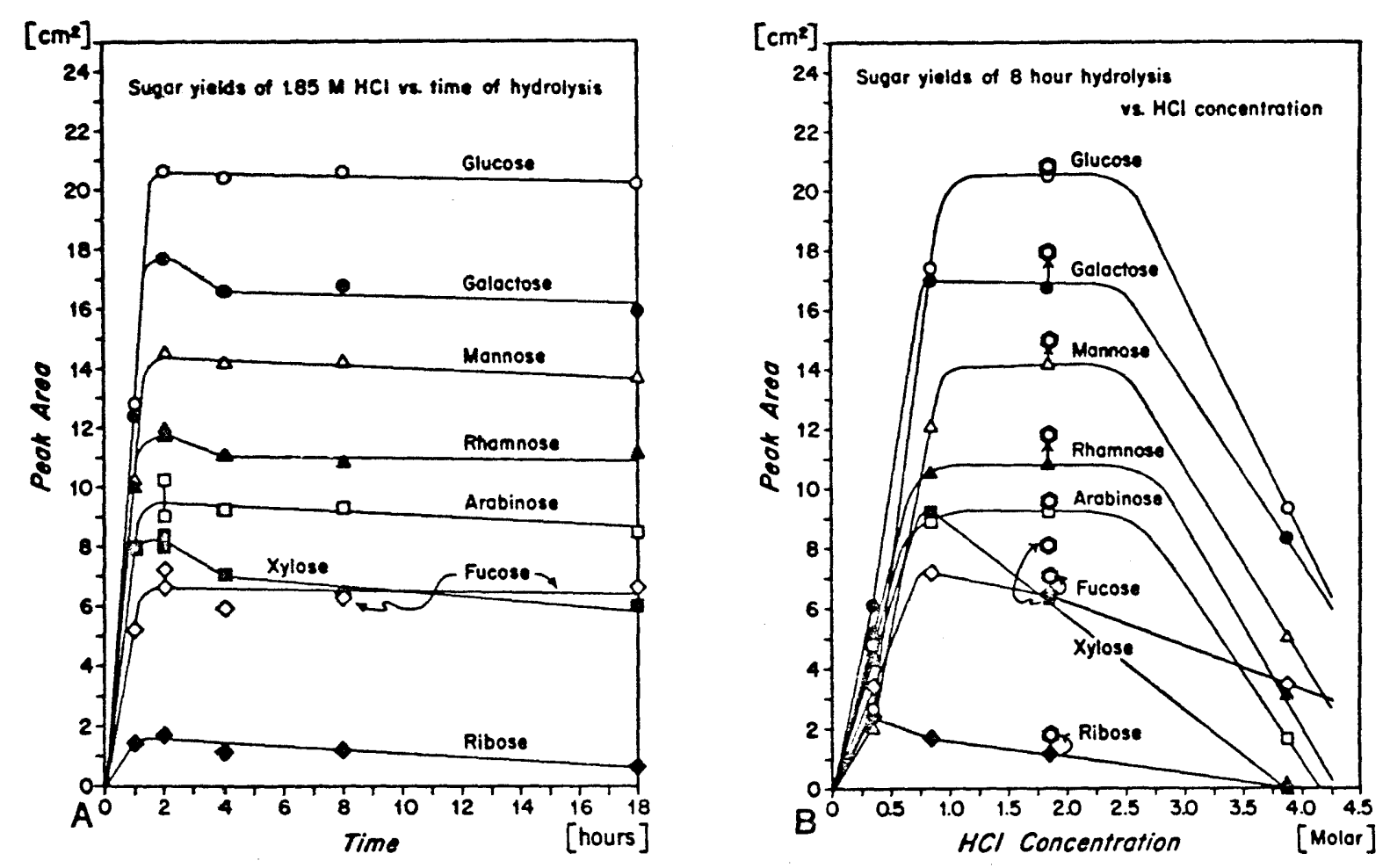

Figure 9

(a) Determination of the optimal hydrolysis time for $1.85 \mathrm{M} \mathrm{HCl}$. Equal aliquots of the above Black Sea sediment were employed for each test. A minimum of 2 hours is required for optimal extraction.

(b) Determination of the optimal $\mathrm{HCl}$ concentration for the extraction of the above Black Sea sediment. Hydrolysis time was 8 hours for each test. The $O$ notation depicts a sample which was hydrolyzed with $12 \mathrm{M}$ $\mathrm{HCl}$ at $0^{\circ} \mathrm{C}$ for 2 hours and then diluted to $1.85 \mathrm{M}$ for further hydrolysis. (Plateau regions are somewhat exaggerated for clarity.) 
TABLE 2

EXTRACTION OF CARBOHYORATES BY ACID HYOROLYSIS OF $1 \mathrm{~g}$ ALIQUOTS OF BLACK SEA CORE $1474 \mathrm{~K}$ (120-130 cm) (peak areas in $\mathrm{cm}^{2}$ )

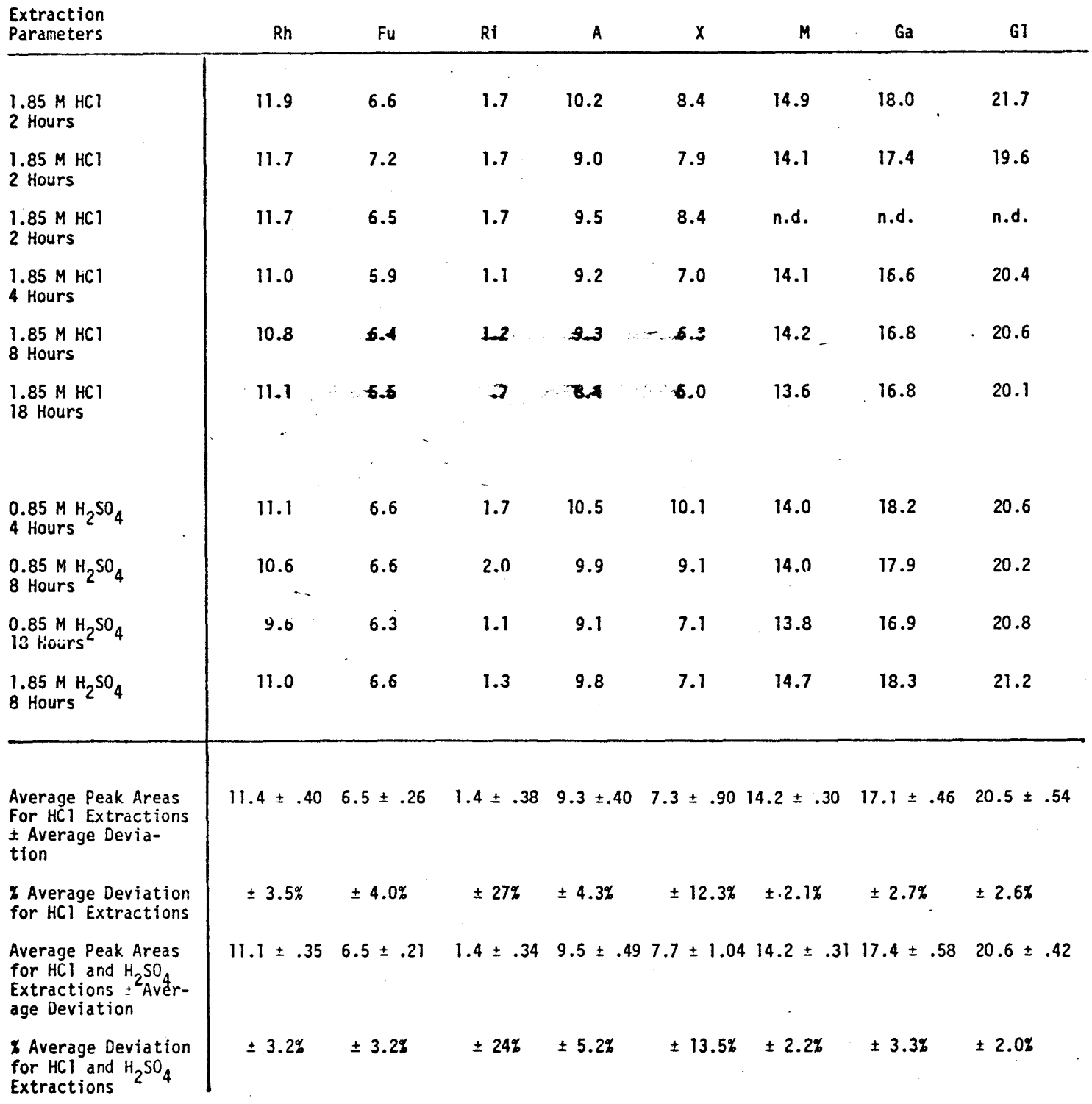


lack of knowledge in the field of carbohydrate geochemistry, a $\pm 10 \%$ reproducibility is more than sufficient to discern general trends. Therefore, in the experiments with standard solutions an overall $\pm 10 \%$ deviation is considered acceptable.

On the non-plateau regions of Figures 8 and 9 small changes in either hydrolysis time or acid concentration result in large variations in sugar yield. For example, Swain (1969) performs hydrolyses with $0.25 \mathrm{M}$ $\mathrm{H}_{2} \mathrm{SO}_{4}\left(100^{\circ} \mathrm{C}\right)$ for $8-10$ hours. Figure 10 compares a $0.35 \mathrm{M}$ hydrolysis (8 hours) with a $1.85 \mathrm{M}$ hydrolysis (8 hours) of the above Black Sea sample. The differences in yields and relative proportions of the sugars between the two methods are evident.

Several investigators (e.g., Degens and Reuter, 1964; and Swain, 1969) treated sediment with cold concentrated $\mathrm{H}_{2} \mathrm{SO}_{4}$ for 2-4 hours followed by dilution and further hydrolysis at $100^{\circ} \mathrm{C}$. This method was tested on the above Black Sea sediment; the results are shown in Figure 8b. Glucose and mannose yields were increased by 20 and 10\% respectively, however, comparable decreases in some of the other sugars occurred (especially the pentoses). This method has proven to be advantageous only when large quantities of cellulose are present in the sample, e.g., sewage sludge and land derived plant material. Polymers of lower molecular weight, such as amylose (starch cellulose), are completely hydrolyzed and recovered as glucose with the $1.8 \mathrm{~N} \mathrm{HCl}$ method. 

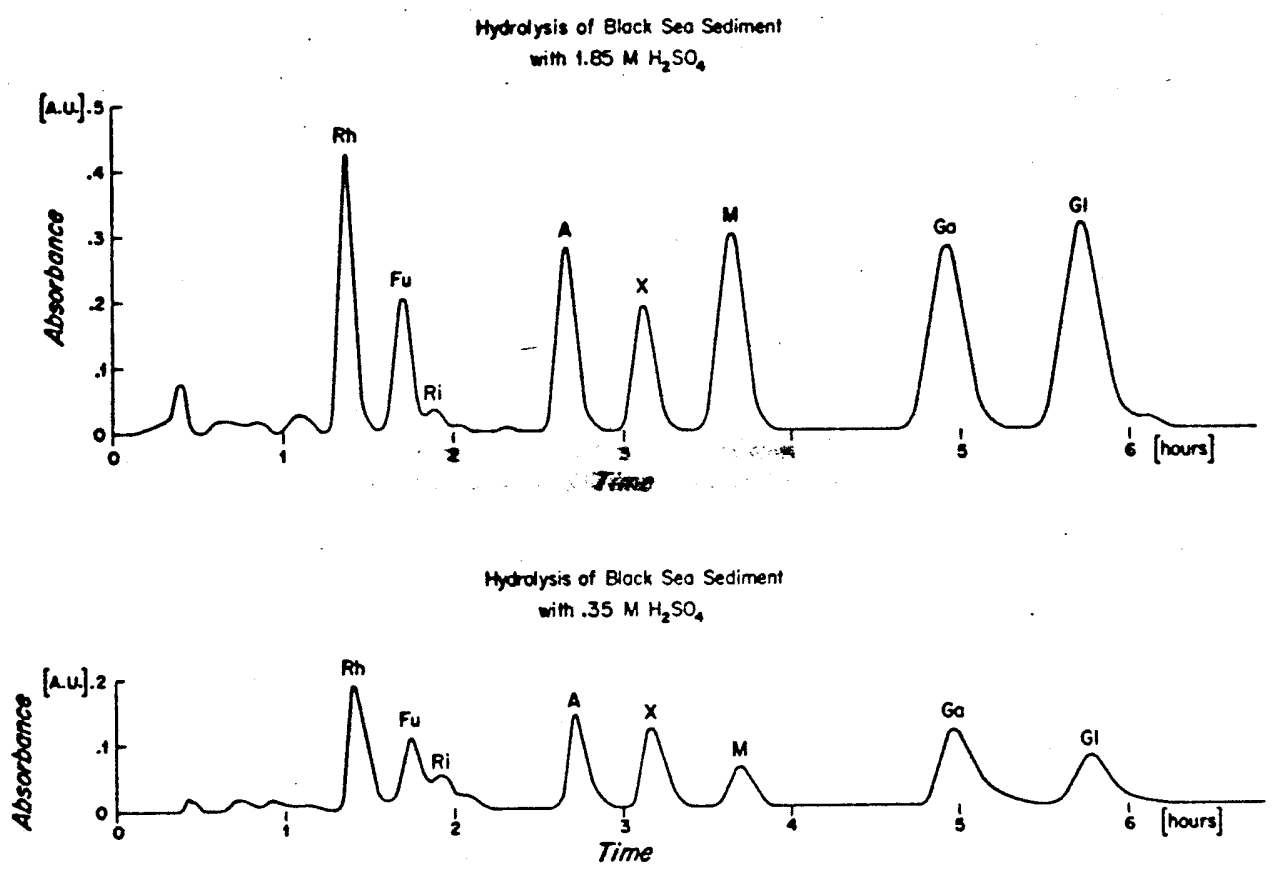

Figure 10

Extraction of carbohydrates from a Black Sea sediment sample with $1.85 \mathrm{M}$ and $0.35 \mathrm{M} \mathrm{H}_{2} \mathrm{SO}_{4}$. A hydrolysis time of 8 hours was used for each test. These chromatograms show that not only is the total yield lower for the $0.35 \mathrm{M}$ extraction, but the relative abundances are significantly different; mannose and glucose are especially reduced. Notation as in Figure 2. 
In addition to determining the optimal hydrolysis parameters, the destructive effect of $\mathrm{HCl}$ and $\mathrm{H}_{2} \mathrm{SO}_{4}$ on the released monomeric sugars was also examined. Figure $6 \mathrm{e}$ depicts a chromatogram of a standard monosaccharide solution ( 9 sugars, $1 \mathrm{mg} / \mathrm{ml}$ each) after treatment under nitrogen with $1 \mathrm{M} \mathrm{H}_{2} \mathrm{SO}_{4}$ at $100^{\circ} \mathrm{C}$ for eight hours. Deoxyribose was destroyed $100 \%$, ribose $30 \%$, and xylose $15 \%$. One $\mathrm{M} \mathrm{HCl}$ gave the same results. Destruction of these sugars during hydrolysis of sediment may be less significant because: i) most sugars are initially either in polymeric form or are bound in humus-type residues and are released as monosaccharides gradually throughout the hydrolysis (Figures $8 \mathrm{~b}, 9 \mathrm{~b}$ ), and ii) 2 to 3 hour hydrolysis times (for $1.8 \mathrm{~N} \mathrm{HCl}$ ) are used with sediment as opposed to 8 hours used -with the standard solution.

The destructive effects of acid hydrolysis were further examined by various spiking experiments. Argentine Basin sediment was spiked with a standard solution prior to hydrolysis. The results are presented in Table la (fucose, arabinose and galactose were not spiked in order to serve as checks against the untreated sediment). Again, ribose was destroyed to a large extent while the other sugars (including xylose) remained virtually unaffected within the experimental error $( \pm 10 \%)$. A fourfold change in the amount of sediment used (the amount of acid was constant) did not significantly alter these results.

The effect of $\mathrm{CaCO}_{3}$ on acid hydrolysis yields was determined for Argentine Basin sediment which is free of $\mathrm{CaCO}_{3}$. Table 3 reveals that the 
TABLE 3

Spiking of Argentine Basin Sediment (2 gm) with $\mathrm{CaCO}_{3}(0.6 \mathrm{gm})$; numbers represent peak areas in $\mathrm{cm}^{2}$

A. HCl Hydrolysis

\begin{tabular}{lcccccccc} 
SUGARS & $\mathrm{Rh}$ & $\mathrm{Fu}$ & $\mathrm{Ri}$ & $\mathrm{A}$ & $\mathrm{X}$ & $\mathrm{M}$ & $\mathrm{Ga}$ & $\mathrm{GI}$ \\
\hline $\begin{array}{l}\text { Unspiked } \\
\text { CaCO }\end{array}$ & 6.6 & 7.8 & 2.7 & 7.0 & 6.8 & 10.9 & 14.0 & 14.8 \\
$\begin{array}{l}\text { Spiked } \\
\begin{array}{l}\% \\
\text { Difference }\end{array}\end{array}$ & 7.0 & 8.4 & 3.6 & 7.2 & 7.9 & 11.6 & 16.7 & 17.2 \\
\hline
\end{tabular}

$\%$ average deviation $13 \%$

B. Hydrolyzed EDTA xt.

\begin{tabular}{lcccccccc} 
Unspiked & 5.0 & 5.6 & 2.8 & 3.8 & 5.9 & 5.2 & 9.0 & 7.2 \\
$\begin{array}{l}\text { CaCO } 3 \text { Spiked } \\
\begin{array}{l}\% \\
\text { Difference }\end{array}\end{array}$ & 4.8 & 5.6 & 2.4 & 3.5 & 4.7 & 4.5 & 8.4 & 7.8 \\
\hline & 0 & 14 & 8 & 20 & 13 & 7 & 8 \\
\hline
\end{tabular}


$\mathrm{CaCO}_{3}$-spiked sample ( $\sim 30 \%$ by weight $\left.\mathrm{CaCO}_{3}\right)$, when compared to the unspiked sample, shows no significant losses, but rather a slight gain is recorded (the gain is fairly close to the experimental error). The relatively large increase in ribose is further evidence that that sugar is particularly sensitive to changes in the extraction procedure. (The initial acid concentration in this experiment was adjusted to compensate for the $\mathrm{CaCO}_{3}$.)

\section{d. Deionization Techniques}

(i) Precipitation of the acid: Swain (1969) eliminates $\mathrm{H}_{2} \mathrm{SO}_{4}$ by addition of barium carbonate to the reaction mixture; this procedure results in the precipitation barium sulfate. After neutralization the mixture is centrifuged and then desalted on ion-exchange resins. In the case of hydrochloric acid, silver carbonate may be substituted for barium carbonate.

Neutralization by precipitation is tedious, especially when large quantities of acid are involved. Furthermore, impurities in the salt will contaminate the sample.

(ii) Ion-exchange resins: Neutralization and desalting may be accomplished in one step with ion-exchange resins. The centrifuged or filtered sample is eluted with $250 \mathrm{ml}$ of triple distilled water through a pair of columns containing excess cation exchange resin, AG 50-X8 in the hydrogen form (50-100 mesh), and excess anion exchange resin, AG 3-X4 in the formate form (20-50 mesh). Initially the anion exchange resin was used in the hydroxyl form; however, the high basicity of the resin caused total destruction of deoxyribose and partial destruction of ribose and xylose in a ${ }^{9}$ Distilled from permanganate. 


\section{3}

solution of standard sugars (Mopper, 1970). Formate and bicarbonate forms of the resin caused no destruction.

The order of elution through the columns is important only when large quantities of salts are present in the sample. For example, when a standard sugar solution containing $0.5 \mathrm{M} \mathrm{NaCl}$ was first passed through the anion exchange resin (formate form), a $60 \%$ destruction of deoxyribose was observed (all other sugars were unaffected). The destruction is attributed to the formation of sodium formate, which in the dissociated form is moderately basic (a condition which is destructive to sugars). Passing the solution through the cation exchange resin first prevents the nercolating solution from becoming basic.

e. Volume Reduction

After elution through the ion-exchange resins the volume of sample is gently reduced $\left(\sim 30\right.$ minutes, $\left.60^{\circ} \mathrm{C}\right)$ from about $300 \mathrm{ml}$ to about $5 \mathrm{ml}$ on a rotary evaporator. This volume is then reduced further by blowing a stream of high purity nitrogen over the surface. Standard sugar solutions diluted to $250 \mathrm{ml}$ are quantitatively recovered after volume reduction on a rotary evaporator at temperatures of 70 and $90^{\circ} \mathrm{C}$.

Throughout the extraction procedure, the sample is never allowed to go to dryness, since this may cause the condensation of sugars and other organic compounds. 


\section{EXTRACTION OF CARBOHYDRATES FROM SEDIMENT: EDTA TREATMENT}

Carbohydrates may be extracted from sediment by EDTA, either followed by acid hydrolysis (the hydrolyzed EDTA extract) or by itself (unhydrolyzed EDTA extract). A comparison of the hydrolyzed EDTA extract and the $\mathrm{HCl}$ extract for a Black Sea sediment is shown in Figure 11. The significance of the EDTA extracts will be discussed in the next chapter. Various questions arise concerning the use of EDTA in the extraction techniques. For example, what is the optimal time for treating the sediment with EDTA? What is the effect of temperature? Since metal ions displace hydrogen ions from EDTA, what $\mathrm{pH}$ variations occur? Do these variations in $\mathrm{pH}$ affect the yields? What is the effect of varying quantities of $\mathrm{CaCO}_{3}$ ? Since EDTA

is a weak acid $\left(\mathrm{pKa}_{1}=2.18\right)$, can it hydrolyze glycosidic bonds? Do varying sediment to EDTA ratios have any effect on the yields? How stable are sugars in the presence of EDTA?

In this section the results of various experiments are presented in order to answer the above questions.

\section{a. Optimal Time of Extraction}

In order to determine the optimal time of extraction, $2 \mathrm{~g}$ of Argentine Basin sediment $\left(30 \mathrm{~cm}, \mathrm{CaCO}_{3}-\right.$ free) were mixed with $1 \mathrm{~g}$ of EDTA and $10 \mathrm{ml}$ of triple distilled $\mathrm{H}_{2} \mathrm{O}$ and sealed in an ampoule under nitrogen. After heating for varying lengths of time at $100^{\circ} \mathrm{C}$ with constant stirring, the sample was centrifuged $(10,000 \mathrm{rpm}, 10$ minutes $)$, the liquid fraction was 

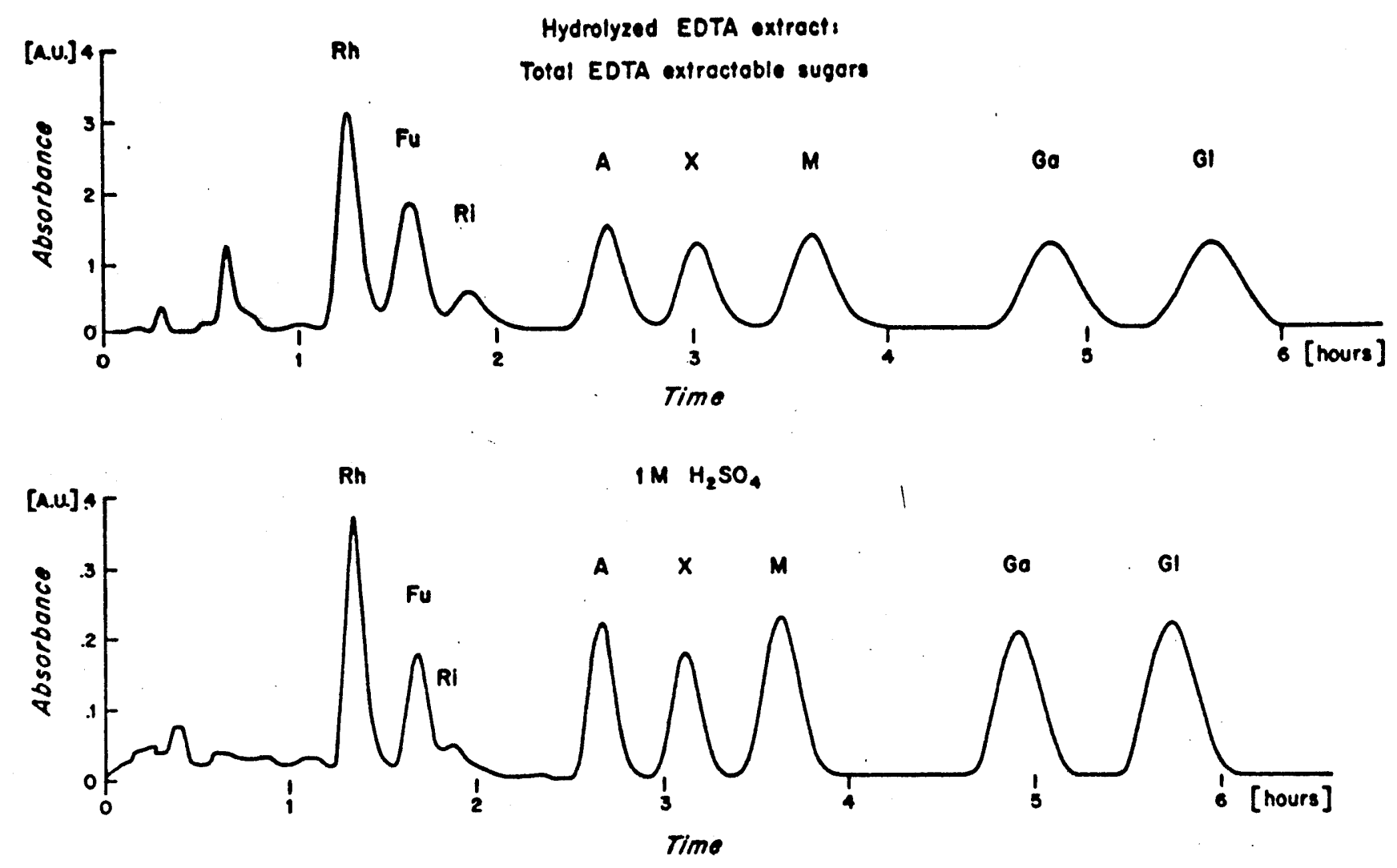

Figure 11

Comparison between total EDTA extracted carbohydrates and total acid extracted carbohydrates from a Black Sea sediment sample $(1474 \mathrm{~K}, 120-130 \mathrm{c}$ ). The hydrolyzed EDTA extract represents about $70 \%$ of the 'total' . acid-extractable sugars. Notation as in Figure 2. 
decanted and the mixture was again centrifuged. Concentrated $\mathrm{HCl}$ (36$38 \%$ was added to the combined supernatant solutions to yield a final acid concentration of $1.8 \mathrm{~N}$. The liquid was then hydrolyzed at $100^{\circ} \mathrm{C}$ for 3 hours followed by deionization and rotary evaporation. The results are presented in Figure 12a. With the exception of glucose, galactose, and mannose, sugars give a constant and maximum recovery after four hours of EDTA treatment. Glucose, galactose, and mannose continue to be extracted and these yields do not level off within the time span examined; however, this does not seriously affect the reproducibility. For example, $a \pm 2$ hour deviation results in only $a \pm 5 \%$ deviation in the amount of glucose released at 8 hours. An eight hour period is presently used for the EDTA treatment. Similar trends and yields were obtained for a one-to-one mixture of EDTA and sediment. Thus, it appears that the sediment-EDTA ratio can be varied considerably without significant effects on the yields (this precludes the presence of $\mathrm{CaCO}_{3}$ which reacts with EDTA). This constancy of sugar yields is probably related to the low solubility $\left(0.5\right.$ ppt at $\left.25^{\circ} \mathrm{C}\right)$ of EDTA. Thus regardless of the quantity of EDTA added, the concentration of EDTA will remain fairly constant。

The question arises: what is the effect of water alone? Figure $12 \mathrm{~b}$ shows the time dependence of the yields of the hydrolyzed $\mathrm{H}_{2} \mathrm{O}$ extract for the above sample. The figure shows that the recovery of 4 of 8 sugars do not level off within the time span examined; in general the trends are similar to those obtained for EDTA even though the yields of the hydrolyzed 

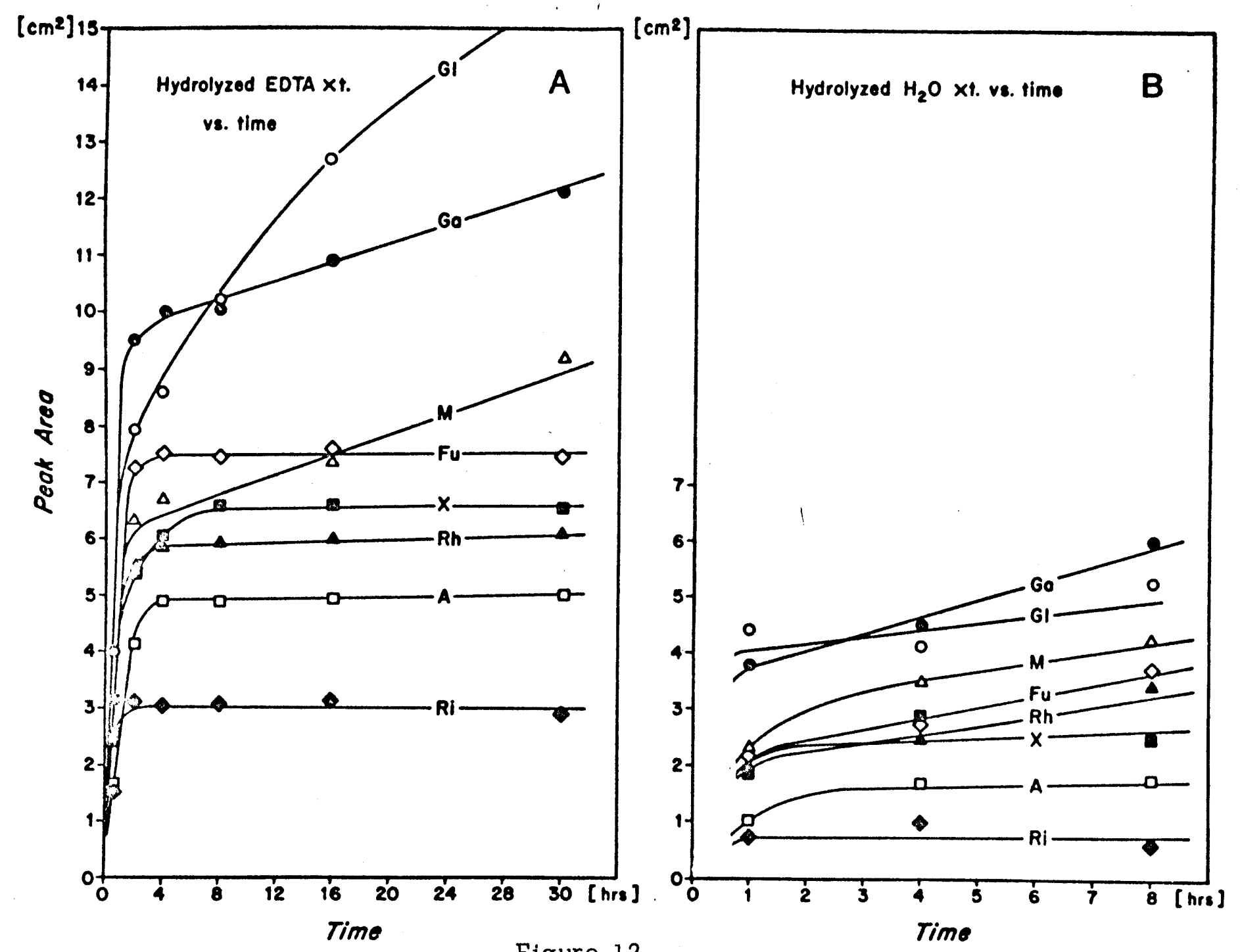

(a) Determination of the optimal EDTA extraction time. Equal aliquots (2 g) of an Argentine Basin sediment sample (st. $21,30 \mathrm{~cm}$ ) were extracted at $100^{\circ} \mathrm{C}$ with $1 \mathrm{~g}$ of EDTA for varying time intervals; the soluble fraction was then hydrolyzed. An extraction time of 8 hours was chosen.

(b) Determination of the optimal $\mathrm{H}_{2} \mathrm{O}$ extraction time for the above Argentine Basin sediment. An extraction time of 8 hours at $100^{\circ} \mathrm{C}$ was chosen. 
$\mathrm{H}_{2} \mathrm{O}$ extract are less in comparison.

b. Temperature Effects

The effect of temperature on EDTA extraction efficiency was determined with Argentine Basin sediment $\left(30 \mathrm{~cm}, \mathrm{CaCO}_{3}^{-}\right.$free). The same procedure as described in the previous section was employed, however, the time of EDTA treatment was fixed at eight hours and the temperature was varied between $40^{\circ} \mathrm{C}$ and $100^{\circ} \mathrm{C}$. The results are plotted in Figure $13 \mathrm{a}$. The results of the hydrolyzed $\mathrm{H}_{2} \mathrm{O}$ extract for the same sediment are shown in Figure 13b. Temperature effects are considerably more pronounced for the EDTA extractions than for the $\mathrm{H}_{2} \mathrm{O}$ extractions. This greater temperature

- dependence appears to be related to the increase in solubility of EDTA (and the decrease in $\mathrm{pH}$ ) with temperature.

The present extraction temperature used is $100^{\circ} \mathrm{C}$. At this temperature $\mathrm{a} \pm 5^{\circ} \mathrm{C}$ deviation will result in a $7 \%$ deviation in the quantity of glucose extracted.

\section{c. Stability of Sugars in EDTA Solution}

In one experiment a sediment sample (Argentine Basin $20-50 \mathrm{~cm}$, $\mathrm{CaCO}_{3}$ free) was spiked with a mixture of sugar standards prior to extraction with EDTA, followed by hydrolysis. Comparison of the spiked and unspiked samples is shown in Table 1b. Within the analytical error no destruction of the standards occurs. 

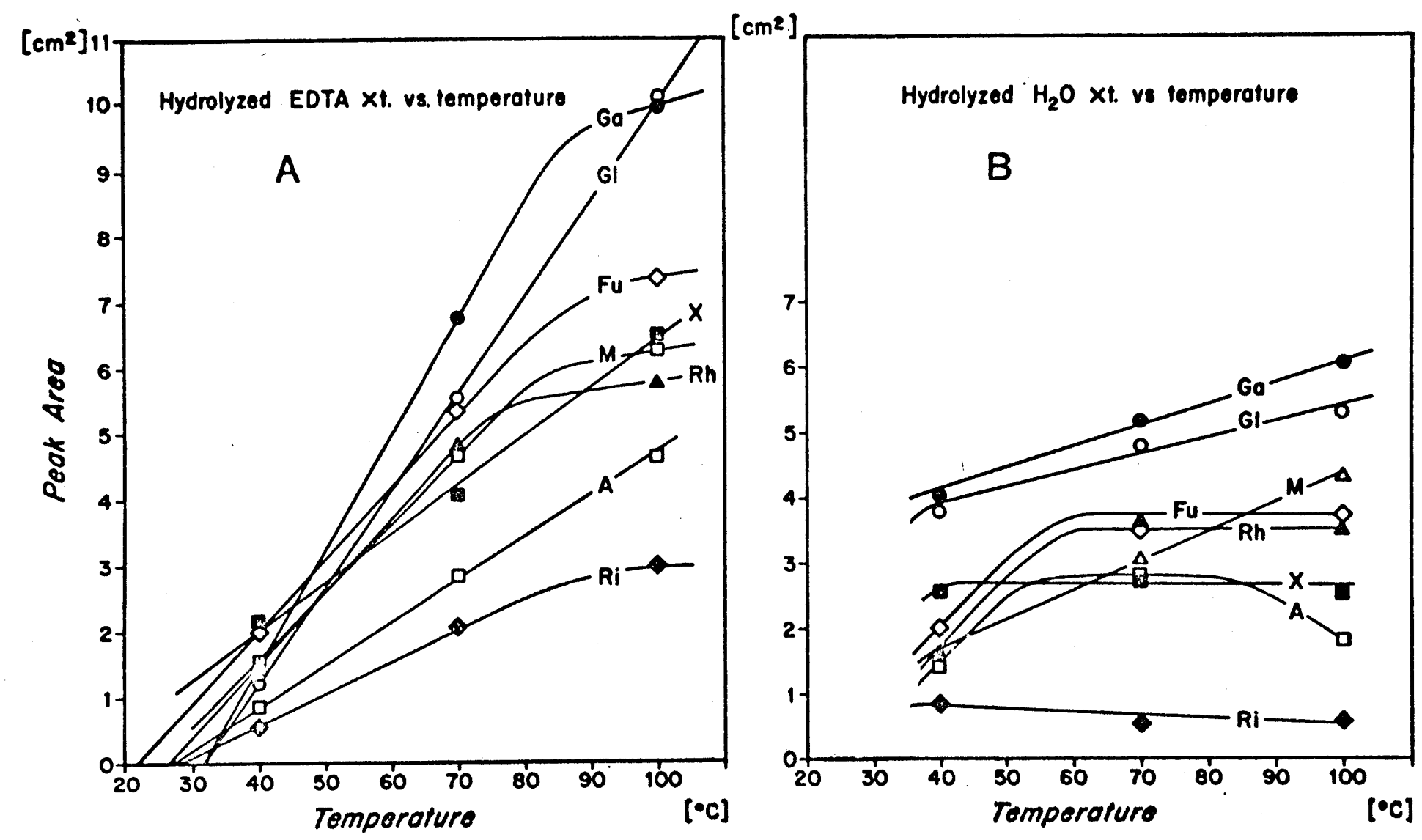

Figure 13

(a) and (b) Effects of temperature on the extraction efficiencies of EDTA and $\mathrm{H}_{2} \mathrm{O}$. The extraction time was 8 hours for each test. An extraction temperature of $100^{\circ} \mathrm{C}$ is used in the present thesis research. 
Figure $12 \mathrm{a}$ indicates that sugars extracted from sediment by prolonged EDTA treatment are not significantly degraded; in fact either a levelling-off or an actual increase in recovery is observed. With the use of sugar standards, the stability of monosaccharides in the presence of EDTA (or Chelex 100, a chelating resin with EDTA-like functional groups) was determined. The results of these experiments are shown in Table 4. Within the analytical error $( \pm 10 \%)$ only the EDTA treatment, followed by acid hydrolysis, yielded results which indicated that some destruction had occurred ( $30 \%$ of xylose). This destruction, however, is primarily due to the acid treatment as explained is a previviosection.

From these experiments it can be concluded that sugars are stable in the presence of EDTA (and Chelex 100) within the experimental parameters employed in the present research.

\section{d. Hydrolysis Effects}

EDTA is a weak acid $\left(\mathrm{pKa}_{1}=2.18\right)$. Therefore, it seems possible that EDTA may promote the hydrolysis of glycosidic bonds; this might account for part or all the monosaccharides released in excess of the simple $\mathrm{H}_{2} \mathrm{O}$ extract.

This hypothesis was tested with a disaccharide, lactose, and a polysaccharide, amylose. In one experiment $200 \mu \mathrm{g}$ of lactose and $1 \mathrm{~g}$ of EDTA in $10 \mathrm{ml}$ of $\mathrm{H}_{2} \mathrm{O}$ were kept at $100^{\circ} \mathrm{C}$ for 8 hours. The quantity of glucose and galactose was then measured; approximately $9 \%$ of the disaccharide was hydrolyzed. This result suggests that, under the worst (and least 
TABLE 4

Effects of EDTA and Chelex 100 on Sugar Standards

(peak areas in $\mathrm{cm}^{2}$ )

\begin{tabular}{|c|c|c|c|c|c|c|c|c|}
\hline Sugar: & $\mathrm{Rh}$ & $\mathrm{Fu}$ & $\mathrm{Ri}$ & A & $x$ & M & $\mathrm{Ga}$ & $\mathrm{Gl}$ \\
\hline untreated std. & 14.1 & 15.9 & 15.0 & 16.5 & 16.0 & 15.4 & 12.6 & 16.1 \\
\hline $\begin{array}{l}\text { std } \mathrm{O}^{*}+10 \mathrm{ml} \mathrm{H}_{2} \mathrm{O}, \\
100^{\circ} \mathrm{C}, 8 \text { hours, } \\
\text { deionized }\end{array}$ & $\begin{array}{l}\text { off- } \\
\text { scale }\end{array}$ & 16.9 & 15.5 & 16.7 & 18.6 & 15.4 & 12.5 & 15.9 \\
\hline $\begin{array}{l}\text { std. } A^{*}+6 \mathrm{ml} \text { Chelex } \\
+10 \mathrm{ml} \mathrm{H}_{2} \mathrm{O}, 100^{\circ} \mathrm{C}, \\
8 \text { hours, deionized }\end{array}$ & $\begin{array}{l}\text { off- } \\
\text { scale }\end{array}$ & $\begin{array}{l}\text { off- } \\
\text { scale }\end{array}$ & 15.6 & $\begin{array}{l}17.3 \\
\cdot\end{array}$ & 16.4 & 17.2 & 13.8 & 17.9 \\
\hline $\begin{array}{l}\text { std. } \mathrm{B}^{*}+1 \mathrm{~g} \text { EDTA } \\
+10 \mathrm{ml} \mathrm{H}_{2} \mathrm{O}, 100^{\circ} \mathrm{C}, \\
8 \text { hours, }\end{array}$ & 14.6 & -- & -- & -- & 16.3 & 15.6 & -- & 16.5 \\
\hline $\begin{array}{l}\text { std. } \mathrm{B}^{*}+1 \mathrm{~g} \text { EDTA } \\
+10 \mathrm{ml} \mathrm{H}_{2} \mathrm{O}, 100^{\circ} \mathrm{C} \text {, } \\
8 \text { hours followed by } \\
1.8 \mathrm{~N} \mathrm{HCl}, 100 \mathrm{C}, \\
3 \text { hours, deionized }\end{array}$ & 13.6 & -- & -- & -- & 10.9 & 14.6 & -- & 19.6 \\
\hline
\end{tabular}

* 500mg of each sugar was initially added; an equivalent of $25 \mathrm{mg}$ of each sugar was analyzed. 
probable) condition when all the carbohydrates in a sediment are present in the form of soluble disaccharides, 9\% will be hydrolyzed by EDTA.

In the second, more realistic experiment, $10 \mathrm{mg}$ of amylose, a partially soluble polysaccharide, and $1 \mathrm{~g}$ of EDTA were mixed in $10 \mathrm{ml}$ of $\mathrm{H}_{2} \mathrm{O}$ and maintained at $100^{\circ} \mathrm{C}$ for 8 hours. An equivalent of $0.31 \mu \mathrm{moles}$ (56 ug) of 'glucose' (e.g., assuming that amylose was totally converted to glucose) was injected and analyzed at high recorder sensitivity. No glucose was detected. Similar results were obtained when $0.3 \mathrm{~g}$ of $\mathrm{CaCO}_{3}$ was added to the above system. Therefore, EDTA and its Ca salts exert no detectable hydrolysis effects on amylose.

It can be concluded from the above experiments that the extent of - hydrolysis of sedimentary carbohydrates by EDTA is probably minor or negligible.

e. $\underline{\mathrm{pH} \text { and } \mathrm{CaCO}_{3} \text { Effects }}$

When EDTA forms chelates with metal ions, hydrogen ions are displaced from its structure and, therefore, a decrease in the $\mathrm{pH}$ is expected. However, since small quantities of sediment are employed $(0.5-2.0 \mathrm{~g})$ and since available metal ions constitute a minor fraction of sediment, one would expect that the pH effect might be negligible. Table 5 shows $\mathrm{pH}$ values of various EDTA extracts of sediment prior to hydrolysis. The $\mathrm{pH}$ values of the sediment extracts are similar to that of EDTA alone. Furthermore, the presence of varying quantities of $\mathrm{CaCO}_{3}$ does not affect the $\mathrm{pH}$ because the hydrogen ions released are incorporated into carbonic 


\begin{tabular}{|c|c|c|c|c|}
\hline Sample & $\begin{array}{l}\text { pH Values } \\
\begin{array}{|l}\text { Weight of } \\
\text { Sample } \\
(g)\end{array}\end{array}$ & $\begin{array}{l}\text { TABLE } 5 \\
\text { of EDTA Extracts } \\
\mathrm{CaCO}_{3} \text { content } \\
(\%)\end{array}$ & $\begin{array}{l}\text { Sediment and } \\
\text { Quantity of } \\
\text { EDTA used } \\
\text { (g) }\end{array}$ & $\begin{array}{l}\text { Plankton } \\
\mathrm{pH} \text { yalue } \\
\text { of extract }\end{array}$ \\
\hline $\begin{array}{l}\text { Argentine Basin } \\
(100 \mathrm{~cm})\end{array}$ & 2 & 0 & 1 & 4.4 \\
\hline $\begin{array}{l}\text { N.Y. Bight } \\
\text { (Buoy Station) }\end{array}$ & .2 & .6 & 1 & 4.5 \\
\hline $\begin{array}{l}\text { Lake Kivu } \\
\quad(240 \mathrm{~cm})\end{array}$ & .4 & 15.2 & 1 & 4.4 \\
\hline $\begin{array}{l}\text { Black Sea } \\
\quad(120-130 \mathrm{~cm})\end{array}$ & 1 & 27.0 & 2 & 4.3 \\
\hline $\begin{array}{l}\text { Cariaco Trench } \\
(.15 \mathrm{~cm})\end{array}$ &. .5 & 41.1 & 1.5 & 4.3 \\
\hline $\begin{array}{l}\text { Oyster Pond } \\
\text { (Surface) }\end{array}$ & .2 & 1.4 & 1 & 4.5 \\
\hline $\begin{array}{l}\text { Walvis Bay } \\
\text { (Surface sediment) }\end{array}$ & .5 & .8 & 1 & 4.5 \\
\hline Distilled $\mathrm{H}_{2} \mathrm{O}$ & -- & $m$ & 1 & 2.7 \\
\hline Distilled $\mathrm{H}_{2} \mathrm{O}$ & -- & -- & -- & 4.7 \\
\hline $\begin{array}{l}\text { Plankton: Cariaco } \\
\text { Trench }\end{array}$ & .05 & 2.1 & 1 & 2.7 \\
\hline
\end{tabular}

* Sediment and EDTA and $10 \mathrm{ml} \mathrm{H} \mathrm{H}_{2} 0 ; 100^{\circ} \mathrm{C}, 8 \mathrm{hrs}$; centrifigued 
acid which rapidly decomposes into $\mathrm{CO}_{2}$ and $\mathrm{H}_{2} \mathrm{O}$ :

$$
\begin{gathered}
\mathrm{CaCO}_{3}+\mathrm{H}_{2} \mathrm{EDTA} \longrightarrow \mathrm{CaEDTA}+\mathrm{H}_{2} \mathrm{CO}_{3} \\
\mathrm{H}_{2} \mathrm{CO}_{3} \longrightarrow \mathrm{H}_{2} \mathrm{O}+\mathrm{CO}_{2}
\end{gathered}
$$

When $\mathrm{CaCO}_{3}$ constitutes a large percentage of the sediment $(>10 \%)$, excess EDTA is added to compensate for the above neutralization reaction. Table $3 \mathrm{~b}$ shows the results of a spiking experiment where $\mathrm{CaCO}_{3}$ was added to carbonate- free Argentine Basin sediment $(20-50 \mathrm{~cm})$ prior to EDTA treatment. The differences between the spiked and unspiked sample are generally within experimental error $( \pm 10 \%)$. Therefore, the presence of $\mathrm{CaCO}_{3}$ in sediment apparently does not significantly alter the sugar yields. 


\section{5}

5. GENERAL SAMPLE WORK-UP

A diagram of the sample work-up is presented in Figure 14. It must be emphasized that the ratio of sediment to the various reagents is largely determined by the organic and $\mathrm{CaCO}_{3}$ contents of the sediment. Thus, a large percentage of $\mathrm{CaCO}_{3}$ necessitates the addition of a sufficient quantity of acid (or EDTA) to compensate. As shown in this and previous sections, this excess reagent does not significantly affect the yields. The quantities of ion exchange resin varied in accordance to the quantity of sediment and reagents employed; basically, $30 \mathrm{ml}$ of each resin (wet) is sufficient to deionize $10 \mathrm{ml}$ of a $1.8 \mathrm{~N} \mathrm{NaCl}$ solution. The actual amounts of sediment and reagents employed in the research are listed in Appendix II. 


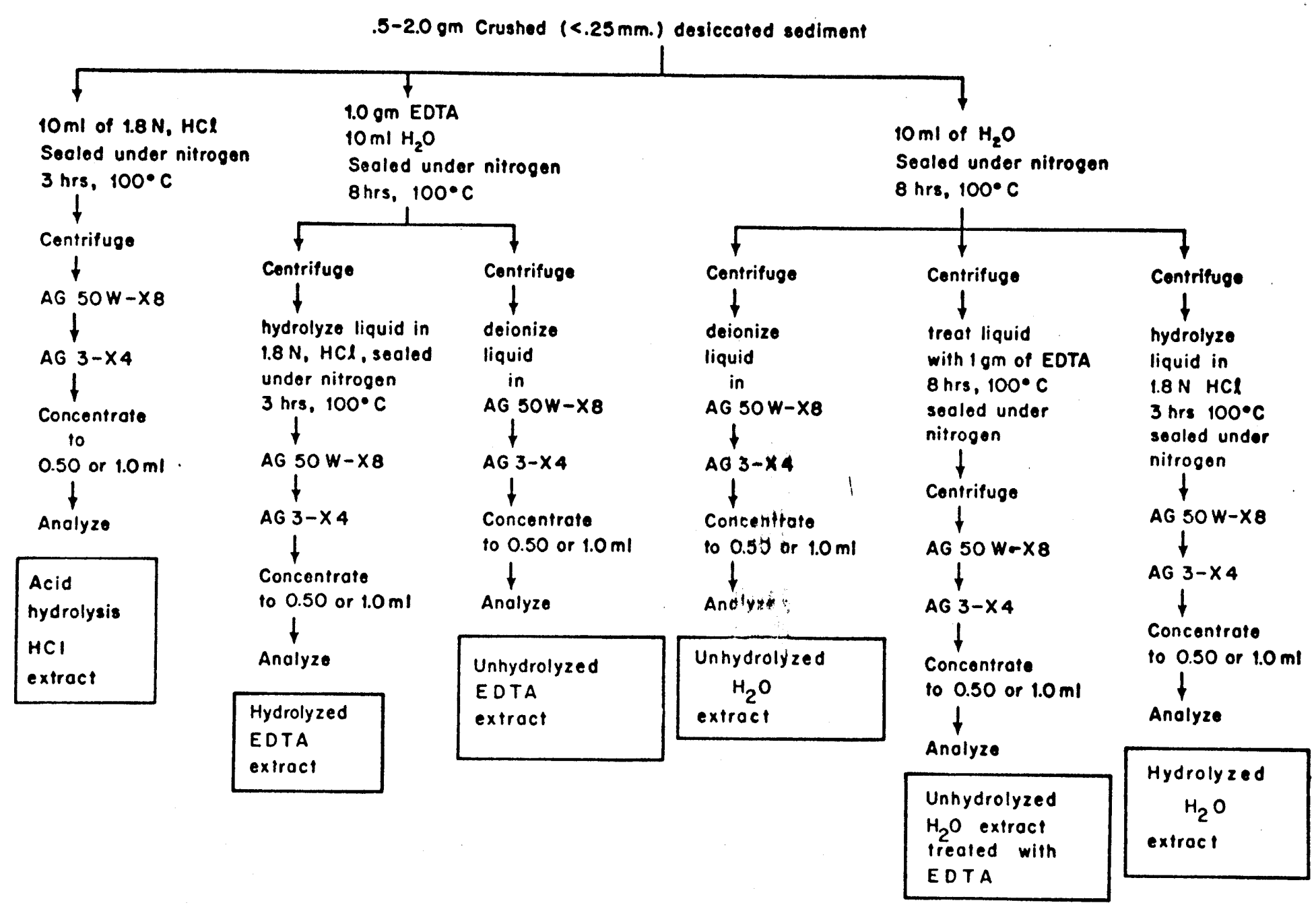

Figure 14

Schematic of carbohydrate extraction techniques. AG $50 \mathrm{~W}-\mathrm{X} 8=$ cation exchange resin $\left(\mathrm{H}^{+}\right.$form) and $\mathrm{AG} 3-$ $\mathrm{X} 4$ = anion exchange resin (formate form). The concentration step is done on a rotary evaporator. 


\section{CHAPTER III}

\section{SIGNIEICANCE OF THE EDTA EXTRACTS AND CARBOHYDRATE-METAL ION INTERACTIONS IN SEDIMENT AND SOIL}

In this chapter I present various lines of evidence to show that organic compounds (carbohydrates in particular) in soils and sediments are complexed with metals to a high degree.

\section{SOIL SCIENCE LITERATURE: HUMIC AND FULVIC - METAL ION INTER- ACTIONS.}

Since no literature exists on sediment organic matter - metal complexes, I review here soil literature which deals with the study of metal complexation of humic and fulvic substances. The soil results can probably be extended to marine sediments which have also been shown to contain humic and fulvic acids (e.g., Rashid and King, 1970). Reviews of the nature of humic and fulvic acids can be found elsewhere (e.g. , Stevenson and Butler, 1969).

Complexation of metals by soil organic matter is probably responsible for the movement of these metals, especially iron, aluminum and manganese, from one horizon to another with their eventual precipitation (Wright and Schnitzer, 1963; and Schnitzer, 1971). Maksimov et al. (1972) demonstrated that humic acids extracted from soils and fossil organic deposits (coals) leach metals from various minerals and that the formation of soluble 
Fe and Al complexes with aromatic hydroxy-acids facilitates their migration and redeposition.

Coleman et al. (1956), with the use of a titration method, studied the complexation capacity of peat; various amounts of $\mathrm{Cu}^{+2}$ were added to peat followed by titration of displaced $\mathrm{H}^{+}$with a base. A modified Bjerrum equation (Bjerrum, 1941; also see Martell and Calvin, 1952) was used to calculate the formation constants of the $\mathrm{Cu}^{+2}$ - peat complexes; the constants obtained were similar to those of polymeric acids. Beckwith (1959), also employing a titration technique, determined that 1 to 2 hydrogen ions were released per $\mathrm{Cu}^{+2}$ complexed. This ispertigator concluded that the binding sites were carboxyl and phenolic oralcoholic OH groups. The results -. of Beckwith (1959) were verified by Khanna and Stevenson (1961) who also employed potentiometric titration techniques; .6 to 1.5 hydrogen ions were released per $\mathrm{Cu}^{+2}$ ion bound to either soil fulvic acids or synthetic melanoidins (sugar and amine condensation products). During the formation of a one-to-one complex, two hydrogen ions are theoretically displaced from ligands (Martell and Calvin, 1952) by one $\mathrm{Cu}^{+2}$ ion. The low yields obtained by Khanna and Stevenson (1961) are explained as follows: (1) $\mathrm{Cu}^{+2}$ may be largely bound to functional groups (e.g. , carboxyl groups) which are normally ionized in aqueous media (this explanation appears to violate electroneutrality); and (2) chelation sites may be partially masked by entrained metals. 
Khanna and Stevenson (1961) also showed that the chelation ability of the transition metals varied but in all cases closely followed the IrvingWilliams stability series. According to Irving and Williams (1948), the stability of divalent metal ion chelates, regardless of the chelating agent, follows the order: $\mathrm{Pd}>\mathrm{Cu}>\mathrm{Ni}>\mathrm{Co}>\mathrm{Zn}>\mathrm{Cd}>\mathrm{Fe}>\mathrm{Mn}>\mathrm{Mg}$. Khanna and Stevenson (1961) used the fact that this series is followed by soil extraction results as evidence of some chelation despite the low hydrogen ion yields.

Schnitzer and Skinner (1965) employed methylation, acetylation, and esterification techniques, respectively, to selectively block alcoholic $\mathrm{OH}$, phenolic $\mathrm{OH}$ and $\mathrm{COOH}$ groups on fulvic acid. The modified fulvic acids were then reacted with various metal ions. These authors concluded that

- the most active coordination sites involved: (1) the simultaneous reaction of metals with both phenolic hydroxyl and the more acidic of the carboxyl groups as shown below:

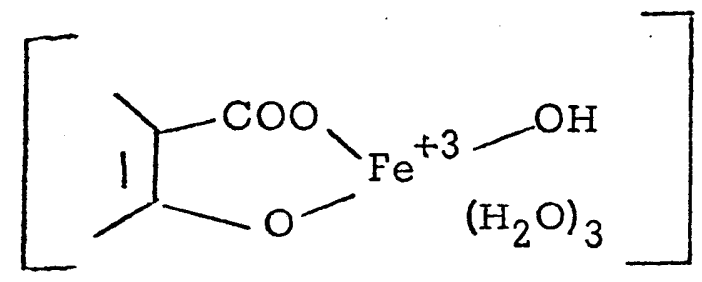

and (2) a minor reaction involving only the less acidic carboxyl groups. It was concluded that alcoholic $\mathrm{OH}$ groups participate in complexes to a negligible extent. Tan et $\underline{\text { al }}$. (1971) by the use of IR studies on the interaction of $\mathrm{Zn}^{+2}$ with sewage sludge fulvic acid, concluded that aliphatic $\mathrm{OH}^{-}$ and $\mathrm{COO}^{-}$groups are mainly responsible for the coordination. His fulvic acid samples showed IR characteristics similar to those of polysaccharides. 
De Datta et al. (1967), by the use of IR methods, were able to isolate and characterize soil-polysaccharide - strontium 90, and yttrium 90 complexes. Wright and Schnitzer (1963) also studied soil organic extracts with IR techniques; they concluded that carboxyl, hydroxyl, and carbonyl groups are mainly responsible for complexation. ${ }^{10}$

Various methods have been employed to determine thermodynamic stability constants of metal complexes with soluble soil organic matter. These techniques involved partition of complexed and uncomplexed forms by solvent extraction (Hodgson et al. , 1965, 1966); a resin exchange method (Miller and Ohlrogge, 1958; Randhawa and Broadbent, 1965; Schnitzer and Skinner, 1966, 1967; Schnitzer and Hansen, 1970; and Ardakani and Stevenson, 1972); and the method of continuous variations (Schnitzer and Hansen, 1970; and Schnitzer, 1971). The latter two techniques appear to give more reliable results, therefore, they are discussed in detail below.

The resin exchange method was first described by Schubert (1948) and was later discussed in detail by Martell and Calvin (1952). The equilibrium reaction for chelate or complex formation can be expressed as:

$$
\mathrm{M}+\mathrm{xC} \rightleftharpoons \mathrm{MC}_{\mathrm{x}}
$$

The formation constant is then:

$$
K=\frac{\left(M C_{x}\right)}{(M)(C)}
$$

${ }_{10}$ Coordination of metals by nitrogen-containing functional groups is probably also significant, however, the IR methods of these investigators are insensitive to nitrogen-metal ion linkages. 


\section{1}

where $\mathrm{M}=$ metal ion, $\mathrm{C}=$ complexing agent, and $\mathrm{x}=$ number of molecules.

Essentially the method depends on the fact that the quantity of cation bound to a definite amount of cation-exchange resin (MR) at equilibrium is proportional to the concentration of the cation in solution $(M) . \lambda_{0}$ is defined as the distribution constant, (MR)/(M), for exchange in the absence of a chelating (or complexing) agent; $\lambda$ is the distribution constant, (MR)/ $\left[(M)+\left(M C_{X}\right)\right]$, in the presence of a chelating agent. By rearranging the above terms $\mathrm{K}$ can be expressed as $[(\lambda / \lambda)-1] /(C)^{\mathrm{x}}$ or $\log [(\lambda / \lambda)-1]$ $=\log \mathrm{K}+\mathrm{x} \log (\mathrm{C})$. The slope and intercept of a plot of $\left.\log \left[\left(\hat{k}_{0} / \lambda\right)-1\right)\right]$ vs $\log (C)$ are the values of $x$ and $\log K$ respectively. The relationships hold only for soluble mononuclear complexes which do not bind to the resin. The cation concentration must be small compared to the complexing agent concentration. Temperature, volume, $\mathrm{pH}$, and ionic strength must be held constant. Extrapolation of the formation constant, $\mathrm{K}$, to zero ionic strength yields the thermodynamic constant. The results of various investigators are presented in Table 6 . For all metal ions studied, the $\mathrm{K}$ values are several orders of magnitude less than those of EDTA (Table 7).

The restriction of the method to mononuclear complexes is not serious in acid solutions, since Geering and Hodgson (1969), Schnitzer and Hansen (1970), and Schnitzer (1971) demonstrated that at pH values $<4.5$ and $\mathrm{I}=$ $0-0.1$, molar divalent metal-fulvic acid ratios are about unity. In the $\mathrm{pH}$ range of 4.5 to 10 , the ratios gradually increase from 1 to 2 . 
TABLE 6

Log of the Equilibrium Constants of Metal-Soil Organic Matter Complexes

\begin{tabular}{|c|c|c|c|c|}
\hline Meta 1 & \multicolumn{2}{|c|}{ Fulvic Acid* } & \multicolumn{2}{|c|}{ Humic Acid** } \\
\hline $\mathrm{Cu}^{+2}$ & 3.3 & 4.0 & -- & -- \\
\hline $\mathrm{CO}^{+2}$ & 2.9 & 3.7 & $-\infty$ & $-\infty$ \\
\hline $\mathrm{Ni}^{+2}$ & 3.1 & 4.2 & --- & -- \\
\hline $\mathrm{Pb}^{+2}$ & 2.6 & 4.0 & -- & -- \\
\hline $\mathrm{Mn}^{+2}$ & 2.5 & 3.7 & --- & --- \\
\hline $\mathrm{Zn}^{+2}$ & 2.3 & 3.6 & $4.4 \ldots$ & $\begin{array}{l}6.8 \\
3.7-5.7(p H=6.5)\end{array}$ \\
\hline $\mathrm{Fe}$ & $6.1 \quad(\mathrm{pH}=2)$ & $-\dot{-}$ & --- & -- \\
\hline $\mathrm{Ca}^{+2}$ & $\begin{array}{l}3.7(p H=2) \\
2.0(p H=3.5)\end{array}$ & $\begin{array}{l}-- \\
3.3\end{array}$ & $\cdots$ & -- \\
\hline $\mathrm{Mg}^{+2}$ & 1.9 & 2.1 & -- & $\cdot$ \\
\hline
\end{tabular}
* after Schutzer and Skinner (1966, 1967); Schnitzer and Hansen (1970);
and Schnitzer (1971)

** after Randhawa and Broadlent (1965) and Ardabani and Stevenson (1972) 


\section{TABLE 7}

LOG OF THE EQUILIBRIUM CONSTANTS $\left(K_{7}\right) *$ OF METAL CHELATOR COMPLEXES

(Sillen and Marte11, 1964)

\begin{tabular}{lrcc|c} 
MetaT & EDTA & Glycine & $\begin{array}{c}\text { Aspartic } \\
\text { Acid }\end{array}$ & $\begin{array}{c}\text { Gluconic } \\
\text { Acid }\end{array}$ \\
\hline $\mathrm{Ba}^{2+}$ & 9.9 & - & - & 1.0 \\
$\mathrm{Ca}^{2+}$ & 10.6 & 1.4 & 1.6 & 1.2 \\
$\mathrm{Cu}^{2+}$ & 18.4 & 8.2 & 8.4 & - \\
$\mathrm{Fe}^{3+}$ & 25.0 & 10.0 & 11.4 & $5.5^{\star *}$ \\
$\mathrm{Mg}^{2+}$ & 8.7 & 3.0 & 2.4 & .7 \\
$\mathrm{~Pb}^{2+}$ & 18.2 & 5.5 & - & 2.6 \\
$\mathrm{Sr}^{2+}$ & 8.6 & 0.9 & 1.5 & 1.0 \\
$\mathrm{Zn}^{2+}$ & 16.6 & 5.0 & 5.8 & 1.7
\end{tabular}

$$
\begin{aligned}
& { }^{*} \mathrm{~K}_{1}=[\mathrm{ML}] /[\mathrm{M}][\mathrm{L}] \\
& { }^{*} \mathrm{~K}_{\mathrm{Fe}^{3+}} \text { (gluconic acid) }=\left[\mathrm{FeL}(\mathrm{OH})_{3}^{-}\right]\left[\mathrm{H}^{+}\right]^{3} /\left[\mathrm{Fe}^{3+}\right]\left[\mathrm{L}^{-}\right]
\end{aligned}
$$




\section{$\cdot 84$}

Modifications of the resin exchange technique to include polynuclear complexes are described by Clark and Turner (1969), Ardakani and Stevenson (1972), and Zunino et al. (1972). The results obtained by these modifications, however, are not significantly different from those obtained by the simplified method of Schubert (1948).

The method of continuous variations was first described by Job (1928) and was later discussed in detail by Martell and Calvin (1952). Color is one of the more characteristic properties of chelate compounds; in fact, a change in color often accompanies a change in the extent of chelation. The method of Job depends on variations of optical densities of solutions containing different ratios of $M$ (metal ion) and $C$ (chelating agent) while keep-

- ing their total concentration constant. By imposing the condition $(M)+(C)$

= constant, it can be shown that at the maximum chelate concentration (when $d(M C) / d(M)=0),(\mathrm{Ke}) /(M)=x$ (Martell and Calvin, 1952). Thus, the concentration of the chelate is highest when metal and chelating agent are reacted in the ratio they exist in the complex. A plot of optical density vs. solution composition yields a curve with a maximum at the composition of the complex. The restriction of mononuclear complexes also applies to this method.

Schnitzer and Hansen (1970) and Schnitzer (1971) compared this technique with the resin exchange method and found that the two methods yielded nearly identical stability constants for all metal - fulvic acid complexes examined. 
For further information, general reviews of the complexing of metals by soil organic matter can be found elsewhere (Mortensen, 1963;

Schnitzer, 1971). 


\section{METAL-CARBOHYDRATE COMPLEXES}

The decay and metabolic degradation of cellular material results in the formation of heterogenous aggregates called humic and fulvic substances. In the previous section it is shown that functional groups in humic and fulvic substances of soil interact with metal ions to form stable complexes. It is also implicit that the degree of interaction is largely dependent on the total of functionality of the constituent molecules in the humic and fulvic substances. Rashid and King (1970) studied the functional groups and cation-exchange capacity of soil and sediment humic and fulvic acids. Comparison of the functional group and elemental compositions of soil and sediment organic extracts, as shown in Table 8 , reveal many underlying 11 similarities which suggests that the results of soil researchers summarized in the previous section are largely applicable to sediment organic extracts.

Carbohydrates have a high degree of functionality and, therefore, may participate in complexes directly through coordination with metals and indirectly through both hydrogen bond formation and condensation with organic ligands. Several investigators have shown that reducing sugars and sugar alcohols form stable, soluble chelates with a wide variety of metals. For example, Bourne et al. (1959) show that soluble chelates form with $\mathrm{Co}^{+2}, \mathrm{Ti}^{+3}, \mathrm{Zr}^{+4}, \mathrm{~Pb}^{+2}, \mathrm{Sb}^{+3}, \mathrm{Bi}^{+3}, \mathrm{Fe}^{+2}, \mathrm{Fe}^{+3}, \mathrm{Co}^{+2}, \mathrm{Ni}^{+2}, \mathrm{Th}^{+4}$ and $\mathrm{VO}_{2}^{+2}$; the sugars employed were d-glucitol, d-mannitol, dulcitol, pentaerythritol, d-glucose, and d-fructose. The formation of chelates

II do not wish to imply that these extracts are exactly the same; e.g., sediment extracts have lower total acidity, lower concentration of phenolic 


\section{7}

TABLE 8

A. COMPARISON OF MAJOR OXYGEN-CONTAINING FUNCTIONAL GROUPS

IN ORGANIC EXTRACTS OF SOILS AND SEDIMENTS

(After Rashid and King, 1970; and Wright and Schnitzer, 1963)

(meq/g, ash and moisture-free)

\begin{tabular}{|c|c|c|c|c|c|c|}
\hline & $\begin{array}{l}\text { Total } \\
\text { acidity }\end{array}$ & $\mathrm{COOH}$ & $\begin{array}{l}\text { Phenolic } \\
\text { OH }\end{array}$ & $\begin{array}{c}\text { Alcoholic } \\
\text { OH }\end{array}$ & $\begin{array}{c}\text { Tota } 1 \\
\text { OH }\end{array}$ & $C=0$ \\
\hline $\begin{array}{l}\text { Soil H.A. } \\
\text { Soil F.A. }\end{array}$ & $\begin{array}{l}5.5 \\
9.0\end{array}$ & $\begin{array}{l}3.0 \\
3.5\end{array}$ & $\begin{array}{l}2.5 \\
5.5\end{array}$ & $\begin{array}{l}1.0 \\
4.0\end{array}$ & $\begin{array}{l}3.5 \\
9.5\end{array}$ & $\begin{array}{l}3.0 \\
2.0\end{array}$ \\
\hline $\begin{array}{l}\text { Sediment H.A. } \\
\text { Sediment F.A. }\end{array}$ & $\begin{array}{l}3.0 \\
2.5\end{array}$ & $\begin{array}{l}2.5 \\
2.0\end{array}$ & $\begin{array}{r}1.0 \\
.5\end{array}$ & $\begin{array}{l}1.5 \\
\text { N.D. }\end{array}$ & $\begin{array}{l}2.5 \\
\text { N.D. }\end{array}$ & $\begin{array}{l}4.0 \\
5.0\end{array}$ \\
\hline
\end{tabular}

B. COMPARISON OF THE ELEMENTAL COMPOSITION OF ORGANIC EXTRACTS

OF SOILS AND SEDIMENTS

(After Rashid and King, 1970)

$(\%$, ash and moisture-free)

\begin{tabular}{lcccccc}
\hline & Ash & Carbon & Hydrogen & Nitrogen & Oxygen & C/N \\
\hline Soi1 H.A. & 6.1 & 52.3 & 5.6 & 3.7 & 38.4 & 14.1 \\
Soil F.A. & 8.5 & 49.2 & 3.2 & 1.7 & 45.9 & 28.9 \\
Sediment & 5.9 & 52.8 & 6.6 & 5.6 & 35.0 & 9.4 \\
$\begin{array}{l}\text { H.A. } \\
\text { Sediment } \\
\text { F.A. }\end{array}$ & 10.6 & 46.2 & 6.6 & 4.5 & 42.7 & 10.3 \\
\hline
\end{tabular}

${ }^{*}$ H.A. = humic acid; F.A. = fulvic acid.

${ }^{* *}$ N.D. $=$ not determined. 
greatly inhibited the precipitation of metal hydroxides even under highly alkaline conditions ( $\mathrm{pH}$ 12). Charley et al. (1963) presented spectral, titrimetric, and potentiometric evidence for complex formation. Their titrimetry revealed that 2 and 3 hydrogen ions were displaced from fructose by the formation of complexes with $\mathrm{Fe}^{+2}$ and $\mathrm{Fe}^{+3}$ respectively. These investigators showed that sugar-metal complexes are stable over wide ranges of $\mathrm{pH}$, and metal ion and sugar concentrations. Using the elemental composition of the precipitated ferric-fructose complex, these authors deduced the following model:
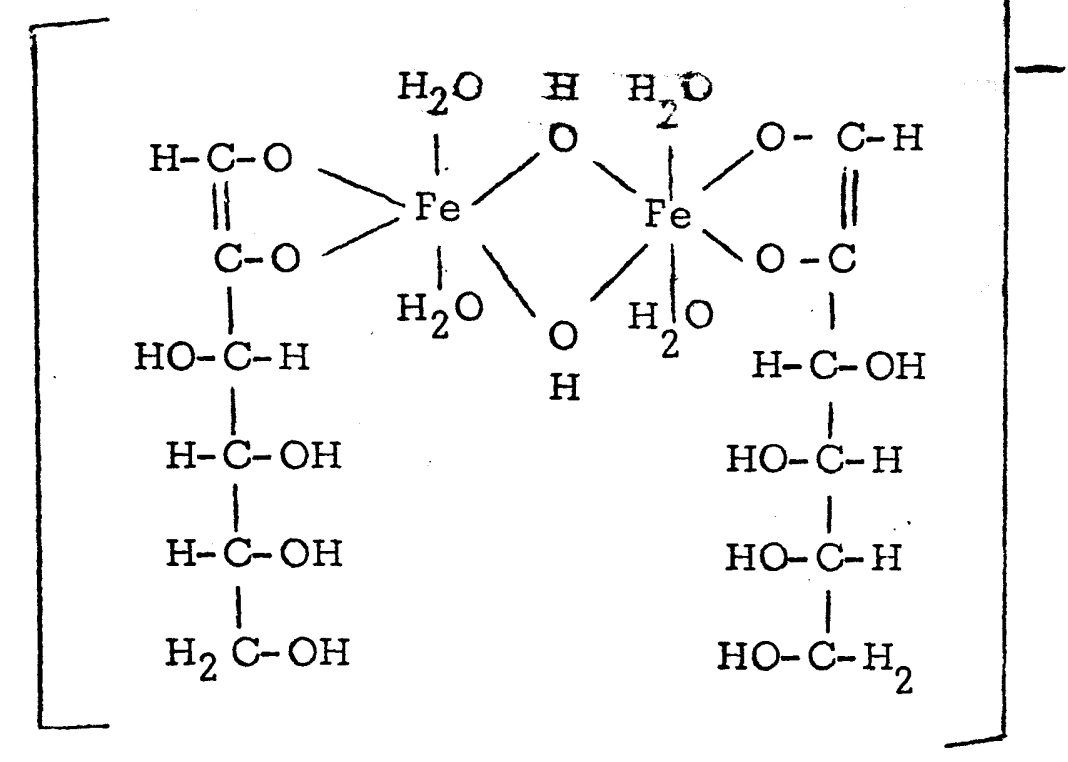

$$
\mathrm{Na}^{+}
$$

The presence of two iron atoms was determined by studies of electron spin and nuclear magnetic resonance.

Infrared studies of zinc complexes of sewage extracts indicated that in the lower molecular weight fulvic acid fraction polysaccharide-appearing substances accounted for most of the complexing activity (Tan et al., 1971). The following reaction was proposed:

$\overline{\mathrm{OH}}$ groups, and lower $\mathrm{C} / \mathrm{N}$ ratios than soil extracts. 


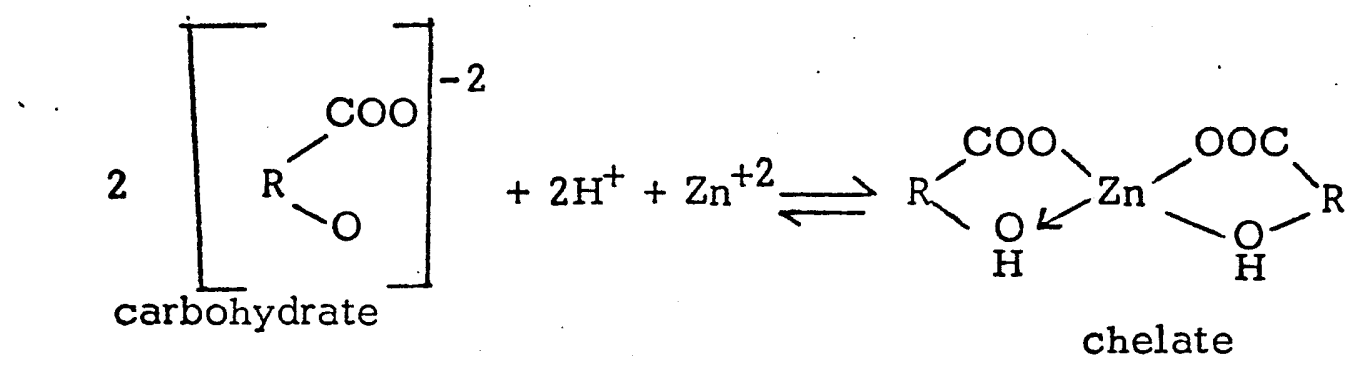

Infrared analyses have been used to characterize soil polysaccharide complexes of strontium 90 and yttrium 90 (De Datta et al.., 1967). 


\section{CHEMISTRY OF EDTA}

Aspects of the chemistry of EDTA relevant to EDTA - carbohydrate interactions (e.g., stability of sugars in the presence of EDTA, hydrolysis effects of EDTA, pH effects, $\mathrm{CaCO}_{3}$ - sugar - EDTA interactions, effects of time and temperature on EDTA extraction, etc.) are presented in the previous chapter. In this section I discuss the general chemistry of EDTA.

Although EDTA is classified as a weak acid ( $\mathrm{pKa}=2.18)$, its major characteristic is its ability to form extremely stable chelates with polyvalent metal ions.

An EDTA molecule coordinates metal ions tinrough six possible sites (4 carboxyl and 2 amino):<smiles>O=C(O)CN(CCN(CC(=O)O)CC(=O)O)CC(=O)O</smiles>

and, thereby, gives rise to a claw-like structure. In basic solutions the oxygens in the 4 carboxyl groups are identical because of resonance.

The structure of the EDTA-manganese complex (as derived from X-ray studies) is shown in Figure 15. The coordination results in formation of an ionic $\mathrm{AB}_{7}{ }^{-2}$ sphere-like complex with a diameter of approximately 6 to $6.5 \AA$. EDTA complexes are able to form strong inter- and intramolecular hydrogen bridges. In the (EDTA $-\mathrm{Mn})^{-2}$ complex all four coordinated oxygens possess a charge of $-1 / 2$; this residual charge increases the solubility of such 
Figure 15

Coordination complex of EDTA and $\mathrm{Mn}^{+} 2$ (after Richards et al., 1964). The coordination $A B 7$ of the manganese: $\mathrm{Mn}$ $\left(\mathrm{N}_{2} \mathrm{O}_{5}\right)$ is shown. The water molecule participating in this manganese complex is incorporated for reasons of coordination. The mean distances for the individual bond types are listed below:

$\frac{\text { Bond Type }}{\mathrm{C}-\mathrm{N}}$

$\mathrm{C}-\mathrm{C}$

$\mathrm{C}-\mathrm{O}$

$\mathrm{Mn}^{+2}-\mathrm{O}$

$\mathrm{Mn}^{+2}-\mathrm{N}$

$\mathrm{Mn}^{+2}-\mathrm{OH}_{2}$
$\mathrm{OH}_{2}$

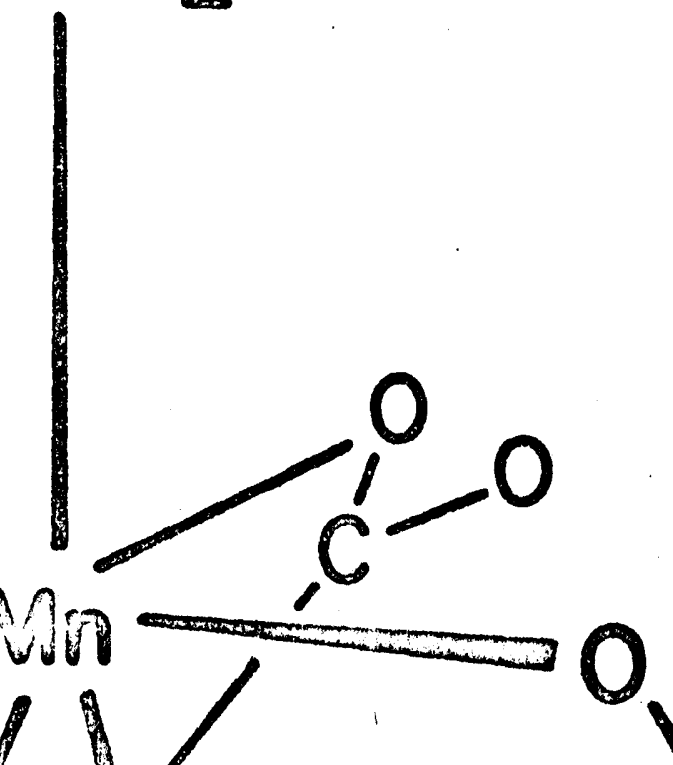


complexes in polar solvents. Figure 16 represents the idealized structure of the (EDTA $-\mathrm{Mn})^{-2}$ complex in solution. Comparing Figure 15 with Figure 16 shows the usefulness of constructing a coordination polyhedron for description of crystallo-chemical relationships exhibited by a complex. The asymmetry of the complex, which is difficult to represent in Figure 15, is easily seen in the coordination polyhedron (Figure 16).

Further details of the chemistry of EDTA can be found elsewhere (Martell and Calvin, 1952; Reilley et al. , 1959; and Martell, 1971). 


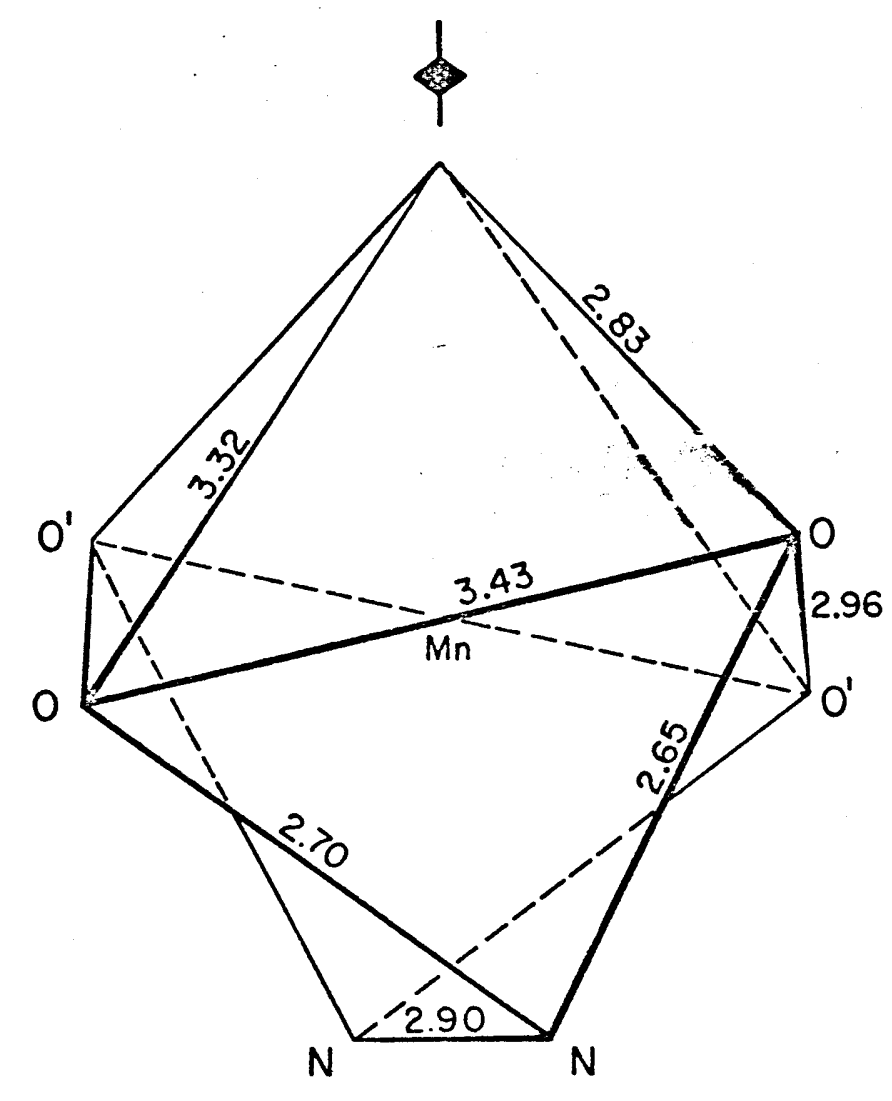

$M n-0=2.236 \AA ; M n-N=2.377 \AA$

Figure 16

The coordination polyhedron: $\mathrm{AB}_{7}$ of the $\mathrm{Mn}$ (EDTA) ${ }^{-2}$ complex as revealed by $X$-ray structure determinations. The numbers refer to the length of the edges in $\AA$ units (after Richards et al. , 1964). 


\section{4}

\section{EXTRACTION OF METAL-BOUND CARBOHYDRATES FROM SEDIMENT}

Bremner et al. (1946) extracted acid-washed soil with several strong chelating agents (e.g., pyrophosphate, sodium citrate, and sodium tartrate). They observed that the quantity of organic matter solubilized correlated with the quantity of metal extracted (exchangeable metal ions were removed by the preliminary acid washing). Dialysis of the extracts removed most of the metals and chelating agents leaving the solubilized organic matter still in solution; addition of manganese, copper, or iron to this solution induced precipitation. These authors found that these newly formed precipitates displayed the same solubility characteristics as shown by the compounds originally present in the soil. In this study it was concluded that some of the organic matter in soil exists as insoluble polyvalent metal ion-organic complexes, and that if the metal ions are removed from the complexes by a strong chelating agent, the organic matter becomes soluble.

This release of bound organic matter by chelating agents is known as the "chelate effect". This effect has been partially attributed to positive entropy changes in the solvent-solute system (Martell and Calvin, 1952). For example, since one EDTA molecule can displace as many as six ligand molecules from a complex, the additional freedom of movement (rotational, translational, etc.) of these displaced molecules increases the entropy of the system. The kinds and numbers of coordination bonds of the metal ion need not change during the displacement of the ligands. 
Table 7 gives the stability constants for EDTA and sugar complexes with various metals. Comparison of the values indicates that the EDTA complexes are many orders of magnitude more stable than the sugar complexes, which suggests that sugar-metal associations can be effectively broken up by EDTA.

The question arises as to whether all the carbohydrates solubilized from sediment (or soil) by EDTA are originally metal-bound. Can EDTA, with its high mobility and claw-like structure, strip carbohydrates from humic and fulvic substances? If this effect is operative what fraction of the released carbohydrates is 'stripped' and what fraction is metal-bound?

In order to answer these questions I substituted Chelex 100, a strong chelating resin with EDTA-like functional groups, for EDTA in the hydrolyzed EDTA extraction of Argentine Basin sediment. The solid phase resin, Chelex 100, was chosen because of its lack of mobility; hence, the stripping effect mentioned above for EDTA does not apply to this system. The results of this experiment are presented in Table 9. It can be seen from this table that approximately $80 \%$ of the sugars solubilized by EDTA are also solubilized by Chelex 100 . The remaining $20 \%$ probably represents the combined effects of stripping and minor hydrolysis (as mentioned in Chapter II). Therefore, I conclude that most of the carbohydrates solubilized from sediment by EDTA are originally bound by metals, though whether directly through coordination with metals or indirectly through either hydrogen bond formation or condensation with organic ligands has not been determined. 


\section{6}

TABLE 9

CHELEX EXPERIMENT

(2 gmArgentine Basin sediment; numbers represent peak areas in $\mathrm{cm}^{2}$ )

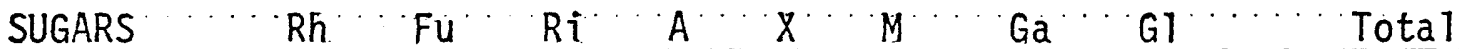

Hydrolyzed Chelex xt.

$\begin{array}{lllllllll}3.7 & 4.1 & 1.6 & 2.7 & 3.8 & 3.2 & 5.6 & 4.6\end{array}$

29.3

Hydrolyzed

Resin

Sum of

Above

$\begin{array}{lllllllll}4.2 & 4.5 & 1.7 & 3.0 & 4.6 & 3.8 & 6.3 & 6.3 & 34.3\end{array}$

Hydrolyzed

EDTA xt.

$5.0 \quad 5.6$

$\begin{array}{llllll}2.8 & 3.8 & 5.9 & 5.2 & 9.0 & 7.2\end{array}$

44.5

$\%$ of Hydro-

lyzed EDTA xt.

Released by

Chelex

Resin

$84 \quad 80$

80

$\begin{array}{llll}61 & 79 & 78 & 73\end{array}$

70

88

77

Hydrolyzed

$\mathrm{H}_{2} \mathrm{O} \times t$.

1.8

2.2

.6

$\begin{array}{llll}6 & 1.2 & 1.9 & 1.6\end{array}$

$2.8 \quad 2.9$

15.0

$\%$ of Hydrolyzed

EDTA xt. Released

by $\mathrm{H}_{2} \mathrm{O}$

36

$\begin{array}{lllll}39 & 21 & 32 & 32 & 31\end{array}$

$31 \quad 40$ 
In the following chapters the sugars observed in the unhydrolyzed EDTA extract will be equated with the metal-bound monosaccharides. Additional sugars observed in the hydrolyzed EDTA extract will be equated with the metal-bound polymers. Total sugars observed in the hydrolyzed EDTA extract will be identified with the total metal-bound carbohydrates (monomers and polymers).

EDTA is a sufficiently strong chelating agent to scavenge metals from carbohydrate-containing associations present in sediments and soils. It is conceivable, however, that some naturally occurring organic associations, such as quinone or sulfhydryl complexes, have a stronger affinity to metals than EDTA or other chelating agents. For example, EDTA extracts $\mathrm{Cu}$ from sewage sludges to a negligible extent compared to the EDTA recoveries of other transition metals (see discussion centered around Table 10, p. 104). Furthermore, since EDTA can effectively scavenge only polyvalent cations, natural complexes involving monovalent cations may be unaffected by the EDTA treatment (the abundance of monovalent cation complexes is probably low since these cations are readily displaced by polyvalent cations [Martell and Calvin, 1972]). Therefore, in the present study it is assumed that the EDTA extraction represents only a low first estimate of the metal-bound carbohydrates in sediment. 
CHAPTER IV

PRESENTATION AND DISCUSSION OF DATA

1. PRESENTATION OF DATA

A general discussion of the sample material is presented in Appendices I and II. The data are presented in terms of mole $\%$ and $\mu$ moles/g dry weight in Tables III- 1 to III-17 in Appendix III. In these tables the following notations are used:

Notation Definition
\end{abstract}

$\begin{array}{ll}\text { ' } \mathrm{HCl} \text { ' } & \mathrm{HCl} \text { extract; considered to reflect total carbohydrates; } \\ & \text { referred to as 'total' in the following discussion. } \\ \text { 'EDTA }+\mathrm{HCl} \text { ' } & \text { hydrolyzed EDTA extract; an estimate of the total } \\ & \text { metal-bound carbohydrates. } \\ \text { 'EDTA' } & \text { unhydrolyzed EDTA extract; an estimate of the total } \\ & \text { metal-bound monosaccharides. } \\ & \text { unhydrolyzed } \mathrm{H}_{2} \mathrm{O} \text { extract; an estimate of the uncom- } \\ & \text { plexed monosaccharides. }\end{array}$

In the following section data for the reducing sugars only are discussed since the non-reducing sugars (e.g., sugar alcohols and acids) are not detected in the present analytical system. 


\section{DISCUSSION OF SAMPLE TYPES}

\section{a. Plankton}

The carbohydrate compositions of plankton from various regions are shown in Tables III- 2 and III- 3 in Appendix III. The total carbohydrate content ranges from $<.5 \%$ to $5 \%$ on a dry weight basis ( $100 \%$ would correspond to about 6000 umoles $/ \mathrm{g}$ ). The carbohydrate composition is variable. The general order of abundance in the $\mathrm{HCl}$ extracts is as follows: $\mathrm{Ga}>\mathrm{Gl}$ $>\mathrm{M}>\mathrm{Ri}>\mathrm{X}>\mathrm{Fu} \widetilde{\mathrm{Rh}}>\mathrm{A}$ (hexoses $>$ pentoses). The function of galactose in plankton is unknown, however, the high vaiiability of glucose is probably related to the biochemical function of this sugar since $\beta$-glucans are the commonest food storage products of algae (Meeuse, 1962; Handa and Yanagi, 1969).

The plankton from the Cariaco Trench and Oyster Pond were also partially extracted in the same manner as sediment: 'EDTA $+\mathrm{HCl}$ ', 'EDTA', ' $\mathrm{H}_{2} \mathrm{O}$ '. The Oyster Pond sample was treated in the wet state immediately after collection in order to minimize microbial degradation. The results are presented in Table III- 1, III-2 and III-3. The unhydrolyzed $\mathrm{H}_{2} \mathrm{O}$ extraction releases 4 to $5 \%$ of the 'total' while the unhydrolyzed EDTA extraction releases about $25 \%$ of the 'total' (it will be recalled from Chapter II that EDTA hydrolyzes $<10 \%$ of simple disaccharides). These analyzes suggest that some monosaccharides present in these plankton samples are metal-bound. 12

12 It must be emphasized that hydrolysis effects of EDTA are probably more significant for plankton than for sediment. Sediments appear to be buffered (probably by inorganic phases) while plankton samples are not, as shown in 
Approximately half of the 'total' is extracted by EDTA; about half of the EDTA extract is present as monomers (Table III-1, line a). EDTA-extracted pentoses (ribose, arabinose, and xylose) occur principally as monosaccharides (line a); EDTA-extracted hexoses (mannose, galactose, and fucose) occur principally as polysaccharides (line b). Line c (Table III-1) shows that hexoses are dominantly present as EDTA-inextractable sugars; deoxyhexoses (rhamnose and fucose) and pentoses are dominantly present as EDTA-extractable sugars (lines $a+b)$.

The EDTA-insoluble sugars are probably present as long-chained structural polysaccharides (hemicellulose). It is of interest to note that Handa and Yanagi (1969) observed that the sugars usually found in such long-chained structural polysaccharides, xylose, mannose, galactose, and glucose, are the dominant sugars in the water-insoluble carbohydrate fraction of particulate organic matter at the surface of the ocean $(0-50 \mathrm{~m})$. From Table III- 3 it can be calculated that mannose, galactose, and glucose constitute about $75 \%$ of EDTA-nonextracted residue. These sugars constitute only $65 \%$ of the 'total' (Table III-2).

The most significant findings are as follows: (1) sugars released by hydrolysis are similar in abundance to those found in sediment and aquatic plants by previous investigators (see Chapter I); (2) although a general order of abundance exists (hexoses $>$ pentoses), no one sugar is present in overwhelming abundance; (3) a large percentage (40-60\%) of the sugars released by acid hydrolysis are also extracted by EDTA and Table $5(p, 73)$. EDTA extraction of plankton in a buffered system would eliminate interference of hydrolysis. 
101

therefore this fraction appears to have been originally present as metalbound monomers and polymers.

A review of the literature of marine algal carbohydrates is given by Percival (1968).

b. Organic Waste Products

(i) Sewage Sludge and Cow Manure: Since organic matter generally represents a small fraction of the total sediment (Bordovskiy, 1965) it is difficult to distinguish alterations that arise from biological degradation from those which may arise from non-biological diagenetic processes. Therefore, in order to clearly discern between these mechanisms, two systems in which microbial degradation is principally involved were studied: sewage sludge treatment and rumination in a cow. The data are presented in Tables III-1, III-4, and III-5 in Appendix III. The following trends are recognized:

1) The degree of metal association (hydrolyzed EDTA xt.) increases from $17 \%$ in the Deer Island primary sludge to about $77 \%$ in the Deer Island secondary sludge (Table III-1). This trend is not as pronounced in the Cranston data because cellulose determinations, which involve concentrated sulfuric acid treatment, were not performed.

2) Table III- I shows that rhamnose, fucose, ribose, arabinose, and galactose are principally present as metal-bound sugars. Ribose and arabinose are dominantly metal-bound monomers. All the other metal-bound sugars are dominantly present as polymers. Line c (Table III-1) shows that glucose, xylose, and mannose are dominantly 
present as EDTA- in extractable sugars. Table III-4 shows that arabinose is the dominant metal-bound monomer.

3) The unhydrolyzed water extractions release $<0.3 \%$ of the 'total' while the unhydrolyzed EDTA extractions release about $5 \%$ in the primary sludge and about $15 \%$ in the secondary sludge (Table III-5).

4) Glucose shows the largest change in concentration after digestion. This trend is expected since cellulose is the major carbohydrate component of the primary sludge.

5) Cow manure is also the product of microbial digestion. Rumination in a cow can be considered analogous to a secondary sludge tank of a sewage treatment plant. The carbohydrate patterns of cow manure (Tables III-1, III-4, and III-5) are very similar to those of sewage sludge. For example, the material is highly metal-bound $(\sim 40 \%)$. Rhamnose, arabinose and galactose (ribose was not detected) are principally present as metal-bound species (Table III-1). Line c shows that glucose, xylose, and mannose are dominantly present as EDTA-in extractable sugars. Arabinose is the dominant metal-bound monomer (Table III-4).

The unhydrolyzed water extraction releases $<0.2 \%$ of the 'total', while the unhydrolyzed EDTA extraction releases $8 \%$. The relative abundance of glucose is reduced in comparison to other sugars in this sample and especially to the straw feed (not shown). The high abundance of xylose (Table III-5) is noteworthy and probably represents an undigested structural fraction of the straw.

From the above trends it can be concluded that microbial degradation 
of organic matter, such as sewage sludge and straw, results in a large increase in the degree of metal as sociation. This increase during microbial degradation of sewage strongly suggests that metal-bound carbohydrates are biologically inaccessible, even though they include a large fraction of easily degradable monosaccharides (up to $15 \%$ of 'total'). Such inaccessibility could be due simply to the low solution levels of free carbohydrates as shown by the unhydrolyzed water extraction, or could be due to inhibitory effects of the metal content of the bound carbohydrates (see discussion of Figures 25 and 26, p. 137).

Concurrent with an increase in metal association after degradation is a large decrease in carbohydrate carbon relative to total organic carbon which suggests that carbohydrates are utilized preferentially to other organic compounds (such as humic and fulvic acids). These trends are further discussed in Chapter V and Figure 27.

(ii) Heavy Metals Extracted from Sewage Sludge: Table 10 compares heavy metal analyses of EDTA extracts, and nitric acid extracts of sewage sludge. Metals constitute up to $10 \%$ of the total (dry weight); most of the metals appear to be almost totally extracted with EDTA. The metal recoveries for the EDTA extraction of the Deer Island secondary sludge are generally higher than for the Deer Island primary sludge. This trend indicates that digestion of sewage sludge renders metal ions more available for extraction with EDTA. The reason for this greater availability is 
104

TABLE 10

METAL ANALYSES OF NITRIC ACID DIGESTED, AND EDTA EXTRACTED SEWAGE SLUDGES ( $\mathrm{g} / \mathrm{g}$ dry wt.)

\begin{tabular}{|c|c|c|c|c|}
\hline Metal & & $\begin{array}{c}\text { Nitric Acid } \\
\text { Digestion } \\
\end{array}$ & $\begin{array}{c}\text { EDTA* } \\
\text { Extracted } \\
\end{array}$ & $\begin{array}{l}\text { \%Extract } \\
\text { with EI }\end{array}$ \\
\hline Lead & $\begin{array}{l}\text { Cranston }(s)^{* * *} \\
\text { Deer Is (p) } \\
\text { Deer Is (s) }\end{array}$ & $\begin{array}{l}365 * * \\
868 \\
722\end{array}$ & $\begin{array}{l}345 \\
975 \\
750\end{array}$ & $\begin{array}{r}95 \\
112 \\
104\end{array}$ \\
\hline Cadmi um & $\begin{array}{l}\text { Cranston (s) } \\
\text { Deer Is (p) } \\
\text { Deer Is (s) }\end{array}$ & $\begin{array}{l}12 \\
36 \\
55\end{array}$ & $\begin{array}{r}5 \\
28 \\
55\end{array}$ & $\begin{array}{r}42 \\
78 \\
100\end{array}$ \\
\hline Nicke] & $\begin{array}{l}\text { Cranston }(s) \\
\text { Deer Is }(p) \\
\text { Deer Is }(s)\end{array}$ & $\begin{array}{r}1,490 \\
153 \\
197\end{array}$ & $\begin{array}{l}480 \\
115 \\
170\end{array}$ & $\begin{array}{l}32 \\
75 \\
86\end{array}$ \\
\hline Chromium & $\begin{array}{l}\text { Cranston (s) } \\
\text { Deer Is (p) } \\
\text { Deer Is (s) }\end{array}$ & $\begin{array}{r}280 \\
895 \\
1,376\end{array}$ & $\begin{array}{r}103 \\
900 \\
1,675\end{array}$ & $\begin{array}{r}37 \\
101 \\
123\end{array}$ \\
\hline Cobalt & $\begin{array}{l}\text { Cranston (s) } \\
\text { Deer Is (p) } \\
\text { Deer Is (s) }\end{array}$ & $\begin{array}{l}19 \\
11 \\
12\end{array}$ & $\begin{array}{l}--- \\
---\end{array}$ & $\overline{---}$ \\
\hline Zinc & $\begin{array}{l}\text { Cranston }(s) \\
\text { Deer Is (p) } \\
\text { Deer Is }(s)\end{array}$ & $\begin{array}{l}6,704 \\
1,747 \\
2,537\end{array}$ & $\begin{array}{l}4,700 \\
1,950 \\
3,200\end{array}$ & $\begin{array}{l}70 \\
112 \\
126\end{array}$ \\
\hline Copper & $\begin{array}{l}\text { Cranston }(s) \\
\text { Deer Is (p) } \\
\text { Deer Is (s) }\end{array}$ & $\begin{array}{r}2,860 \\
870 \\
1,200\end{array}$ & $\begin{array}{l}70 \\
15 \\
15\end{array}$ & $\begin{array}{l}2 \\
2 \\
1\end{array}$ \\
\hline
\end{tabular}

*Analysis of the EDTA reagent revealed only trace quantities of heavy meta1s. A water extraction $\left(8 \mathrm{hrs}, 100^{\circ} \mathrm{C}\right)$ of the Deer Is (s) sample released negligible amounts of heavy metals relative to the nitric acid digestion; e.g., $0.25 \% \mathrm{Cu}, .70 \% \mathrm{Cd}, .34 \% \mathrm{Zn}$, and $22 \% \mathrm{Ni}$. Metal analyses were run by Andy Jacobs.

** Metal analyses performed by Andy Jacobs by atomic absorption.

***s = secondary treated sludge

$p=$ primary treated sludge 
unknown, although it seems possible that the by-products of microbial degradation (e.g., humic and fulvic substances) may extract heavy metals from any inorganic phases present, as shown by Maksimov (1972) for soil humic acids.

The low Cu recovery of the EDTA extractions (Table 10) is not clearly understood. It is possible that the $\mathrm{Cu}$ is bound in in situ complexes which have a stronger affinity for that metal (e.g., sulfhydryl complexes) than EDTA. Further research is necessary to clarify this point.

Despite the high concentrations of potentially toxic heavy metals, they do not appear to interfere with microbial degradation. This suggests that these metals are bound with organic matter which in turn greatly reduces their activity (and hence their toxicity). Tan et al. (1971) measured a stability constant of 6.8 (at $\mathrm{pH} 7$ ) for zinc-sewage sludge extract complexes (see Table 7 for other stability constants).

c. New York Bight and Hudson Canyon: Oxic, Shallow Oceanic Shelf

The data is listed in Tables III-1, III- 4 and III- 5 in Appendix III. The sample labelled 'Buoy Station' was collected from the periphery of the sewage disposal area. Control samples, labelled Mid Gully and Deep Gully, were collected from the uncontaminated nearby Hudson Canyon. In almost all aspects the carbohydrate composition (Table III-4) of the sewage-containing sediment ('Buoy Station') is identical to that of the control sediments. For example the relative abundances in the $\mathrm{HCl}$ ${ }^{13}$ The carbohydrate content at 'Buoy Station' is the greatest found for any non-reducing sediment analyzed. 
extracts are similar, although xylose and glucose may be slightly enriched in the sewage-containing sediment. The degree of metal binding is 60-70\%. Hexoses are less bound than both deoxyhexoses and pentoses. The total sugar content relative to total organic carbon is about $5 \%$ for the 'Buoy Station' sample and 7-8\% for the Hudson Canyon samples.

Thus, despite the differences in types (plankton debris vs. sewage sludge) and rates of organic input of these two shallow oxygenated marine environments, the end-product of biological degradation at these sedimentwater interfaces is remarkably similar.

Furthermore, the results imply that in oxic environments the rate of benthic consumption is able to match even a large rate of organic input which further suggests that benthic consumption is limited by the rate of organic input. Thus, the high organic input rate at the 'Buoy Station' is matched by an equally high consumption rate (Smith et al. , 1973).

The treatment of raw sewage on land prior to shallow ocean dumping may be unnecessary because the rate of biological degradation of this substance at the sediment-water interface in shallow oxic environments may be comparable to and perhaps more efficient than primary and secondary sewage treatment. However, care should be taken to maintain a dumping rate which does not overload the environment since this may lead to the formation of anoxic conditions and death of benthic metazoan life (Mopper, 1971). 


\section{7}

\section{d. Argentine Basin: Oxic, Deep Oceanic Basin}

The carbohydrate results of seven sediment samples from the Argentine Basin ranging in age from 0 to 90,000 years B.P. are shown in Tables III- 1 , III-8, and III-9. The compositions of various extracts are remarkably uniform for the time span sampled, although a diagenetic relationship between arabinose and xylose in the $\mathrm{HCl} \mathrm{xt}$. may exist: at the top of the core arabinose $>$ xylose, in the middle arabinose $\sim x y l o s e$, and at the bottom arabinose <xylose. Furthermore, an inverse relationship between glucose and ribose exists as shown in Figure 17. This inverse relationship may have resulted from changes in terrigenous and marine organic inputs. Figure 23 (Chapter V) shows that terrigenous materials such as wood, peat, and sewage sludge are depleted in ribose and enriched in glucose; plankton material, on the other hand, is depleted in glucose and enriched in ribose.

The relative abundance of the sugars in the $\mathrm{HCl}$ extract of Argentine Basin sediment is: $\mathrm{Ga}>\mathrm{Gl}>\mathrm{M}>\mathrm{X} \sim \mathrm{A}>\mathrm{Rh} \sim \mathrm{Fu}>\mathrm{Ri}$; hexoses $>$ pentoses (Table III-8). In the unhydrolyzed EDTA extract (EDTA extracted monomers; $\sim 30 \%$ of the 'total') the reverse trend is observed: pentoses $>$ hexoses, which suggests that hexoses are deminantly present as polysaccharides (an alternative explanation for this trend is that hexoses are preferentially adsorbed by clays; this possibility is discussed further in the next chapter). Fucose, ribose, arabinose, and xylose are dominantly present as metalbound monomers (Table III-1). In the hydrolyzed EDTA extract the order of abundance is $\mathrm{Ga}>\mathrm{Gl}>\mathrm{M} \sim \mathrm{X} \sim \mathrm{Fu}>\mathrm{Rh}>\mathrm{A}>\mathrm{Ri}$. No one sugar in any of the 




Figure 17

Ribose and glucose fluctuations in Argentine Basin sediments. The inverse relationship between these sugars is noteworthy. The glucose to ribose ratio in sediment may reflect relative changes in the terrigenous and marine organic inputs. 
extracts is present in overwhelming abundance.

Comparison of the Argentine Basin data with the New York Bight and Hudson Canyon data reveals many underlying similarities. For example, the relative abundance of sugars in the extracts are almost identical. The degree of metal binding is $60-70 \%$; about $25 \%$ of the 'total' is present as metal bound monosaccharides. Fucose, ribose, arabinose, and xylose are dominantly present as metal-bound monomers (Table III-1). These similarities suggest that in deep and shallow-sea oxygenated environments the end-product of biological degradation at the sediment-water interface is remarkably similar.

Figure 18 indicates that the total sugar content relative to the total 14 organic carbon content is fairly uniform with depth with the exception of the surface samples, which show a slight enrichment. This enrichment may simply reflect time-dependent changes in benthic consumption and sedimentation rates. At high sedimentation rates carbohydrates may be buried at a faster rate than the biological consumption rate at the sedimentwater interface. Thus, the enrichment of sugar at the surface may be the result of a recent change in the balance between consumption and sedimention. Alternatively, the surface enrichment may reflect the breakdown period of readily consumable carbohydrates; the residue, which is presumably resistant to further consumption, is buried.

The results of section $b$ for sewage sludge and cow manure strongly suggest that metal-bound organic matter is largely inert to and also 14 Which fluctuates; see Appendix Figure I- 1. 
PERCENT CARBOHYORATE-CARBON IN TOTAL ORGANIC CARBON
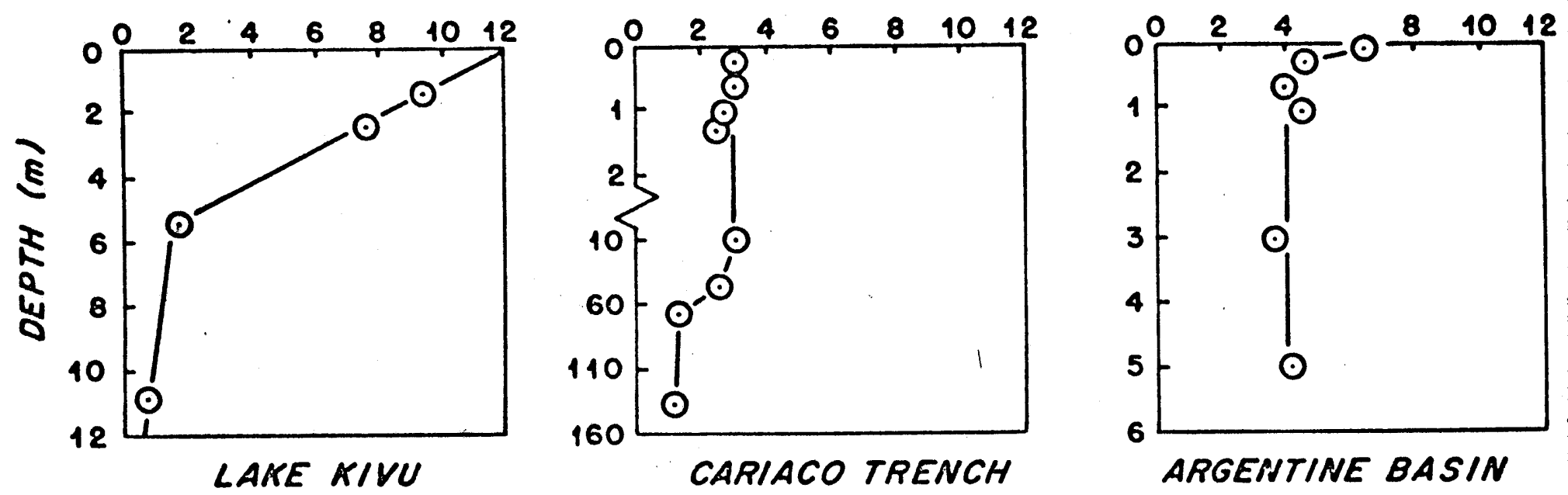

Figure 18

Depth changes in carbohydrate carbon relative to total organic carbon. Lake Kivu sediments show the largest change with depth. This change is probably the result of thermal degradation of sugars. The change in the Cariaco Trench sediments at 40-60 m is probably due to a change in the composition of the organic input. The reason for the change in the Argentine Basin surface sediments is presently unknown. 
the residue of biological degradation. Along with an increase in metal binding with degradation, a decrease in sugar carbon (relative to total organic carbon) is observed. Thus, if either of the explanations mentioned in the previous paragraph is true, then one would expect to observe in the Argentine Basin an inverse relationship between the degree of metal association and the percent sugar carbon (in the total organic carbon). That is, as the sugar carbon (as $\%$ of total) decreases with depth (Figure 18), an increase in metal association is expected.

Figure 19 shows the temporal change of the hydrolyzed EDTA extraction (as $\%$ of the total). Although the average value is $63 \%$, an actual decrease with depth of EDTA extracted sugars occurs. This unexpected decrease may be explained by any of the following:

(1) the assumption that an inverse relationship exists between \% sugar carbon and EDTA-extractable sugars only applies to recent degradation in surface sediments;

(2) the enrichment in sugar carbon and EDTA-extractable sugars at the surface may reflect a recent change in nature of the organic input; (3) a diagenetic decrease in metal binding with depth occurred; metal ions may have been extracted from organic associations by diagenetic incorporation into clays; and

(4) the diagonetic formation of $\mathrm{H}_{2} \mathrm{O}$ and EDTA insoluble organic condensation products occurred; thus, although the degree of binding may not have decreased, the degree of intermolecular cross-linking 


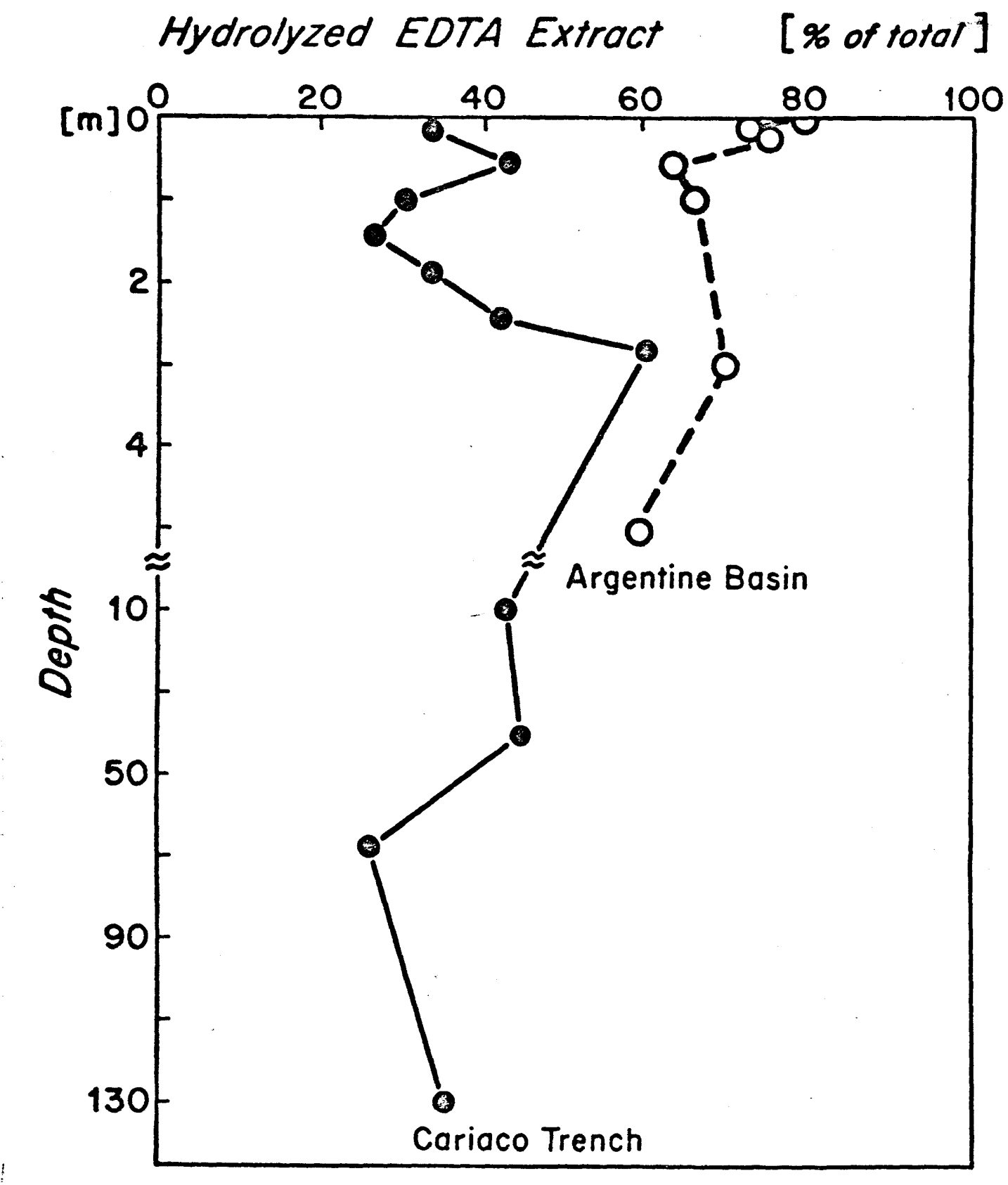

Figure 19

Comparison of the temporal changes in the degree of metal binding of carbohydrates in Cariaco Trench (reducing) and Argentine Basin (oxidizing). The peak at $2.65 \mathrm{~m}$ in the Cariaco Trench represents a band of oxic sediment. The degree of binding of carbohydrates in these sediments appears to be related to the Eh at the time of deposition. 
between organic molecules may have increased (since EDTA is a weak acid, it is probably not capable of hydrolyzing these cross-linkages; see Chapter II) .

At present, the data is insufficient to determine which ones (or one) of the above explanations are (is) correct.

\section{e. Cariaco Trench: Anoxic Oceanic Trench}

The carbohydrate results of twelve core samples from the reducing zone of the Cariaco Trench are listed in Tables III-1, III-6, and III-7. Omitting the wood sample $(.64-.68 \mathrm{~m})$, which is discussed below, the carbohydrate compositions for all three extracts $(\mathrm{HCl}, \mathrm{EDTA}+\mathrm{HCl}$, and EDTA) are remarkably uniform down to $40 \mathrm{~m}$ even though the organic carbon - content of the sediment drops from $6 \%$ to $1.9 \%$. Figures 18 and 20 indicate that the total sugar concentration correlates well with the drop in organic carbon. These results suggest that the effects of diagenesis down to $40 \mathrm{~m}$ is either negligible (variations in the total carbon being due to variations of organic input rates) or remarkably nonselective.

The break in the sugar composition between $40 \mathrm{~m}$ and $67 \mathrm{~m}$ (Table III-6) along with the depletion of sugars relative to total organic carbon below $40 \mathrm{~m}$ (Figures 18 and 20) may be explained by one of the following: i) a sudden diagenetic change; ii) a change in the composition of the organic input; and iii) a change in the sediment surface microbial population. The inverse correlation in glucose and ribose shown in Figure 21 strongly suggests a change in the composition of the organic input occurred below 


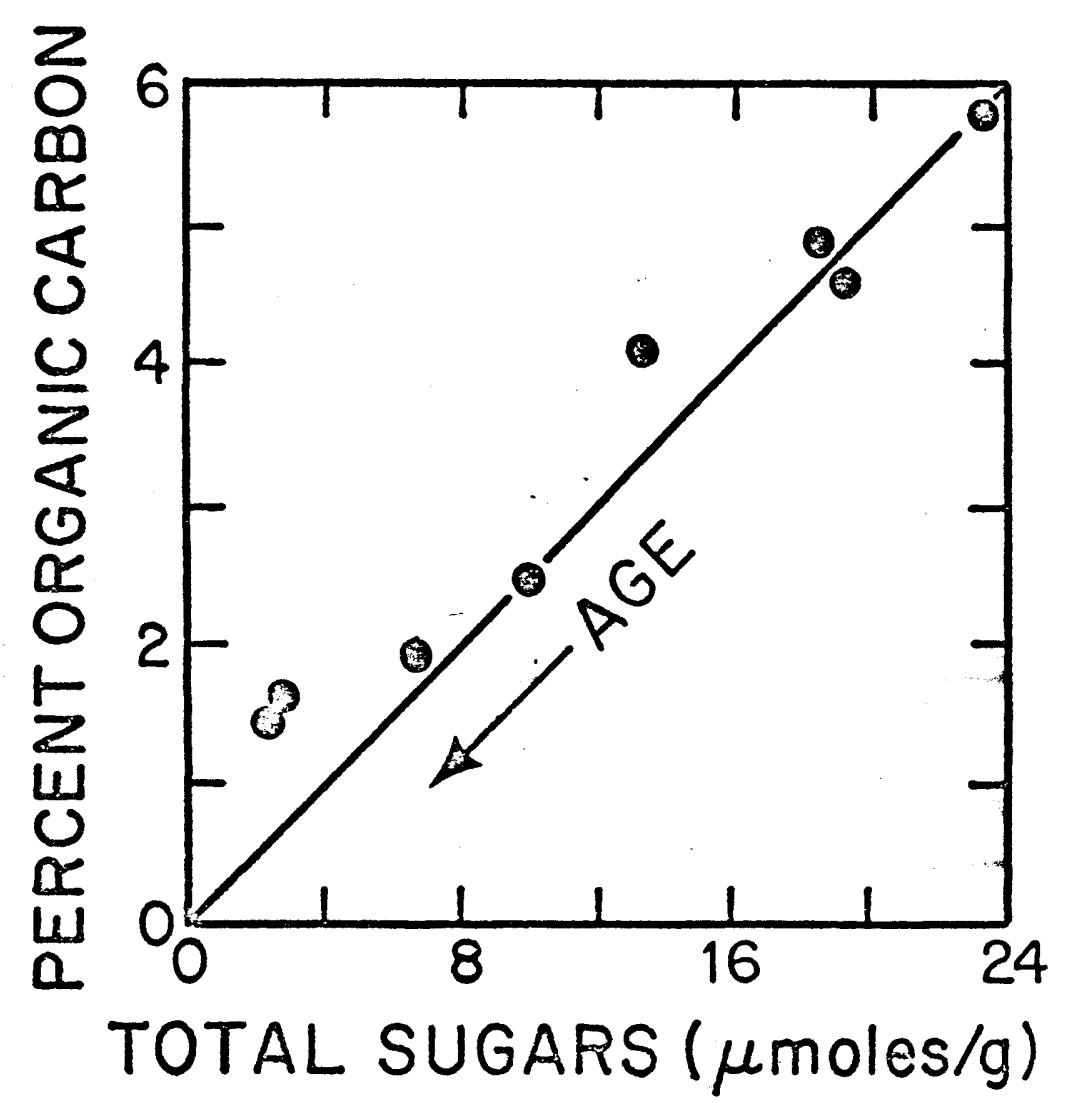

Figure 20

Relationship between total organic carbon and total sugars in Cariaco Trench sediments. 


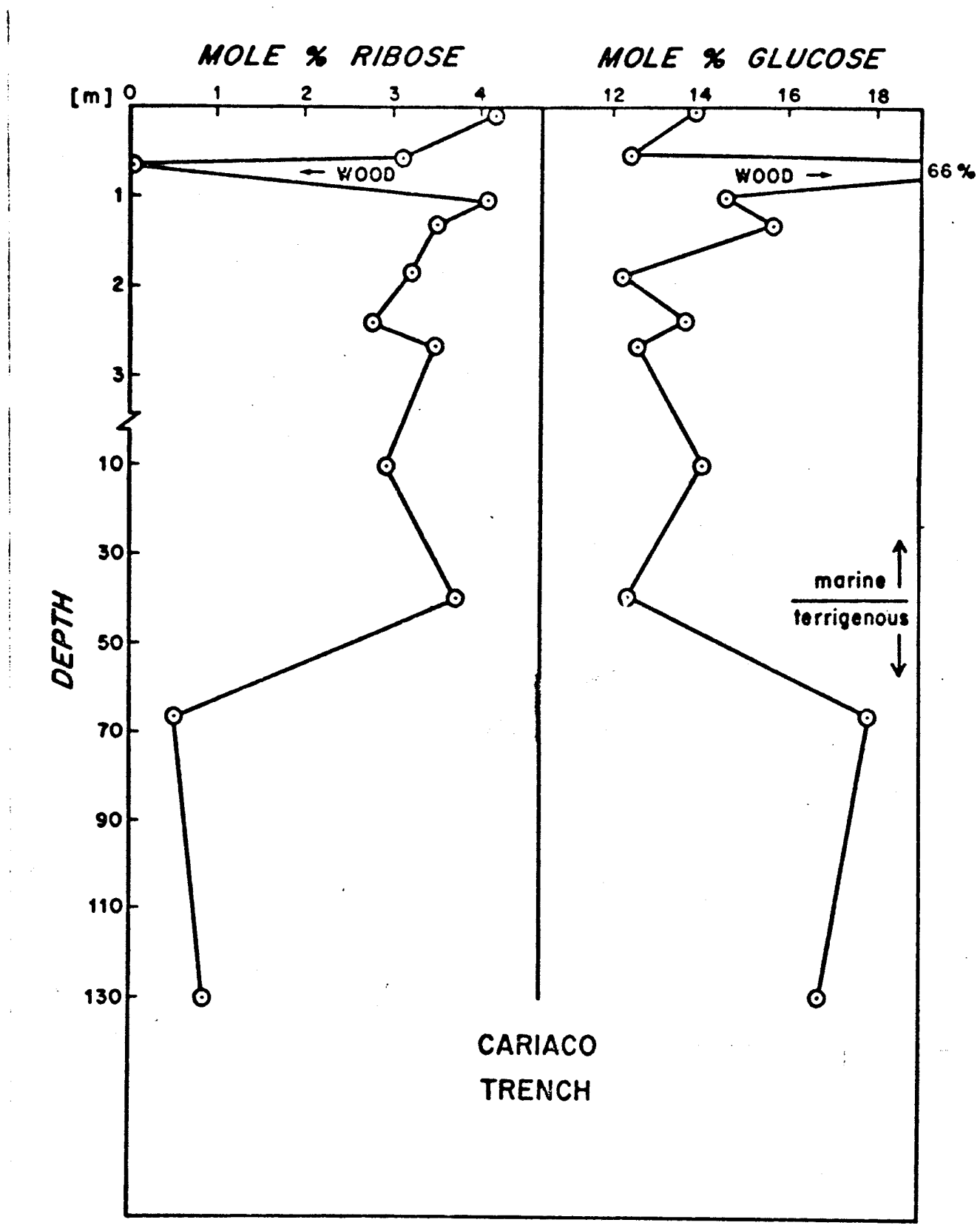

Figure 21

Ribose and glucose fluctuations in Cariaco Trench sediments. The inverse relationship between these sugars is striking. The lower sediments $(>40 \mathrm{~m})$ probably reflect an increased terrigenous organic input. 
$40 \mathrm{~m}$; these sediments appear to have a larger terrigenous input as evidenced by the increased glucose and decreased ribose contents..$^{15}$

The relative abundance of the sugars in the $\mathrm{HCl}$ extract at all depths down to $40 \mathrm{~m}$ is invarient: $\mathrm{Ga}>\mathrm{M}>\mathrm{Gl}>\mathrm{X} \sim \mathrm{Rh}>\mathrm{Fu}>\mathrm{A}>\mathrm{Ri}$. The order of abundance is similar to that of the Argentine Basin from which it differs only in the inversion of mannose and glucose and the lower abundance of arabinose. The order of abundance is less similar to that of the plankton sample immediately above the trench. The orders of abundance within the unhydrolyzed and hydrolyzed EDTA extracts also more closely resemble that of the Argentine Basin than the Cariaco plankton. Fucose, ribose, arabinose, xylose, and galactose are the dominant metal-bound monomers (Table III-6).

The relative abundance in the $\mathrm{HCl}$ extract below $40 \mathrm{~m}$ is somewhat different from that of the overlying sediment: $\mathrm{M} \sim \mathrm{Ga}>\mathrm{Gl}>\mathrm{X}>\mathrm{A}>\mathrm{Rh}>$ Fu $>\mathrm{Ri}$, which again suggests a change in the source material and/or a change in the sediment surface microbial population.

The $2.65 \mathrm{~m}$ sample represents sediment deposited under oxidizing conditions as shown by metal analyses (Brian Price, pers. comm.). Relative abundances within the $\mathrm{HCl}$ extract and the hydrolyzed EDTA extract (Table III-6) are nearly identical to the overlying and underlying reducing sediment. If it is assumed that the carbohydrate composition of the organic input during this interval (reducing-oxidizing-reducing) remained fairly constant, then these results imply that a change in the sedimentary $\overline{15}$ Fluctuations in the glucose-ribose ratio appear to correlate with $\delta \mathrm{C}^{13}$ 


\section{7}

environment from reducing to oxidizing, with the concomitant change in micro- and macrofauna, has little or no effect upon the composition of the sedimented carbohydrates.

The main difference in the carbohydrates extracts between the oxic and reducing zones lies in their degree of metal-binding. Figure 19 shows that for the reducing sediments the hydrolyzed EDTA extraction (metal-complexed monomers and polymers) releases about $40 \%$ of the 'total'; for the oxidizing band at $2.65 \mathrm{~m}$ the hydrolyzed EDTA extraction releases about $60 \%$, a value which is similar to that of other oxidizing sediments, such as the Argentine Basin, New York Bight, and Hudson

Canyon. These results first suggested that a correlation exists between the degree of metal-binding of sedimentary carbohydrates and the Eh at the sediment-water interface at the time of deposition.

The wood at .64-.68 cm is over 5000 years old, however, it is in remarkably good preservation; structural details such as intact cell walls still exist. However, this structure is actually very fragile and is easily destroyed in the dried specimen. An increase in the glucose yield by only 30 mole \% after concentrated sulfuric acid treatment (Table III-6) suggests that the original cellulose has undergone some in situ hydrolysis (the Deer Island sewage sludge shows about a 60 mole \% increase in glucose yield after sulfuric acid treatment, as shown in Table III-4).

In the wood sample, $14 \%$ of the 'total' is released by the unhydrolyzed EDTA extraction; hydrolysis of this extract released an additional $2 \%$ of the

fluctuations (Werner Deuser, pers. comm.). 
'total'. Arabinose is the dominant metal-bound monomer (Table III-6). Although I6\% of the wood carbohydrates can be brought into solution by removal of the metals by EDTA, no equivalent process appears to have occurred in situ; the carbohydrate composition of the surrounding sediment is completely unaffected by the presence of this carbohydrate-rich wood (Table III-6). These observations indicate that metal binding of soluble carbohydrates in the wood fixes that fraction in situ, thereby, inhibiting its diffusion. This conclusion contrasts with previous work by Prashnowsky et 찌. (1961) and Degens (1965) who hypothesized the chromatographic separation of carbohydrates along mineral surfaces.

\section{f. Santa Barbara Basin: Anoxic Oceanic Basin}

Two samples, dated at $\sim 50$ years and $\sim 750$ years B.P., are presented in Tables III-14 and III-15. The carbohydrate compositions of these samples are remarkably similar. In the $\mathrm{HCl}$ extracts the order of abundance is: $\mathrm{Ga}>\mathrm{Gl} \widetilde{>} \mathrm{M}>\mathrm{X}>\mathrm{Rh}>\mathrm{Fu} \widetilde{>} \mathrm{A}>\mathrm{Ri}$, which is almost identical to that obtained for the Cariaco Trench sediments. There does appear to be a slight enrichment of mannose and xylose and a slight depletion of arabinose with age. However, the data is insufficient to conclude whether these trends are diagenetic in origin or simply the result of secular changes in the composition of the input. As in the case of the Cariaco data, I lean to the latter.

The hydrolyzed EDTA extraction releases $43 \%$ of the 'total', a value which is similar to that of the reducing Cariaco Trench sediments; this zontal extension greater than the core diameter $(\sim 8 \mathrm{~cm})$. The overlying and underlying sediment samples approached the wood within a centimeter. 
result further suggests that carbohydrates have a lower degree of metal association in reducing sediments than in oxidizing sediments. The order of abundance within this extract is also similar to that of Cariaco Trench sediments (hexoses $>$ pentoses).

The hydrolyzed $\mathrm{H}_{2} \mathrm{O}$ extract represents the difference between the 'total' $\left(\mathrm{H}_{2} \mathrm{O}\right.$ insoluble + soluble extract) and the $\mathrm{H}_{2} \mathrm{O}$ insoluble extract (2nd and 3rd lines in Tables III-14 and III-15). The hydrolyzed $\mathrm{H}_{2} \mathrm{O}$ extract is similar in composition to the $\mathrm{HCl}$ extracts with minor exceptions: rhamnose and fucose are slightly enriched, while arabinose and glucose are slightly depleted.

Again, no one sugar in any of the above extracts is present in overwhelming abundance.

\section{g. Walvis Bay: Anoxic, Shallow Oceanic Shelf}

The carbohydrate data for the Walvis Bay surface sediment are shown in Tables III- 1 and III-10. Walvis Bay sediments, like Cariaco Trench sediments, are also deposited under reducing conditions. Tables III- 1 and III-10 show that the carbohydrate composition of surface sediment from these areas are remarkably similar with the exception of

17 The extraction techniques used for the Santa Barbara Basin sediments were different from those used for other sediments in this thesis because of an intercalibration study (see Chapter II). The $\mathrm{H}_{2} \mathrm{O}$ insoluble + soluble extract = 'total'; the $\mathrm{H}_{2} \mathrm{O}$ insoluble extract = hydrolysis of the $\mathrm{H}_{2} \mathrm{O}$ insoluble sediment residue (sediments were washed 4 times with $25 \mathrm{ml}^{2}$ of $\mathrm{H}_{2} \mathrm{O}$ ); and the hydrolyzed $\mathrm{H}_{2} \mathrm{O}$ extract = hydrolysis of the combined washings. 
mannose which is somewhat reduced in the Walvis Bay sediment. The hydrolyzed EDTA extraction releases $39 \%$ and $42 \%$ of the 'total' in these reducing sediments, respectively. The content of metal-bound monosaccharides is about $15 \%$ for both areas; fucose, ribose, arabinose, xylose, and galactose are again the dominant metal-bound monomers (Table III-10).

\section{h. Black Sea: Restricted Inland Basin}

The carbohydrate data of three samples, representing the three major sedimentary units of Black Sea core 1474 (see Appendix I for details), are presented in Tables III-1, III-12 and III-13. The deepest sample (120-130 Cm, B.S. fresh) represents the freshwater, oxic period of the Black Sea. The order of abundance in the $\mathrm{HCl}$ extract (Table III-12) is: $\mathrm{Ga}>\mathrm{Gl}>\mathrm{M}>$ $\mathrm{Rh}>\mathrm{X} \sim \mathrm{A}>\mathrm{Fu}>\mathrm{Ri}$. This order is similar to that of Argentine Basin and Cariaco sediments. Table III- 1 indicates that about $65 \%$ of the 'total' sugars are metal-bound (EDTA $+\mathrm{HCl})$, a value which compares well with sediment from other oxic environments (e.g., Argentine Basin, New York Bight); $14 \%$ of the 'total' is extracted as metal-bound monosaccharides. Ribose, fucose, rhamnose, arabinose, and xylose are predominantly metal-bound (Table III- 1 ).

The 65-70 cm sample (B.S. transition) is from the organic-rich unit and represents the transition period from oxic fresh water to anoxic marine (4000-7000 B.P.). The hydrolyzed EDTA extraction releases $54 \%$ of the 'total', a value which is between oxic and anoxic sediments. The 


\section{1}

high organic content of this sample $(30-40 \%$ as shown in Figure I- 1 , Appendix I) suggests a terrigenous source. However, $\delta \mathrm{C}^{13}$ values of -24 to -26 for the organic matter are between that of marine and terrigenous organic matter (Deuser, 1972; Degens, 1969). Furthermore, a 'normal' order of sugar abundance in the $\mathrm{HCl}$ extract, $\mathrm{Ga} \sim \mathrm{Gl}>\mathrm{Rh}>\mathrm{X}>$, $\mathrm{M} \sim \mathrm{Fu}>\mathrm{A}>\mathrm{Ri}$, and the low glucose concentration indicate an indigenous source for the organic matter.

Table 11 compares the Black Sea organic-rich sample with a marine peat deposit from George's Bank dated at about 10,000 years B.P. The contrast in sugar compositions is striking. -iucose accounts for only about $20-25 \%$ of the total sugars of the Black Sea sample (even after concentrated sulfuric acid treatment), while in the true peat deposit glucose represents $70 \%$ of the total sugars. Furthermore, the peat sample contains only traces of rhamnose, fucose and ribose while in the Black Sea sample these sugars constitute $25-30 \%$ of the total. The relatively high abundance of these latter sugars suggests an algal source for the organic matter in the Black Sea, which, in turn, implies that the primary marine productivity must have been extremely high in order to yield a $30-40 \%$ organic content in the sediment.

Electron micrographs of the organic matter in the organic-rich zone, Figures $22 \mathrm{a}, \mathrm{b}, \mathrm{c}$, and $\mathrm{d}$, reveal intact membranes and cell wall fragments (Degens et al. , 1970). No terrigenous plant detritus are observed. It is interesting to note that the organic matter shown in these figures did not 
TABIE 11

COMPARISON OF THE CARBOHYDRATE COMPOSITION OF TRUE LAND-DERIVED

MARINE SEDIMENT AND POSSIBLE LAND-DERIVED SEDIMENT

MOLE\&

\begin{tabular}{|c|c|c|c|c|c|c|c|c|c|c|}
\hline $\begin{array}{l}\text { Sample } \\
\text { (Conc. } \mathrm{H}_{2} \mathrm{SO}_{4} \\
\text { Treatment) }\end{array}$ & $R h$ & Fu & $R i$ & A & $x$ & M & $\mathrm{Ga}$ & GI & $\mu$ & $\begin{array}{l}\text { Total } \\
\text { moles } / 9\end{array}$ \\
\hline $\begin{array}{c}\text { Peat, George's Bank } \\
\text { 10,000 years B.P. }\end{array}$ & 3.1 & 1.0 & 0 & 2.3 & 7.3 & 8.4 & 8.9 & 68.9 & & 354.8 \\
\hline $\begin{array}{l}\text { Wood, Cariaco Trench } \\
5000 \text { years B.P. }\end{array}$ & 3.9 & .73 & 0 & 7.0 & 12.5 & 2.6 & 7.6 & 65.7 & & 422.2 \\
\hline $\begin{array}{l}\text { Black Sea Sapropel } \\
\text { Layer } 7000 \text { years B.P. }\end{array}$ & 14.9 & 8.9 & 4.5 & 6.1 & 12.4 & 19.2 & 19.5 & 24.5 & & 246.1 \\
\hline $\begin{array}{l}\text { Sample } \\
\text { ( } 1.8 \mathrm{~N} \mathrm{HCl} \\
\text { Treatment) }\end{array}$ & & & & & & & & & & \\
\hline $\begin{array}{c}\text { Peat, George's Bank } \\
\text { 10,000 years B.P. }\end{array}$ & 4.8 & 1.6 & 0 & 3.0 & 8.7 & 12.3 & 17.0 & 52.6 & & 253.5 \\
\hline $\begin{array}{l}\text { Wood, Cariaco Trench } \\
5000 \text { years B.P. }\end{array}$ & 6.5 & 1.8 & 0 & 15.1 & 23.1 & 4.4 & 13.7 & 35.4 & & 258.9 \\
\hline $\begin{array}{l}\text { Black Sea Sapropel } \\
\text { Layer } 7000 \text { years B.P. }\end{array}$ & 15.1 & 10.9 & 5.5 & 8.9 & 12.6 & 10.0 & 18.3 & 18.8 & & 250.8 \\
\hline $\begin{array}{l}\text { Lake Kivu, Top Sediment } \\
2000 \text { years B.P. }\end{array}$ & 5.3 & 3.0 & .5 & 2.9 & 3.7 & 5.3 & 36.9 & 42.5 & & 195.9 \\
\hline
\end{tabular}




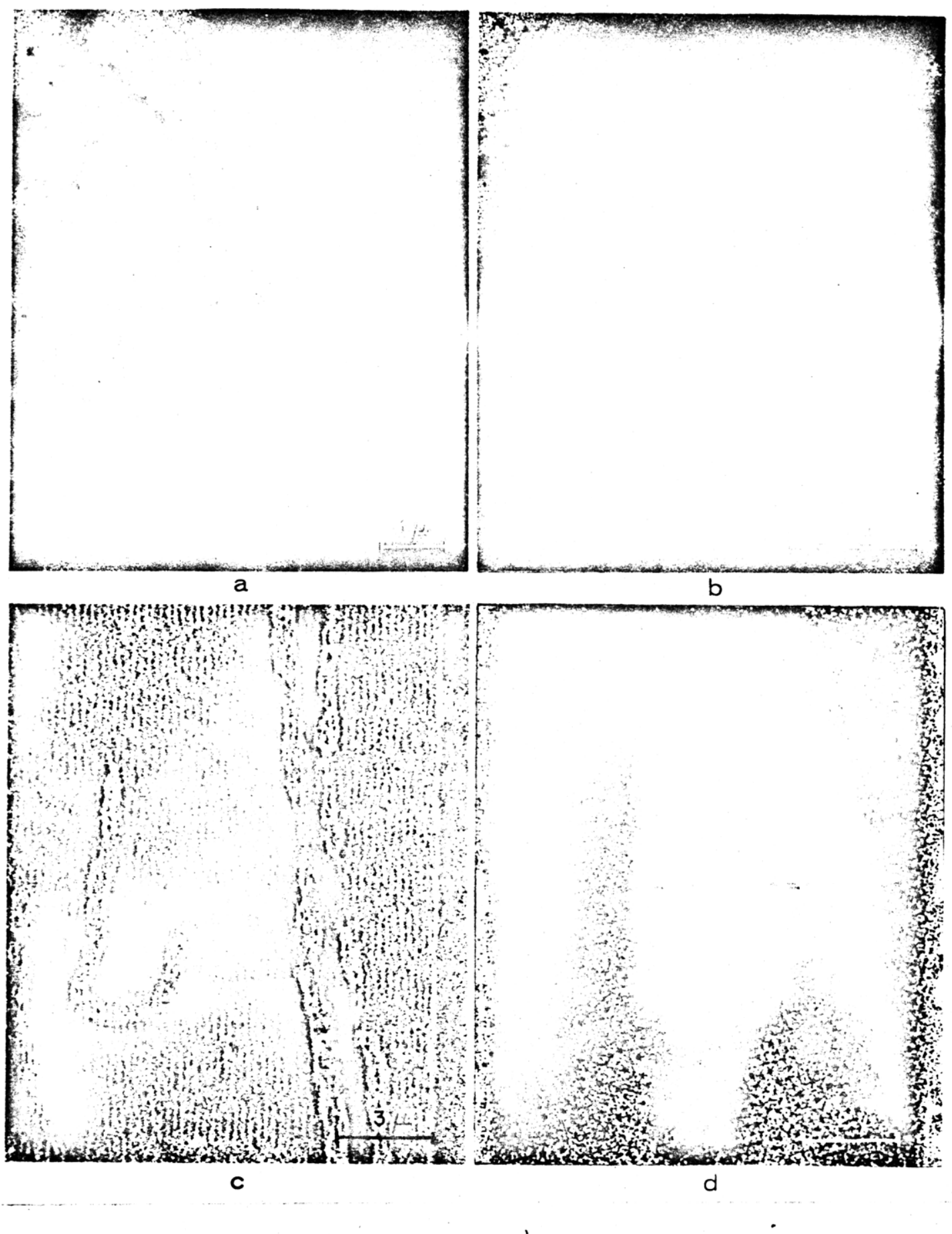

Figure 22. Caption on following page. 
Figure 22

(a) Branched, tubular membranes.

(b) Large tubular membranes having a diameter of 700-800 $\AA$ and consisting of unit-membranes having a width of $80 \AA$.

(c) Organic substance resembling a bacterial cell wall and showing a unique pattern of subunits which have a $40 \AA$ periodicity.

(d) Portion of an organic substance resembling a bacterial cell wall and consisting of a crystalline arrangement of subunits.

All four electron micrographs were taken of Black Sea sediment (core $1474 \mathrm{~K}, 20-70 \mathrm{~cm}$ ) in the sapropel layer. The samples did not need to be stained prior to microscopy because in situ heavy metal staining made visualization possible (after Degens et al。 1970). 


\section{5}

need to be stained with a heavy metal (e.g., Os or $\mathrm{Au}$ ) prior to microscopy. In situ heavy metal 'staining' made visualization possible (Degens et al.., 1970). Thus, electron microscopy provides direct evidence for existence of some kind of metal-organic matter association in this sediment.

The third sample (15 cm, B.S. marine) represents the marine anoxic coccolith-rich zone. The hydrolyzed EDTA extract releases $40 \%$ of the 'total', a value which compares well with that of anoxic sediment from the Cariaco Trench and Walvis Bay. Rhamnose, fucose, arabinose, and galactose are dominantly metal-bound (Table III-1): The order of abundance within the $\mathrm{HCl}$ extract is somewhat different from that of other sediments: $\mathrm{M}>\mathrm{Ga}>\mathrm{X}>\mathrm{Gl}>\mathrm{Ri}>\mathrm{Fu}>\mathrm{Rh} \sim \mathrm{A}$. The particularly high abundance of ribose and xylose is noteworthy (Table III-12). This unusual distribution may be related to the dominant coccolith input which contrasts with the dominant algal input for sediments in other areas.

\section{i. Oyster Pond: Anoxic Coastal Pond (Brackish)}

Carbohydrate data for the Oyster Pond surface sample are shown in Tables III-1, III-10, and III-11. The order of abundance within the $\mathrm{HCl}$ extract is: $\mathrm{Gl}>\mathrm{Ga}>\mathrm{M}>\mathrm{X} \sim \mathrm{Rh}>\mathrm{A}>\mathrm{Fu}>\mathrm{Ri}$. The high abundance of glucose in this sample (Table III-10) relative to Oyster Pond plankton (III-2) and to sediment from other areas suggests the presence of a small terrigenous organic input. Considering that Oyster Pond is almost completely land-locked and is only $1100 \mathrm{~m}$ long and $300 \mathrm{~m}$ wide (Emery, 1969), this is a reasonable possibility. 
The hydrolyzed EDTA extraction releases $44 \%$ of the 'total', a figure which is similar to that of other anoxic sediments. Metal-bound monomers account for $11 \%$ of the 'total' with arabinose, ribose, fucose, xylose, and rhamnose being principally metal-bound (Table III-1).

\section{j. Lake Kivu: Anoxic Fresh Water Lake}

The carbohydrate data of four Lake Kivu samples are listed in Tables III-1, III-10, and III-11. The relative abundance of sugars in the $\mathrm{HCl}$ extract is generally: $\mathrm{Gl}>\mathrm{Ga}>\mathrm{M}>\mathrm{X} \sim \mathrm{Rh}>\mathrm{Fu}>\mathrm{A}>\mathrm{Ri}$ (hexoses $>$ pentoses). Glucose exhibits the highest fluctuations which range from 43 mole $\%$ at the top to 25 mole \% at the bottom of the core. The high glucose content of these sediments (especially the upper sample) may reflect a terrigenous organic input. Geochemical and paleontological evidence (Degens et al., 1973) indicates that during certain periods the lake level rose dramatically due to high pluvial activity and discharges of hydrothermal waters. Flooding of nearshore swamps and increased run-off of humic materials from surrounding forests contributed substantially to the terrigenous organic input of the sediments, as reflected in the unusually high glucose content and low ribose content (Figure 23, Chapter V).

On the average, the hydrolyzed EDTA extract releases about $37 \%$ of the 'total', which is a value similar to that found for other anoxic sediments. The unhydrolyzed EDTA extraction releases $10-20 \%$ of the total; the monomers principally metal-bound in this extract are: rhamnose, fucose, arabinose, and xylose (Table III- 1 ). 
The high geothermal input in this area is expected to have profound effects on diagenetic patterns. Figure 18 demonstrates that total sugar carbon drops dramatically with depth relative to total organic carbon. The rapid decrease in sugar carbon stops at about 15,000 years B.P., after which further decrease occurs much more slowly. These trends are probably the result of the high temperatures $\left(>26^{\circ} \mathrm{C}\right)$. The initial rapid decrease may be due to preferential destruction of carbohydrates either by oxidation to $\mathrm{CO}_{2}$ and $\mathrm{H}_{2} \mathrm{O}$ or by conversion to furfural derivatives (the latter compounds did not show up in significant quantities in these chromatograms). The second and slower decrease might be due to formation of highly condensed, inextractable humic substances.

If these variations in sugar carbon are due instead to secular changes of the carbohydrate composition of the organic input, these changes must be more complicated than for other sediments studied. For example, if the terrigenous input increased gradually from 15,000 years B.P. to present, then the carbohydrate fraction of the total organic matter also increased gradually with time, thereby, giving rise to the trends in Figure 18. However, Table III-10 shows that the glucose contents of samples 530,240 , and $125 \mathrm{~cm}$ do not show a gradual increase, but rather a sharp increase between 240 and $125 \mathrm{~cm}$. Furthermore, the percent sugar in the organic carbon for the $530 \mathrm{~cm}$ and $930 \mathrm{~cm}$ samples is significantly lower than that of sediment from all other areas sampled, which suggests that factors other than a change in composition of the input, such as geothermal energy, are operative. 
CHAPTER V

\section{DISCUSSION OF GENERAL TRENDS}

Table 12 presents a summary of the mole \% composition of $\mathrm{HCl}$ extracts of sediment and plankton from different environments. Generally, no one sugar in any of these extracts is present in an overwhelming concentration. The general order of abundance in sediment is: $G a>G l>M>X \widetilde{X}_{R h}>$ $\mathrm{Fu}>\mathrm{A}>\mathrm{Ri}$; the order in plankton is: $\mathrm{Ga}>\mathrm{Gl}>\mathrm{M}>\mathrm{Ri}>\mathrm{X}>\mathrm{Fu} \sim \mathrm{Rh}>\mathrm{A}$. The orders of abundance are almost identical with the exception of ribose which shows a considerable depletion in sediment. This relative loss is probably attributable to the instability of ribose-containing organo-phosphate compounds, such as the adenosine phosphates and nucleic acids. Harvey (1960) observes that these compounds hydrolyze rapidly after cell lysis. Thus, the loss of ribose may have occurred in the water column shortly after the death of the organisms.

The above observations are consistent with the simple hypothesis that plankton is the source material for sedimentary carbohydrates. This hypothesis is further supported by stable carbon isotope analyses. In temperate regions marine plankton has a $\delta \mathrm{C}^{13}$ value of about -20 per mil (relative to PDB standard) with no apparent differences for zoo- and phytoplankton populations. Common land plants are 5 to 10 per mil lighter (Craig, 1953; Degens, 1969). In a number of studies it has been shown that the isotopic composition of organic matter in recent marine sediments 
SUMMARY OF MOLE \% COMPOSITION OF CARBOHYDRATES IN SEDIMENT AND PLANKTON (HC1 HYDROLYSIS)

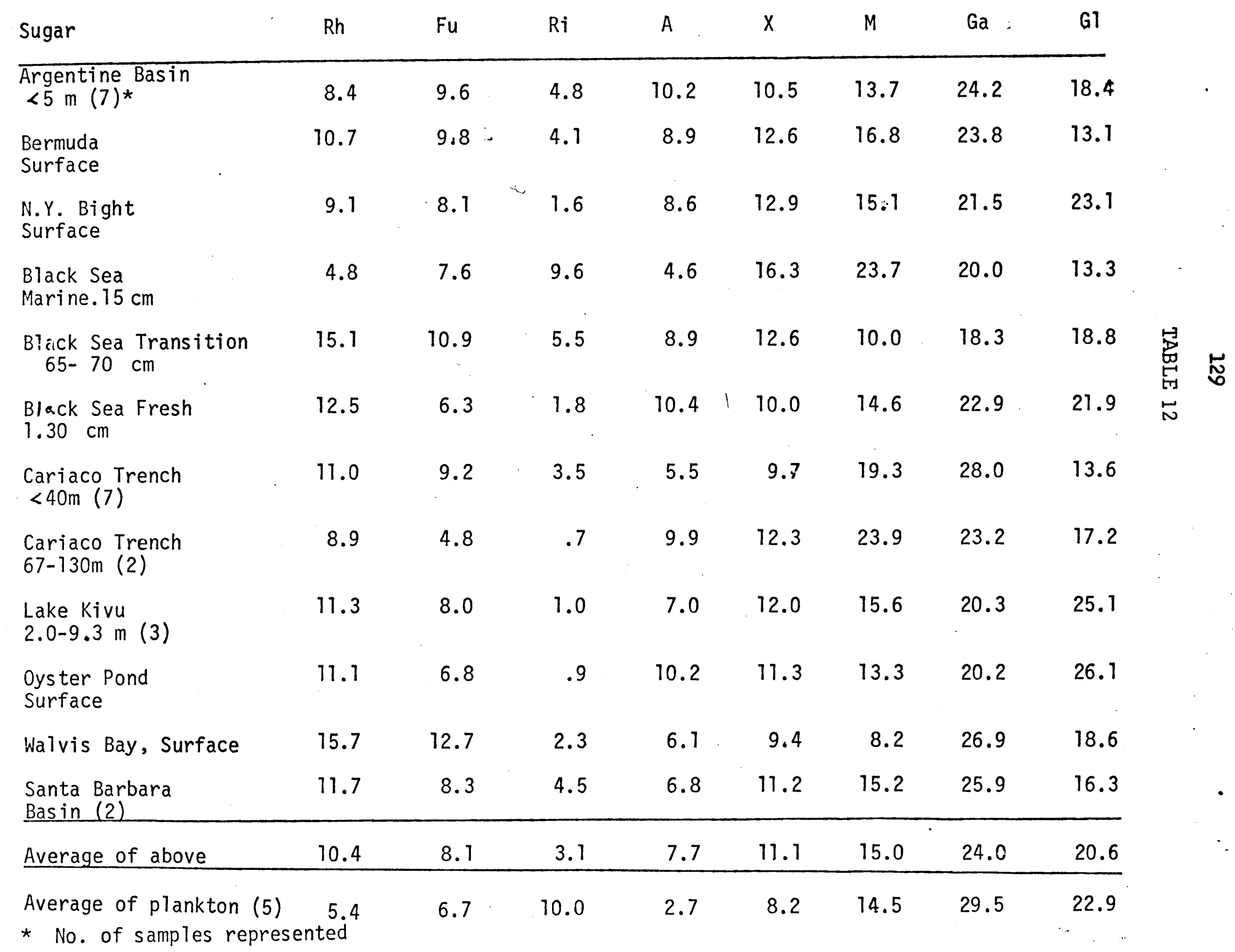


130

is identical to that of marine plankton (e.g. Sackett and Thompson, 1963;

Hunt, 1968). In fact, local variations in $\delta C^{13}$ values of plankton due to temperature and respiration effects are reflected in $\delta \mathrm{C}^{13}$ values of the underlying sediment. Only sediments deposited in river estuaries and close to shorelines reveal a terrigenous isotopic influence. The bulk of the organic debris contained in recent marine deposits seems to be derived from the local biomass.

The glucose and ribose concentrations in marine sediments also may be used to determine the relative terrigenous organic input of sediment. Table 11 and Figures 17,21 , and 23 reveal that terrigenous material contains a high percentage of glucose and a low percentage of ribose; in marine -. plankton the reverse is true. Thus, in sediment where glucose $>$ galactose (or where glucose is $>20$ mole \% [Table 12]) and ribose is negligible, a major terrigenous fraction should be suspected.

Figure 23 shows that the relative abundances of glucose and ribose in most sediments are greatly reduced in comparison to terrigenous and marine sources respectively. The glucose-ribose relationship in sediment was not uncovered in the work of previous investigators in the field of carbohydrate geochemistry.

From the viewpoint of characterizing sedimentary environments the uniformity of the results in Table 12 is rather disappointing. Even when one examines sedimentary carbohydrates in terms of apparent metal complexation (Tables 13 and 14), few underlying trends become apparent. A summary 


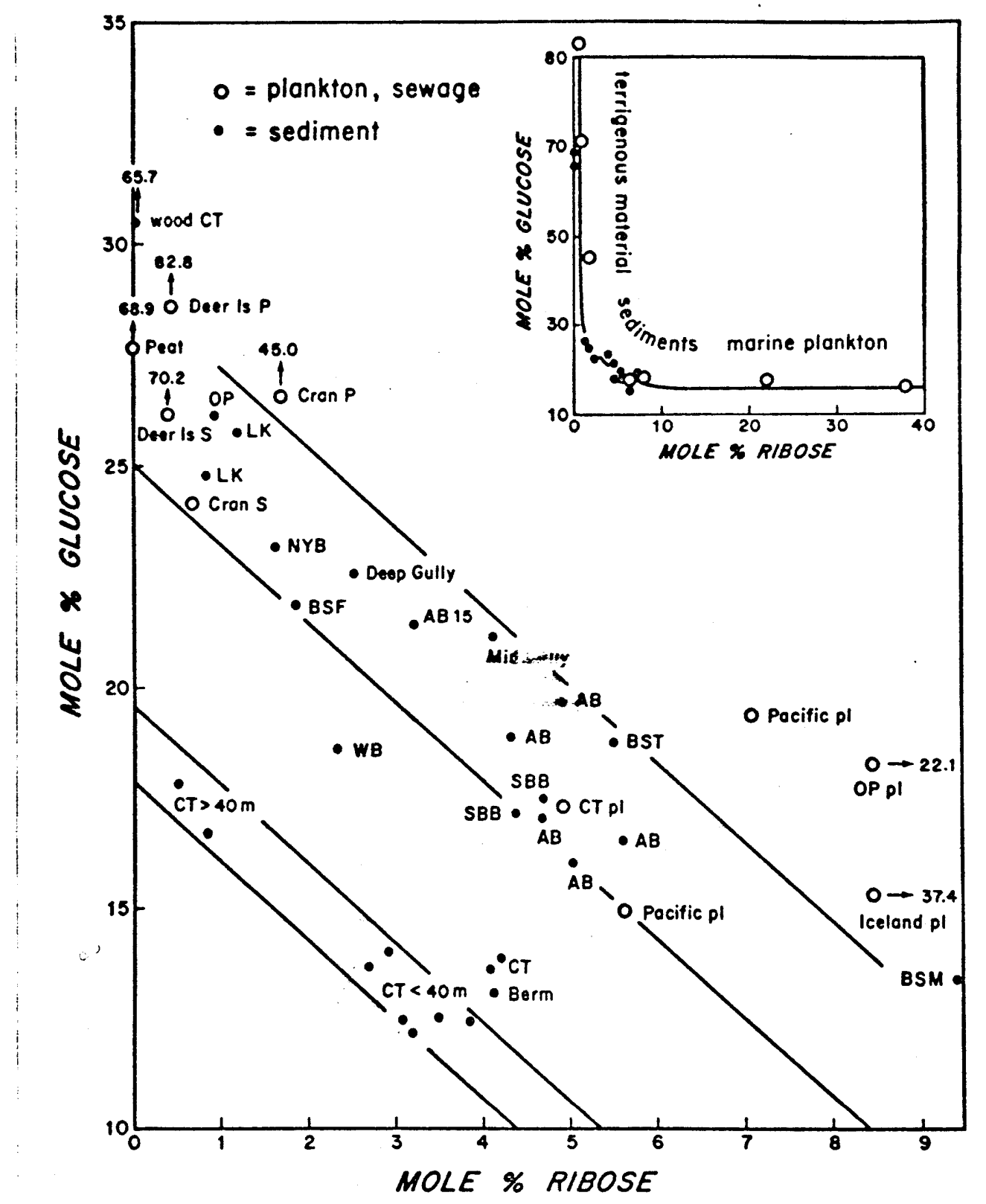

Figure 23

Relationship between glucose and ribose in samples studied in this thesis. An inverse reiation exists: terrigenous material is enriched in glucose and depleted in ribose; marine plankton shows the reverse trend. The following notations are used: $A B=$ Argentine Basin; $C T=$ Cariaco Trench; NYB = New York Bight; OP = Oyster Pond; BSF, T, M= Black Sea fresh, transition, and marine; Berm = Bermuda; $W B=$ Walvis Bay; $\mathrm{SBB}=$ Santa Barbara Basin; $\mathrm{LK}=$ Lake Kivu; Cran = Cranston sewage sludge; Deer Is = Deer Island sewage sludge; $\mathrm{P}=$ primary sludge; $\mathrm{S}=$ secondary sludge; and $\mathrm{pl}=$ plankton. 
TABLE 13

SUMMARY OF MOLE \% COMPOSITION OF CARBOHYDRATES IN SEDIMENTS

(HYDROLYZED EDTA EXTRACT)

\begin{tabular}{|c|c|c|c|c|c|c|c|c|}
\hline Sugar: & $\mathrm{Rh}$ & $\mathrm{Fu}$ & $\mathrm{Ri}$ & A & $x$ & M & $\mathrm{Ga}$ & Gl \\
\hline $\begin{array}{l}\text { Argentine Basin } \\
<5 \mathrm{~m}(7)\end{array}$ & 10.2 & 12.0 & 5.7 & 8.7 & 11.6 & 12.3 & 25.1 & 14.6 \\
\hline $\begin{array}{l}\text { N.Y. Bight Buoy St. } \\
\text { Surface }\end{array}$ & 10.8 & 10.8 & 2.5 & 10.8 & 12.5 & 12.5 & 22.5 & 17.5 \\
\hline $\begin{array}{l}\text { Hudson Canyon Deep Gully } \\
\text { Surface }\end{array}$ & 12.4 & 12.9 & 6.1 & 8.3 & 12.2 & 10.4 & 22.6 & 15.1 \\
\hline $\begin{array}{l}\text { B] deck Sea Marine } \\
.15 \mathrm{~cm}\end{array}$ & 11.9 & 12.4 & 10.3 & 7.0 & 10.3 & 10.8 & 26.5 & 10.8 \\
\hline $\begin{array}{l}\text { Black Sea Transition } \\
.65-.70 \mathrm{~cm}\end{array}$ & 19.3 & 13.0 & 5.5 & 6.8 & 14.0 & 8.7 & 15.6 & 17.0 \\
\hline $\begin{array}{l}\text { Black Sea Fresh } \\
1.3 \mathrm{~cm}\end{array}$ & 15.5 & 11.8 & 4.3 & 11.2 & 11.2 & 12.6 & 18.5 & 15.4 \\
\hline $\begin{array}{l}\text { Cariaco Trench }<40 \mathrm{~m} \\
(9)\end{array}$ & 13.2 & 13.9 & 5.6 & 7.4 & 11.3 & 10.9 & 26.8 & 11.3 \\
\hline $\begin{array}{l}\text { Cariaco Trench } \\
67-130 \mathrm{~m}(2)\end{array}$ & 12.6 & 6.7 & 1.7 & 7.4 & 14.9 & 18.9 & 22.5 & 15.5 \\
\hline $\begin{array}{l}\text { Lake Kivu } \\
2.0-9.3 \mathrm{~m}(3)\end{array}$ & 14.3 & 12.3 & 3.8 & 7.9 & 9.4 & 13.4 & 20.6 & 18.3 \\
\hline Oyster Pond, surface & 13.6 & 10.3 & 2.0 & 15.0 & 12.5 & 9.5 & 21.4 & 15.6 \\
\hline Walvis Bay, surface & 16.6 & 10.8 & $3.8^{\circ}$ & 5.4 & 11.5 & 12.4 & 24.5 & 15.0 \\
\hline $\begin{array}{l}\text { Santa Barbara } \\
\text { Basin (50years) } \\
\end{array}$ & 13.3 & 12.5 & 7.8 & 7.8 & 14.1 & 10.2 & 24.2 & 10.2 \\
\hline Average of the abov & 13.6 & 11.6 & 4.9 & 8.6 & 12.1 & 11.9 & 22.6 & 14.7 \\
\hline
\end{tabular}


TABLE 14

SUMMARY OF MOLE \% COMPOSITION OF CARBOHYDRATES IN SEDIMENT (UNHYDROLYZED EDTA EXTRACT)

\begin{tabular}{|c|c|c|c|c|c|c|c|c|}
\hline Sugar: & $\mathrm{Rh}$ & $\mathrm{Fu}$ & $\mathrm{Ri}$ & $A$ & $x$ & $M$ & $\mathrm{Ga}$ & Gl \\
\hline $\begin{array}{l}\text { Argentine Basin } \\
<5 \mathrm{~m}(2)\end{array}$ & 8.7 & 15.8 & 15.3 & 14.3 & 15.3 & 4.8 & 17.4 & 8.4 \\
\hline $\begin{array}{l}\text { N.Y. Bight Buoy St. } \\
\text { Surface }\end{array}$ & 6.7 & 14.4 & $9: 2$ & 21.5 & 21.5 & 3.5 & 17.8 & 5.4 \\
\hline $\begin{array}{l}\text { Black Sea Marine } \\
1.5 \mathrm{~cm}\end{array}$ & 3.5 & 14.2 & 33.3 & 9.6 & 19.3 & 1.5 & 17.5 & 1.2 \\
\hline $\begin{array}{l}\text { Bläck Sea Transition } \\
.65-.70 \mathrm{~cm}\end{array}$ & 14.9 & 15.9 & 21.7 & 9.6 & 19.2 & 1.4 & 15.9 & 2.2 \\
\hline $\begin{array}{l}\text { Black Sea Fresh } \\
1.3 \mathrm{~cm}\end{array}$ & 12.3 & 11.5 & 10.0 & 24.6 & 10.8 & 3.4 & 18.5 & 5.5 \\
\hline $\begin{array}{l}\text { Cariaco Trench } \\
<40 \mathrm{~m}(5)\end{array}$ & 8.0 & 16.6 & 21.2 & 12.3 & 13.3 & 3.3 & 22.7 & 3.7 \\
\hline $\begin{array}{l}\text { Cariaco Trench } \\
67-130 \mathrm{~m} \quad(2)\end{array}$ & 9.3 & 11.8 & 3.7 & 9.9 & 24.7 & 11.1 & 19.8 & 11.0 \\
\hline $\begin{array}{l}\text { Lake Kivu } \\
2.0-9.3 \mathrm{~m}\end{array}$ & 13.8 & 17.3 & 5.8 & 14.0 & 15.2 & 5.8 & 20.4 & 7.2 \\
\hline $\begin{array}{l}\text { Oyster Pond } \\
\text { Surface }\end{array}$ & 9.9 & 15.6 & $\begin{array}{l}5.2 \\
\cdot\end{array}$ & 32.3 & 16.2 & 2.7 & 15.0 & 3.7 \\
\hline $\begin{array}{l}\text { Walvis Bay } \\
\text { Surface }\end{array}$ & 11.3 & 18.1 & 15.9 & 12.5 & 17.0 & 3.6 & 19.3 & 2.4 \\
\hline Average of the above. & 9.8 & 15.1 & 14.1 & 16.1 & 17.3 & 4.1 & 18.4 & 5.1 \\
\hline
\end{tabular}




\section{4}

of the mole \% composition of hydrolyzed EDTA extracts of sediment from different environments is presented in Table 13. The general order of abundance is: $\mathrm{Ga}>\mathrm{Gl}>\mathrm{Rh}>\mathrm{M} \sim \mathrm{X} \sim \mathrm{Fu}>\mathrm{A}>\mathrm{Ri}$. This order is similar to that observed for the $\mathrm{HCl}$ extract (Table 12) with a few differences. Mannose, glucose, and galactose decrease in relative abundance (galactose decreases by a lesser extent); this decrease is compensated for by a relative increase in the other sugars.

The general order of abundance in the unhydrolyzed EDTA extract (Table 14) is: $\mathrm{Ga}>\mathrm{X} \widetilde{\mathrm{A}} \widetilde{>} \mathrm{Fu} \sim \mathrm{R} i>\mathrm{Rh}>\mathrm{Gl} \sim \mathrm{M}$. Comparison of this extract with the $\mathrm{HCl}$ extract reveals that the relative compositional changes are similar to but more exaggerated than those found for the hydrolyzed EDTA extract (discussed above).

Figure 24 illustrates the compositional changes in the averages of the different extracts from Tables 12,13 , and 14. With each extraction $(\mathrm{HCl}$, $\mathrm{HCl}+\mathrm{EDTA}, \mathrm{EDTA})$ the compositions generally become progressively different from that of plankton (presumably the source of sedimentary carbohydrates). The hexoses, glucose, mannose, and galactose, decrease in relative abundances, with galactose decreasing to a lesser extent. These decreases appear to be compensated for by increases in the pentoses and deoxyhexoses. The initially high value of ribose in plankton relative to sediments was explained previously. The reason for the drop in rhamnose between the EDTA $+\mathrm{HCl}$ and EDTA extracts is presently unclear. The trends mentioned above appear to hold for nearly every sediment sample analyzed. 

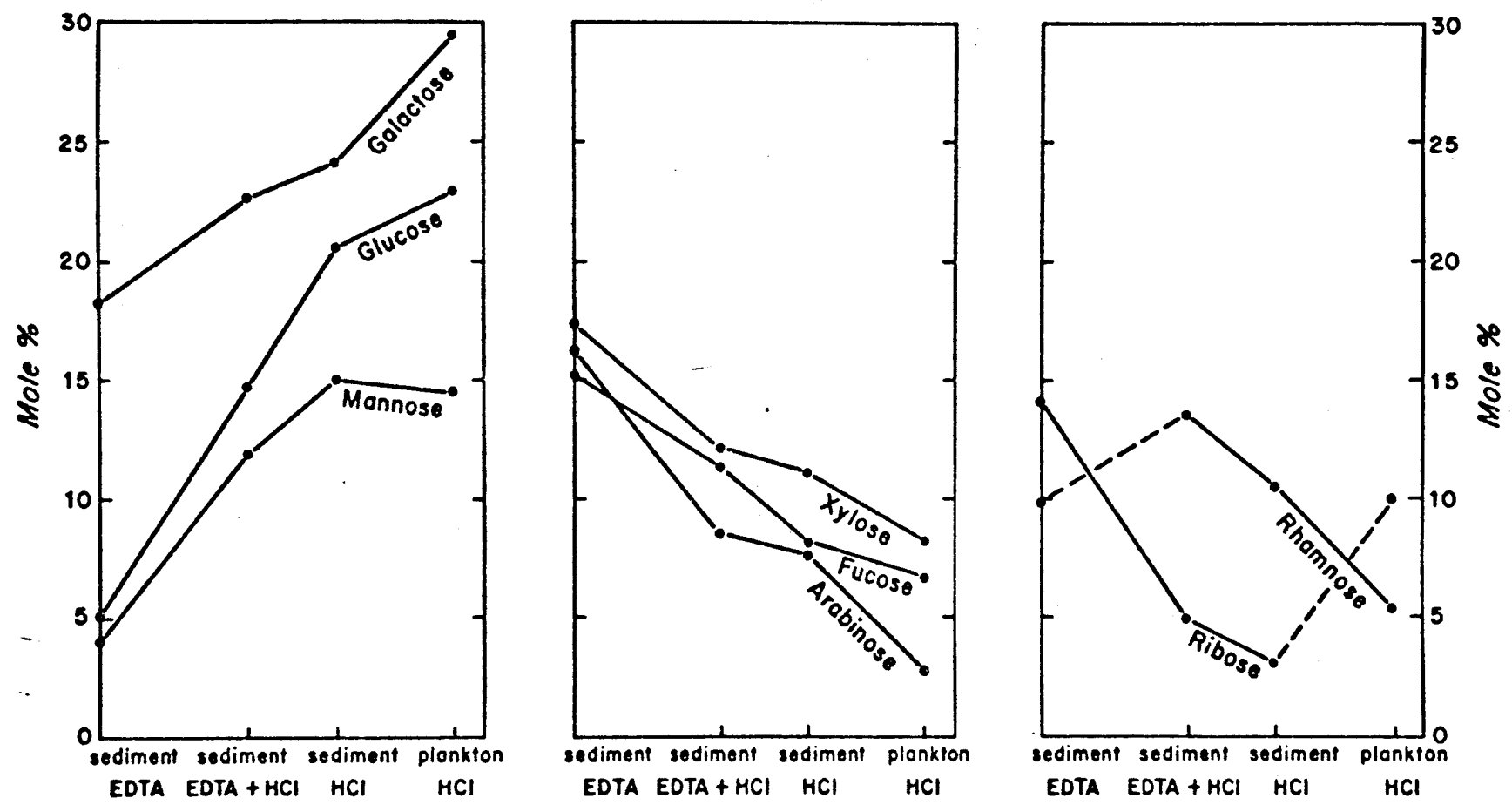

Figure 24

Relationships among the relative sugar compositions in different sediment and plankton extracts; data was drawn from the averages in Table: 12,13 , and 14 in the text; these relations hold for individual samples as well as the averages; EDTA = unhydrolyzed EDTA extract, EDTA + $\mathrm{HCl}=$ hydrolyzed EDTA extract, and $\mathrm{HCl}=$ 'total' hydrolyzable carbohydrates. 


\section{6}

The trends in Figure 24 might be explained in terms of differences in metal ion affinities; thus pentoses and deoxyhexoses would have a greater affinity than hexoses for metals. However, in light of the fact that hexoses have more functional groups than the other sugars, this explanation is unlikely •

Alternatively, it might be argued that hexoses are more strongly bound to mineral phases than are pentoses. The validity of this argument was tested with the following experiment: $0.1 \mathrm{ml}$ of a solution of nine sugar standards $\left(1000 \mu \mathrm{g} / \mathrm{ml}\right.$ of each sugar) was mixed with $10 \mathrm{ml} \mathrm{H}_{2} \mathrm{O}$ and $\mathrm{lg}$ of organic-free kaolinite; after standing 20 hours in a desiccator at $25^{\circ} \mathrm{C}$ the sugars were extracted from the mixture with $20 \mathrm{ml}$ of $\mathrm{H}_{2} \mathrm{O}$ and analyzed. The results, which are shown in Figure $6 \mathrm{a}, \mathrm{b}$ (Chapter II), indicate that within the analytical error $(t 10 \%)$ only deoxyribose is absorbed by the clay (or eliminated by condensation reactions). From this experiment I conclude that preferential absorption of sugars by mineral phases in sediment is probably negligible.

The reasons for the compositional changes shown in Figure 24 may be related to differences in the molecular weight distribution of the carbohydrates. For example, it seems probable that mannose, glucose, and galactose are more associated with high molecular weight water-insoluble polysaccharides than other sugars. Thus, after EDTA treatment these polysaccharides are centrifuged down along with the sediment residue. Table III- 1 shows that glucose, galactose, and mannose are indeed dominantly 
associated with the EDTA-insoluble residue.

Since the composition of the unhydrolyzed EDTA extract is furthest removed from that of plankton (Figure 24), the size of this extract (relative to 'total') is probably related to the degree of degradation in sediments. Thus, one would expect to find that metal-bound monomers represent a larger fraction in oxic sediments than in reducing sediments. Figure 25, which is drawn from data in Table III-1, shows that for total sugars in oxic sediments the concentration of EDTA extracted monomers is indeed greater than the conceritration of EDTA extracted polymers; in reducing sediment the reverse trend holds. Furthermore, Figure 25 shows that reducing sediments cluster closer to the origins of the graphs than oxic sediments, which indicates that the concentrations of sugars extracted with EDTA for reducing sediments are lower than that for oxic sediments.

In Figure 26, which is also drawn from data in Table III-1, the percent of the 'total' released by the hydrolyzed EDTA extraction is plotted against the different sample types. EDTA extracts $60-70 \%$ of the 'total' for oxidizing sediments and $35-45 \%$ of the 'total' for reducing sediments. These trends again suggest that carbohydrates are considerably more metal bound in oxidizing sediments than in reducing sediments.

The difference in metal binding of carbohydrates between oxidizing and reducing environments may be explained in terms of differences in: (i) degree of biological activity, and (ii) degree of metal ion availability. 

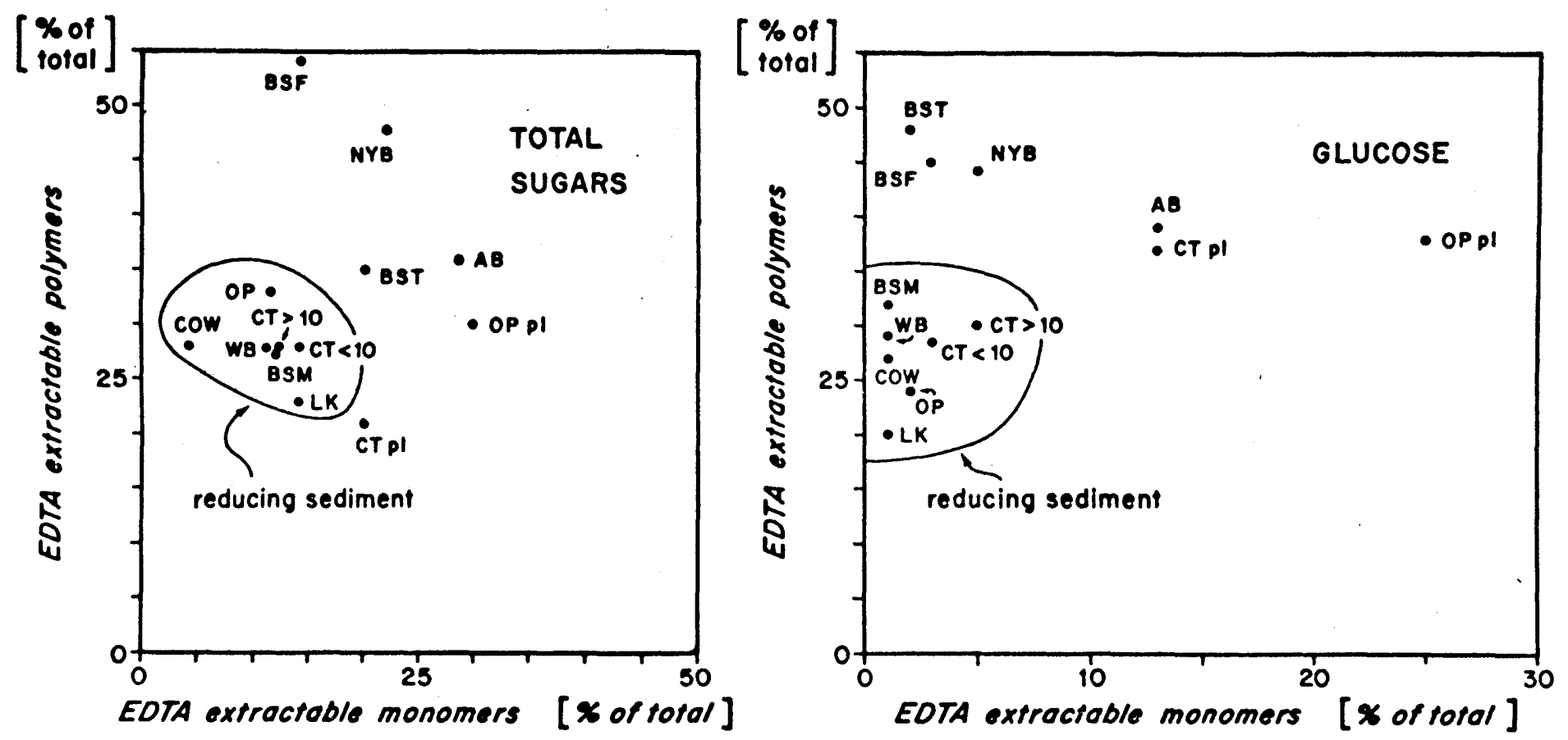

\section{Figure 25}

Relationship between EDTA extractable monomers and polymers in different sediment samples; data was drawn from Table III- 1 in Appendix III; notation as in Figure 23. 




Figure 26

Comparison of the degree of metal binding of carbohydrates from various sedimentary environments. The \% of $\mathrm{HCl}$ extractable sugars which is released by EDTA is $25-45 \%$ for reducing sediments and $55-75 \%$ for oxidizing sediments. The 'Black Sea Intermediate' sample represents the transition period from oxidizing to reducing. Digestion of primary sewage sludge has the effect of drastically increasing the degree of metal binding of the carbohydrate residue. represents number of samples averaged. 
(i) Degree of biological activity: Analyses of primary and digested sewage sludges suggest that metal-bound carbohydrates are refractory since they are the end-product of biological degradation. For example, Figure 26 shows that the percent of metal-bound (EDTA-extracted) sugars in the total acid extracted sugars increases from $17 \%$ in Deer Island primary sludge to 77\% in the microbially digested Deer Island secondary sludge. The degree of metal binding induced by digestion of sewage sludge is similar to that of organic matter in oxic sediments. Thus, by analogy, the high degree of metal binding of organic matter in oxic sediments is probably attributable to intensive biological consumption.

The low degree of metal binding in reducing sediments implies that a large fraction of the carbohydrateresidue of these sediments is potentially degradable, and hence, has been consumed to a lesser degree than in oxidizing sediments. The low rate of consumption in reducing environments reflects the low biological activity associated with the presence of an anaerobic population and with the absence of a metazoan biomass. Foree and McCarty (1970) demonstrated that anaerobic and aerobic microbial consumption rates are nearly identical under laboratory conditions, which suggests that the intensive consumption at oxic sediment-water interfaces is the result of the metazoan population, not the microbial population. (It is possible, however, that an active microbial community within the digestive tracts of the metazoan population is largely responsible for the degradation 
(Allen and Sanders, 1966), as in the rumen of a cow.) This conclusion contradicts the frequently expressed opinion that free microorganisms rapidly degrade sedimentary organic matter even in deep-sea environments. This has seemed plausible because microbial counts may yield up to several million bacteria per gram of deep-sea surface sediment (e.g., Rittenberg et al., I963). Based on the work of Jannasch et al. (1971) and Jannasch and Wirsen (1973), who examined in situ microbial degradation of organic substrates at the sediment-water interface, this viewpoint no longer seems tenable. Food stored at a water depth of $1500 \mathrm{~m}$ for several months showed negligible bacterial degradation. Organic substrates (e.g., agar, polysaccharides) inoculated at depth and embedded for several months in deepsea sediment were utilized at rates up to several hundred times lower than control samples kept under refrigeration. In contrast, organic substrates placed in shallow water sediments were utilized at comparable or slightly lower rates than the controls. When clay was added to the substrates, decomposition rates did not increase even though the number of bacteria increased by a factor of 100 to 1000 relative to clay-free samples.

Thus, the absence of a metazoan population can explain the low rate of biological degradation in reducing environments and, hence, the low degree of metal binding.

Figure 27 shows that a relationship exists between the degree of metal binding, the total sugar carbon as \% of the total organic carbon, and the degree of biological degradation. At the extremes of this plot are 


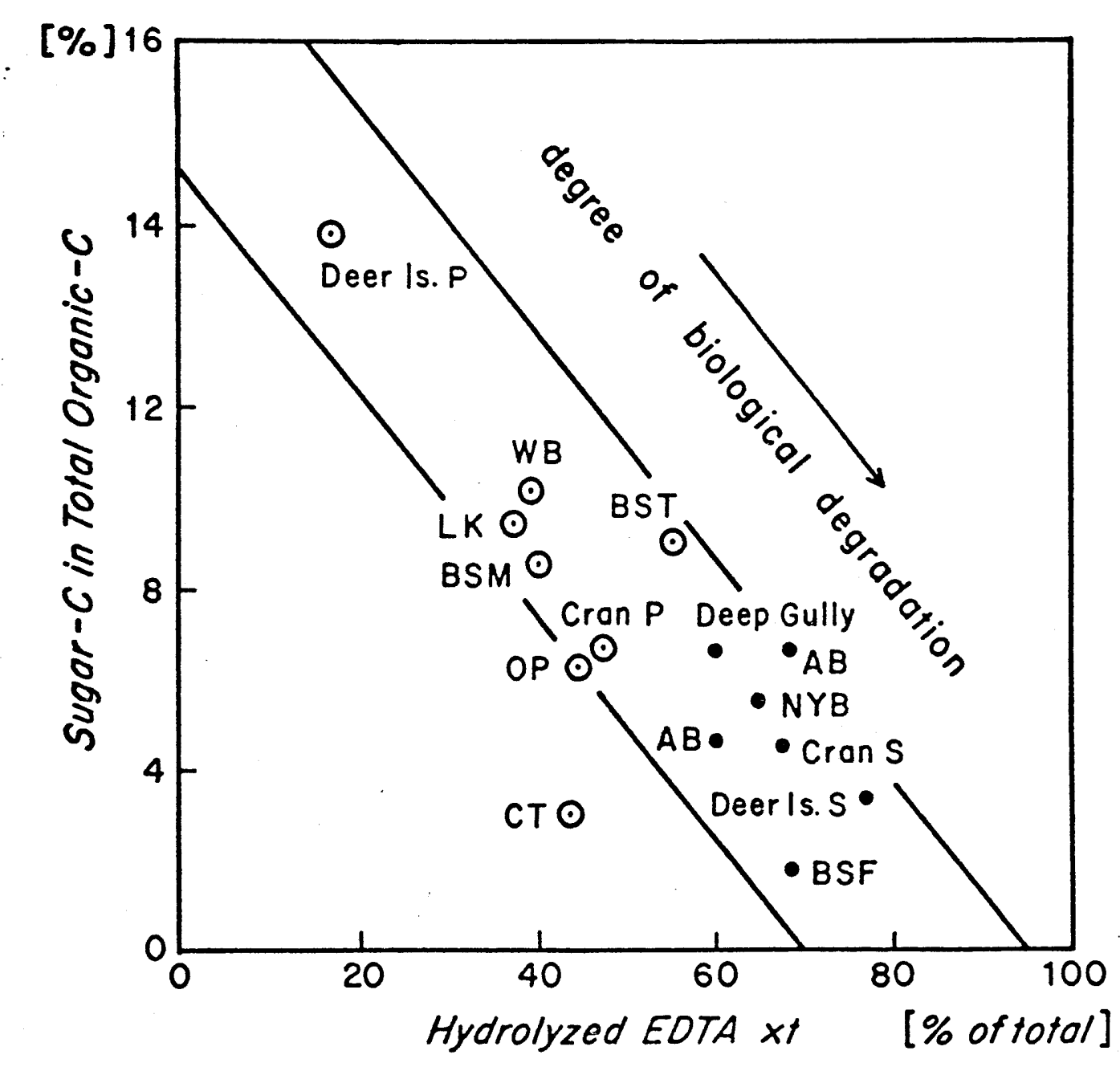

Figure 27

Relationship between sugar carbon (as \% of total carbon) and hydrolyzed EDTA extracts of samples studied in this thesis. An inverse relationship exists: reducing sediments have high sugar carbon values and low degrees of metal binding; oxic sediments show the reverse trends; the degree of metal binding appears to be related to the degree of biological degradation; notation as in Figure 23; $\odot=$ reducing sediments and primary sewage sludges; $0=$ oxic sediments and secondary sewage sludges. 


\section{3}

the Deer Island primary and secondary sewage sludges. The primary sludge has a high sugar carbon value which corresponds to its large cellulose content; the degree of metal binding is low. After intensive microbial degradation (secondary treatment) the sugar carbon has greatly decreased and the degree of metal .. binding has correspondingly increased. Most sediments lie in between these extremes; reducing sediments lie closer to the undigested sludge while oxidizing sediments lie closer to the digested sludge.

(ii) Degree of metal ion availability: On the basis of $\mathrm{K}_{\mathrm{sp}}$ data and the known concentrations of heavy metals in sulfide-free and sulfidebearing seawater, one can calculate that the thermodynamic solubility of heavy metals in reducing environments is exceedingly low in comparison to that of oxidizing environments. The results of Presley et al. (1972), who analyzed heavy metals in the interstitial waters of reducing and oxidizing Saanich Inlet sediments, contradicts this expected trend. Very little difference in heavy metal concentrations exists between oxidizing and reducing sediment (with the exception of manganese which shows a 10-fold higher concentration in the reducing sediment). Generally, heavy metals show a 2 to 5-fold enrichment relative to seawater $(\mathrm{Fe}, \mathrm{Mn}$, and $\mathrm{Zn}$ demonstrate even higher enrichments). Thus, thermodynamic equilibria apparently do not control heavy metal concentrations in interstitial solutions. The authors attribute the enrichments to: (1) complexation by soluble organic matter; and/or (2) equilibration with unidentified mineral phases. No evidence was 


\section{4}

given in support of either hypothesis. The former explanation is more consistent with the conclusions of this thesis.

It appears that the degree of metal binding of carbohydrates in sediments is primarily dependent upon the degree of biological degradation at the sediment-water interface. This conclusion is supported by the temporal distribution of bound carbohydrates in Argentine Basin (oxic) and Cariaco Trench (reducing) sediments shown in Figure 19. If it is assumed for the moment that continuing abiotic processes control the degree of binding of carbohydrates, then a diagenetic increase of metal binding with depth is expected, especially in Cariaco Trench sediments where carbohydrates are dominantly unassociated with metals. A temporal increase, however,

is not apparent (it will be recalled that the peak of $2.65 \mathrm{~m}$ in the Cariaco Trench represents a band of oxic sediment). Thus, the degree of binding established at the zone of biological activity $(0-10 \mathrm{~cm})$ is maintained after burial within the time span sampled.

No correlation exists between the total sugar carbon (as \% of the total organic carbon) and the $\mathrm{C} / \mathrm{N}$ values of the sediments (Appendix II) . Therefore it appears that carbohydrates are not preferentially consumed relative to nitrogenous organic compounds. However, a relationship does appear to exist between the degree of biological activity (expressed as the degree of metal binding of carbohydrates) and the $\mathrm{C} / \mathrm{N}$ values as shown in Figure 28. Reducing sediments appear to have higher $\mathrm{C} / \mathrm{N}$ values than oxidizing sediments, which suggests: (1) non-nitrogenous compounds, 


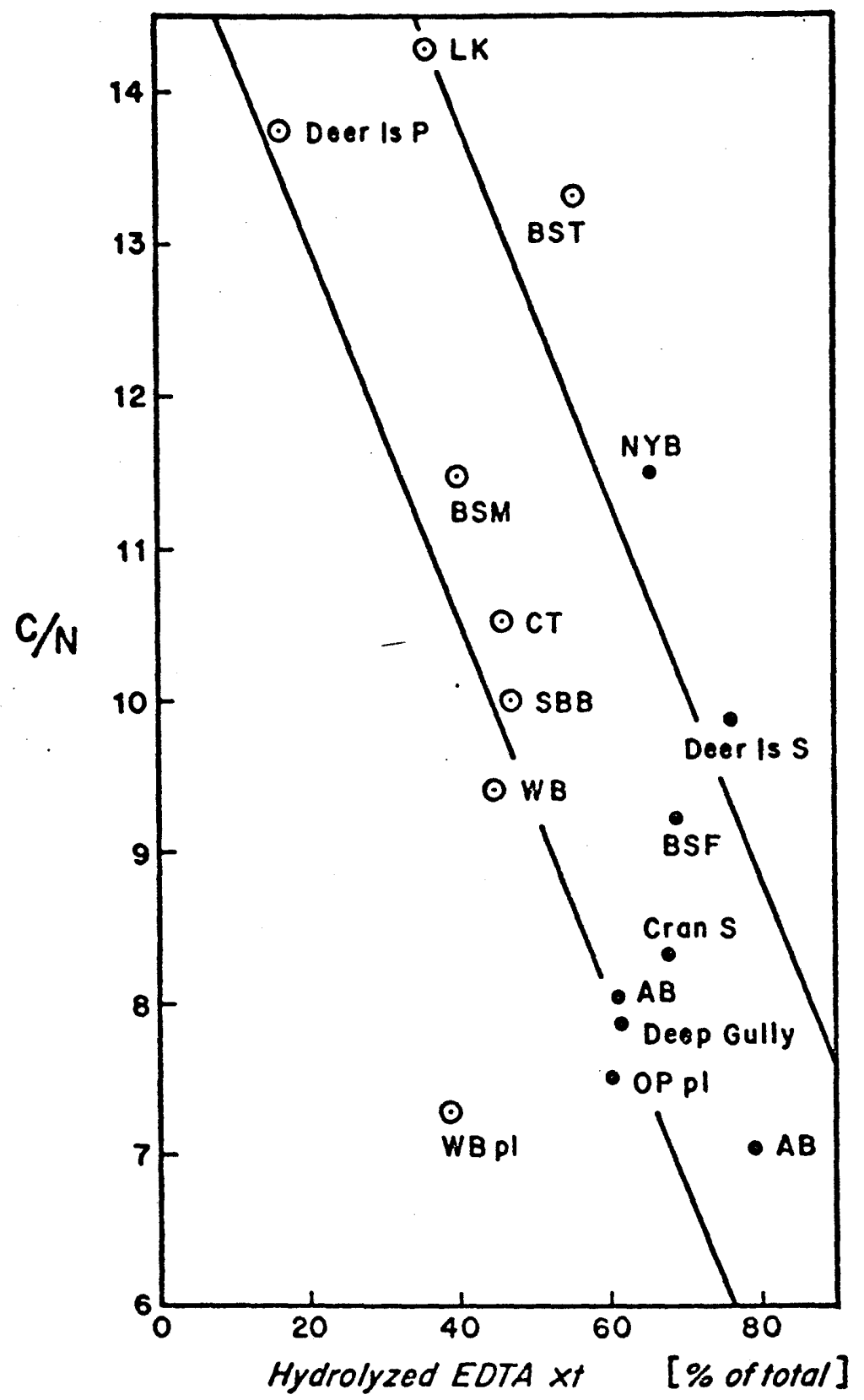

Figure 28

Relationship between $\mathrm{C}-\mathrm{N}$ ratios (Appendix II) and hydrolyzed EDTA extracts of samples studied in this thesis. Reducing sediments and primary sewage sludges $(\odot)$, which are characterized by a low degree of biological degradation, have higher $\mathrm{C}-\mathrm{N}$ ratios than oxic sediments and secondary sludges ( $\bullet$ ), which are characterized by a high degree of biological degradation. Notation as in Figure 23. 
with the exception of carbohydrates, are consumed preferentially in oxidizing environments, or (2) nitrogenous compounds are consumed preferentially in reducing environments. 


\section{7}

\section{PALEOENVIRONMENTAL CRITERIA}

Figure 26 indicates that the degree of metal binding of sedimentary carbohydrates is related to the Eh at the sediment-water interface. Furthermore, Figure 19 shows that the degree of metal binding appears to remain fairly unaltered after burial; therefore, changes in environment at the sediment-water interface from oxidizing to reducing may be discerned as shown for the Cariaco Trench. In reducing environments the percent of the 'total' extracted with EDTA ranges from $30-45 \%$; and in oxidizing environments the range is $60-75 \%$.

Figures 17, 21, and 23 indicate that the glucose and ribose contents of sediment may be used to estimate the terrigenous input. Normal marine sediment generally contains about $20 \%$ glucose, and $3-6 \%$ ribose (Table 12 ) while sediment of a purely terrigenous origin (i.e., wood, peat, etc.) contains about $70 \%$ glucose and only traces of ribose. Sediment in which glucose represents $>20 \%$ of the total (or where glucose $>$ galactose) and where ribose represents $<1 \%$ of the total should be examined for a terrigenous organic input. Changes in the glucose to ribose ratios in sediment may correspond to changes in land run-off; this hypothesis is presently under examination.

Paleo-eutrophication conditions also may be discerned from carbohydrate analyses. For example, organic-rich sediments ! such as the Black Sea sapropel layer) which contain a 'normal' algal sugar distribution (galactose dominant) probably reflect eutrophication in the surface waters. 


\section{8}

CHAPTER VI

\section{SUMMARY AND CONCLUSIONS}

Aspects of the biogeochemical cycle in the ocean are shown in Figure 29. Two major organic inputs to sediment are emphasized: (i) labile particulate organic matter (P.O.M.) or seston, and (ii) inert P.O.M. The organic input of shallow water sediments is probably dominated by labile P.O.M. due to the high primary productivity and the low degree of degradation in the short water column. The organic input of deep-sea sediments is probably dominated by inert P.O.M. since the organic input from labile seston is probably less significant due to extensive degradation in the long water column and also to lower surface water productivity (for further details see Mopper a:id Degens, 1972; and Degens and Mopper, 1974).

Despite the differences in the organic inputs of shallow-sea and deepsea oxic environments, carbohydrate compositions of surface sediments from these environments are almost identical (in terms of relative abundance of sugars, degree of metal binding, and \% of total organic matter represented by carbohydrates) as shown for the Argentine Basin (deep), New York Bight (shallow), and Hudson Canyon (shallow). This uniformity is probably attributable to benthic bio-activity, which is high in shallow regions where 'edible' organics (seston) are abundant, and low in deep regions where 'edible' organics are probably scarce (Sanders and Hessler, 1969; Jannasch et al. , 1971; Rowe,. 1971; and Smith and Teal, 1973). 




Figure 29

Hypothetical schematic of the biogeochemical cycle in the ocean; in this diagram the organic input of shallow- sea sediments is dominantly labile tripton derived from the local biomass; the organic input of deepsea sediments is dominantly refractory particulate organic matter derived from both the degradation of tripton and the condensation of dissolved organic matter. 
Thus, the carbohydrate composition of the end-products of metazoan degradation appears to be uniform, regardless of water depth. Surprisingly the orders of abundance of sugars extracted from sediment from reducing environments are also very similar to those of oxic environments (e.g., Table 12). Furthermore, for most sediments the orders of sugar abundance are similar to that of plankton, the ultimate source material. No one sugar is present in an overwhelming abundance, except for samples for which the organic input is dominantly terrigenous (glucose then dominates). The major difference between carbohydrates extracted from sediment from different depositional environments lies in their degree of metal binding.

In an oxic environment, biological degradation produces a highlymetal-bound (60-75\%), water-insoluble carbohydrate residue. In a reducing environment, the degree of biological activity is low (relative to oxic environments) and hence the degree of metal binding of the resulting carbohydrate residue is low $(30-45 \%)$. There is no evidence for further abiotic alteration after burial in either environment.

Sewage material dumped into a shallow-water oxic environment is degraded rapidly despite the high content of potentially toxic metals. It seems likely that those metals are tied-up in the ultimate metal bound carbohydrate residue. If sewage were dumped into a reducing or deep-sea environment, degradation would probably proceed very slowly.

Metal binding appears to fix potentially soluble carbohydrates (e.g., monosaccharides) in situ, thereby inhibiting diffusion (as shown 
for the wood sample in Cariaco Trench sediments). This finding undercuts the previous belief that chromatographic separation of organic molecules along mineral surfaces is a significant early diagenetic process. Organic matter containing no (or low) functionality, such as hydrocarbons, would not be immobilized by such metal complexes.

Carbohydrates in sediment may be used to interpret paleo-environmental fluctuations. The degree of metal-organic interaction appears to reflect the Eh at the sediment-water interface. The cellulose content of the sediment may be used to estimate the terrigenous organic input. Paleoeutrophic conditions in the surface waters may be discerned from organicrich sediments by determining the relative proportions of algal and terrigenous sugars.

In conclusion, organic molecules in a living cell have a very complex structural order and are also far removed from thermodynamic equilibrium. Diagenesis of organic matter in sediment is expected to proceed in the direction of increasing thermodynamic stability. Initially, the organic input of sediment might be characterized as a loosely-structured conglomeration of various biomolecules in different states of preservation. Diagenesis probably leads to higher degrees of cross-linking of various kinds. The final product of late diagenesis, graphite, has achieved a very simple structural order. This order was obtained by the elimination of functional groups through condensation, deaminization, decarboxylation, etc.; $\mathrm{CO}_{2}, \mathrm{CH}_{4}, \mathrm{NH}_{3}, \mathrm{H}_{2} \mathrm{O}$, and small organic molecules are released as by-products . 


\section{2}

Although the structural nature of the carbohydrate containing residue of recent sediment has not been examined in this thesis, I present in Figure 30 an 'imagined' schematic model of this residue. I realize that at the present stage of research this model is highly hypothetical, however, I think that this type of model is useful in depicting possible interactions among organic molecules, metal ions, and minerals in sediment. Shown in Figure 30 are: (i) organic-organic condensations among carbohydrate, protein, lipid and lignin substances (the hashed lines represent hydrogen bonds); (ii) organic-mineral interactions such as condensation and adsorption of organic compounds onto the surface of a kaolinite-type mineral; (iii) organic-metal ion interactions; this type of interaction might help simplify the structural order of the residue through the formation metal? ion coordination polyhedra; the functional groups of different organic molecules might participate in the coordination; in one of the polyhedra shown a sulfide group (from cysteine) coordinates with a metal ion, and the larger ionic radius of the sulfide ion distorts the polyhedron; (iv) mineral-metal ion-organic interactions; oxygens on the mineral surface might also participate in metal-ion coordination polyhedra; (v) micelle formation; molecules which contain both hydrophobic and hydrophilic portions (e.g. , fatty acids) might tend to aggregate so that the hydrophilic portion interacts with the aqueous environment and the hydrophobic portion is protected from the aqueous environment; indirect proof of the existence of micelles in sediment fulvic acid is given by Ogner and Schnitzer (1970). 


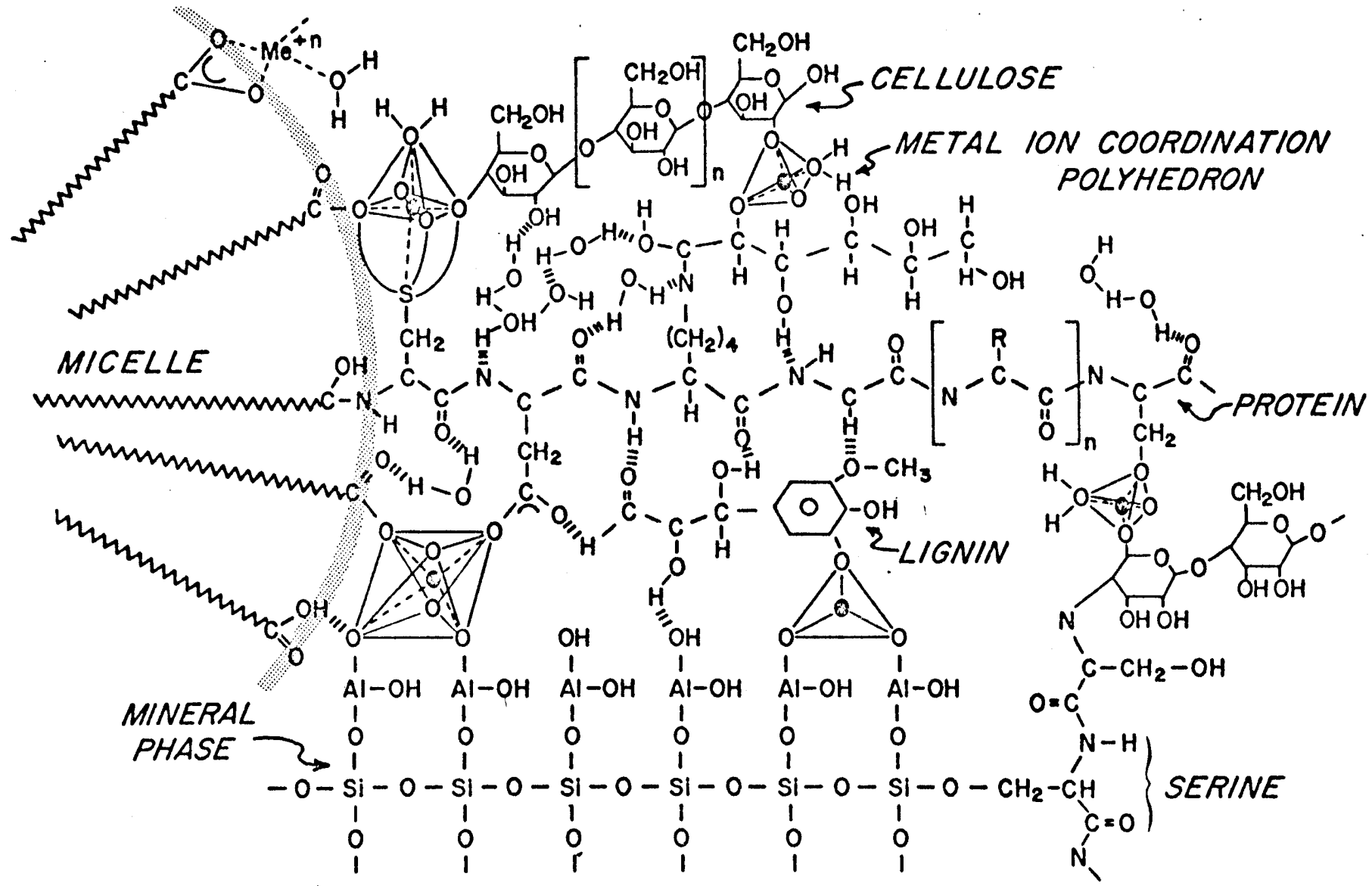

\section{Figure 30}

A highly hypothetical schematic of the carbohydrate-çontaining residue of sediment. Various possible interactions among organic molecules, metal ions, and minerals are shown. 


\section{4}

\section{REFERENCES}

Allen J. A., and Sanders H. L. (1966) Adaptations to abyssal life as shown by the bivalve Abra profundorum (Smith). Deep-Sea Res. 13, 11751184.

Ardakani M。S。 and Stevenson F. J. (1972) A modified ion-exchange technique for the determination of stability constants of metal-soil organic matter complexes. Soil Sci. Soc. Amer. Proc. 36, 884-890.

Atlas of Pilot Charts (1955) Central American waters and South Atlantic Ocean. 2nd Ed, U.S. Navy Hydrographic Office, H.O. Pub. No. $\underline{576}$, Washington, D.C.

Beckwith R. S. (1959) Titration curves of soil organic matter. Nature 184, 745-746.

Bjerrum J. (1941) Metal Ammine Formation in Aqueous Solution, P. Haase and Son, Copenhagen.

Blumer M. (1967) Equilibria and nonequilibria in organic geochemistry: In Equilibrium Concepts in Natural Water Systems. Advances in Chemistry Series 67 (editor R. F. Gould). American Chemical Society Publications, Washington D. C., pp. 312-318.

Bordovskiy O. K. (1965) Accumulation and transformation of organic substances in marine sediments. 2. Sources of organic matter in marine basins. Mar. Geol. 3 , 5-31.

Bourne, E. J., Nery R., and Weigel H. (1959) Metal chelates of polyhydroxy compounds. Chem. Ind., 998-999.

Breger I. A. and Brown A. (1962) Kerogen in the Chattanooga Shale. Science 137, 221-224.

Bremner J. M., Heintze S. G., Mann P. J. G., and Lees H. (1946) Metallo-organic complexes in soil. Nature 158, 790-791.

Broecker W. S., Turekian K. K. and Heezen B. C. (1958) The relation of deep-sea sedimentation rates to variations in climate. Amer. J. Sci. 256, 503-517.

Charley P. J., Sarka B., Stitt C. F., and Saltman P. (1963) Chelation of iron by sugars. Biochim. Biophys. Acta 69, 3.13-321. 


\section{5}

Cheronis N. D. and Zymaris M. C. (1957) The microdetermination of reducing sugars in blood by means of p-anisyl tetrazolium blue. Mikrochim. Acta $\underline{6}, 769-783$.

Clark J. S. and Turner R. C. (1969) An examination of the resin exchange method for the determination of stability constants of metal-soil organic matter complexes. Soil Sci. 107, 8-11.

Coleman N. T., McClung A. C., and Moore D. P. (1956) Formation constants for copper-peat complexes. Science 123, 330-331.

Corwin N. (1969) Reduced data reports for Atlantis II 31, 42, and 48: Appendix I. Techn. Rep. Woods Hole Oceanogr. Inst. Ref. No. $\underline{69-20}, 1-4$.

Craig H. (1953) The geochemistry of stable carbon isotopes. Geochim. Cosmochim. Acta 3 , 53-92.

Dayhoff M. O., Lippincott E. R. and Eck R. V. (1964) Thermodynamic equilibrium in prebiological atmospheres. Science 146, 1461-1464.

De Datta S. K., Franklin R. E., and Himes F. L. (1967) Partial characterization of soil polysaccharide-strontium 90 -yttrium 90 complexes. Soil Sci. 103, 47-55.

Deacon G. E. R. (1963) The southern ocean. In The Sea (editor M. N. Hill), Interscience Publishers, New York, pp. 281-296.

Degens E. T. (1965) Geochemistry of Sediments: A Brief Survey. PrenticeHall, New Jersey。

Degens E. T., Emergy K. O., and Reuter J. H. (1963) Organic materials in recent and ancient sediments: III Biochemical compounds in San Diego Trough, California. N. Jb. Geol. Paläont., Mh. 5, 231-248.

Degens E. T. and Reuter J. H. (1964) Analytical techniques in the field of organic geochemistry. In Advances in Organic Geochemistry (editors U. Colombo and G. O. Hobson), Pergamon Press, Oxford, pp. 377402 .

Degens E. T., Reuter J. H., and Shaw N. F. (1964) Biochemical compounds in offshore California sediments and sea waters. Geochim. Cosmochim. Acta 28, 45-66. 
Degens E. T. (1969) Biogeochemistry of stable carbon isotopes. In Organic Geochemistry (editors G. Eglinton and M. T. J. Murphy), Springer-Verlag, New York, pp. 304-329.

Degens E. T. and Ross D. A. (1970) Oceanographic expedition in the Black Sea: A preliminary report. Naturwissenschaften $\underline{57}, 349-353$.

Degens E. T., Watson S. W. and Remsen C. C. (1970) Fossil membranes and cell wall fragments from a 7000-year old Black sea sediment. Science 168, 1207-1208.

Degens E. T., Deuser W. G., von Herzen R. P., Wong H. K., Jannasch H. W. , and Kanwisher J. W. (1971) Lake Kivu expedition: geophysics, hydrography, sedimentology (a preliminary report). Techn. Rep. Woods Hole Oceanogr. Inst. Ref. No. 71-52, 1-20.

Degens E. T. and Ross D. A. (1972) Chronology of the Black Sea over the last 25,000 years. Chem. Geol. 10, 1-16.

Degens E. T. and Ross D. A. (1973) (editors) The Black Sea: Its Geology, Chemistry, and Biology. Mem. Amer. Assoc. Petrol. Geol. (in press).

Degens E. T., von Herzen R. P., Wong H. K. , Deuser W. G., and Jannasch H. W. (1973) Lake Kivu: Structure, chemistry, and biology of an East African rift lake. Geol. Rdsch. 62, 245-277.

Deuser W. G. (1972) Late-Pleistocene and Holocene history of the Black Sea as indicated by stable-isotope studies. J. Geophys. Res. 77, 1071-1077.

Deuser W. G. (1973) Cariaco Trench: Oxidation of organic matter and residence time of the anoxic water. Nature, in press.

Deuser W. G., Degens E. T., Harvey G. R. and Rubin M. (1973) Methane in Lake Kivu: New data bearing on its origin. Science, in press.

Ebeling A. W. (1962) Melamphaidae I. Systematics and zoogeography of the species in the bathypelagic fish genus Melamphaes Günther. In Dana Report of the Carlsberg Foundation's Oceanographical Expedition Vol. XI no. $58, \mathrm{pp} .164$.

Emery K. O. (1969) A Coastal Pond: Studied by Oceanographic Methods, Elsevier, New York, pp. 1-80 . .

Foree E. G. and McCarty P. L. (1970) Anaerobic decomposition of algae. Environ. Sci. Techn. $\underline{4}, 842-849$. 


\section{7}

Geering H. R. and Hodgson J. F. (1969) Micronutrient cation complexes in soil solution: 3 . Characterization of soil solution ligands and their complexes with $\mathrm{Zn}^{++}$and $\mathrm{Cu}^{++}$. Soil Sci. Amer. Proc. 33, 54-59.

Halvorson A. D. and Lindsay W. L. (1972) Equilibrium relationships of metal chelates in hydroponic solutions. Soil Sci. Amer. Proc. $\underline{36}$, 755-761.

Handa N. and Yanagi K. (1969) Studies on the water-extractable carbo- , hydrates of the particulate matter from the northwest Pacific Ocean. Mar. Biol. 4, 197-207.

Hare P. E. (1969) Geochemistry of proteins, peptides, and amino acids. In Organic Geochemistry: Methods and Results (editors G. Eglinton and M. T. J. Murphy), Springer-Verlag, New York, pp. 438-463.

Harvey H. W. (1960) The Chemistry and Fertility of Sea Waters. University Press, Cambridge, pp. 1-240.

Hodgson J. F., Geering H. R., Noryell W. A (1965) Micronutrient cation complexes in soil solution: Partition between complexed and uncomplexed forms by solvent extraction. Soil Sci. Soc. Amer. Proc. 29. $665-669$.

Hodgson J. F., Lindsay W. L。, and Trierweiler J. F. (1966) Micronutrient cation complexes in soil solution: II. Complexing of zinc and copper in displaced solution from calcareous soils. Soil Sci. Soc. Amer. Proc. $\underline{30}$, 723-726.

Hunt J. M. (1968) The significance of carbon isotope variations in marine sediments. In Adv. in Org. Geochem. 1966 (editor G. D. Hobson), Pergamon Press, Oxford, pp.461-483.

Irving H. and Williams R. J. P. (1948) Order of stability of metal complexes. Nature 162, 746-747.

Jannasch H. W., Eimhjellen K., Wirsen C. O. and Farmanfarmaian A. (1971) Microbial degradation of organic matter in the deep sea. Science $171,672-275$.

Jannasch H. W. and Wirsen C. O. (1973) In situ response of deep-sea microorganisms to nutrient enrichment. Science, in press.

Job P. (1928) Recherches sur la formation de complexes minéraux en solution, et sur leur stabilité. Ann. Chim. 9 , 113-134. 
Jonsson P. and Samuelson O. (1967) Automated chromatography of monosaccharides on anion exchange resins. J. Chromatogr. 26, 194-201.

Kesler R. B. (1967) Rapid quantitative anion-exchange chromatography of carbohydrates. Anal. Chem. 39, 1416-1422.

Khanna S. S., and Stevenson F. J. (1962) Metallo-organic complexes in soil: I. Potentiometric titration of some soil organic matter isolates in the presence of transition metals. Soil Sci. 93, 298-305.

Larsson L. and Samuelson O. (1965) An automated procedure for separation of monosaccharides on ion exchange resins. Acta Chem. Scand. 19. 1357-1364.

Maksimov O. B., Prishchepo R. S., and Shvets T. V. (1972) The geochemical role of humic acid oxidation products. Geochem. Intl. 9 , 135- 141 .

Martell A. E. (1971) Principles of complex formation. In Organic Compounds in Aquatic Environments (editors S. J. Faust and J. V. Hunter), Marcel Dekker, New York, pp. 239-263.

Martell E. A. and Calvin M. (1952) Chemistry of Metal Chelate Compounds, Prentice-Hall Inc., New York.

Meeuse B. J. D. (1962) Storage products. In Physiology and Biochemistry of Algae (editor R. A. Lewin), Academic Press, New York.

Miller M. H. and Ohlrogge A. J. (1958) Water-soluble chelating agents in organic materials: I. Characterization of chelating agents and their reactions with trace metals in soils. Soil Sci. Soc. Amer. Proc. 22, 225-228.

Modzeleski J. E., Laurie W. A., and Nagy B. (1971) Carbohydrates from Santa Barbara Basin sediments: Gas chromatographic-mass spectrometric analysis of trimethylsilyl derivatives. Geochim. Cosmochim. Acta $\underline{35}, 825-838$.

Moore S. and Stein W. H. (1951) Chromatography of amino acids on sulfonated polystyrene resins. J. Biol. Chem. 192, 663 .

Mopper K. (1970) A New Micro-Analytical System for Reducing Sugars. Masters Thesis, Mass. Inst. Technol. 
Mopper K. (1971) Some considerations of the effects of natural and manmade anoxic conditions on the surrounding environment. In Papers on National Land Use Policy Issues (Chairman H. M. Jackson), Senate, 92d Congress, pp. 189-198.

Mopper K. and Degens E. T. (1972) Aspects of the biogeochemistry of carbohydrates and proteins in aquatic environments. Techn. Rep. Woods Hole Oceanogr. Inst. Ref. No. 2-68.

Mopper K. and Degens E. T. (1972) A new chromatographic sugar autoanalyzer with a sensitivity of $10^{-10}$ moles. Anal. Biochem. 45 , 147-153.

Mopper K. and Degens E. T. (1974) Distribution and diagenesis of amino acids and sugars in sediments. Geochim. Cosmochim. Acta, submitted for publication.

Mortensen J. L. (1963) Complexing of metals by' soil organic matter. Soil Sci. Soc. Proc. 27, 179-186.

Ogner G. and Schnitzer M. (1970) Humic substances: fulvic acid-dialkyl phthalate complexes and their role in pollution. Science 170, 317318.

Palacas J. G., Swain F. M. and Smith F。 (1960) Presence of carbohydrates and other organic compounds in ancient sedimentary rocks. Nature 185,234 .

Percival E. (1968) Marine algal carbohydrates. Oceanogr. Mar. Biol. Ann. Rev。 $6,137-161$.

Prashnowsky A., Degens E. T., Emery K. O., and Pimenta J. (1961) Organic materials in recent and ancient sediments: I. Sugars in marine sediment of Santa Barbara Basin, California. N. Jb. Geol. Paläont., Mh. $8,400-413$.

Presley B. J., Kolodny Y., Nissenbaum A., and Kaplan I. R. (1972) Early diagenesis in a reducing fjord, Saanich Inlet, British Columbia - II. Trace element distribution in interstitial water and sediment. Geochim. Cosmochim. Acta 36, 1073-1090.

Randhawa N. S. and Broadbent F. E. (1965) Soil organic matter - metal complexes: 6 . Stability constants of zinc-humic acid complexes at different $\mathrm{pH}$ values. Soil Sci. $\underline{99}, 362-366$. 
Rashid M. A. and King L. H. (1970) Major oxygen-containing functional groups present in humic and fulvic fractions isolated from contrasting environments. Geochim. Cosmochim. Acta 34, 193-201.

Reilley C. N.. Schmid R. W., and Sadek F。S。 (1959) Chelon approach to analysis (I): Survey of theory and application. J. Chem. Ed. 36 , 555-564.

Richards F. A. and Vaccaro R. F. (1956) The Cariaco Trench, an anaerobic basin in the Caribbean Sea. Deep-Sea Res. $\underline{3}, 214-228$.

Richards F. A. (1965) Anoxic basins and fjords. In Chemical Oceanography, (editors J. P. Riley and G.Skirrow), Academic Press, London, pp. $611-645$.

Richards S., Pedersen B., Silverton J. V., and Hoard J. L. (1964) Stereochemistry of ethylenediamine-tetraacetate complexes. Inorg. Chem. 3. 27-33.

Rittenberg S. C., Emery K. O., Hülsemann J., Degens E. T., Fay C., Reuter J. H., Grady J. R., Richardson S. H. and Bray E. E. (1963) Biogeochemistry of sediments in experimental mohole. J. Sed. Petr. 33, 140-172.

Rogers M. A. (1965) Carbohydrates in aquatic plants and associated sediments from two Minnesota lakes. Geochim. Cosmochim. Acta 29, 183-200.

Ross D. A., Degens E. T., and MacIlvaine J. (1970) Black Sea: Recent sedimentary history. Science 170, 163-165.

Rowe G. T. (1971) Benthic biomass and surface productivity. In Fertility of the Sea (editor J. D. Costlow), Gordon and Breach Science Publ., New York-London-Paris, pp. 441-454.

Ryther J. H. (1963) Geographic variations in productivity. In The Sea (editor M. N. Hill), Interscience Publishers, New York, pp. 347-380.

Sackett W. M. and Thompson R. R. (1963) Isotopic organic carbon composition of recent continental derived clastic sediments of eastern Gulf Coast, Gulf of Mexico. Bull. Am. Assoc. Petrol. Geol. 47, 525-528.

Samuelson O. (1963) Ion Exchange Separations in Analytical Chemistry, Almquist \& Wiksell, Stockholm; Wiley, New York. 
Samuelson O. and Strömberg H. (1968) Partition chromatography of mono-, di- and trisaccharides on ion-exchange resins. Z. Anal. Chem. $\underline{236}, 506-513$.

Sanders H. L. and Hessler R. R. (1969) Ecology of the deep-sea benthos. Science 163, 1419-1424.

Schnitzer M. and Skinner S. I. M. (1965) Organo-metallic interactions in soils: 4. Carboxyl and hydroxyl groups in organic matter and metal. retention. Soil Sci. $99,278-284$.

Schnitzer M. and Skinner S. I. M. (1966) Organo-metallic interactions in soils: 5. Stability constants of $\mathrm{Cu}^{++}-, \mathrm{Fe}^{++}$, and $\mathrm{Zn}^{++}$- fulvic acid complexes. Soil Sci. 102, 361-365.

Schnitzer M. and Skinner S. I. M. (1967) Organo-metallic interactions in soils: 7. Stability constants of $\mathrm{Pb}^{++}, \mathrm{Ni}^{++}, \mathrm{Mn}^{++}, \mathrm{Co}^{++}, \mathrm{Ca}^{++}$, and $\mathrm{Mg}^{++}$- fulvic acid complexes. Soil Sci. 103, 247-252.

Schnitzer M. and Hansen E. H. (1970) Organo-metallic interactions in soils: 8. An evaluation of methods for the determination of stability constants of metal-fulvic acid complexes. Soil Sci. 109, 333-340.

Schnitzer M. (1971) Metal-organic interactions in soils and waters. In Organic Compounds in Aquatic Environments (editors S. J. Faust and J. V. Hunter), Marcel Dekker, New York, pp. 297-315.

Schubert J. (1948) Use of ion exchangers for the determination of physicalchemical properties of substances, particularly radiotracers: I. J. Phys. Coll. Chem. 52, 340-350.

Sillen L. G. and Martell A. E. (1964) Stability constants of metal-ion complexes. Special Publication \#17, The Chemical Society, London.

Simoneit B. R. and Burlingame A. L. (1972) Preliminary organic analyses of the DSDP (JOIDES) cores, Legs V-IX. In Advances in Organic Geochemistry 1971 (editors H. R. v Gaertner and H. Wehner), Pergamon Press, Oxford, pp. 189-228.

Smith K. L. and Teal J. M. (1973) Deep-sea benthic community respiration: An in situ study of 1850 meters. Science 179, 282-283.

Smith K. L., Rowe G. T. and Clifford C. H. (1973) New York Bight sludge dumping area: In-situ measurements of benthic oxygen demand. Science, submitted for publication. 
Stevenson F. J. and Butler J. H. A. (1969) Chemistry of humic acids and related pigments. In Organic Geochemistry: Methods and Results (editors G. Eglinton and M. T. J. Murphy), Springer-Verlag, New York, pp. 334-357.

Stevenson F. J. and Cheng C.- N. (1970) Amino acids in sediments: Recovery by acid hydrolysis and quantitative estimation by a colorimetric procedure. Geochim. Cosmochim. Acta 34, 77-88.

Stevenson F. J. and Cheng C.-N. (1972) Organic geochemistry of the Argentine Bas in sediments: Carbon-nitrogen relationships and Quaternary correlations. Geochim. Cosmochim. Acta 36, 653-671.

Swain F. M. (1958) Organic materials of early Middle Devonian, Mt. Union area Pennsylvania. Bull. Amer. Ass. Petrol. Geol. 42, 28582891.

Swain F. M. (1963) Stratigraphic distribution of some residual organic compounds in Upper Jurassic. Bull. Amer. Ass. Petrol. Geol. 47, 777803 .

Swain F. M. and Rogers M. A. (1966) Stratigraphic distribution of carbohydrate residues in Middle Devonian Onondaga beds of Pennsylvania and western New York. Geochim. Cosmochim. Acta 30, 497-509.

Swain F. M. , Rogers M. A. , Evans R. D. and Wolfe R. W. (1967). Distribution of carbohydrate residues in some fossil specimens and associated sedimentary matrix and other geologic samples. J. Sed. Petr. 37, 12-24.

Swain F. M. , Pakalns G. V. and Brett J. G. (1968) Possible taxonomic interpretation of some Paleozic and Precambrian carbohydrate residues. In Advances in Organic Geochemistry 1966 (editor G. D. Hobson), Pergamon Press, Oxford, pp. 461-483.

Swain F. M. (1969) Fossil carbohydrates. In Organic Geochemistry: Methods and Results (editors G. Eglinton and M. T. J. Murphy), SpringerVerlag, New York, pp. 374-401.

Swain F. M. and Bratt J. M. (1972) Comparative carbohydrate geochemistry of bay, salt marsh, and deep gulf sediments. In Advances in Organic Geochemistry 1971 (editors H. R. v. Gaertner and H. Wehner), Pergamon Press, Oxford, pp. 415-425.

Tan K. H., King L. D., and Morris H. D. (1971) Complex reactions of zinc with organic matter extracted from sewage sludge. Soil Sci. Soc. Amer. Proc. 35, 748-752. 
Vallentyne J. R. and Bidwell R. G. S. (1956) The relation between free sugars and sedimentary chlorophyll in lake muds. Ecology 37 , 495-500.

Waksman S. A. (1933) The distribution of organic matter on the sea bottom and the chemical nature of humic acid. Soil Sci. 36, 125-147.

Whittaker J. R. and Vallentyne J. R. (1957) On the occurrence of free sugars in lake sediment extracts. Limnol. Oceanogr. 2, 98-110.

Wright J. R., and Schnitzer M. (1963) Metallo-organic interactions associated with podzolization. Soil Sci. Soc. Proc. 27, 171-176.

ZoBell C. E. (1939) Occurrence and activity of bacteria in marine sediment. In Recent Marine Sediments (editor P. D. Trask), Amer. Ass. Petr. Geol., Tulsa, Oklahoma.

ZoBell C. E. and Grant C. W. (1943) Bacterial utilization of low concentrations of organic matter. J. Bact. 45 555-564.

Zunino H. , Galindo G., Peirano P., and Aguilera M. (1972) Use of the resin exchange method for the determination of stability constants of metal-soil organic matter complexes. Soil Sci. 114, 229-233. 
164

APPENDIX I

DISCUSSION OF SAMPLE. MATERIAL 


\section{5}

\section{APPENDIX I}

\section{$\checkmark$ DISCUSSION OF SAMPLE MATERIAL}

Details of the organic carbon, organic nitrogen, organic hydrogen, water and $\mathrm{CaCO}_{3}$ content of the samples discussed here are listed in Appendix II. Standard analytical techniques were employed to measure these parameters (Mopper and Degens, 1972).

\section{a. Plankton}

Plankton samples were obtained from different parts of the world; i.e., Cariaco Trench, Walvis Bay, off Iceland, off Bermuda, Humboldt Current, Lake Kivu and Oyster Pond (near Woods Hole). All samples (ex- cept Oyster Pond) were collected by an oblique tow from 200 meters to the surface with a \#10 net. The samples represented a mixture of phytoplankton and zooplankton. No attempt was made to separate the two types prior to analysis.

\section{b. Organic Waste Products}

(i) Sewage Sludge: Primary and secondary sludges were obtained from treatment plants at Deer Island (Deer Island Treatment Plant, Winthrop, Massachusetts) and Cranston, Rhode Island (Water Pollution Control Facility). Briefly, screened and degritted raw sewage is pumped into a sedimentation tank (primary) after which the settled sludge is pumped into a series of digestion tanks (secondary) where it is aerobically and anaerobically consumed. The efficiency of digestion is 60 to $70 \% \cdot \mathrm{CH}_{4}$ ' 
$\mathrm{CO}_{2}, \mathrm{~N}_{2}$, and $\mathrm{H}_{2}$ are released as by-products of the digestion processes. Dried primary sludge has a fibrous texture which made crushing in a mortar difficult. Examination of the material through an optical microscope revealed the presence of such artifacts as hairs, cellulose fibers and glass fragments. Dried secondary sludge has a more amorphous texture and wás easily crushed and homogenized in a mortar; no fibers or hairs were observed. The organic carbon contents of the Deer Island primary and secondary sludges are $36.0 \%$ and $35.9 \%$ respectively. The $\mathrm{C} / \mathrm{N}$ ratio changes from 13.7 for the primary sludge to 9.9 for the secondary sludge. The $\delta \mathrm{C}^{13}$ values for the primary and secondary sludges are -24.2 and -23.3 , respectively. The gross chemical and isotopic compositions apparently reveal little about structural changes and biochemical processes active in sludge digestion.

The sludges contain several percent heavy metals; secondary sludges have a $30-40 \%$ higher metal content than primary sludges .

(ii) Cow Manure: The manure sample was collected fresh from a local farm (Cape Cod). The sample was dried and analyzed immediately after collection. The sample had a fibrous appearance but was crushed easily after drying. The ease of crushing and homogenization suggested that structural components of the straw feed had been broken down by digestive processes in the cow. The material is almost exclusively organic as revealed by an organic carbon content of $43 \%$. The $\mathrm{C} / \mathrm{N}$ ratio is about 18. 


\section{c. Argentine Basin (ATLANTIS II Cruise \#60, Leg 2, Station 21, February-March 1971)}

A $5 \mathrm{~m}$ gravity core in the northern part of the Argentine Basin (latitude $33^{\circ} 50.09^{\prime} \mathrm{S}$, longitude $47^{\circ} 48.62^{\prime} \mathrm{W}$ ) was taken at a water depth of approximately 3500 meters. Two distinct sedimentary units exist and their geo-' logical ages were determined by carbon-14 dating.

The upper unit, approximately $15 \mathrm{~cm}$ in length, consists of a light red-brown homogeneous clay. This unit approximately represents the present sediment-water interface because the gravity coring technique used does not severely disturb top sediments, as opposed to piston coring techniques where the top $10-50 \mathrm{~cm}$ may be lost. The organic carbon content of this unit is about $0.35 \%$, which is the lowest value in the core. The low organic content of the surface sediment is probably due to the present-day low primary productivity in the region of the core as discussed below. The base of the unit was dated at 2000-3000 years B.P.

The lower unit $(15 \mathrm{~cm}$ to $500 \mathrm{~cm}$ ) is a grey-green clay. This unit is dominantly homogeneous, however, an occasional layer (1-2 mm thick) of sand and gravel is present. The source of these layers is probably icerafting or turbidity currents. The organic carbon content is variable but generally clusters between 0.6 to $0.7 \%$. The age at the base of the core is approximately 90,000 years B.P.

The source of the inorganic fraction (clay) is probably the Rio de la Plata River, which drains the southern part of South America. No carbonates 
Organic Corbon
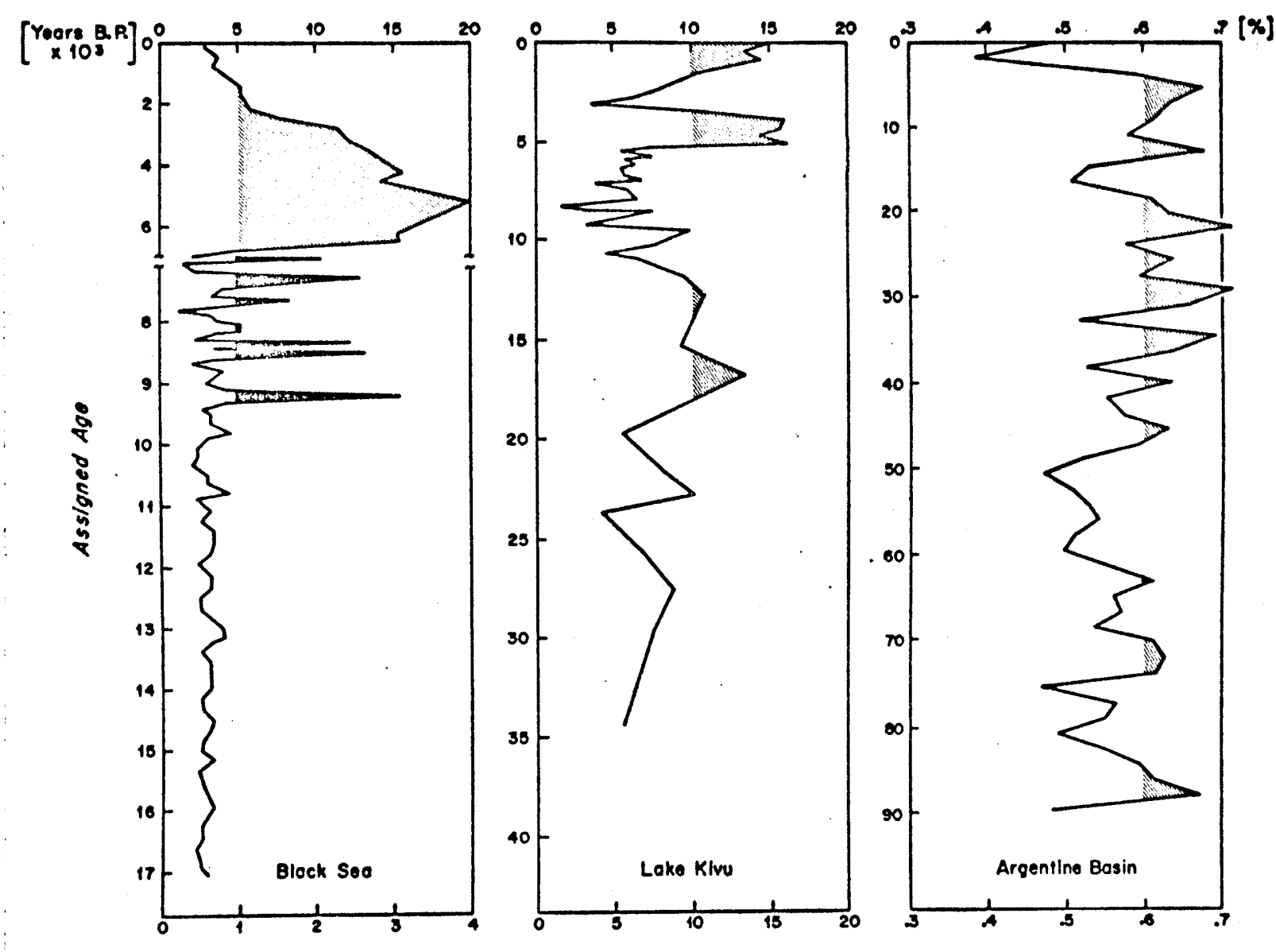

Figure I - 1

Fluctuations of organic carbon in cores from three different sedimentary environments: 1) Black Sea- Inland sea; ii) Lake Kivu - fresh lake; and 1ii) Argentine Basin - open ocean. Note that the lower portion of the Black Sea curve ( $>6000$ years) is plotted on an expanded scale in order to snhance the fluctuations. 
were detected in the core.

Argentine Basin sediments are low in organic carbon relative to inland seas and lakes, such as the Black Sea and Lake Kivu (Figure I-1); however, in comparison to 'normal' open ocean sediments which generally contain 0.1-0.5\% urganic carbon (Bordovskiy, 1965), Argentine Basin sediments are enriched in organic carbon $(0.5-1.0 \%)$. This relatively high organic content is probably related to high primary productivity in the surface water which, in turn, is probably related to upwelling in the area of the subtropical convergence near the edge of the continent (Ryther, 1963; Deacon, 1963). The subtropical converyterce separates northward moving, nutrient-rich sub-Antarctic water from southward moving, nutrient-poor sub- tropical water. The productivity of the sub-Antarctic water is $150-250 \mathrm{~g}$ $\mathrm{C} / \mathrm{m}^{2} / \mathrm{yr}$, while the productivity of the subtropical water is about $50 \mathrm{~g}$ $\mathrm{C} / \mathrm{m}^{2} /$ yr (Ebling, 1962).

The distinct temporal variations of organic carbon shown in Figure I- 1 for the Argentine Basin are not correlative with sea level fluctuations or glacial periods as found by Stevenson and Cheng (1972). The organic carbon fluctuations in the present core may be attributed to the following: i) variations in surface productivity as a result of shifts in the subtropical convergence; these shifts may be initiated by changes in mean surface water temperature during glacial and interglacial periods; i.e., during glacial periods the mean position of the subtropical convergence moves northward in response to colder surface temperatures; seasonal shifts of several 
hundred kilometers are well documented (Atlas of Pilot Charts, 1955) and are shown in Figure I- 2 along with core positions; and ii) variations in land run-off due to eustatic changes in sea level; i.e., during glacial periods land run-off increases which results in higher sedimentation rates in the ocean (Broecker et al. , 1958) which, in turn, results in dilution of the organic input of sediment. Therefore, fluctuations in the organic carbon content of the present Argentine Basin sediment appear to represent a resolution of two factors: sedimentation rate and primary productivity.

The water column in the area of the core has the following characteristics (Corwin, 1969): i) temperature and salinity vary from $21^{\circ} \mathrm{C}$ and $36.0 \%$ at the surface to $0.8^{\circ} \mathrm{C}$ and $34.7 \%$ at the sediment-water interface;

-. and ii) the oxygen content is $5.1 \mathrm{ml} /$ liter at the surface, $4.5 \mathrm{ml} /$ liter at about $2000 \mathrm{~m}$, and $5.1 \mathrm{ml} /$ liter near the sediment-water interface $(3500 \mathrm{~m})$; the average oxygen content for the water column is $5.2 \mathrm{ml} / \mathrm{liter}$.

\section{d. New York Bight and Hudson Canyon (GOSNOLD Cruise 187,} April 1972)

Three surface samples were collected in the vicinity of the New York Bight sewage disposal area. The samples were frozen immediately after collection. The sediment was placed through a $0.5 \mathrm{~mm}$ screen prior to extraction to remove large animals.

One sample (labelled 'Buoy Station') is from the periphery of the disposal area (water depth $\sim 30 \mathrm{~m}$ ). Raw, primary and secondary treated sewage are dumped in this area. The water is oxic down to the 
Figure I- 2

Seasonal positions of the subtropical convergence in the Argentine Basin (Atlas of Pilot Charts, 1955). The productivity south of the con-

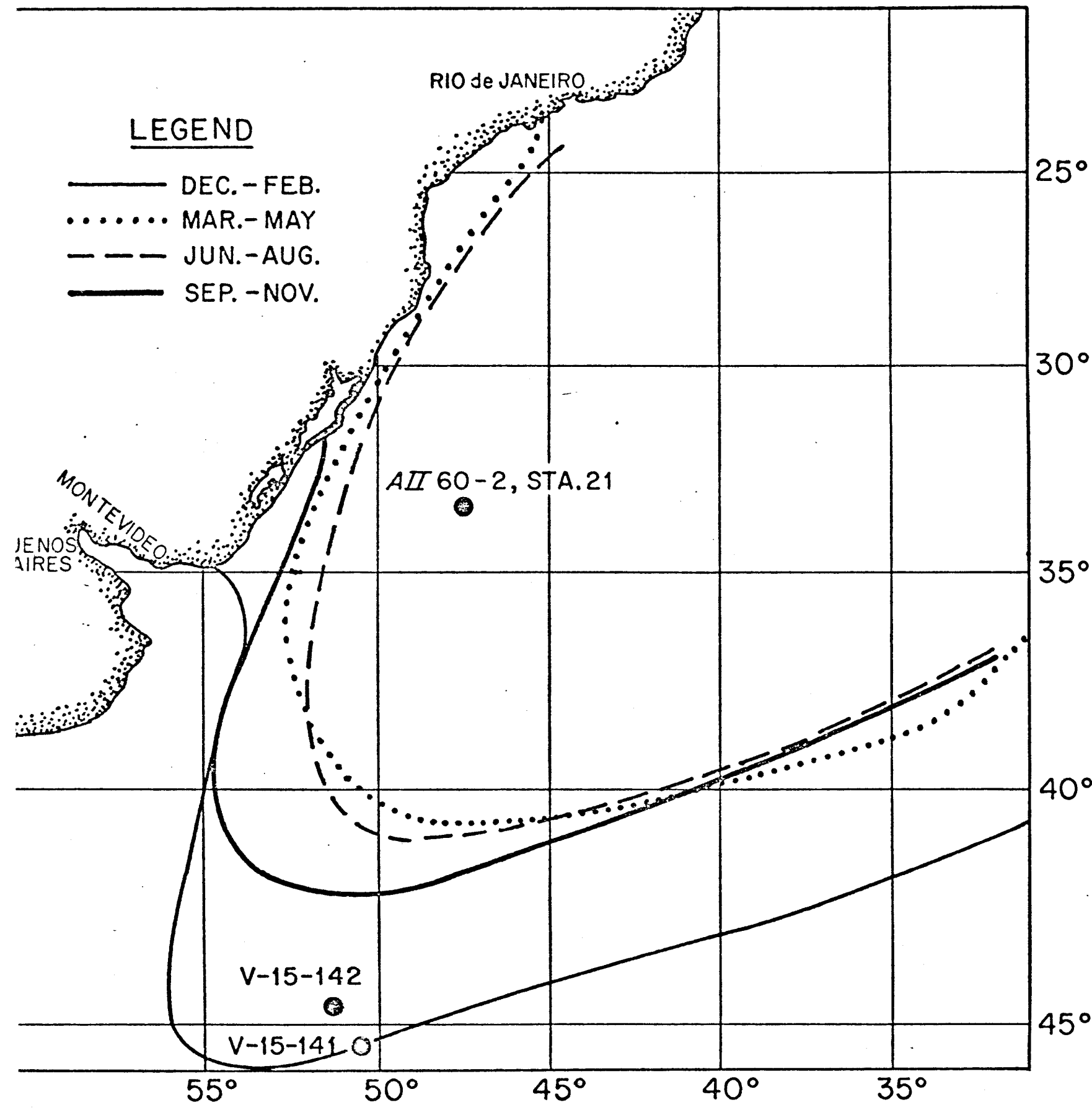

vergence is high $\left(\sim 150-250 \mathrm{~g} \mathrm{C} / \mathrm{m}^{2} / \mathrm{yr}\right.$.) while the productivity north of the convergence is low $\left(\sim 50 \mathrm{~g} \mathrm{C} / \mathrm{m}^{2} / \mathrm{yr}\right.$.). Movements of the subtropical convergence may affect the organic carbon content of the sediment. The AII-60 station is described in this thesis; V-15 stations are described in Stevenson and Cheng (1972)。 
sediment-water interface. The surface sediments at the Buoy Station are characterized by having one of the highest biological consumption rates in the world's oceans (Smith et al. , 1973).

The other samples (Mid-Gully and Deep Gully) are from the Hudson Canyon near the disposal area. These samples are more characteristic of normal shallow-sea sediments with respect to organic carbon contents and biological consumption rates.

e. Cariaco Trench (ATLANTIS II Cruise \#60, Stations 1788P and 1798P 2 July-August 1971; J.O.I.D.E.S. Leg 15, Drilling Site 147, January 1971)

The Cariaco Trench is a marine anoxic basin off the coast of Venezuela. It measures $180 \mathrm{~km}$ long in the east-west direction and up to $60 \mathrm{~km}$ wide in the north-south direction. The trench has a maximum depth of $1400 \mathrm{~m}$ and is separated from the rest of the Caribbean Sea by a sill which has a maximum depth of $140 \mathrm{~m}$. The residence time for the deep water is about 100-200 years (Deuser, 1973). The $\mathrm{O}_{2}-\mathrm{H}_{2} \mathrm{~S}$ interface occurs at about $300 \mathrm{~m}$. The maximum $\mathrm{H}_{2} \mathrm{~S}$ concentration is about $0.03 \mathrm{mg} \mathrm{A}$ sulfide - S/1. For details, see Richards and Vaccaro (1956) and Richards (1965).

A piston core at station $1788 \mathrm{P}$ was taken at water depth of $435 \mathrm{~m}$ in the eastern portion of the trench; $315 \mathrm{~cm}$ of sediment were recovered. Two sedimentary units exist; the top unit $(0-120 \mathrm{~cm})$ is a dark green-grey $\mathrm{H}_{2} \mathrm{~S}-$ rich laminated sediment. Wood is encountered at a sediment depth of about 


\section{3}

60-80 cm; evidently a log buried in the sediment was penetrated by the coring device. The age of the wood as determined by $\mathrm{C}-14$ methods is 5400 years B.P.; based on this date, a sedimentation of $10-20 \mathrm{~cm} / 1000$ years was estimated.

This sedimentation rate is low since it is not known how long the $\log$ floated before settling to the bottom. J.O.I.D.E.S. results indicate a sedimentation rate of $50 \mathrm{~cm} / 1000$ years is more appropriate. Omitting the wood, the average organic carbon content of this unit is $5 \%$ and the $\mathrm{CaCO}_{3}$ content is about $35 \%$.

The second unit $(12 \mathrm{D}-315 \mathrm{~cm})$ is also truninated and $\mathrm{H}_{2} \mathrm{~S}-\mathrm{rich}$; however, the color is generally a lighter green-grey. The laminated sediment is interspersed with three $10-20 \mathrm{~cm}$ gelatinous water-rich bands. The average organic carbon content of the unit is $4 \%$ and the $\mathrm{CaCO}_{3}$ content is about $15 \%$.

The core at Station $1798 \mathrm{P}_{2}$ resembles the above core (but with no wood); a third unit consisting of oxidized sediment is encountered $255 \mathrm{~cm}$ below the top of the core. This unit is uniformly light grey with no apparent laminations. The organic carbon content is $1-2 \%$ and the $\mathrm{CaCO}_{3}$ content is 25\%. Metal analyses indicated that this unit was deposited under oxidizing conditions (Price, pers. comm.).

The J.O.I.D.E.S, core at drilling site 147 in the western portion of the Cariaco Trench is described in detail in the Initial Report \#15 (1973, in preparation). The core length is $189 \mathrm{~m}$. Four distinct sedimentary rhythms 
274

are observed. Briefly, each rhythm is composed of: i) greyish olive-green calcareous clay; ii) grey and brown calcareous clays; and iii) vari-colored calcareous and dolomitic clays. The first rhythm is $13 \mathrm{~m}$ long; the second, $90 \mathrm{~m}$ long; the third, $16 \mathrm{mlong}$; and the fourth, $70+\mathrm{m}$ long.

Pyrite is abundant throughout the length of the core (except in the oxic zones). The detrital minerals, such as plagioclase, orthoclase, hornblende and zoisite, indicate a metamorphic province as the source of the inorganic fraction. Clay and $\mathrm{CaCO}_{3}$ (predominately nanno-fossils and foraminifera) abundances appear to be inversely related; this trend may reflect changes in land run-off.

\section{f. Santa Barbara Basin $\left(34^{\circ} 17^{\prime} N, 120^{\circ} 05^{\prime} \mathrm{W}\right)$}

Two marine sediment samples were collected and described by Modzeleski et al.(1971). The samples were taken at depths of 35 and 160 $\mathrm{cm}$ below the sediment-water interface and were dated at $50 \pm 10$ years and $750 \pm 50$ years, respectively. Dating was accomplished by counting seasonal varves with an X-ray technique. The samples consist of dark brown-green $\mathrm{H}_{2} \mathrm{~S}$-rich mud. The samples were frozen immediately after collection. Prior to analyses the frozen samples were washed with distilled water and freeze-dried for storage. For details of the Santa Barbara Basin see Emery (1960).

g. Walvis Bay (ATLANTIS II Cruise \#42, Station 187, May 1968) An anchor dredge (surface sediment) sample was collected at a water depth of about $600 \mathrm{~m}$. The sample was frozen immediately after preliminary 


\section{5}

examination of the indigenous fauna. The sample is a dark green-grey

$\mathrm{H}_{2} \mathrm{~S}$-rich mud. The organic carbon content is $6-7 \%$ and the $\mathrm{C} / \mathrm{N}$ ratio is about 7. The high organic content probably reflects high primary productivity at the surface waters $\left(\sim 400 \mathrm{~g} \mathrm{C} / \mathrm{m}^{2} / \mathrm{yr}\right)$. Examination of the oxygen profile in the overlying water (Corwin, 1969) indicates that oxygen concentrations decrease rapidly from a normal value of about $5 \mathrm{ml} / \mathrm{liter}$ at the surface to $>1 \mathrm{ml} /$ liter near the bottom. The oxygen concentration just above the sediment-water interface is zero. The bottom temperature is about $5^{\circ} \mathrm{C}$.

h. Black Sea (ATLANTIS II Cruise \#49, Station 1474, April-May 1969)

Two cores in the eastern basin were taken at a water depth of about $2,200 \mathrm{~m}$. A square box core $(15 \times 15 \mathrm{~cm}) 6 \mathrm{~m}$ long, and a piston core $12 \mathrm{~m}$ long were examined. The upper $50 \mathrm{~cm}$ of the piston core were lost during the coring operation. Three distinct sedimentary units were defined and their geologic ages were determined by radiocarbon methods.

The uppermost unit, $30 \mathrm{~cm}$ thick, is composed of alternating black and white layers, 50 to 100 per $\mathrm{cm}$. The white layers are calcitic and are composed almost entirely of the coccolithophorid Emiliana huxleyi, and the darker layers are composed of organic-rich material. The base of the unit is about 3000 years B.P.

The second unit, about $40 \mathrm{~cm}$ thick, is dark brown and has a jellylike appearance. On the dry weight basis, the content of organic matter is as high as $40 \%$. Microlaminae are still recognizable, but because of lower 
color contrast, they are less pronounced than in the uppermost unit. The second unit is further characterized by the occurrence of three distinct white bands, a millimeter or less thick and consisting dominantly of various species of coccolithophorid and aragonite grains. The base of the unit corresponds to a $\mathrm{C}^{14}$ age of 7000 years.

The third unit consists of a sequence of alternating light and dark lutite bands. The upper meter of the unit is marked by a drop in organic carbon from about 2 percent to 0.3 percent. These changes take place in the time interval between 7000 and 10,000 years B.P. The indigenous coccoliths of the upper two units are absent in the basal section. Only a few fragments of Eocene and Cretaceous coccoliths are found and are probably of terrigenous origin. The base of the piston core has a carbon-14 age of about 25,000 years B.P.

It is of interest to note that not only can these three sedimentary units be traced along the entire length of the Black Sea, but layers as thin as $1 \mathrm{~mm}$ are correlative over $1000 \mathrm{~km}$. This ubiquity of distinct layers suggests that uniform environmental conditions prevailed over most of the basin at any one time.

In the Black Sea the environment at the sediment-water interface has changed several time from oxic fresh water to anoxic marine during the last 25,000 years (Degens and Ross, 1972). The frequency of marine spills and fresh water dominance is recorded by the fossils assemblages; the redox conditions at the sediment-water interface is reflected in the mineralogy of 
the sediments. The organic carbon content also mirrors these changes as shown in Figure I- 1 .

The interpretation was offered (Degens and Ross, 1970) that between 17,000 and 9300 B.P. the Black Sea constituted an oxygenated fresh water body for its entire depth. Around 9300 years B.P. the first invasion of . Mediterranean water occurred, which produced reducing conditions at the sediment-water interface for about 200 years. The frequency of saline spills with concurrent reducing conditions at the sea bottom over the next 2000 years was reflected in the sedimentary organic carbon fluctuations (Figure I-1). Findiy, at 7300 years B.P. the influx of Mediterranean water became so pronounced that saline (brackish) and reducing conditions were permanently established at the sediment-water interface. The shape of the organic carbon curve from 7000 years B.P. to present was principally the result of changes in the rate of deposition which, in turn, was controlled by variations in the productivity of calcareous organisms (coccoliths).

For further information see Ross et al. (1970), Degens and Ross $(1970,1973)$.

i. Oyster Pond, Woods Hole (May 1972)

Oyster Pond is a coastal pond, $1100 \mathrm{~m}$ long in the north-south direction and up to $300 \mathrm{~m}$ wide. The maximum water depth is $6 \mathrm{~m}$. A strong hilocline exists for most of the year in the southern portion of the pond; in the upper $4 \mathrm{~m}$ the chlorinity is $1.0-2.0 \% \circ$ while in the lower meter the chlorinity is $5.0-6.0 \%$. The presence of this halocline gives rise to 


\section{8}

anoxic conditions at the sediment-water interface (infrequent overturns have been observed).

A surface sediment sample was taken in the southern central portion of the pond. The sediment-water interface at the time of sampling was anoxic. The sediment is a dark brown $\mathrm{H}_{2} \mathrm{~S}$-rich clay. The $\mathrm{CaCO}_{3}$ content is less than $1 \%$. The organic carbon content is $11 \%$ and the $\mathrm{C} / \mathrm{N}$ ratio is 10 .

The high organic content reflects high primary productivity at the surface $\left(100-200 \mathrm{~g} \mathrm{C} / \mathrm{m}^{2} / \mathrm{yr}\right)$. Although land-derived organic input is more important near the shore than at the center of the pond, as revealed by normal marine $\mathrm{C} / \mathrm{N}$ ratios and $\delta \mathrm{C}^{13}$ values. A complete description of Oyster Pond is given by Emery (1969).

j. Lake Kivu (D-4 Cruise, February-March 1971 and March 1972)

Lake Kivu is situated at the highest point along the East African Rift Valley and is surrounded by active volcanos and geothermal springs. The lake measures $100 \mathrm{~km}$ in north-south and up to $40 \mathrm{~km}$ in east-west directions. The maximum water depth is $500 \mathrm{~m}$. Two cores were studied in the present investigation. On the basis of radiocarbon dates and estimated sedimentation rates, the base of the longest core, $930 \mathrm{~cm}$, was assigned an age of approximately 35,000 years .

In the deep basins $(350 \mathrm{~m})$ four distinct sedimentary units are defined. The upper unit, about $150 \mathrm{~cm}$ thick, is composed of alternating dark brown gel-like bands and white layers, about 50 layers per $\mathrm{cm}$. This 


\section{9}

varve-like pattern is enhanced due to the high water content of the sediment $(90-95 \%)$. The second unit is also finely laminated and contains up to 100 layers per $\mathrm{cm}$; however, the dark brown gel-like bands which are dominant in the top unit are missing. Ash layers occur frequently at the base of this unit. The third unit is characterized by reappearance of brown sapropelic layers at a depth of approximately 300 to $400 \mathrm{~cm}$ in deep basin cores. The basal unit of the longest core $(930 \mathrm{~cm})$ consists dominantly of microlaminations.

Diatoms are the principal fossils in all units. In the three lower units $(35,000$ to 6000 years B.P.), sedisents alternate between Stephanodiscus astrea dominance and Nitzschia fonticola dominance. In the upper -. unit, various uncommon species of Nitzschia are dominant.

The organic carbon pattern in Lake Kivu sediments reveals three major peaks at 15,000,5000, and zero years B.P. (Fig. I-1). Paleontological and geochemical evidence indicate that the lake level was high at these periods due to increased pluvial activity and an increased discharge of hydrothermal waters as a result of volcanic activity (for further details see Degens et al. , 1971, 1973; and Deuser et al. , 1973).

k. $\mathrm{C} / \mathrm{N}$ Ratios of Various Sediments

The $\mathrm{C} / \mathrm{N}$ ratios of the Black Sea, Cariaco Trench, Argentine Basin, Santa Barbara Basin and Lake Kivu sediments are plotted in Fig. I-l. Lake Kivu shows a systematic increase in $\mathrm{C} / \mathrm{N}$ ratios with time, while the other areas show constant ratios with time. Lake Kivu is in an area of active 
C/N RATIO

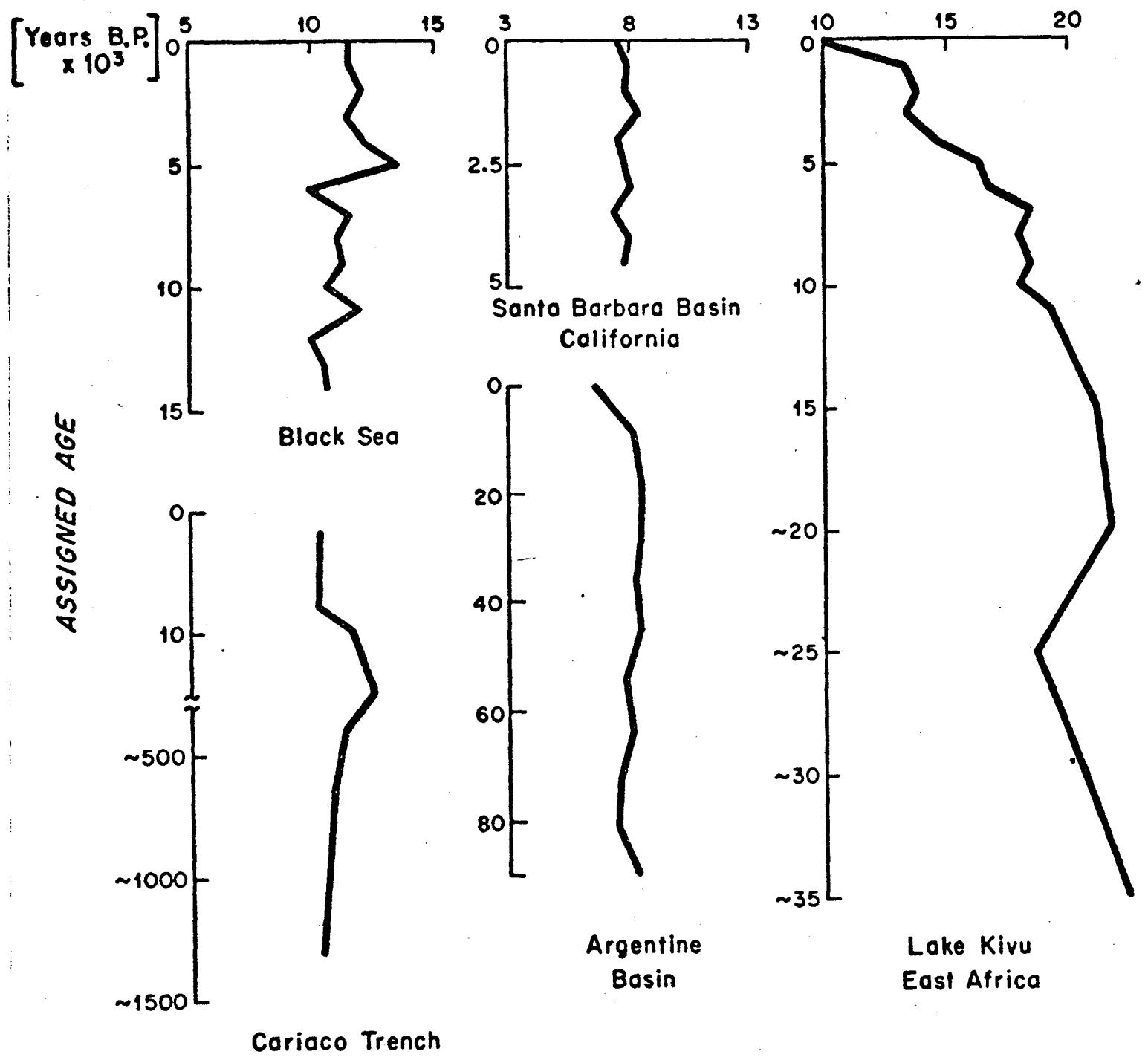

Figure I- 3

Carbon-nitrogen ratios $(\mathrm{C} / \mathrm{N})$ in cores from areas studied. Lake Kivu sediment exhibits a regular increase in the $\mathrm{C} / \mathrm{N}$ ratio. This increase is probably due to heat-induced deaminization reactions. 
volcanism and hydrothermal activity; emissions of volcanic gasses and hydrothermal waters from the lake floor have been observed. Therefore, nitrogen-containing compounds in the sediment probably undergo thermal decomposition. The ammonia produced is flushed from the sediment by percolating hydrothermal solutions (Degens et al. , 1973). 
APPENDIX II

BACKGROUND DATA 


\begin{tabular}{|c|c|c|c|c|c|c|c|c|c|}
\hline Sample & $\underset{(\%)}{\operatorname{Organic} C}$ & $\underset{(\%)}{\operatorname{Organic}} \mathrm{N}$ & $\underset{(\%)}{\operatorname{Organic}} H$ & $C / N$ & $\underset{(\%)}{\mathrm{CaCO}} 3$ & $\begin{array}{l}\mathrm{H}_{2} \mathrm{O} \\
(\%)\end{array}$ & $\begin{array}{c}\text { dry wt. } \\
\text { analyzed } \\
(g)\end{array}$ & $\begin{array}{l}1.8 \mathrm{~N} \\
\mathrm{HCl} \\
(\mathrm{mI}) \\
\end{array}$ & $\begin{array}{l}\text { EDTA } \\
(g)\end{array}$ \\
\hline$\frac{\text { Piankton: }}{\text { Cariaco }}$ & 43.9 & 7.3 & 6.2 & 6.0 & 2.1 & N.D. & .05 & 10 & 1 \\
\hline off Iceland & 54.4 & 6.0 & 7.7 & 9,1 & -- & N.D. & .05 & 10 & N.D \\
\hline Walvis Bay & N.D.* & N.D. & N.D. & N.D. & N.D. & N.D. & .05 & 10 & N.D. \\
\hline $\begin{array}{l}\text { Humboldt } \\
\text { Current } 1 \mathrm{a}\end{array}$ & 45.3 & 7.7 & 6.2 & 5.9 & 15.0 & N. D. & .05 & 10 & N.D. \\
\hline $7 a$ & 48.5 & 7.3 & 7.0 & 6.6 & 2.6 & N.D. & .05 & 10 & N.D. \\
\hline $15 a$ & 41.1 & 5.4 & 5.9 & 7.7 & 8.0 & N.D. & .05 & 10 & N.D. \\
\hline Lake Kivu & N.D. & N.D. & N.D. & N.D. & N.D. & N.D. & $\sim .005$ & 10 & N.D. \\
\hline off Bermuda & 50.0 & 5.9 & 7.0 & 8.4 & 1.0 & N.D. & .05 & 10 & N.D. \\
\hline Oyster Pond & 54.5 & 7.3 & 7.5 & 7.5 & 2.0 & 90 & .53 (wet) & 10 & 1 \\
\hline 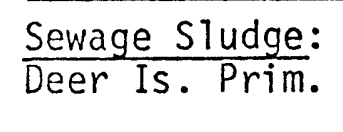 & 36.0 & 2.6 & 4.9 & 13.7 & -- & $\sim 99$ & .1 & 10 & 1 \\
\hline Deer Is. Sec. & 35.9 & 3.6 & 5.1 & 9.9 & - & $\sim 99$ & .1 & 10 & $i$ \\
\hline Cranston Prim. & 39.5 & 3.8 & 5.5 & 10.4 & - & $\sim 99$ & .1 & 10 & 1 \\
\hline Cranston Sec. & 30.3 & 3.7 & 4.2 & 8.2 & -- & $\sim 99$ & .1 & 10 & 1 \\
\hline cow manure & 42.8 & 2.3 & 5.4 & 18.4 & -- & $\sim 99$ & .5 & 10 & 2 \\
\hline
\end{tabular}




\section{Background Data (cont.)}

\begin{tabular}{|c|c|c|c|c|c|c|c|c|c|}
\hline Sample & $\underset{(\%)}{\text { Organic }} \mathrm{C}$ & $\underset{(\%)}{\text { Organic }} N$ & $\underset{(\%)}{\text { Organic }} H$ & $\mathrm{C} / \mathrm{N}$ & $\underset{(\%)}{\mathrm{CaCO}} 3$ & ${ }^{\mathrm{H}_{2}} \mathrm{O}(\%)$ & $\begin{array}{l}\text { dry wt. } \\
\text { analyzed } \\
\text { (g) }\end{array}$ & $\begin{array}{l}1.8 \mathrm{~N} \\
\mathrm{HCl} \\
(\mathrm{mI})\end{array}$ & $\begin{array}{l}\text { EDTA } \\
(\mathrm{g})\end{array}$ \\
\hline$\frac{\text { N.Y. Bight: }}{\text { Buoy St. }}$ & 2.5 & .22 & .37 & 11.5 & .59 & 55 & .2 & 10 & 1 \\
\hline Mid Gully & 1.3 & .15 & .27 & 8. & 1.0 & 43 & .4 & 10 & N.D. \\
\hline Deep Gully & 1.0 & .13 & .22 & 7.9 & .60 & 45 & .4 & 10 & 1 \\
\hline \multicolumn{10}{|l|}{$\begin{array}{l}\text { Argentine } \\
\text { Basin }(\mathrm{cm}):\end{array}$} \\
\hline 0 & .48 & .070 & N.D. & 6.9 & -- & 44 & 2 & 10 & 1 \\
\hline 5 & .23 & .063 & .09 & 2.7 & -. & 42 & 2 & 10 & 1 \\
\hline 15 & .60 & .062 & .09 & 7.3 & -- & 44 & 2 & 10 & 1 \\
\hline $20-50$ & .64 & .063 & .08 & 8.0 & -- & 46 & $.5-2$ & 10 & 1 \\
\hline 60 & .58 & .075 & N.D. & 7.7 & -- & 45 & 2 & 10 & 1 \\
\hline 100 & .61 & .073 & N.D. & 8.3 & -- & 45 & 2 & 10 & 1 \\
\hline 300 & .52 & .062 & N.D. & 8.5 & -- & 42 & 2 & 10 & 1 \\
\hline 500 & .48 & .044 & N.D. & 10.9 & -- & 45 & 2 & 10 & $!$ \\
\hline $\begin{array}{l}\frac{\text { Black Sea }}{(\mathrm{cm}):} \\
15\end{array}$ & 3.9 & .34 & .72 & 11.5 & 61.0 & 44 & .4 & 10 & 1.5 \\
\hline $65-70$ & 20.0 & 1.5 & 3.3 & 13.3 & 6.0 & 45 & $.2-.4$ & 10 & 1 \\
\hline $120-130$ & 1.2 & .13 & .57 & 9.2 & 26.3 & 46 & 1 & 10 & $1-2$ \\
\hline
\end{tabular}


Background Data (Cont.)

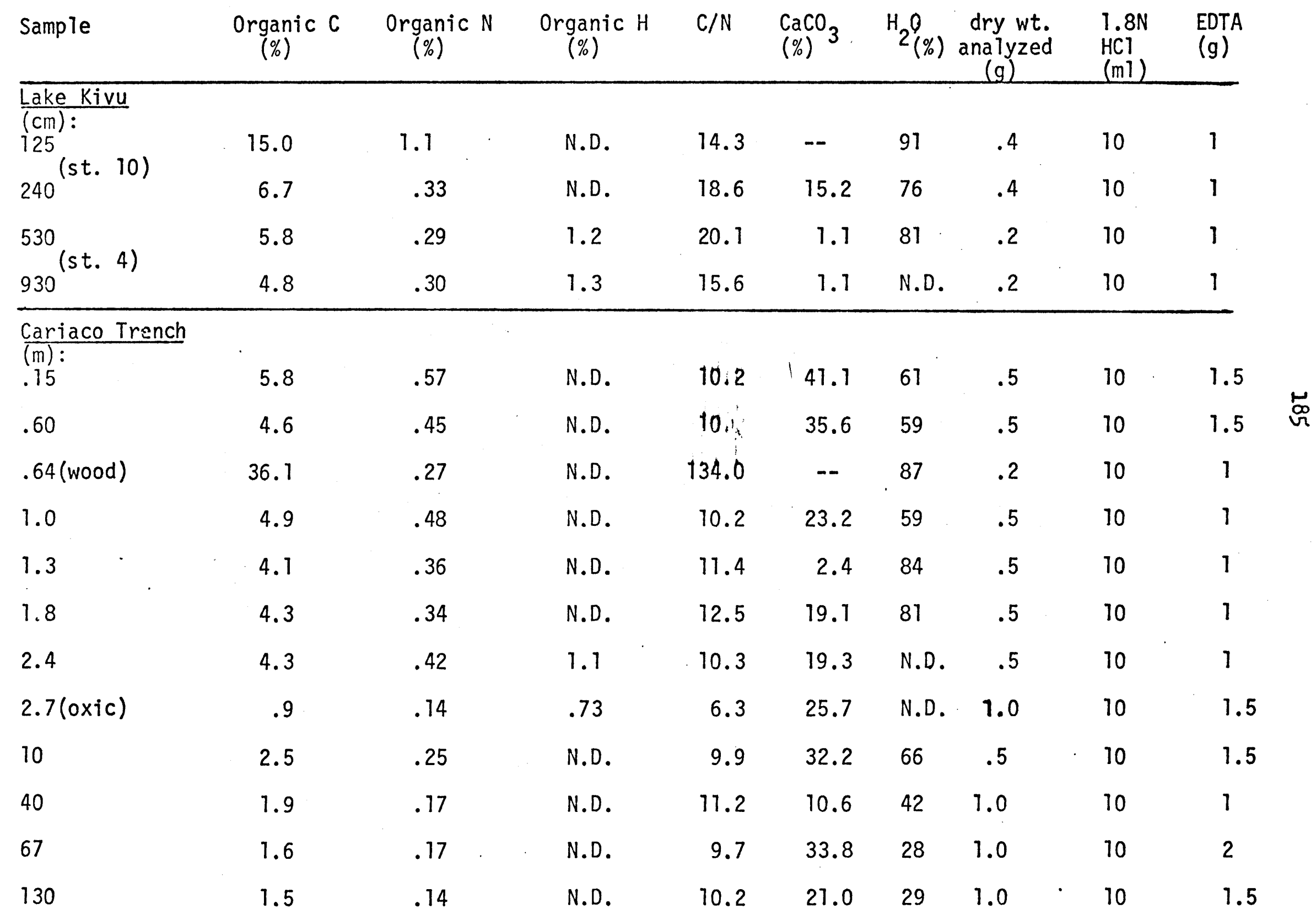


Background Data (cont.)

\begin{tabular}{|c|c|c|c|c|c|c|c|c|c|}
\hline Sample & $\underset{(\%)}{\text { Organic C }}$ & $\underset{(\%)}{\operatorname{Organic}} \mathrm{N}$ & $\underset{(\%)}{\text { Organic }} \mathrm{H}$ & $\mathrm{C} / \mathrm{N}$ & $\begin{array}{l}\mathrm{CaCO}_{3} \\
(\%)\end{array}$ & $\mathrm{H}_{2} \mathrm{O}_{(\%)}$ & $\begin{array}{l}\text { dry wt. } \\
\text { analyzed } \\
\text { (a) }\end{array}$ & $\begin{array}{l}1.8 \mathrm{~N} \\
\mathrm{HCl} \\
\text { (m1) }\end{array}$ & $\begin{array}{c}\text { EDTA } \\
(g)\end{array}$ \\
\hline Walvis Bay & 5.9 & .81 & N.D. & 7.3 & .82 & 79 & .5 & 10 & 7 \\
\hline Bermuda & .57 & .05 & N.D. & 11.1 & 24.9 & 41 & 2 & 10 & N.D. \\
\hline Oyster Pond & 9.4 & 1.0 & N.D. & 9.4 & 1.4 & N.D. & .2 & 10 & 1 \\
\hline $\begin{array}{l}\text { Santa Barbara } \\
(\sim 50 \text { years })\end{array}$ & 11.6 & N.D. & N.D. & N.D. & 170.0 & N.D. & 1 & 10 & 1 \\
\hline$(\sim 750$ years $)$ & 12.3 & N.D. & N.D. & N.D. & 13.8 & N.D. & 1 & 10 & N.D. \\
\hline
\end{tabular}

Peat:

Georges Bank

46.8

1.1

4.6

43.0

-- N.D.

.110

N.D. 
APPENDIX III

DATA FILE OF CARBOHYDRATE ANALYSES 
TABLE III-1

TOTAL PERCENTAGES OF SUGARS EXTRACTABLE BY EDTA - TREATMENT

OF SEDIMENTS AND ORGANIC WASTE PRODUCTS

Sugar:

$\mathrm{Rh}$

Fu

Ri

$\begin{array}{llll}\text { A } & \mathrm{X} & \mathrm{M} & \mathrm{Ga}\end{array}$

G1

Total

Cariaco Trench

$<10 \mathrm{~m}$

(6) $\begin{array}{lrllllllll}\mathrm{a}^{*} & 9 & 25 & 93_{* * *} & 30 & 19 & 2 & 10 & 3 & 14 \\ \mathrm{~b} & 34 & 34 & --7 & 21 & 23 & 20 & 28 & 28 & 28 \\ \mathrm{c} & 57 & 41 & 7 & 49 & 58 & 78 & 62 & 69 & 58\end{array}$.

Cariaco Trench

$>10 \mathrm{~m}$

\begin{tabular}{|c|c|c|c|c|c|c|c|c|c|}
\hline \multirow{3}{*}{ (3) } & 12 & 25 & 49 & 19 & 20 & 5 & 10 & 5 & 12 \\
\hline & 48 & 34 & -- & 19 & 25 & 24 & 29 & 30 & 28 \\
\hline & 40 & 41 & 51 & 62 & 55 & 71 & 61 & 64 & 60 \\
\hline
\end{tabular}

Plankton above

Cariaco Trench

\begin{tabular}{|c|c|c|c|c|c|c|c|c|c|c|}
\hline & a & 15 & 54 & 93 & 97 & 31 & 4 & 7 & 13 & 20 \\
\hline 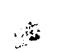 & $b$ & 31 & 19 & - & 9 & 21 & 27 & 20 & 37 & 21 \\
\hline & c & 54 & 27 & 7 & - & 48 & 69 & 73 & 50 & 59 \\
\hline
\end{tabular}

Black Sea

(Marine) $15 \mathrm{~cm}$

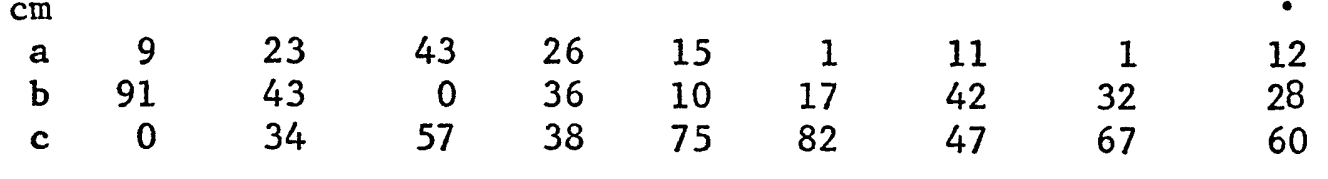

Black Sea (Transition)

$65 \mathrm{~cm}$

$\begin{array}{rlllllrlrl}\text { a } & 20 & 30 & 79 & 22 & 31 & 3 & 18 & 2 & 20 \\ \text { b } & 50 & 35 & -- & 20 & 30 & 45 & 29 & 48 & 35 \\ \text { c } & 30 & 35 & 21 & 58 & 39 & 52 & 53 & 50 & 45\end{array}$

Black Sea (Fresh)

$125 \mathrm{~cm}$

$\begin{array}{rrrrrrrrrr}\text { a } & 13 & 25 & 76 & 32 & 15 & 3 & 11 & 3 & 14 \\ \text { b } & 71 & 103 & 89 & 41 & 61 & 56 & 44 & 45 & 54 \\ \text { c } & 16 & --- & -- & 27 & 24 & 41 & 45 & 52 & 32\end{array}$

Walvis Bay, Sediment

Surface

$\begin{array}{rrrrrrrrrr}\text { a } & 8 & 15 & 74 & 22 & 19 & 5 & 8 & 1 & 11 \\ \text { b } & 33 & 18 & -- & 12 & 28 & 48 & 27 & 29 & 28 \\ \text { c } & 59 & 67 & 26 & 66 & 53 & 47 & 65 & 70 & 61\end{array}$

Lake Kivu,

$130 \mathrm{~cm}$

\begin{tabular}{|c|c|c|c|c|c|c|c|c|}
\hline 19 & 38 & 53 & 51 & 32 & 2 & 23 & 1 & 14 \\
\hline 52 & 31 & -- & 26 & 36 & 48 & 16 & 20 & 23 \\
\hline 29 & 31 & 47 & 23 & 31 & 50 & 61 & 79 & 63 \\
\hline
\end{tabular}

Argentine Basin

\begin{tabular}{|c|c|c|c|c|c|c|c|c|c|}
\hline $5 \mathrm{~m}$ (2) & $\begin{array}{l}\mathrm{a} \\
\mathrm{b} \\
\mathrm{c}\end{array}$ & $\begin{array}{l}30 \\
52 \\
19\end{array}$ & $\begin{array}{l}43 \\
37 \\
20\end{array}$ & $\begin{array}{r}94 \\
-6\end{array}$ & $\begin{array}{l}39 \\
14 \\
47\end{array}$ & $\begin{array}{l}38 \\
30 \\
32\end{array}$ & $\begin{array}{r}9 \\
44 \\
47\end{array}$ & $\begin{array}{l}20 \\
50 \\
30\end{array}$ & $\begin{array}{l}13 \\
39 \\
48\end{array}$ \\
\hline
\end{tabular}




\section{9}

TABLE III-1 continued

TOTAL PERCENTAGES OF SUGARS EXTRACTABLE BY EDTA - TREATMENT

OF SEDIMENTS AND ORGANIC WASTE PRODUCTS

Sugar:

$\mathrm{Rh}$

$\mathrm{Fu}$

$\mathrm{Ri} \quad \mathrm{A}$

A $\quad \mathrm{X} \quad \mathrm{M}$

$\mathrm{Ga}$

G1

Total

Oyster Pond, Sediment

Surface

\begin{tabular}{|c|c|c|c|c|c|c|c|c|}
\hline 10 & 24 & 63 & 34 & 15 & 2 & 8 & 2 & 11 \\
\hline 44 & 43 & 37 & 31 & 34 & 29 & 39 & 24 & 33 \\
\hline 46 & 33 & 0 & 35 & 51 & 69 & 53 & 74 & 56 \\
\hline
\end{tabular}

Oyster Pond,

Plankton

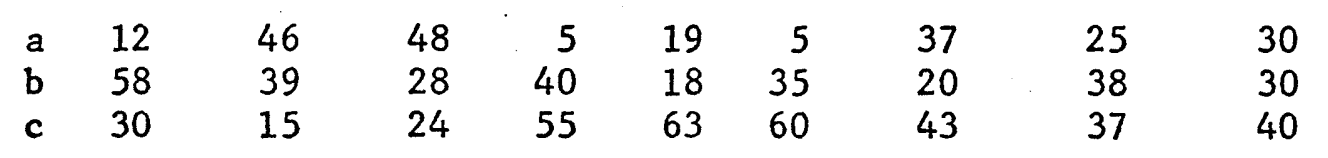

N.Y. Bight, Sediment

Surface

$\begin{array}{rlrlrrrrrr}\text { a } & 16 & 39 & 123 & 54 & 36 & 5 & 18 & 5 & 22 \\ \text { b } & 60 & 48 & --- & 27 & 27 & 49 & 50 & 44 & 43 \\ \text { c } & 24 & 13 & --- & 19 & 37 & 46 & 32 & 51 & 35\end{array}$

Wood in Cariaco Trench

Sediment, $.64 \mathrm{~m}$

$\begin{array}{lrrrrrrrrr}\mathrm{a} & 16 & 63 & 0 & 88 & 23 & 5 & 19 & 1 & 15 \\ \mathrm{~b} & 26 & 7 & 100 & -- & -- & 6 & 9 & 0 & 1 \\ \mathrm{c} & 58 & 30 & 0 & 12 & 77 & 89 & 72 & 99 & 84\end{array}$

$\begin{array}{rrrrrrrrrrr}\text { Cow Manure } & \text { a } & 5 & 33 & --- & 44 & 2 & 3 & 9 & 1 & 8 \\ & \text { b } & 53 & -- & -- & 25 & 26 & 11 & 57 & 27 & 28 \\ & \text { c } & 42 & 67 & --- & 31 & 72 & 86 & 34 & 72 & 64\end{array}$

Deer Island Sewage

Sludge Primary

$\begin{array}{rrrrrrrrrr}\mathrm{a} & 19 & 52 & 120 & 102 & 8 & 2 & 13 & 1 & 6 \\ \mathrm{~b}^{* *} & 54 & 27 & --- & --- & 17 & 17 & 56 & 4 & 11 \\ \mathrm{c}^{* *} & 27 & 21 & --- & -- & 75 & 81 & 31 & 95 & 83\end{array}$

Deer Island Sewage

Sludge Digested

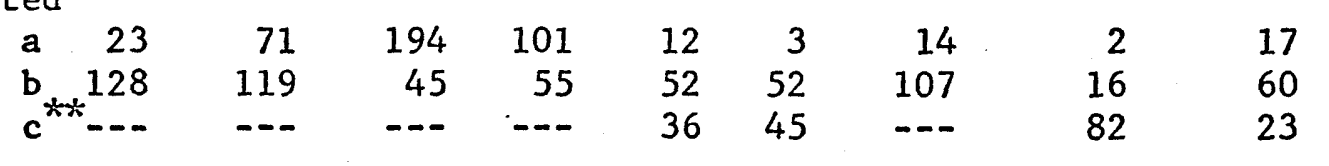

Cranston Sewage Sludge

Primary (1972)

$\begin{array}{rrrrrrrrrr}\text { a } & 6 & 19 & 45 & 61 & 2 & 1 & 4 & 2 & 6 \\ \text { b } & 70 & 51 & 36 & 22 & 6 & 22 & 67 & 46 & 41 \\ \text { c } & 24 & 30 & 19 & 17 & 92 & 77 & 29 & 52 & 53\end{array}$


TABLE III-1 continued

TOTAL PERCENTAGES OF SUGARS EXTRACTABLE BY EDTA - TREATMENT

OF SEDTMENTS AND ORGANIC WASTE PRODUCTS

Sugar:

$\mathrm{Rh}$

Ri

A $\quad x$

$\mathrm{X}$

M

$\mathrm{Ga}$

GI Tota1

Cranston Sewage Sludge

Digested (1972)

$\begin{array}{rrrrrrrrrr}\text { a } & 7 & 37 & 93 & 60 & 2 & 2 & 7 & 1 & 11 \\ \text { b } & 76 & 56 & -- & 36 & 11 & 28 & 76 & 58 & 45 \\ \text { c } & 17 & 7 & 7 & 4 & 87 & 70 & 17 & 41 & 44\end{array}$,

Cranston Sewage Sludge

Digested (1971)

$\begin{array}{rrrrrrrrrr}\text { a } & 11 & 22 & 150 & 45 & 4 & 1 & 5 & 1 & 8 \\ \text { b } & 97 & 87 & 0 & 67 & 40 & 52 & 65 & 53 & 60 \\ \text { c } & -- & -- & --- & -- & 56 & 47 & 30 & 46 & 32\end{array}$

\footnotetext{
${ }^{*} \mathbf{a}=($ EDTA $/ \operatorname{tota} 1) \times 100 \%=$ EDTA extracted monomers as $\%$ of total.

$\mathbf{b}=($ EDTA $+\mathrm{HC} 1) /$ total $\times 100 \%-\mathbf{a}=$ EDTA extracted polymers as $\%$ of total.

$c=100 \%-(a+b)=$ EDTA-nonextracted residue as $\%$ of total.

** $=$ treated with cold conc. $\mathrm{H}_{2} \mathrm{SO}_{4}$ followed by dilution to $1.3 \mathrm{M}$ for futher hydrolysis.

*** -.- = Concentration is less than other extracts.

( $\quad$ ) No. of samples represented.
} 
191

TABLE III-2

CARBOHYDRATE COMPOSITION OF PLANKTON

(MOLE \%)

\begin{tabular}{|c|c|c|c|c|c|c|c|c|c|}
\hline Sugar: & $\mathrm{Rh}$ & $\mathrm{Fu}$ & Ri & A & $\mathrm{x}$ & $\mathbf{M}$ & $\mathrm{Ga}$ & GI & $\begin{array}{c}\text { Total } \\
(\mu \text { moles } / g)\end{array}$ \\
\hline \multicolumn{10}{|c|}{ Cariaco Trench } \\
\hline $\begin{array}{l}\mathrm{HCl} \\
\text { EDTA + HC1 } \\
\text { EDTA }\end{array}$ & $\begin{array}{l}7.4 \\
8.3 \\
5.7\end{array}$ & $\begin{array}{r}7.8 \\
13.9 \\
21.6\end{array}$ & $\begin{array}{r}4.9 \\
6.8 \\
23.3\end{array}$ & $\begin{array}{r}2.1 \\
5.6 \\
10.6\end{array}$ & $\begin{array}{l}5.7 \\
7.3 \\
9.2\end{array}$ & $\begin{array}{r}15.0 \\
11.3 \\
3.4\end{array}$ & $\begin{array}{l}39.7 \\
25.8 \\
14.5\end{array}$ & $\begin{array}{l}17.3 \\
21.1 \\
11.7\end{array}$ & $\begin{array}{r}144.9 \\
59.2 \\
28.3\end{array}$ \\
\hline \multicolumn{10}{|l|}{ Off Iceland } \\
\hline $\mathrm{HCl}$ & 2.7 & 6.2 & 37.4 & 2.5 & 3.2 & 16.0 & 16.8 & 15.3 & 13.1 \\
\hline Walvis Bay & & & & - & & & & & \\
\hline $\mathrm{HCl}$ & 3.0 & 4.2 & 2.8 & .5 & 4.3 & 7.5 & 12.2 & $65.6^{*}$ & 217.9 \\
\hline \multicolumn{10}{|c|}{ Pacific Humboldt Current } \\
\hline $\begin{array}{l}\text { 1a } \mathrm{HCl} \\
7 \mathrm{a} \mathrm{HCl} \\
15 a \mathrm{HCl}\end{array}$ & $\begin{array}{l}4.0 \\
5.1 \\
5.9\end{array}$ & $\begin{array}{l}3.0 \\
7.1 \\
9.7\end{array}$ & $\begin{array}{r}14.8 \\
7.1 \\
5.6\end{array}$ & $\begin{array}{l}3.0 \\
6.0 \\
2.9\end{array}$ & $\begin{array}{r}3.7 \\
19.4 \\
9.0\end{array}$ & $\begin{array}{l}13.1 \\
13.2 \\
16.0\end{array}$ & $\begin{array}{l}18.0 \\
22.5 \\
35.9\end{array}$ & $\begin{array}{l}40.5 \\
19.4 \\
14.9\end{array}$ & $\begin{array}{l}40.5 \\
44.8 \\
44.3\end{array}$ \\
\hline
\end{tabular}

Lake Kivu

\begin{tabular}{llllllllll}
$\mathrm{HC1}$ & 7.1 & 5.4 & - & 5.7 & 9.1 & 15.6 & 14.6 & 42.5 & 269.7 \\
\hline Off Bermuda, 32N, & $64 \mathrm{~W}$ & & & & & & & & \\
\hline $\mathrm{HC1}$ & 4.6 & 6.4 & 5.6 & 1.1 & 5.5 & 11.9 & 37.3 & 27.6 & 86.9 \\
\hline
\end{tabular}

Oyster Pond, Woods Hole

$\begin{array}{lcccccccrr}\text { HC1 } & 5.4 & 6.3 & 22.1 & .8 & 6.0 & 18.0 & 23.8 & 17.7 & 113.2 \\ \text { EDTA, HCl } & 6.3 & 8.8 & 28.0 & .6 & 3.7 & 11.9 & 22.4 & 18.3 & 68.2 \\ \text { EDTA } & 2.2 & 9.9 & 35.9 & .1 & 3.9 & 3.3 & 29.9 & 14.7 & 33.4 \\ \mathrm{H}_{2} \mathrm{O} & - & - & 25.9 & - & 9.3 & 5.7 & - & 59.3 & 5.4\end{array}$

* Cellulose fiber contamination present. 
TABLE III-3

\section{CARBOHYDRATE COMPOSITION OF PLANKTON}

(ymoles/g)

\begin{tabular}{|c|c|c|c|c|c|c|c|c|c|}
\hline Sugar: & $\mathrm{Rh}$ & $\mathrm{Fu}$ & $\mathrm{Ri}$ & A & $\mathrm{x}$ & $M$ & $\mathrm{Ga}$ & GI & Tota 1 \\
\hline \multicolumn{10}{|c|}{ Cariaco Trench } \\
\hline $\begin{array}{l}\mathrm{HCl} \\
\text { EDTA + HC1 } \\
\text { EDTA }\end{array}$ & $\begin{array}{r}10.7 \\
4.9 \\
1.6\end{array}$ & $\begin{array}{r}11.3 \\
8.2 \\
6.1\end{array}$ & $\begin{array}{l}7.1 \\
4.0 \\
6.6\end{array}$ & $\begin{array}{l}3.1 \\
3.3 \\
3.0\end{array}$ & $\begin{array}{l}8.3 \\
4.3 \\
2.6\end{array}$ & $\begin{array}{r}21.8 \\
6.7 \\
1.0\end{array}$ & $\begin{array}{r}57.5 \\
15.3 \\
4.1\end{array}$ & $\begin{array}{r}25.1 \\
12.5 \\
3.3\end{array}$ & $\begin{array}{r}144.9 \\
59.2 \\
28.3\end{array}$ \\
\hline
\end{tabular}

Off Iceland

$\begin{array}{llllllllll}\mathrm{HCl} & .4 & .8 & 4.9 & .33 & .42 & 2.1 & 2.2 & 2.0 & 13.1\end{array}$

Walvis Bay

$\begin{array}{llllllllll}\text { HC1 } & 6.5 & 9.1 & 6.0 & 1.1 & 9.3 & 16.3 & 26.6 & 143.0^{*} & 217.9\end{array}$

Pacific, Humboldt Current

$\begin{array}{lrrrrrrrrr}1 \text { a HCl } & 1.6 & 1.2 & 5.0 & 1.2 & 1.5 & 5.3 & 7.3 & 16.4 & 40.5 \\ \text { 7a HC1 } & 2.3 & 3.2 & 3.2 & 2.7 & 8.7 & 5.9 & 10.1 & 8.7 & 44.8 \\ 1 \text { a a HCl } & 2.6 & 4.3 & 2.5 & 1.3 & 4.0 & 7.1 & 15.9 & 6.6 & 44.3\end{array}$

Lake Kivu

\begin{tabular}{lllllllllll} 
HC1 & 19.1 & 14.5 & $\operatorname{Tr}$ & 15.3 & 24.6 & 42.2 & 39.3 & 114.7 & 269.7 \\
\hline
\end{tabular}

Off Bermuda, $32 \mathrm{~N}, 64 \mathrm{~W}$

\begin{tabular}{lllllllllll}
$\mathrm{HCl}$ & 4.0 & 5.6 & 4.9 & .9 & 4.8 & 10.3 & 32.4 & 24.0 & 86.9 \\
\hline
\end{tabular}

Oyster Pond, Woods Hole

$\begin{array}{lccccccccc}\mathrm{HCl} & 6.1 & 7.1 & 25.0 & .9 & 6.8 & 20.4 & 26.9 & 20.0 & 113.2 \\ \text { EDTA + HC1 } & 4.3 & 6.0 & 19.1 & .4 & 2.5 & 8.1 & 15.3 & 12.5 & 68.2 \\ \text { EDTA } & .73 & 3.3 & 12.0 & .04 & 1.3 & 1.1 & 10.0 & 4.9 & 33.4 \\ \mathrm{H}_{2} \mathrm{O} \text { xt. } & \operatorname{Tr} & \operatorname{Tr} & 1.4 & \operatorname{Tr} & .5 & .3 & \operatorname{Tr} & 3.2 & 5.4\end{array}$

* Cellulose fiber contamination present 
TABLE III-4

CARBOHYDRATE COMPOSITION OF ORGANIC WASTE MATERIALS

(MOLE \%)

Tota1

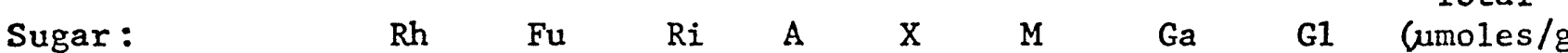

$\begin{array}{llllllllll}\text { Cranston, R.I. } & 7.3 & 2.5 & 1.7 & 4.7 & 10.3 & 17.0 & 11.5 & 45.0 & 271.1\end{array}$

Sewage Sludge

Primary (1972)

HCI

$\begin{array}{llllllllll}\mathrm{EDTA}+\mathrm{HCl} & 11.7 & 3.7 & 3.0 & 8.3 & 1.8 & 8.2 & 17.5 & 45.9 & 127.1\end{array}$

$\begin{array}{llllllllll}\text { EDTA } & 7.1 & 7.7 & 12.5 & 45.8 & 2.8 & 2.6 & 6.5 & 14.9 & 16.8\end{array}$

\begin{tabular}{llllllllll}
\hline Cranston, R.I. & 12.1 & 3.2 & 2.4 & 7.2 & 14.0 & 24.3 & 14.5 & 22.2 & 187.1
\end{tabular}

Sewage Sludge

Digested (1972)

HC1



\begin{tabular}{llllllllll} 
EDTA & 8.5 & 11.0 & 20.6 & 40.7 & 2.7 & 4.5 & 9.5 & 2.2 & 19.9 \\
\hline Cranston, R.I. & 11.2 & 2.9 & .7 & 6.6 & 11.6 & 24.4 & 18.6 & 24.0 & 258.0
\end{tabular}

Sewage Sludge

Digested (1971)

HCI



\begin{tabular}{lrrrrrrrrr} 
EDTA & 16.2 & 8.6 & 13.6 & 38.4 & 5.4 & 3.4 & 11.1 & 3.4 & 19.8 \\
\hline Deer Island, MA. & 3.1 & 1.0 & .4 & 6.9 & 26.5 & 25.3 & 13.6 & 23.3 & 276.7
\end{tabular}

Sewage Sludge

Primary, $\mathrm{HCl}$

\begin{tabular}{lcrrrrrrrr} 
Conc. $\mathrm{H}_{2} \mathrm{SO}_{4}$ & - & - & - & .7 & 7.7 & 8.6 & .8 & 82.2 & 695.8 \\
$\mathrm{EDTA}+\mathrm{HCl}$ & 5.3 & 2.0 & 1.1 & 16.3 & 15.4 & 11.3 & 22.3 & 26.5 & 117.3 \\
$\mathrm{EDTA}$ & 4.0 & 3.8 & 3.0 & 48.3 & 15.5 & 3.3 & 12.3 & 10.0 & 40.0 \\
$\mathrm{H}_{2} \mathrm{O}$ & - & - & 6.6 & 6.6 & - & - & - & 87.3 & 1.0 \\
\hline $\begin{array}{l}\text { Deer Island, MA. } \\
\text { Sewage Sludge } \\
\text { Digested, HCl }\end{array}$ & 5.1 & 1.4 & .4 & 9.1 & 21.7 & 20.3 & 15.9 & 26.1 & 152.7 \\
\hline Conc. $\mathrm{H}_{2} \mathrm{SO}_{4}$ & 3.2 & .5 & -3.3 & 4.8 & 11.9 & 6.0 & 70.2 & 167.7
\end{tabular}


294

TABLE III -4 continued

CARBOHYDRATE COMPOSITION OF ORGANIC WASTE MATERIALS

\begin{tabular}{lccccccccc} 
& \multicolumn{9}{c}{ (MOLE \%) } \\
Sugar: & $\mathrm{Rh}$ & $\mathrm{Fu}$ & $\mathrm{Ri}$ & $\mathrm{A}$ & $\mathrm{X}$ & $\mathrm{M}$ & $\mathrm{Ga}$ & $\mathrm{G1}$ & $\begin{array}{c}\text { Total } \\
(\mu \mathrm{moles} / \mathrm{g})\end{array}$ \\
\hline $\mathrm{EDTA}+\mathrm{HCl}$ & 9.2 & 3.1 & 1.2 & 16.9 & 16.6 & 13.2 & 22.9 & 16.9 & 128.5 \\
EDT & 6.1 & 5.1 & 4.3 & 48.3 & 13.4 & 3.0 & 11.3 & 8.2 & 29.2 \\
$\mathrm{H}_{2} \mathrm{O}$ & - & - & 25.5 & 52.9 & - & 21.6 & - & - & .5
\end{tabular}


TABLE III-4 continued

CARBOHYDRATE COMPOSITION OF ORGANIC WASTE MATERIALS

(MOLE PERCENT)

\begin{tabular}{|c|c|c|c|c|c|c|c|c|c|}
\hline Sugar & $\mathrm{Rh}$ & $\mathrm{Fu}$ & $\mathrm{Ri}$ & A & $x$ & M & Ga & G1 & $\begin{array}{r}\text { Total } \\
\text { (umoles/g }\end{array}$ \\
\hline $\begin{array}{l}\text { N. Y. Bight } \\
\text { Buoy Sta. } \\
\text { HCl }\end{array}$ & 9.1 & 8.1 & 1.6 & 8.6 & 12.9 & 15.1 & 21.5 & 23.1 & 18.6 \\
\hline EDTA + $\mathrm{HCl}$ & 10.8 & 10.8 & 2.5 & 10.8 & 12.5 & 12.5 & 22.5 & 17.5 & 12.0 \\
\hline $\begin{array}{l}\text { EUTA } \\
\text { N. Y. Bight }\end{array}$ & -6.7 & $-\frac{14.4}{8.3}$ & $\frac{9.2}{4.1}$ & $\begin{array}{l}21.5 \\
-7.3\end{array}$ & $\frac{21.5}{10.3}$ & $\begin{array}{r}-3.5 \\
16.7\end{array}$ & $\frac{17.8}{22.7}$ & $\frac{5.4}{27.2}$ & $-\frac{4.04}{6.6}$ \\
\hline
\end{tabular}

Mid-Gulty HCl

N. Y. Bight, Deep

Gully HiC

10.0

EDTA + $\mathrm{HCl}$

$12.4 \quad 12.9$

8.0

2.5

7.3

$\begin{array}{lll}7.3 & 10.8 & 15.1\end{array}$

6.1

$\begin{array}{lll}8.3 & 12.2 \quad 10.4\end{array}$

$23.7 \quad 22.6$

9.3

(1)

Cow Manure:

$\mathrm{HCl}$

$E D T A+H C]$

2.7

.4

$-\quad 13.6 \quad 61.0$

2.3

$22.6 \quad 15.1$.

5.9

EDTA

4.4

.3

$-$

$25.7 \quad 47.6$

.9

$10.0 \quad 11.1$

499.5

$\mathrm{H}_{2} \mathrm{O}$

$1.8 \quad 1.8$

$-\quad 75.0 \quad 12.8 \quad .8$

$\begin{array}{ll}6.1 & 1.6\end{array}$

110.1

$\begin{array}{lll}16.5 & 13.5 \quad 70.0\end{array}$


TABLE III-5

CARBOHYDRATE COMPOSITION OF ORGANIC WASTE MATERIALS

(umoles/g).

Sugar

$\mathrm{Rh}$

$\mathrm{Fu}$

Ri A

$\mathrm{X} \quad \mathrm{M}$

Cranston, R.I.

$19.7 \quad 6.7$

4.

Sewage Sludge

Primary (1972)

$\mathrm{HCl}$.

EDTA + HCl

$14.9 \quad 4.7$

3.810 .

$2.3 \quad 10.4$

22.2

$58.3 \quad 127.1$

EDTA

1.

Cranston, R.I.

Sewage Sludge

Digested (1972)

$\mathrm{HCl}$

$\mathrm{EDTA}+\mathrm{HCl}$

18.95.

$2.7 \quad 12.9$

$\begin{array}{rr}3.3 & 13.7\end{array}$

22.5

$24.4 \quad 104.0$

EDTA

1.72.

Cranston, R.I.

Sewage Sludge

Digested (1971)

HC1

$\mathrm{EDTA}+\mathrm{HCl}$

31.1

8.3

2.

4.18 .1

$.5 \quad .9$

$9 \quad 1.9$

$1.9 \quad .4 \quad 19.9$

$\begin{array}{lllllllll}28.8 & 7.6 & 1.8 & 17.0 & 29.8 & 62.9 & 48.1 & 62.0 & 258.0\end{array}$

EDTA

3.21

Deer Island, MA.

Sewage Sludge

8.52 .9

Primary

HC1

Conc. $\mathrm{H}_{2} \mathrm{SO}_{4}$

$\operatorname{Tr} \operatorname{Tr}$

$\begin{array}{llll}\operatorname{Tr} & 5.0 & 53.3 \quad 60.0\end{array}$

$5.8 \quad 571.7$

695.8

$\mathrm{EDTA}+\mathrm{HCl}$

$6.2 \quad 2.3$

1.319 .1

18.1

13.2

26.1

31.1

117.3

EDTA

1.61.

$\mathrm{H}_{2} \mathrm{O}$

$\operatorname{Tr}$

$1.2 \quad 19.3$

6.21 .3

4.9

$4.0 \quad 40.0$

$\operatorname{Tr} \quad \operatorname{Tr}$

$.07 .07 \operatorname{Tr}$

$\operatorname{Tr}$

$\operatorname{Tr}$

$\operatorname{Tr}$

1.0 
TABLE III-5 continued

CARBOHYDRATE COMPOSITION OF ORGANIC WASTE MATERIALS

(u moles/g)

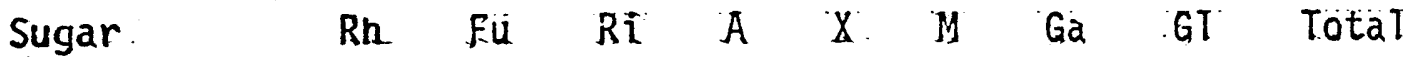

$\begin{array}{llllllllll}\text { Deer Istand, } & 7.8 & 2.1 & .67 & 13.9 & 33.1 & 31.0 & 24.3 & 39.8 & 152.7\end{array}$

MA. Sewage

Sludge

Digested

$\mathrm{HCl}$

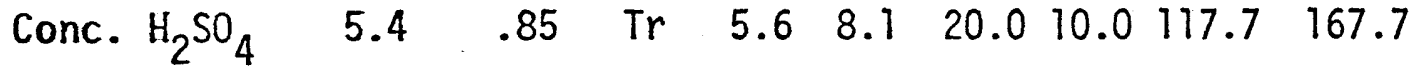

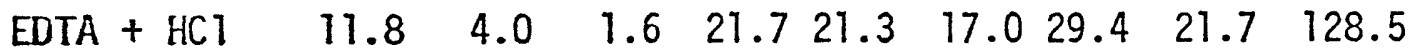

$\begin{array}{llllllllll}\text { EDTA } & 1.8 & 1.5 & 1.3 & 14.1 & 3.9 & .89 & 3.3 & 2.4 & 29.2\end{array}$

$\begin{array}{llllllllll}\mathrm{H}_{2}{ }^{0} & \text { Tr } & \text { Tr } & .13 & .27 & \text { Tr } & .11 & \text { Tr } & \text { Tr } & .51\end{array}$

$\begin{array}{llllllllll}\text { N. Y. Bight } & 1.7 & 1.5 & .30 & 1.6 & 2.4 & 2.8 & 4.0 & 4.3 & 18.6\end{array}$

Byoy Sta.

$\mathrm{HCl}$

$\begin{array}{llllllllll}\mathrm{EDTA}+\mathrm{HCl} & 1.3 & 1.3 & .30 & 1.3 & 1.5 & 1.5 & 2.7 & 2.1 & 12.0\end{array}$

$\begin{array}{llllllllll}\text { EDTA } & .27 & .58 & .37 & .87 & .87 & .14 & .72 & .22 & 4.04\end{array}$

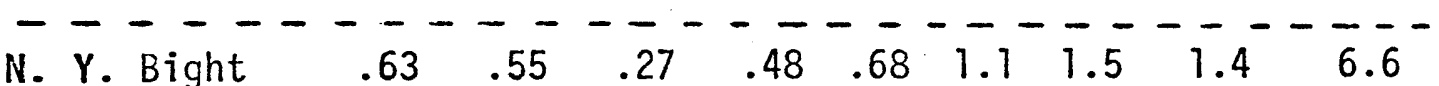

Mid-Gully

$\mathrm{HCl}$

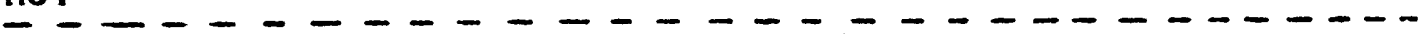

$\begin{array}{llllllllll}\text { N. Y. Bight } & .93 & .74 & .23 & .68 & 1.0 & 1.4 & 2.2 & 2.1 & 9.3\end{array}$

Deep Gully

$\mathrm{HCl}$

$\begin{array}{llllllllll}\mathrm{EDTA}+\mathrm{HCl} & .73 & .76 & .36 & .49 & .72 & .61 & 1.33 & .89 & 5.9\end{array}$

Cont...... 
TABLE III-5 (Cont.)

\begin{tabular}{lccccccccr} 
Sugar & $\mathrm{Rh}$ & $\mathrm{Fu}$ & $\mathrm{Ri}$ & $\mathrm{A}$ & $\mathrm{X}$ & $\mathrm{M}$ & $\mathrm{Ga}$ & $\mathrm{Gl}$ & Total \\
\hline $\begin{array}{l}\text { Cow Manure: } \\
\text { HCl }\end{array}$ & 37.5 & 6.0 & $\mathrm{Tr}$ & 187.4 & 839.3 & 31.1 & 75.4 & 199.7 & 1376.4 \\
EDTA $+\mathrm{HCl}$ & 21.9 & 1.3 & $\mathrm{Tr}$ & 128.6 & 237.8 & 4.4 & 50.0 & 55.5 & 499.5 \\
EDTA & 2.0 & 2.0 & $\mathrm{Tr}$ & 82.6 & 14.1 & .89 & 6.7 & 1.8 & 110.1 \\
$\mathrm{H}_{2} \mathrm{O}$ & $\mathrm{Tr}$ & $\mathrm{Tr}$ & .33 & .27 & 1.4 & $\mathrm{Tr}$ & $\mathrm{Tr}$ & $\mathrm{Tr}$ & 2.0
\end{tabular}


TABLE ${ }^{-} I I I-6$

CARBOHYDRATE COMPOSITION OF CARIACO TREICH SEDIMENT:

MOLE X

HCl Xt.

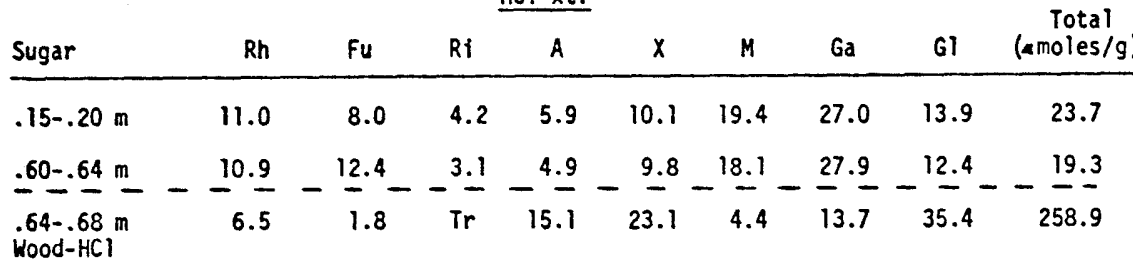

$\begin{array}{llllllllll}.64-.68 \mathrm{~m} \text { Wood } & 3.9 & .73 & \operatorname{Tr} & 7.0 & 12.5 & 2.6 & 7.6 & 65.7 & 422.2\end{array}$ Conc. $\mathrm{H}_{2} \mathrm{SO}_{4}$

$\overline{1.0-1.05} \mathrm{~m}-\overline{10.3}-\frac{-}{8.2}-{ }_{4.1}-{ }_{5.2}-\overline{10.3}-\frac{1}{17.9}-\frac{-}{29.3}-\frac{-}{14.6}-\frac{-}{18.4}$

$\begin{array}{llllllllll}1.30-1.35 m & 11.8 & 8.9 & 3.5 & 5.1 & 6.1 & 20.0 & 28.9 & 15.6 & 13.5\end{array}$

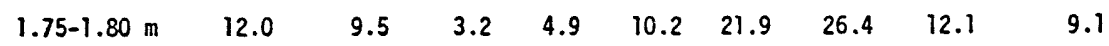

$\begin{array}{llllllllll}2.40 \mathrm{~m} & 11.2 & 8.7 & 2.7 & 5.2 & 10.6 & 18.6 & 29.2 & 13.7 & 16.1\end{array}$

$\begin{array}{lllllllllll}2.65 \mathrm{~m} & 10.8 & 7.6 & 2.8 & 7.3 & 11.7 & 18.7 & 28.1 & 12.9 & 6.4\end{array}$

$\begin{array}{llllllllll}2.65 \mathrm{~m} \text { (repeat) } & 11.4 & 8.0 & 4.3 & 8.2 & 12.1 & 16.1 & 27.3 & \ddot{12.5} & 6.2\end{array}$

$\begin{array}{llllllllll}10 \mathrm{~m} & 11.0 & 8.8 & 2.9 & 5.7 & 11.0 & 20.0 & 27.0 & 14.0 & 10.0\end{array}$

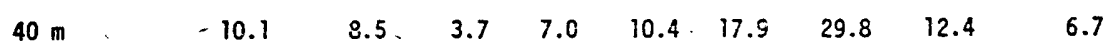

$\begin{array}{llllllllllll}67 \mathrm{~m} & 8.9^{-} & 4.4^{-} & .5 & 10.0 & 12.2 & 25.6 & 22.2 & 17.8 & 2.7\end{array}$

$\begin{array}{llllllllll}130 \mathrm{~m} & 8.9 & 5.1 & .8 & 9.8 & 12.3 & 22.1 & 24.3 & 16.6 & 2.4\end{array}$



$\begin{array}{llllllllll}\text { I.U-1.vड III } & 13.3 & 10.5 & 3.3 & 7.1 & 10.4 & 12.2 & 25.1 & 8.0 & 5.5\end{array}$

$1.30-1.35 \mathrm{~m} \quad-13.6-16.2 \quad 4.2-7.5 \quad-6.9-7.2 \quad-27.8 \ldots-16.9-3.6 \ldots$

$\begin{array}{llllllllll}1.75-1.80 \mathrm{~m} & 15.2 & 15.5 & 7.1 & 6.7 & 13.1 & 9.8 & 22.6 & 10.1 & 3.0\end{array}$

$\begin{array}{llllllllll}2.40 \mathrm{~m} & 12.4 & 12.7 & 7.9 & 7.9 & 12.4 & 10.0 & 27.0 & 9.4 & 6.7\end{array}$

$\begin{array}{llllllllll}2.65 \mathrm{~m} & 13.3 & 10.7 & 4.5 & 7.5 & 13.6 & 13.6 & 24.3 & 12.5 & 3.8\end{array}$

$\begin{array}{llllllllll}10 \mathrm{~m} & 11.4 & 13.7 & 5.6 & 7.4 & 12.8 & 11.4 & 27.9 & 10.9 & 4.3\end{array}$

$\begin{array}{llllllllll}40 \mathrm{~m} & 15.2 & 11.9 & 2.4 & 8.1 & 11.6 & 12.6 & 28.1 & 11.6 & 3.1\end{array}$

$\begin{array}{llllllllll}67 \mathrm{~m} & 11.6 & 5.1 & 1.8 & 6.4 & 15.1 & 21.9 & 23.3 & 15.1 & .73\end{array}$

$\begin{array}{llllllllll}130 \mathrm{~m} & 13.6 & 8.3 & 1.5 & 8.3 & 14.8 & 15.9 & 21.6 & 15.9 & .88\end{array}$ 


\section{0}

TABLE III-6 continued

CARBOHYDRATE COMPOSITION OF CARIACO TRENCH SEDIMENT

(MOLE \%)

UNHYDROLYZED EDTA XT

\begin{tabular}{|c|c|c|c|c|c|c|c|c|c|}
\hline Sugar & $\mathrm{Rh}$ & $\mathrm{Fu}$ & $\mathrm{Ri}$ & A & $\mathrm{x}$ & M & $\mathrm{Ga}$ & G1 & $\begin{array}{c}\text { Total } \\
(\mu \text { moles } / g)\end{array}$ \\
\hline $.15-.20 \mathrm{~m}$ & 6.4 & 15.8 & 30.3 & 12.4 & 12.1 & 2.7 & 19.4 & .7 & 3.3 \\
\hline $.60-.64 \mathrm{~m}$ & 7.0 & 20.0 & 28.3 & 10.4 & 14.3 & 1.4 & 17.4 & 1.0 & 2.3 \\
\hline $\begin{array}{l}.64-.68 \mathrm{~m} \\
\text { Wood-EDTA ext. }\end{array}$ & 4.3 & 4.6 & - & 54.9 & 21.7 & .9 & 11.0 & 2.5 & 63.0 \\
\hline $\begin{array}{l}.64-.68 \mathrm{~m} \\
\text { Wood́- }{ }_{2} \mathrm{O} \text { ext. }\end{array}$ & - & - & - & - & - & - & - & - & 0 \\
\hline $1.0-1.05 \mathrm{~m}$ & n.d. & $\mathrm{n} . \mathrm{d}$. & n.d. & n.d. & n.d. & n.d. & n.d. & n.d. & n.d. \\
\hline $1.30-1.35 \mathrm{~m}$ & 7.9 & 13.6 & 16.4 & 11.4 & 9.3 & 2.4 & 27.9 & 8.6 & 1.4 \\
\hline $1.75-1.80 \mathrm{~m}$ & n.d. & n.d. & n.d. & n.d. & n.d. & n.d. & n.d. & n.d. & $\mathrm{n} \cdot \mathrm{d}$. \\
\hline $10 \mathrm{~m}$ & 8.5 & 18.3 & 17.6 & 13.1 & 16.3 & 4.4 & 24.8 & 5.1 & 1.5 \\
\hline $40 \mathrm{~m}$ & 10.0 & 15.4 & 13.2 & 14.3 & 14.3 & 5.5 & 24.2 & 3.1 & .91 \\
\hline $67 \mathrm{~m}$ & 10.9 & 13.6 & 3.2 & 9.1 & 21.4 & 7.7 & 20.0 & 15.0 & .22 \\
\hline $130 \mathrm{~m}$ & 7.7 & 10.0 & 4.2 & 10.6 & 28.1 & 14.2 & 19.7 & 7.1 & .31 \\
\hline
\end{tabular}


201

TABLE .III-7

CARBOHYDRATE COMPOSITION OF CARIACO TRENCH SEOIMENT: (uMOles/g)

HCl XT.

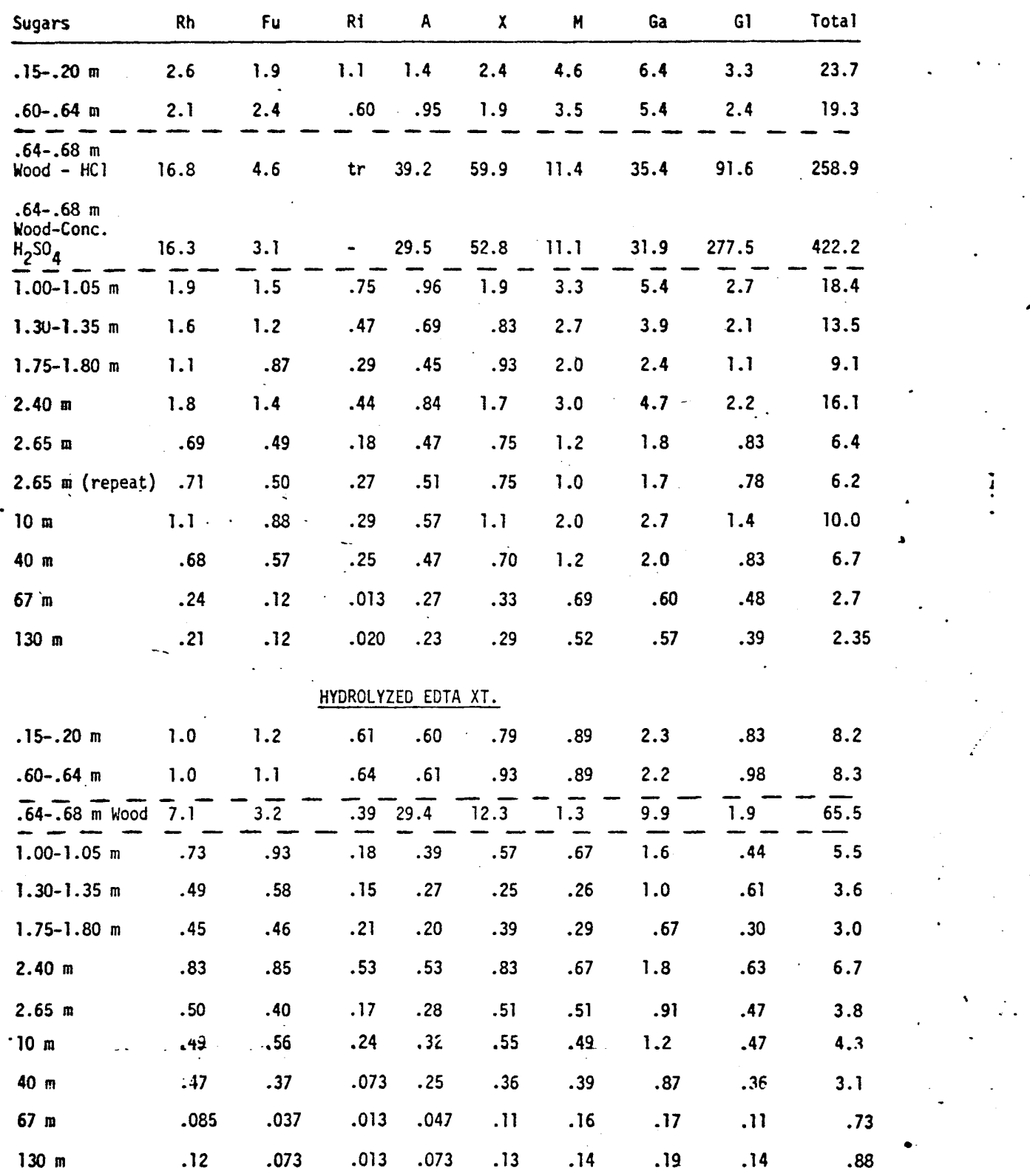


TABLE III-7 continued

CARBOHYDRATE COMPOSITION OF CARIACO TRENCH SEDIMENT: ( $\mu$ moles/g)

UNHYDROLYZED EDTA XT

\begin{tabular}{|c|c|c|c|c|c|c|c|c|c|}
\hline Sugar: & $\mathrm{Rh}$ & $\mathbf{F u}$ & $\mathrm{Ri}$ & A & $\mathrm{x}$ & M & $\mathrm{Ga}$ & G1 & Total \\
\hline $.15-.20 \mathrm{~m}$ & .21 & .52 & 1.0 & .41 & .40 & .09 & .64 & .02 & 3.3 \\
\hline $.60-.64 \mathrm{~m}$ & .16 & .46 & .65 & .24 & .33 & .03 & .40 & .02 & 2.3 \\
\hline $.64-.68 \mathrm{~m}$ Wood & 2.7 & 2.9 & - & 34.6 & 13.7 & .56 & 6.9 & 1.6 & 63.0 \\
\hline $\begin{array}{c}.64-.68 \mathrm{~m} \text { Wood } \\
\mathrm{H}_{2} \mathrm{O} \text { extract }\end{array}$ & - & - & - & - & - & - & - & - & 0 \\
\hline $1.00-1.05 \mathrm{~m}$ & n.d. & n.d. & n.d. & n.d. & n.d. & n.d. & n.d. & $\mathrm{n} \cdot \mathrm{d}$. & n.d. \\
\hline $1.30-1.35 \mathrm{~m}$ & .11 & .19 & .23 & .16 & .13 & .03 & .39 & .12 & 1.4 \\
\hline $1.75-1.80 \mathrm{~m}$ & n.d. & n.d. & n.d. & n.d. & n.d. & n.d. & n.d. & n.d. & n.d. \\
\hline $10 \mathrm{~m}$ & .13 & .28 & .27 & .20 & .25 & .07 & .38 & .08 & 1.53 \\
\hline $40 \mathrm{~m}$ & .091 & .14 & .12 & .13 & .13 & .05 & .22 & .03 & .91 \\
\hline $67 \mathrm{~m}$ & .02 & .03 & .01 & .02 & .05 & .02 & .04 & .03 & .22 \\
\hline $130 \mathrm{~m}$ & .02 & .03 & .01 & .03 & .09 & .04 & .06 & .02 & .31 \\
\hline
\end{tabular}


TABLE III-8

CARBOHYDRATE COMPOSITION OF SEDIMENT FROM ARGENTINE BASIN, BERMUDA AND BLAKE PLATEAU (MANGANESE NODULE)

(MOLE \%)

Tota1

$\begin{array}{llllllllll}\text { Sugar: } & \text { Rh } & \text { Fu } & \text { Ri } & \text { A } & X & M & \text { Ga } & \text { Gl } & (\mu \text { moles } / g)\end{array}$

ARGENTINE BASIN

$\begin{array}{llllllllll}0 \mathrm{~cm} & 8.8 & 8.1 & 6.2 & 10.2 & 9.5 & 13.7 & 23.7 & 19.9 & 4.2\end{array}$

HC1

$\begin{array}{llllllllll}0 \mathrm{~cm} & 10.1 & 9.5 & 8.9 & 8.9 & 13.1 & 12.5 & 24.3 & 12.8 & 3.4\end{array}$

$\mathrm{EDTA}+\mathrm{HCl}$

\begin{tabular}{llllllllll}
\hline $5 \mathrm{~cm}$ & 8.1 & 10.1 & 4.9 & 11.5 & 10.1 & 12.2 & 23.6 & 19.6 & 1.5
\end{tabular}

$\mathrm{HCl}$

$\begin{array}{llllllllll}5 \mathrm{~cm} & 8.3 & 11.9 & 6.7 & 10.1 & 11.0 & 11.9 & 23.8 & 16.5 & 1.1\end{array}$ EDTA + HC1

\begin{tabular}{lllllllllll}
\hline $15 \mathrm{~cm}$ & 8.5 & 9.1 & 3.2 & 9.1 & 9.8 & $13.9^{*}$ & 24.9 & 21.4 & 3.2
\end{tabular}
$\mathrm{HC1}$

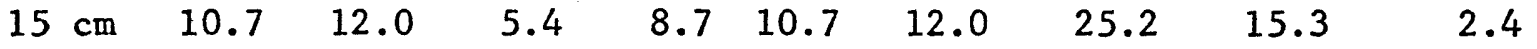
EDTA + HC1

\begin{tabular}{llllllllll}
\hline $60 \mathrm{~cm}$ & 9.0 & 9.7 & 4.7 & 10.3 & 11.2 & 13.7 & 24.3 & 17.1 & 3.2
\end{tabular}
$\mathrm{HCl}$

$\begin{array}{llllllllll}60 \mathrm{~cm} & 11.6 & 12.6 & 6.3 & 8.7 & 12.6 & 11.6 & 23.2 & 13.5 & 2.1\end{array}$ EDTA + HC1

\begin{tabular}{|c|c|c|c|c|c|c|c|c|}
\hline $\begin{array}{l}100 \mathrm{~cm} \\
\mathrm{HCl}\end{array}$ & 9.3 & 4.3 & 10.6 & 10.3 & 14.1 & 23.9 & 18.8 & 3.7 \\
\hline $\begin{array}{l}100 \mathrm{~cm} 10.4 \\
\text { EDTA }+\mathrm{HCl}\end{array}$ & 11.6 & 2.7 & 8.4 & 11.6 & 11.6 & 26.9 & 16.5 & 2.5 \\
\hline $\begin{array}{l}100 \mathrm{~cm} \quad 7.9 \\
\text { EDTA }\end{array}$ & 15.0 & 15.0 & 15.0 & 16.0 & 4.4 & 18.0 & 8.3 & 1.0 \\
\hline $\begin{array}{l}300 \mathrm{~cm} \\
\mathrm{HCl}\end{array}$ & 10.2 & 5.6 & 9.8 & 10.9 & 13.5 & 23.3 & 16.5 & 2.6 \\
\hline $\begin{array}{l}300 \mathrm{~cm} \quad 10.2 \\
\text { EDTA + HC1 }\end{array}$ & 12.9 & 3.6 & 8.1 & 9.7 & 14.5 & 25.3 & 16.7 & 1.9 \\
\hline $\begin{array}{l}500 \mathrm{~cm} \\
\mathrm{HCl}\end{array}$ & 10.5 & 5.0 & 9.6 & 12.0 & 14.9 & 25.4 & 15.8 & 3.4 \\
\hline $\begin{array}{l}500 \mathrm{~cm} 10.2 \\
\text { EDTA + HCl }\end{array}$ & 13.2 & 6.3 & 8.3 & 12.2 & 12.2 & 26.8 & 10.7 & 2.1 \\
\hline $\begin{array}{l}500 \mathrm{~cm} \\
\text { EDTA }\end{array}$ & 16.7 & 15.6 & 13.5 & 14.6 & 5.2 & 16.7 & 8.6 & 1.0 \\
\hline
\end{tabular}


204

TABLE III-8 continued

CARBOHYDRATE COMPOSITION OF SEDIMENT FROM ARGENTINE BASIN,

BERMUDA AND BIAAKE PLATEAU (MANGANESE NODULE)

(MOLE \%)

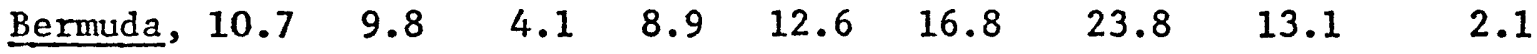
Surface $\mathrm{HCl}$

\begin{tabular}{llllllllll}
\hline Mn Nodule & 9.5 & 10.7 & - & 6.2 & 12.9 & 9.8 & 18.8 & 31.8 & .085 \\
\hline EDTA, HCl
\end{tabular}


TABLE III-9

CARBOHYDRATE COMPOSITION OF SEDIMENT FROM ARGENTINE BASIN, BERMUDA, AND BLAKE PLATEAU (MANGANESE NODULE)

(u moles/g)

$\begin{array}{llllllllll}\text { Sugars: } & \text { Rh } & F u & \text { Ri } & A & X & M & \text { Ga } & \text { G1 } & \text { Total }\end{array}$ ARGENTINE BASIN

\begin{tabular}{llllllllll}
\hline $0 \mathrm{HCl}$ & .37 & .34 & .26 & .43 & .40 & .58 & 1.0 & .84 & 4.22
\end{tabular}

\begin{tabular}{llllllllll}
$0 \mathrm{EDTA}+\mathrm{HCl}$ & .34 & .32 & .30 & .30 & .44 & .42 & .82 & .43 & 3.37 \\
\hline $5 \mathrm{HCl}$ & .12 & .15 & .07 & .17 & .15 & .18 & .35 & .29 & 1.48
\end{tabular}

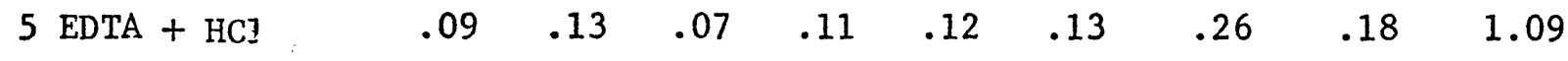

\begin{tabular}{llllllllll}
\hline $15 \mathrm{HCl}$ & .27 & .29 & .10 & .29 & .31 & .44 & .79 & .68 & 3.17
\end{tabular}



\begin{tabular}{lllllllllll}
\hline $60 \mathrm{HCl}$ & & .29 & .31 & .15 & .33 & .36 & .44 & .78 & .55 & 3.21
\end{tabular}

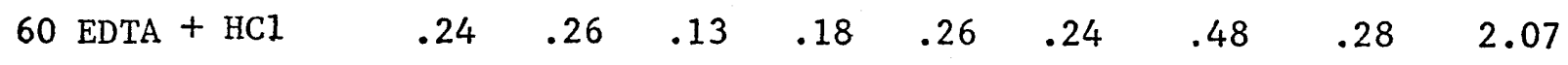

\begin{tabular}{llllllllll}
\hline $100 \mathrm{HCl}$ & .32 & .34 & .16 & .39 & .38 & .52 & .88 & .69 & 3.68
\end{tabular}

$\begin{array}{lllllllllll}100 \mathrm{EDTA}+\mathrm{HCl} & .26 & .29 & .07 & .21 & .29 & .29 & .67 & .41 & 2.49\end{array}$

\begin{tabular}{llllllllll}
$100 \mathrm{EDTA}$ & .08 & .15 & .15 & .15 & .16 & .04 & .18 & .08 & 1.00 \\
\hline $300 \mathrm{HCl}$ & .24 & .27 & .15 & .26 & .29 & .36 & .62 & .44 & 2.63
\end{tabular}

$\begin{array}{lllllllllll}300 & \mathrm{EDTA}+\mathrm{HC} 1 & .19 & .24 & .07 & .15 & .18 & .23 & .47 & .31 & 1.86\end{array}$

\begin{tabular}{lllllllllll}
\hline $500 \mathrm{HCl}$ & .23 & .36 & .17 & .33 & .41 & .51 & .87 & .54 & 3.42
\end{tabular}

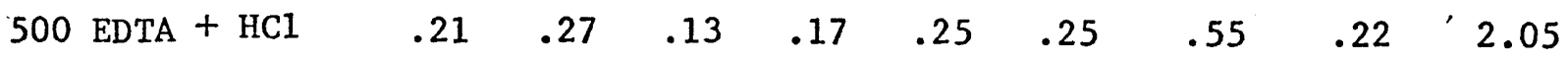

\begin{tabular}{lllllllllllll}
$500 \mathrm{EDTA}$ & & .09 & .16 & .15 & .13 & .14 & .05 & .16 & .08 & .96 \\
\hline Bermuda & $\mathrm{HCl}$ & .23 & .21 & .09 & .19 & .27 & .36 & .51 & .28 & 2.14
\end{tabular}

Mn Nodule, Blake

Plateau

$\begin{array}{llllllllllllll}\text { EDTA }+ \text { HC1 } & .008 & .009 & - & .005 & .011 & .008 & .016 & .027 & .085\end{array}$ 


\section{6}

TABLE III-10

CARBOHYDRATE COMPOSITION OF SED IMENT FROM LAKE KIVU,

WALVIS BAY AND OYSTER POND

(MOLE \%)

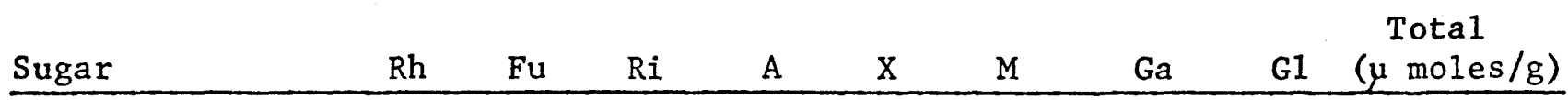

Lake Kivu

\begin{tabular}{|c|c|c|c|c|c|c|c|c|c|}
\hline $\begin{array}{l}125 \mathrm{~cm} \\
\mathrm{HC1} \\
\text { St. } 10,1971\end{array}$ & 5.3 & 3.0 & .5 & 2.9 & 3.7 & 5.3 & 36.9 & 42.5 & 195.9 \\
\hline $\begin{array}{l}125 \mathrm{~cm} \\
\text { EDTA }+\mathrm{HCl}\end{array}$ & 10.0 & 5.5 & .7 & 6.1 & 6.9 & 7.2 & 38.8 & 24.7 & 72.2 \\
\hline $\begin{array}{l}125 \mathrm{~cm} \\
\text { EDTA }\end{array}$ & 7.1 & 7.8 & 1.9 & 10.3 & 8.5 & .8 & 59.2 & 4.3 & 28.2 \\
\hline $\begin{array}{l}240 \mathrm{~cm} \\
\mathrm{HCl} \\
\text { St. } 10,1971\end{array}$ & 13.0 & 11.1 & - & 7.7 & 12.6 & 13.5 & 17.3 & 24.8 & 63.7 \\
\hline $\begin{array}{l}240 \mathrm{~cm} \\
\text { EDTA }+\mathrm{HCl} 1\end{array}$ & 18.6 & 12.8 & - & 9.5 & 10.7 & 11.9 & 13.7 & 22.9 & . 32.8 \\
\hline $\begin{array}{l}240 \mathrm{~cm} \\
\text { EDTA }\end{array}$ & 19.6 & 22.9 & 3.5 & 19.4 & 15.2 & 2.0 & 13.5 & 2.9 & 4.8 \\
\hline $\begin{array}{l}530 \mathrm{~cm} \\
\mathrm{HC1} \\
\text { St. } 4,1972\end{array}$ & 11.1 & 5.6 & 1.2 & 6.5 & 12.9 & 15.7 & 21.2 & 25.8 & 10.8 \\
\hline $\begin{array}{l}530 \mathrm{~cm} \\
\text { EDTA }+\mathrm{HCl} 1\end{array}$ & 14.1 & 9.2 & 9.8 & 7.3 & 8.2 & 14.4 & 21.7 & 15.2 & 3.7 \\
\hline $\begin{array}{l}530 \mathrm{~cm} \\
\text { EDTA }\end{array}$ & 11.7 & 13.3 & 9.4 & 13.3 & 14.8 & 6.2 & 21.9 & 9.4 & 1.3 \\
\hline $\begin{array}{l}930 \mathrm{~cm} \\
\text { HCl } \\
\text { St. 4, } 1972\end{array}$ & 9.7 & 7.2 & .8 & 6.7 & 10.6 & 17.7 & 22.4 & 24.8 & 8.5 \\
\hline $\begin{array}{l}930 \mathrm{~cm} \\
\text { EDTA + HC1 }\end{array}$ & 10.1 & 14.9 & 1.7 & 6.9 & 9.4 & 13.8 & 26.4 & 16.7 & 2.8 \\
\hline 930 EDTA & 10.2 & 15.7 & 4.6 & 9.3 & 15.7 & 9.3 & 25.9 & 9.3 & 1.1 \\
\hline
\end{tabular}




207
$\frac{\text { TABLE III-10 continued }}{\text { CARBOHYDRATE COMPOSITION OF SEDIMENT FROM LAKE KIVU, }}$
$\frac{\text { WALVIS BAY AND OYSTER POND }}{(\text { MOLE } \%)}$

Walvis Bay

$\begin{array}{llllllllll}\text { HCl } & 15.7 & 12.7 & 2.3 & 6.1 & 9.4 & 8.2 & 26.9 & 18.6 & 81.7\end{array}$

$\begin{array}{llllllllll}\mathrm{EDTA}+\mathrm{HCl} & 16.6 & 10.8 & 3.8 & 5.4 & 11.5 & 12.4 & 24.5 & 15.0 & 31.4\end{array}$

$\begin{array}{llllllllll}\text { EDTA } & 11.3 & 18.1 & 15.9 & 12.5 & 17.0 & 3.6 & 19.3 & 2.4 & 8.8\end{array}$

Oyster Pond

$\begin{array}{llllllllll}\mathrm{HCl} & 11.1 & 6.8 & .9 & 10.2 & 11.3 & 13.3 & 20.2 & 26.1 & 81.1\end{array}$

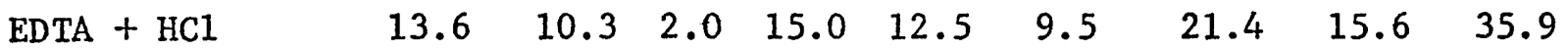

$\begin{array}{llllllllll}\text { EDTA } & 9.9 & 15.6 & 5.2 & 32.3 & 16.2 & 2.7 & 15.0 & 3.7 & 8.7\end{array}$ 
TABLE III-11

CARBOHYDRATE COMPOSITION OF SEDIMENT FROM LAKE KIVU, WALVIS BAY AND OYSTER POND

(umoles/g)

Sugars:

$\mathrm{Rh} \quad \mathrm{Fu} \quad \mathrm{Ri}$

A $\quad \mathrm{X} \quad \mathrm{M}$

$\mathrm{Ga}$

G1 Tota1

Lake Kivu

$125 \mathrm{~cm} \mathrm{HC1}$

$\begin{array}{lllllllll}10.3 & 5.8 & 1.0 & 5.7 & 7.2 & 10.4 & 72.2 & 83.3 & 195.9\end{array}$

St. 10,1971

$125 \mathrm{~cm}$

$\begin{array}{lllll}7.3 & 4.0 & .5 & 4.4 & 5.0\end{array}$

EDTA + HC1

$125 \mathrm{~cm}$

$2.0 \quad 2.2 \quad .5$

EDTA

$240 \mathrm{~cm} \mathrm{HCl}$

St. 10,1971

$\begin{array}{lllllllll}8.3 & 7.1 & \operatorname{Tr} & 4.9 & 8.0 & 8.6 & 11.0 & 15.8 & 63.7\end{array}$

$240 \mathrm{~cm}$

$\mathrm{EDTA}+\mathrm{HCl}$

$\begin{array}{lllllllll}6.1 & 4.2 & \text { I } & 3.3 & 3.5 & 3.9 & 4.5 & 7.5 & 32.8\end{array}$

240 $\begin{array}{lllllllll}.94 & 1.1 & .17 & .93 & .73 & .10 & .65 & .14 & 4.8\end{array}$

\section{EDTA}

$530 \mathrm{~cm} \mathrm{HCl}$

$\begin{array}{lllll}1.2 & .61 & .13 & .70 & 1.4\end{array}$

1.7

$\begin{array}{lll}2.3 & 2.8 & 10.8\end{array}$

St. 4, 1972

$\begin{array}{lllllllllll}530 & \mathrm{~cm} & .52 & .34 & .36 & .27 & .30 & .53 & .80 & .56 & 3.68\end{array}$

$\mathrm{EDTA}+\mathrm{HCl}$

$530 \mathrm{~cm}$

EDTA

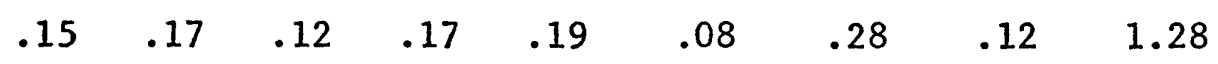

\begin{tabular}{|c|c|c|c|c|c|c|c|c|c|}
\hline $\begin{array}{lll}930 \mathrm{~cm} & \mathrm{HCl} \\
\text { St. } & 4,1972\end{array}$ & .82 & .61 & .07 & .57 & .90 & 1.5 & 1.9 & 2.1 & 8.47 \\
\hline $\begin{array}{l}930 \mathrm{~cm} \\
\text { EDTA }+\mathrm{HC1} 1\end{array}$ & .28 & .41 & .05 & .19 & .26 & .38 & .73 & .46 & \\
\hline $\begin{array}{l}930 \mathrm{~cm} \\
\text { EDTA }\end{array}$ & .11 & .17 & .05 & .10 & .17 & .10 & .28 & .10 & \\
\hline \multicolumn{10}{|c|}{ Walvis Bay: Surface } \\
\hline $\mathrm{HCl}$ & 12.8 & 10.4 & 1.9 & 5.0 & 7.7 & 6.7 & 22.0 & 15.2 & 81.7 \\
\hline EDTA + HC1 & 5.2 & 3.4 & 1.2 & 1.7 & 3.6 & 3.9 & 7.7 & 4.7 & 31.4 \\
\hline EDTA & 1.0 & 1.6 & 1.4 & 1.1 & 1.5 & .3 & 1.7 & .2 & 8.8 \\
\hline
\end{tabular}


TABLE III-11 continued

CARBOHYDRATE COMPOSITION OF SED TMENT FROM LAKE KIVU,

WALVIS BY AND OYSTER POND

(ymoles/g)

Oyster Pond: Surface

\begin{tabular}{|c|c|c|c|c|c|c|c|c|c|}
\hline HC1 & 9.0 & 5.5 & .72 & 8.3 & 9.2 & 10.8 & 16.4 & 21.2 & 81.1 \\
\hline $\mathrm{EDTA}+\mathrm{HCl}$ & 4.9 & 3.7 & .72 & 5.4 & 4.5 & 3.4 & 7.7 & 5.6 & 35.9 \\
\hline EDTA & .86 & 1.3 & .45 & 2.8 & 1.4 & .23 & 1.3 & .32 & \\
\hline
\end{tabular}


TABLE III-12

CARBOHYDRATE COMPOSITION OF BLACK SEA SEDIMENT

(MOLE \%)

\begin{tabular}{|c|c|c|c|c|c|c|c|c|c|}
\hline Sugar & $\mathrm{Rh}$ & $\mathbf{F u}$ & $\mathrm{Ri}$ & A & $\mathrm{x}$ & $\mathrm{M}$ & $\mathrm{Ga}$ & G1 & $\begin{array}{c}\text { Total } \\
(\mu \mathrm{moles} / \mathrm{g})\end{array}$ \\
\hline $\begin{array}{l}15 \mathrm{~cm} \\
\mathrm{HCl}\end{array}$ & 4.8 & 7.6 & 9.6 & 4.6 & 16.3 & 23.7 & 20.0 & 13.3 & 45.9 \\
\hline $\begin{array}{l}15 \mathrm{~cm} \\
\text { EDTA + HCl }\end{array}$ & 11.9 & 12.4 & 10.3 & 7.0 & 10.3 & 10.8 & 26.5 & 10.8 & 18.5 \\
\hline $\begin{array}{l}15 \mathrm{~cm} \\
\text { EDTA }\end{array}$ & 3.5 & 14.2 & 33.3 & 9.6 & 19.3 & 1.5 & 17.5 & 1.2 & 5.7 \\
\hline $\begin{array}{l}65-70 \mathrm{~cm} \\
\mathrm{HCl}\end{array}$ & 15.1 & 10.9 & 5.5 & 8.9 & 12.6 & 10.0 & 18.3 & 18.8 & 250.8 \\
\hline $\begin{array}{l}65-70 \mathrm{~cm} \\
\mathrm{EDTA}+\mathrm{HCl}\end{array}$ & 19.3 & 13.0 & 5.5 & $\therefore 6.8$ & 14.0 & 8.7 & 15.6 & 17.0 & 137.5 \\
\hline $\begin{array}{l}65-70 \mathrm{~cm} \\
\text { EDTA }\end{array}$ & 14.9 & 15.9 & 21.1 & 9.6 & 19.2 & 1.4 & 15.9 & 2.2 & 51.1 \\
\hline $\begin{array}{l}120-130 \mathrm{~cm} \\
\mathrm{HCl}\end{array}$ & 12.5 & 6.3 & 1.8 & 10.4 & 10.0 & 14.6 & 22.9 & 21.9 & 9.6 \\
\hline $\begin{array}{l}120-130 \mathrm{~cm} \\
\mathrm{EDTA}+\mathrm{HCl}\end{array}$ & 15.5 & 11.8 & 4.3 & 11.2 & 11.2 & 12.6 & 18.5 & 15.4 & 6.5 \\
\hline $\begin{array}{l}120-130 \mathrm{~cm} \\
\mathrm{EDTA}\end{array}$ & 12.3 & 11.5 & 10.0 & 24.6 & 10.8 & 3.4 & 18.5 & 5.5 & 1.3 \\
\hline $\begin{array}{l}120-130 \\
\mathrm{H}_{2} \mathrm{O}\end{array}$ & - & - & - & - & - & - & - & - & - \\
\hline $\begin{array}{l}120-130 \mathrm{~cm} \\
\mathrm{H}_{2} \mathrm{O}+\mathrm{HCl}\end{array}$ & 19.7 & 16.7 & 2.0 & 7.1 & 8.0 & 6.7 & 13.5 & 27.8 & .66 \\
\hline $\begin{array}{l}120-130 \mathrm{~cm} \\
\mathrm{H}_{2} \mathrm{O}+\text { EDTA }\end{array}$ & 23.9 & 16.7 & - & 33.3 & 7.2 & - & 6.1 & 12.2 & .18 \\
\hline
\end{tabular}


211

TABLE III-13

CARBOYHXDRATE COMPOSITION OF BLACK SEA SED IMENT

(umoles/g)

\begin{tabular}{lccccccccc} 
Sugars: & $\mathrm{Rh}$ & $\mathrm{Fu}$ & $\mathrm{Ri}$ & $\mathrm{A}$ & $\mathrm{X}$ & $\mathrm{M}$ & $\mathrm{Ga}$ & $\mathrm{Gl}$ & Total \\
\hline $15 \mathrm{~cm} \mathrm{HC1}$ & 2.2 & 3.5 & 4.4 & 2.1 & 7.5 & 10.9 & 9.2 & 6.1 & 45.9 \\
$\begin{array}{l}15 \mathrm{~cm} \text { EDTA } \\
+\mathrm{HCl}\end{array}$ & & & & & & & & & \\
Extract & 2.2 & 2.3 & 1.9 & 1.3 & 1.9 & 2.0 & 4.9 & 2.0 & 18.5
\end{tabular}

$15 \mathrm{~cm}$ EDTA

\begin{tabular}{lrrrrrrrrr} 
extract & .2 & .81 & 1.9 & .55 & 1.1 & .08 & 1.0 & .07 & 5.7 \\
\hline $65-70 \mathrm{~cm} \mathrm{HCl}$ & 37.9 & 27.4 & 13.7 & 22.2 & 31.6 & 25.0 & 45.8 & 47.2 & 250.8
\end{tabular}

65-70 EDTA

$+\mathrm{HCl}$

$\begin{array}{llllllllll}\text { Extract } & 26.6 & 17.9 & 7.5 & 9.4 & 19.3 & 11.9 & 21.5 & 23.4 & 137.5\end{array}$

65-70 EDTA

\begin{tabular}{llllllllll} 
Extract & 7.6 & 8.1 & 10.8 & 4.9 & 9.8 & .72 & 8.1 & 1.1 & 51.1 \\
\hline $120-130 \mathrm{HCl}$ & 1.2 & .60 & .17 & 1.0 & .96 & 1.4 & 2.2 & 2.1 & 9.6
\end{tabular}

120-130 EDTA

$+\mathrm{HCl}$

$\begin{array}{llllllllll}\text { Extract } & 1.0 & .77 & .28 & .73 & .73 & .82 & 1.2 & 1.0 & 6.5\end{array}$

120-130 EDTA

$\begin{array}{llllllllll}\text { Extract } & .16 & .15 & .13 & .32 & .14 & .04 & .24 & .07 & 1.3\end{array}$

$120-130 \mathrm{H}_{2} \mathrm{O}$

Extract

tr.

$120-130 \mathrm{H}_{2} \mathrm{O}$

$+\mathrm{HCl}$

$\begin{array}{llllllllll}- \text { Extract } & .13 & .11 & .01 & .05 & .05 & .04 & .09 & .17 & .66\end{array}$

$120-130 \quad \mathrm{H}_{2} \mathrm{O}$

+ EDTA

$\begin{array}{lllllllll}.04 & .03 & - & .06 & .01 & - & .01 & .02 & .18\end{array}$ 
212

TABLE III-14

CARBOHYDRATE COMPOSITION OF SEDIMENT FROM SANTA BARBARA BASIN

(Off California)

Mole \%

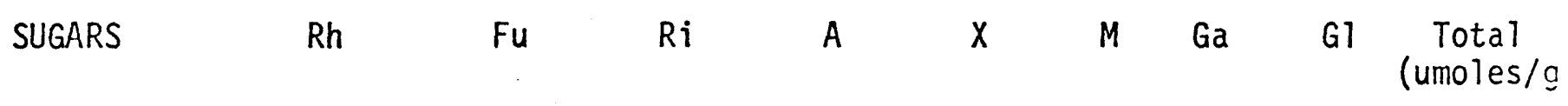

$\sim 50$ yrs. $\mathrm{H}_{2} \mathrm{SO}_{4}$ after Modzeleskiet al. (1971) $\mathrm{H}_{2} \mathrm{O}$ insoluble

$\begin{array}{lllllllll}11.8 & 8.7 & 5.2 & 7.0 & 12.7 & 12.7 & 26.2 & 15.7 & 22.9\end{array}$

$\sim 50$ yrs., $\mathrm{HCl}, \mathrm{H}_{2} \mathrm{O}$ insoluble

$\begin{array}{lllllllll}10.2 & 8.0 & 4.9 & 6.8 & 11.7 & 15.9 & 25.8 & 16.7 & 26.4\end{array}$

$\sim 50$ yrs., $\mathrm{HCl}, \mathrm{H}_{2} \mathrm{O}$ insoluble + soluble

$\begin{array}{lllllllll}11.7 & 8.4 & -4.7 & 8.4 & 10.7 & 13.8 & 25.8 & 16.4 & 29.8\end{array}$

$\sim 50$ yrs., EDTA + HCl

$\begin{array}{lllllllll}13.3 & 12.5 & 7.8 & 7.8 & 14.1 & 10.2 & 24.2 & 10.2 & 12.8\end{array}$

$\sim 50$ yrs., $\mathrm{H}_{2} \mathrm{O}$ soluble (Hydrolyzed)

$\begin{array}{lllllllll}16.6 & 12.2 & 2.2 & 4.4 & 10.5 & 14.9 & 28.2 & 11.0 & 3.6\end{array}$

$\sim 750$ yrs., $\mathrm{H}_{2} \mathrm{SO}_{4}$ after

Modzeleski et ât. (1971)

$\mathrm{H}_{2} \mathrm{O}$ insolbule

11.7

9.4

8.6

8.6

18.0

$\begin{array}{llll}10.2 & 24.2 & 10.2 & 12.8\end{array}$

insoluble 750 yrs. $\mathrm{HCl}, \mathrm{H}_{2} \mathrm{O}$

12.6

8.2

5.7

6.9

12.6

17.0

$22.6 \quad 14.5$

15.9

$\sim 750$ yrs., $\mathrm{HCl}, \mathrm{H}_{2} \mathrm{O}$

11.8

8.1

4.3

$\begin{array}{lll}5.2 & 11.8 & 16.6\end{array}$

$26.1 \quad 16.1$

21.1

$\sim 750$ yrs., $\mathrm{H}_{2} \mathrm{O}$ soluble (Hydrolyzed)

$16.3 \quad 14.0$

3.9

3.9

$10: 1$

14.7

$24.8 \quad 12.4$

2.6 
TABLE III- 15

CARBOHYDRATE COMPOSITION OF SEDIMENT FROM SANTA BARBARA BASIN

(Off California)

$\underline{\mu \mathrm{moles} / \mathrm{g}}$

$\begin{array}{llllllllll}\text { SUGARS } & \text { Rh } & \mathrm{Fu} & \mathrm{Ri} & \mathrm{A} & \mathrm{X} & \mathrm{M} & \mathrm{Ga} & G 1 & \text { Total }\end{array}$

$\sim 50$ yrs. $\mathrm{H}_{2} \mathrm{SO}_{4}$ after

Modzeleski et al. (1971)

$\mathrm{H}_{2} \mathrm{O}$ insoluble

2.7

$\sim 50$ yrs., $\mathrm{HCl}, \mathrm{H}_{2} \mathrm{O}$

insoluble

2.7

2.1

2.0

$1.2 \quad 1.6$

2.9

$2.9 \quad 6.0$

3.6

22.9

$\sim 50$ yrs., $\mathrm{HCl}, \mathrm{H}_{2} \mathrm{O}$

insoluble + sofuble

$\checkmark 50$ yrs., EDTA + HCl

3.5

2.5

1.4

2.5

1.6

1.0

1.7

.60

$\checkmark 50$ yrs., $\mathrm{H}_{2} \mathrm{O}$ Soluble

(Hydrolyzed)

$\begin{array}{llllllll}.44 & .08 & .16 & .38 & .54 & .1 .02 & .40 & 3.6\end{array}$

$\begin{array}{ll}4.2 & 6.8\end{array}$

$4.4 \quad 26.4$

$4.1 \quad 7.7$

4.9

29.8

$\checkmark 750$ yrs., $\mathrm{H}_{2} \mathrm{SO}_{4}$ after

Modzeleski et âl. (1971)

$\mathrm{H}_{2} \mathrm{O}$ insoluble

1.5

1.2

1.1

1.1

2.3

-750 yrs., $\mathrm{HCl}, \mathrm{H}_{2} \mathrm{O}$

2.0

1.3

$.9 \quad 1.1$

2.

2.7

2750 yrs., $\mathrm{HCl}, \mathrm{H}_{2} \mathrm{O}$

insoluble + solable

2.5

1.7

$.9 \quad 1.1$

2.5

3.5

5.5

3.4

21.1

$\checkmark 750$ yrs., $\mathrm{H}_{2} \mathrm{O}$ insoluble (Hyarolyzed) 
224

TABLE III- 16

CARBOHYDRATE COMPOSITION OF ARGENTINE BASIN, LAKE KIVU,

AND CARIACO TRENCH SEDIMENTS

Hydrolyzed EDTA xt.

(\% of HCl xt.)

SUGAR

$\mathrm{Rh} \quad \mathrm{Fu}$

Fu Ri

Ri $\quad A \quad x$

$M$

Ga

G1

Total

(\%)

\begin{tabular}{|c|c|c|c|c|c|c|c|c|c|}
\hline $\begin{array}{l}\text { Argentine } \\
\text { Basin }(\mathrm{cm})\end{array}$ & & & & & & & & & - \\
\hline 0 & 91 & 94 & 100 & 70 & 100 & 72 & 82 & 51 & 80 \\
\hline 5 & 76 & 87 & 100 & 65 & 80 & 72 & 74 & 62 & 74 \\
\hline 15 & 96 & 100 & 100 & 72 & 84 & 66 & 77 & 54 & 76 \\
\hline 60 & 92 & 84 & 87 & 55 & 72 & 55 & 62 & 51 & 64 \\
\hline 100 & 81 & 85 & 42 & -54 & 76 & 56 & 76 & 59 & 68 \\
\hline 300 & 79 & 89 & 45 & 56 & 62 & 64 & 76 & 70 & 71 \\
\hline 500 & 9] & 75 & 76 & 52 & 61. & 49 & 63 & 41 & 60 \\
\hline Average & 85 & 87 & 72 & 60 & 75 & 61 & 72 & 54 & 70 \\
\hline $\begin{array}{l}\text { Lake Kivu } \\
-(\mathrm{cm})\end{array}$ & & & & & & & & & \\
\hline 125 & 71 & 69 & 47 & 77 & 69 & 50 & 39 & 21 & 37 \\
\hline 240 & 73 & 59 & - & 63 & 44 & 45 & 41 & 47 & 51 \\
\hline 530 & 43 & 56 & 100 & 39 & 21 & 31 & 35 & 20 & 34 \\
\hline 930 & 34 & 67 & 72 & 33 & 29 & 25 & 38 & 22 & 33 \\
\hline Average & 50 & 63 & 77 & 48 & 33 & 36 & 38 & 24 & 37 \\
\hline \multicolumn{10}{|l|}{$\begin{array}{l}\text { Cariaco } \\
\text { Trench } \\
\text { (m) }\end{array}$} \\
\hline .15 & 38 & 63 & 56 & 43 & 33 & 19 & 36 & 25 & 34 \\
\hline .60 & 48 & 45 & 100 & 63 & 50 & 26 & 40 & 42 & 43 \\
\hline .64 & 42 & 71 & - & 77 & 20 & 11 & 28 & 24 & 16 \\
\hline 1.00 & 38 & 63 & 24 & 40 & 30 & 20 & 29 & 16 & 30 \\
\hline 1.30 & 30 & 48 & 32 & 38 & 30 & 19 & 26 & 29 & 26 \\
\hline 1.80 & 41 & 53 & 72 & 44 & 42 & 15 & 28 & 27 & 33 \\
\hline 2.40 & 46 & 61 & 100 & 63 & 49 & 22 & 38 & 29 & 42 \\
\hline ic) 2.65 & 72 & 82 & 100 & 57 & 68 & 46 & 52 & 59 & 60 \\
\hline 10.0 & 45 & $\varepsilon 3$ & 83 & 50 & $5 \overline{0}$ & 24 & 43 & 33 & 43 \\
\hline 40.0 & 71 & 67 & 29 & 53 & 53 & 32 & 43 & 43 & 45 \\
\hline 67.0 & 36 & 31 & 100 & 18 & 33 & 23 & 29 & 23 & 27 \\
\hline 130.0 & 56 & 63 & 67 & 31 & 45 & 27 & 33 & 37 & 37 \\
\hline
\end{tabular}


TABLE III- 17

CARBOHYDRATE COMPOSITION OF ARGENTINE BASIN, LAKE KIVU,

AND CARIACO TRENCH SEDIMENTS

Unhydrolyzed EDTA xt.

(\% of Hydrolyzed EDTA $x t$. )

SUGAR

$\mathrm{Rh}$

$\mathrm{Fu}$

$\mathrm{Ri}$

A $\quad X$

M Ga

G1 Total

\begin{tabular}{|c|c|c|c|c|c|c|c|c|c|}
\hline $\begin{array}{l}\text { Argentine } \\
\text { Basin }(\mathrm{cm})\end{array}$ & & & & & & & & & \\
\hline 100 & 30 & 52 & 100 & 71 & 55 & 15 & 27 & 20 & 40 \\
\hline 500 & 43 & 59 & 100 & 76 & 56 & 20 & 29 & 38 & 47 \\
\hline $\begin{array}{l}\text { Lake Kivu } \\
(\mathrm{cm})\end{array}$ & & & - & & & & & & \\
\hline 125 & 27 & 55 & 100 & 66 & 48 & 4 & 60 & 7 & 39 \\
\hline 240 & 15 & 26 & - & 30 & 21 & 2 & 14 & 2 & 15 \\
\hline 530 & 29 & 50 & 33 & 63 & 63 & 15 & 28 & 21 & 35 \\
\hline-930 & 39 & 41 & 100 & 53 & 65 & 26 & 38 & 22 & 39 \\
\hline $\begin{array}{l}\text { Cariaco } \\
\text { Trench } \\
\text { (m) }\end{array}$ & & & & & & & & & \\
\hline .15 & 21 & 43 & 100 & 68 & 51 & 10 & 28 & 3 & 40 \\
\hline .60 & 16 & 42 & 100 & 39 & 35 & 4 & 18 & 2 & 28 \\
\hline$($ wood $) .64$ & 38 & 91 & - & 100 & 100 & 43 & 70 & 84 & 96 \\
\hline 1.3 & 22 & 33 & 100 & 59 & 52 & 13 & 39 & 20 & 39 \\
\hline 10 & 26 & 50 & 100 & 63 & 45 & 14 & 32 & 17 & 36 \\
\hline 40 & 19 & 38 & 100 & 52 & 36 & 13 & 25 & 8 & 29 \\
\hline 67 & 28 & 81 & 54 & 43 & 43 & 11 & 26 & 30 & 30 \\
\hline 130 & 20 & 41 & 100 & 45 & 67 & 31 & 32 & 16 & 35 \\
\hline
\end{tabular}




\section{APPENDIX IV}

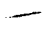

GLOSSARY 


\section{APPENDIX IV}

\section{GLOSSARY}

Carbohydrates: polyhydroxy aldehydes or polyhydroxy ketones, or substances that yield such compounds on hydrolysis.

Chitin: a polysaccharide similar in structure to cellulose except that an acetylamine group replaces a hydroxyl group:

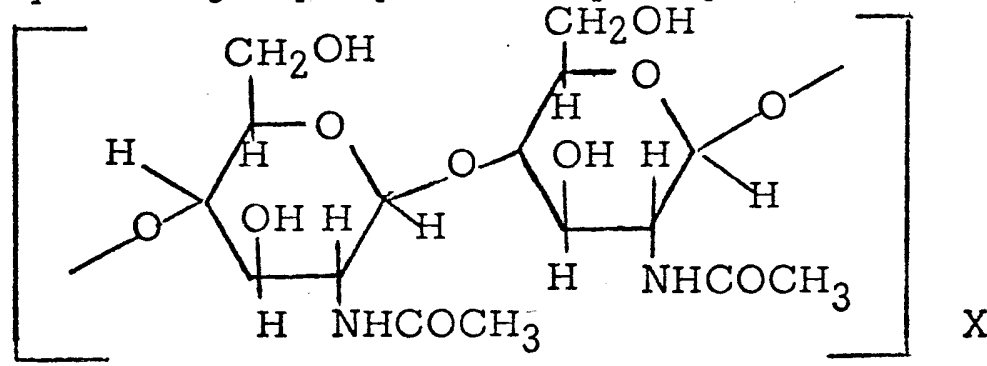

Chitin is found in the shells of crustacea and is the structural substance of insects and fungi; chitin is extremely resistant to biological and chemical degradation.

Disaccharides: carbohydrates which yield two molecules of monosaccharides on hydrolysis; e.g. , maltose $=2$ glucose; lactose $=1$ glucose and 1 galactose; and sucrose $=1$ glucose and 1 fructose .

Fulvic acid: derived from humus; alkali-soluble, acid-soluble fraction; it is composed of heterogeneous molecules and contains a high degree of functionality .

Humic acids: derived from humus; alkali-soluble, acid-insoluble fraction; it contains a lower degree of functionality and higher molecular weight range than fulvic acids.

-Humus (or humic substances): acidic, yellow-to black-colored, moderately high molecular weight polymers which are composed of extremely heterogeneous mixtures of molecules (presumably of biological origin); the molecular weight range of humus in soils or sediments usually varies between 2000 and 300,000 ; humus has a considerably higher degree of functionality than kerogen, especially with respect to $\mathrm{COOH}$ and $\mathrm{OH}$ groups; humus is the major organic constituent of soils and sediments.

Kerogen: the major organic component of sedimentary rocks; kerogen is probably derived from the metamorphism of humus; kerogen contains a high degree of aromaticity and a low degree of functionality; this 
high molecular weight polymeric substance is relatively inert and therefore requires drastic chemical means for its extraction and degradation.

Lignin: a polymeric structural constituent of woody tissue in vascular plants; it is not found in marine plants; lignin-related substances are major components of soil humus; alkaline hydrolysis of lignin dominantly yields various aromatic hydroxy-acids and aldehydes such as p-hydroxybenzaldehyde and vanillin.

Monosaccharides: carbohydrates that do not hydrolyze; the following monosaccharides have been discussed in the thesis:

1. pentoses: five-carbon sugars; hexoses: six-carbon sugars; a. $\mathrm{L}$ - arabinose $=$<smiles>O=CC(O)C(O)C(O)CO</smiles>

occurs widely in plants in both free and combined (in gums) forms; its function marine algae is unknown.

b. $D-x y l o s e=$<smiles>O=CC(O)C(O)C(O)CO</smiles>

an all trans sugar; found in a combined form in woody materials; probably a component of structural polysaccharides; function in marine algae is unknown but might also be partial structural; xylose always appears fourth or fifth in the orders of abundance of sugars in sediments and plankton.

C. D-ribose $=$<smiles>O=CC(O)C(O)C(O)CO</smiles> 
an all cis sugar; glycosidically linked to nitrogen compounds in nucleotides, several vitamins and coenzymes; this sugar may account for up to $40 \%$ of the total sugars in marine plankton; it is probably a much smaller fraction of the total sugars of terrigenous plants.

d. $D$ - galactose $=$<smiles>O=CC(O)C(O)C(O)C(O)CO</smiles>

constituent of oligosaccharides (e.g., lactose and raffinose); also a major constituent of polysaccharides (e.g., agar and plant germs); the function in marine plankton is unknown, however, it is probably not incorporated into structural polysaccharides to any great degree.

\section{e. D - fructose:}<smiles>CCOC(=O)C(O)C(O)C(O)CO</smiles>

this keto sugar is principally found in terrigenous plants as a food storage product; it is called 'fruit sugar'; it is a constituent of the disaccharide, sucrose; fructose is not detected in either marine algae or marine sediment.

f. $D-$ glucose $=$<smiles>CC(O)C(O)C(O)C(O)C=O</smiles>

the commonest sugar of terrigenous plants; occurs in both free and combined forms; cellulose, the most important structural polysaccharide, is composed only of this sugar; starch, the major food storage polysaccharide, is also composed only of 
this sugar; in marine plankton this sugar is dominantly present in food storage polysaccharides such as laminaran; it might also play a minor role in structural polysaccharides.

g. D- mannose $=$<smiles>O=CC(O)C(O)C(O)C(O)CO</smiles>

occurs dominantly in a combined form and is present in polysaccharides of wood, yeast, and red algae; the function of this sugar in marine plankton is unknown, but it seems plausible that it is incorporated into structural polysaccharides.

2. deoxyhexoses; six carbon sugars:

a. $\mathbf{L}$ - rhamnose $(6-$ deoxy-I-mannose $)=$<smiles>CC(O)C(O)C(O)C(O)C=O</smiles>

a major constituent of glycosides and some polysaccharides of plant gums; the function in marine planton is unknown.

b. $\mathrm{L}-$ fucose $(6-$ deoxy-L-galactose $)=$<smiles>CC(O)C(O)C(O)C(O)C=O</smiles>

a constituent of some polysaccharides of plant gums; a major constituent of cell walls of some marine algae (seaweed); its function in marine algae is probably structural. 
Polysaccharides: carbohydrates that yield a large number of molecules of monosaccharides on hydrolysis; polysaccharides made up of only a single type of building unit are known as homopolysaccharides; cellulose is a good example of this type:



polysaccharides that yield more than one kind of sugar on hydrolysis are called glycans; e.g. , mannans (mostly mannose) and xylans (mostly xylose). 